


Editora Poisson

\section{Gestão da Produção em Foco Volume 42}

1a Edição

Belo Horizonte

Poisson

2020 
Editor Chefe: Dr. Darly Fernando Andrade

\section{Conselho Editorial}

Dr. Antônio Artur de Souza - Universidade Federal de Minas Gerais

Ms. Davilson Eduardo Andrade

Dra. Elizângela de Jesus Oliveira - Universidade Federal do Amazonas

MS. Fabiane dos Santos

Dr. José Eduardo Ferreira Lopes - Universidade Federal de Uberlândia

Dr. Otaviano Francisco Neves - Pontifícia Universidade Católica de Minas Gerais

Dr. Luiz Cláudio de Lima - Universidade FUMEC

Dr. Nelson Ferreira Filho - Faculdades Kennedy

Ms. Valdiney Alves de Oliveira - Universidade Federal de Uberlândia



O conteúdo dos artigos e seus dados em sua forma, correção e confiabilidade são de responsabilidade exclusiva dos seus respectivos autores.

Baixe outros títulos gratuitamente em www.poisson.com.br contato@poisson.com.br 


\section{SUMÁRIO}

Capítulo 1: Análise das práticas de qualidade realizadas pelos ganhadores do Concurso de Qualidade e Sustentabilidade do Café de Rondônia. 7

Karoline Conte dos Santos, Camila Wolffgramm Otto, Suellen Silva de Oliveira, Tatiane Aparecida de Lazari, Enaile Maria de Moraes Oliveira

DOI: $10.36229 / 978-65-86127-13-3 . C A P .01$

Capítulo 2: Proposta de melhorias no controle de estoque utilizando a ferramenta MASP em uma fábrica de descartáveis . 22

Marcone Freitas dos Reis, Barbara Stephany Serra Litter, Marcos dos Santos, Angélica Rodrigues de Lima, Alexandre Camacho da Paixão

DOI: $10.36229 / 978-65-86127-13-3 . C A P .02$

Capítulo 3: Descrição do Controle Estatístico de Processos (CEP) implantado nas indústrias de autopeças 36

Fabiano Rodrigues Soriano, Pedro Carlos Oprime, Fabiane Leticia Lizarelli

DOI: 10.36229/978-65-86127-13-3.CAP.03

Capítulo 4: 0 impacto do facelift no contexto de P\&D com ênfase em qualidade total

Felipe Ferreira Sereno, Francisco Ignácio Giocondo Cesar

DOI: 10.36229/978-65-86127-13-3.CAP.04

Capítulo 5: A utilização de ferramentas de gestão de tempo em Projetos WEB: Um estudo de caso em ambiente Website Multi-Idioma.

Raul César do Carmo Matos, Jefferson de Souza Pinto, Aelso Rocha Brito, Carlos Roberto Dantas DOI: 10.36229/978-65-86127-13-3.CAP.05

Capítulo 6: Pesquisa operacional: Um estudo de caso para minimização de custos em uma barbearia. 64

Devisson Mesquita dos Santos, Fernanda Leandra Leal Lopes, Pedro Matheus d'Oliveira, Syanne do Socorro Lobato Gonçalves, Yvelyne Bianca Iunes Santos

DOI: 10.36229/978-65-86127-13-3.CAP.06

Capítulo 7: Aplicação do Software Arena para simulação e modelagem de filas em um restaurante universitário. 73

Vitor Abel Monteiro Alves, Leonardo Rosa Rohde, Ari Mateus Carvallio Neto, Renato Oliveira Serafim, Philip Soares do Amaral

DOI: 10.36229/978-65-86127-13-3.CAP.07 


\section{SUMÁRIO}

Capítulo 8: Utilização do Recurso de Callback para a eliminação de subrotas em um problema de roteamento de veículos com entrega e coleta simultaneas de múltiplos produtos

Roza Maria Zoellner Lopes, Ruany Batista Leite Doehnert, Gustavo Valentim Loch, José Eduardo Pécora Junior, Cassius Tadeu Scarpin

DOI: $10.36229 / 978-65-86127-13-3 . C A P .08$

Capítulo 9: Mobilidade universitária: Um estudo de caso da Universidade Federal do Amazonas 90

Fernando Henrique da Paixão Duarte, Ariane Pereira Gatti, Willians Antônio Malveira da Silva DOI: 10.36229/978-65-86127-13-3.CAP.09

Capítulo 10: Aplicação do Método THOR ao problema de seleção de um Enterprise Resource Planning (ERP) para uma fábrica de tortas 96

Rachel Medina Trindade, Thays Marques Rodrigues, Marcos dos Santos, Fabricio Maione Tenório, Angélica Rodrigues de Lima, Carlos Francisco Simões Gomes

DOI: 10.36229/978-65-86127-13-3.CAP.10

Capítulo 11: Aplicação do Método SAPEVO-M para seleção de uma transpaleteira em uma Empresa do Setor Moveleiro - RJ.. 106

Cristiano da Silva Severino, Lucas Santiago de Sousa, Marcos dos Santos, Rubens Aguiar Walker DOI: $10.36229 / 978-65-86127-13-3 . C A P .11$

Capítulo 12: Estudo da influência da geometria de rotores no armazenamento de energia em baterias eletromecânicas

Daniel Coppedé, Wagner Costa Botelho

DOI: $10.36229 / 978-65-86127-13-3 . C A P .12$

Capítulo 13: Nível de sustentabilidade dos Municípios do Estado do Rio de Janeiro: Uma análise sob a luz do Triple Bottom Line.

Ana Luiza Mendes Silva, Sávio Mendes Silva, Luan dos Santos

DOI: 10.36229/978-65-86127-13-3.CAP.13

Capítulo 14: Evolução tecnológica na produção de calçados esportivos: Da produção convencional à Indústria 4.0

Adriana Yumi Sato Duarte, Fernando Soares de Lima, Regina Aparecida Sanches, Rayana Santiago de Queiroz, Franco Giuseppe Dedini

DOI: $10.36229 / 978-65-86127-13-3 . C A P .14$ 


\section{SUMÁRIO}

Capítulo 15: Desafios da Siderurgia na Indústria 4.0 no Brasil

148

Ricardo Luiz Perez Teixeira, Cynthia Helena Soares Bouças Teixeira, Max Leandro de Araújo Brito, Priscilla Chantal Duarte Silva

DOI: $10.36229 / 978-65-86127-13-3 . C A P .15$

Autores: 


\section{Capítulo 1}

Análise das práticas de qualidade realizadas pelos ganhadores do Concurso de Qualidade e Sustentabilidade do Café de Rondônia

\section{Karoline Conte dos Santos \\ Camila Wolffgramm Otto \\ Suellen Silva de Oliveira \\ Tatiane Aparecida de Lazari \\ Enaile Maria de Moraes Oliveira}

Resumo: 0 presente trabalho baseia-se no conhecimento dos ganhadores do concurso de qualidade e sustentabilidade do café do estado de Rondônia, conhecido como Concafé, tendo como objetivo principal analisar as práticas de qualidades que os ganhadores do concurso nas três últimas edições exercem e realizar um comparativo entre eles. Para tal finalidade foi realizado levantamento bibliográfico acerca do referencial teórico e visitas às propriedades e a Emater de Cacoal, e entrevistas semi-estruturadas realizadas com os produtores e agente de assistência técnica da Emater, a fim de conhecer melhor cada ganhador do prêmio. Para uma boa qualidade do grão do café faz necessário a aplicação das práticas principais de manejo que são: boa adubação do solo, seleção de bons clones, uma secagem adequada e uma ótima armazenagem. Portanto com o desenvolvimento deste estudo foi possível saber quais práticas voltadas à qualidade foram adotadas pelos cafeicultores, bem como a importância de incentivar os produtores a investirem na produção do café no estado.

Palavras chave: Concafé, Agroindústria, Lavoura. 


\section{INTRODUÇÃO}

De acordo com Ministério da Agricultura, Pecuária e Abastecimento - MAPA (2017), a agroindústria no Brasil, e principalmente no estado de Rondônia, se estabelece em uma significativa alternativa de geração de emprego e renda no meio rural. É uma opção para o estabelecimento dos agricultores familiares no campo e para a construção de um novo modelo de desenvolvimento sustentável na cadeia agrícola.

É notável que a prática da cafeicultura, uma atividade agrícola, representa uma importância significativa na economia do Brasil, e também no estado de Rondônia. Conforme dados fornecidos em 2015 pelo Portal do Governo do Estado de Rondônia, ela foi a atividade rural responsável pelo início da formação econômica das principais regiões do Brasil e continua tendo uma grande relevância atualmente.

A cadeia produtiva do café é uma cadeia curta e de pouca complexidade, sendo no entanto, formada por um número significativo de participantes. Fazem parte da cadeia: os fornecedores de insumos à cafeicultura, setor industrial a montante da produção agrícola; o setor agrícola que engloba a produção de café nas propriedades agrícolas; o setor exportador de café em grão (verde); a indústria de beneficiamento e processamento de café torrado e moído e a indústria de processamento de café solúvel (RIBEIRO, 2005).

Visto a importância da atividade agroindustrial, é necessário citar também a relevância da aplicação da gestão da qualidade em cada ponto de sua cadeia produtiva. Com o mercado cada vez mais competitivo e clientes cada vez mais exigentes, é necessário que as agroindústrias se preocupem com o contentamento de seus consumidores. Isso se torna possível quando há um melhoramento contínuo de seus processos e produtos, para que obtenham resultados positivos. Portanto, é essencial que os fornecedores estejam sempre em sintonia com seus clientes, estabelecendo metas e evoluindo dentro de sua organização.

Logo, para impulsionar a competitividade, por conseguinte, incentivando as empresas agroindustriais a aprimorarem suas técnicas de produção, foram criados eventos de premiações, tal como o Prêmio Nacional da Qualidade (PNQ). Com tudo, nesse estudo, será feita uma análise a partir dos produtores agroindustriais que ganharam o prêmio Concafé (Concurso de Qualidade e Sustentabilidade do Café de Rondônia) dos últimos anos, e a partir daí, entender quais práticas que levaram esses produtores a ganhar um prêmio regional de grande relevância, como é o Concafé.

0 presente artigo conta com dados coletados dos próprios agricultores, e a interpretação dos mesmos, acerca de métodos e formas utilizadas em dados pontos da cadeia produtiva do café. Tais dados, ao serem explanados, ajudarão a compreender as razões que levaram os ganhadores das três últimas edições do prêmio Concafé a alcançarem tamanho êxito.

\section{REFERENCIAL TEÓRICO}

É fato que o conceito de gestão da qualidade pode variar muito de acordo com o ambiente, situação, pessoas, empresas, cliente, etc. De acordo com Paladini (2010), os conceitos sobre qualidade estão, em sua maioria, incorretos, e isso é um problema, pois não se pode "redefinir" um termo que todos já conhecem, ou restringir seu uso à situações específicas, sendo ele de domínio público.

Qualidade costuma ser sinônimo de perfeição, e é um aspecto subjetivo das pessoas, podendo variar demasiadamente. Crosby, um empresário e escritor estadunidense que contribuiu para a teoria da gestão e métodos de gestão da qualidade, define que "qualidade é estar em conformidade com os requisitos"

A qualidade é então reconhecida como sendo o "cumprimento dos requisitos". 0 fato de um produto, serviço ou processo de trabalho cumprir ou não seus requisitos não é questão de opinião. 0 cumprimento dos requisitos pode ser prontamente observado e medido. Quando os requisitos não são cumpridos, temse o não cumprimento. (ROBLES e BONELLI, 2008. PG 2)

Portanto, seria equívoco resumir qualidade em apenas algumas palavras ou características, pois envolve múltiplos elementos, com diferentes níveis de importância. Deixar de considerar algum desses elementos ou centralizar a atenção em outro pode prejudicar consideravelmente o ambiente no qual ele está sendo aplicado.

\subsection{A AGROINDÚSTRIA}

Os produtos do campo e do mar e sua comercialização posterior formam o setor da agroindústria. Sendo artesanais ou industriais, os processos do setor se baseiam em transformar produtos de atividades agrícolas, florestais ou pecuárias. Desde a Revolução Industrial, iniciada no século XVIII, a agroindústria 
vem ampliando e progredindo suas técnicas visando aumentar os padrões de produção (DELGADO e BERGAMASC0, 2017).

De acordo com dados da EMBRAPA (Empresa Brasileira de Pesquisa Agropecuária, 2017), a agroindústria tem participação de aproximadamente 5,9\% no Produto Interno Bruto (PIB) brasileiro, no beneficiamento, na transformação dos produtos e no processamento de matérias-primas provenientes da agropecuária, promovendo dessa forma maior integração do meio rural com a economia do mercado. A pesquisa agropecuária tem contribuído para a melhoria da qualidade dos produtos agroindustriais, oferecendo soluções tecnológicas inovadoras e de grande impacto, como a biofortificação de alimentos, processo utilizado para aumentar o conteúdo nutricional de micronutrientes, como vitaminas e minerais específicos, por meio de técnicas de melhoramento convencional de plantas ou da biotecnologia, e até mesmo a clonagem de mudas, uma técnica muito importante no setor cafeeiro que será abordada mais especificamente a seguir.

\subsection{GESTÃO DA QUALIDADE NO AGRONEGóCIO}

Compreendendo a importância da gestão da qualidade e do agronegócio pode-se perceber que é importante que a associação das duas ocorra, visto a intenção do crescimento da agroindústria no país e no mundo.

No caso da agroindústria, de acordo com Batalha (2011), algumas de suas características tornam a gestão da qualidade mais complicada. Em primeiro lugar, o tamanho e a profissionalização das cadeias agroindustriais são muito variados. 0 que não impede, mas torna difícil a uniformização da visão e da prática da gestão da qualidade. Em alguns casos a distância se torna um agravante, em outros a falta de padronização. Em segundo lugar, a produção, em geral alimentos, tem um individualizador de alguns aspectos da qualidade serem ocultos e indispensáveis para a comercialização - as questões de segurança do alimento. Isto é visto como um sinônimo de qualidade, mas é apenas um das várias caraterísticas que um produto pode apresentar.

Nessa concepção, é imprescindível investimentos na formação de recursos humanos , mudança de hábitos culturais, aplicação em tecnologias e implantação de sistemas de gestão de forma a assegurar a produção de um alimento seguro. Nesse sentido, há uma grande contribuição por meio de algumas ferramentas da qualidade.

\subsection{FERRAMENTAS DA QUALIDADE NO FAVORECIMENTO DA AGROINDÚSTRIA}

Conceitualmente, de acordo com Carvalho e Paladini (2012), ferramentas da gestão da qualidade são mecanismos simples para selecionar, instituir ou avaliar alterações no processo produtivo por meio de análises objetivas de partes bem definidas deste processo. Incontestavelmente, o propósito é gerar melhorias.

Nesse sentido, uma grande contribuição é a ISO 22000 e seus programas pré-requisitos, sendo eles o APPCC (Análise de Perigos e Pontos Críticos de Controle), o BPF (Boas Práticas de Fabricação), o PPOH (em português, Procedimento Padronizado de Higiene Operacional), rastreabilidade e POP (Procedimento Operacional Padrão) que, por força de regularização, propagam as práticas de produção de um alimento seguro. Lembrando que, as ferramentas citadas acima, garantem apenas a qualidade sanitária. Ainda resta fornecer aos clientes produtos que estejam em sintonia com suas necessidades e expectativas, que, nesse caso, são as características básicas esperadas quanto ao café, como o paladar, aroma, acidez, doçura, amargor, etc.

Apesar de todas as práticas citadas acima serem muito importantes no ramo alimentício, na área rural pode-se dizer que o POP se destaca. De acordo com Colenghi (1997), o POP consiste em descrever em detalhes todas as operações que são necessárias para realizar um determinado procedimento, ou seja, "um roteiro padronizado para realizar uma determinada atividade", sendo de grande importância dentro de qualquer processo funcional para garantir, mediante uma uniformização, os resultados desejados por cada tarefa realizada.

Por fim, existe uma gama de ferramentas para melhor gestão da qualidade da cadeia produtiva do agronegócio, além das citadas acima. É de suma relevância a aplicação de tais ferramentas, de forma a contribuir para o aumento da competitividade do agronegócio brasileiro. 


\subsection{A DINÂMICA DO CAFÉ NO BRASIL}

De acordo com a revista virtual Cafeicultura (2011), o café chegou ao norte do Brasil, mais precisamente em Belém, em 1727, trazido da Guiana Francesa. Devido às condições climáticas brasileiras, o cultivo de espalhou rapidamente, com produção voltada para o mercado doméstico. Num espaço de tempo relativamente curto, o café passou de uma posição relativamente secundária para a de produto-base da economia brasileira, desenvolvendo-se com total independência, ou seja, apenas com recursos nacionais, sendo, afinal, a primeira realização exclusivamente brasileira que visou a produção de riquezas.

Já no Estado de Rondônia, de acordo com Nasser (2018) com o começo da colonização agrária do estado muitos imigrantes vinham o estado e se estabeleciam, assim ganhando o título de posse e desenvolvendo da região dando início ao cultivo do café, uma vez que a região se caracteriza pelo clima quente, úmido e com estações bem definidas. Na qual de acordo com o site virtual Governo do Brasil, atualmente Rondônia é o maior produtor de café da região norte e o quinto maior produtor do país, com $4 \%$ do total da produção nacional o que equivale a 2,19 milhões de sacas.

Contudo a cultivação do café de modo geral é feita por mão de obra familiar e os tipos de café que podem ser cultivados com alta taxa de viabilidade de grande produção delimita-se a espécie coffea canephora, mas popularmente chamado de robusta ou conilon. As características do estado, de acordo com o Jornal Online Rondoniagora em uma pesquisa realizada conjuntamente com a Superintendência Estadual de Comunicação de Rondônia (2018), se faz propícia para essas espécies, na qual a maior produção está condensada na região da zona da mata - Cacoal, Alta Floresta e São Francisco do Guaporé - embora podese encontrar lavouras de cafés em todo o estado.

\subsubsection{COFFEA CANEPHORA}

Segundo Ronchi (2009), no mundo todo existem mais de 100 diversas espécies do agrupamento genético coffea. Na qual somente a espécie Coffea Canephora representa aproximadamente 38\% da produção mundial de café. Posto que o nome 'robusta' remete a rusticidade e resistência pois no Brasil seu cultivo ocorre a altitudes inferiores a 500 metros, temperaturas médias de 22 a $26{ }^{\circ} \mathrm{C}$ e somente Espírito Santo e Rondônia produzem $87 \%$ do café robusta nacional. De acordo com Brasil (2003) a instrução normativa no 8, de 11 de junho, do MAPA, a classificação do café robusta (grupo II) de acordo com a bebida, realizada pela prova de xícara é distinta da classificação do café arábica (grupo I), sendo o café robusta é utilizado nos blends (mistura de grãos), com o arábica, com a finalidade de 'encorpar' a bebida, diminuir sua acidez e reduzir o custo do café torrado e moído à venda para o consumidor.

\subsubsection{CLONAGEM DO CAFÉ}

A clonagem é a formação de seres com a genética idêntica, ou seja, a produção de uma cópia de um determinado ser vivo, sendo possível a reprodução de plantas sem a necessidade do plantio de sementes como as produções clonais dos cafeeiro (PROCAFÉ, 2018). No qual esse tipo de procedimento é executado por meio de etapas, onde primeiro baseado-se na produtividade se escolhe uma matriz, em seguida se prepara a matriz para a produção de estacas por meio do envergamento, uma vez que cada matriz pode produzir de 200 a 400 clones, posto que dentre de um período de 4 a 6 meses tira-se as brotações para passar pela limpeza e posterior ser levada para o jardim clonal por um período de 120 a 150 dias para ser levadas de volta para os campo de plantio (EMBRAPA, 2014).

Uma vez que a Revista Cafés de Rondônia (2018) destaca que um dos estado que mais utiliza a técnica de clonagem é o de Rondônia desde os últimos anos da década de 90, com centenas de mudas do tipo conilon de genética desconhecida vindas do Espírito Santo. Visto que depois do controle destas mudas, a técnica passou a ser um indicador de aumento para a produtividade no estado, pois a segurança do café ter uma alta qualidade é maior.

\subsection{PREMIAÇÃO NACIONAL E ESTADUAL DE CAFÉ}

Os segmentos da área do café é um dos os maiores lances na produção nacional, desta forma ganhando o seu próprio meio de reconhecimento para quem mais se destaca no âmbito nacional, de acordo com a Associação Brasileira da Indústria De Café (2018) o Concurso Nacional ABIC de Qualidade do Café foi criado em 2004 e que em 2018 apresentou a sua 14로 Edição tendo como finalidade oferecer aos brasileiros os melhores cafés industrializados e cultivados do Brasil por meio da união das pontas da 
cadeia produtiva: lavoura e torrefação. Posto que o atual campeão do concurso é Letícia Alcântara com o seu microlote de café produzido na Fazenda Divino Espírito Santo na Bahia, tendo em uma escala de 0 a 10 a nota final de 8,62 pontos. Em paralelo também se destaca o Prêmio Coffee Of The Year Brasil que ocorre durante a Semana Internacional do Café o qual se divide em duas categoria: arábica e canéfora (SEMANA INTERNACIONAL DO CAFÉ, 2018).

De acordo com Entidade Autárquica de Assistência Técnica e Extensão Rural do Estado de Rondônia EMATER/RO (2018) o estado de Rondônia também tem o seu próprio meio de reconhecimento para os produtores que produzem um café com maior qualidade, o Concafé - Concurso de Qualidade e Sustentabilidade do Café de Rondônia com o propósito de incentivar, promover melhorias e a competitividade da cafeicultura no mercado nacional que foi criado no ano de 2016 e reafirma o aumento de $100 \%$ da produtividade se comparado com 5 anos atrás, pois conta com parcerias estaduais, melhoramento genético, incentivo de técnicas sustentáveis e novas tecnologias.

\subsection{OS REQUISITOS DE QUALIDADE DO CONCAFÉ}

O Concurso de Qualidade e Sustentabilidade do Café de Rondônia (Concafé) surgiu com o intuito de aumentar a produção de grãos e melhorar ainda mais a qualidade do produto que já vem crescendo no estado. Teve sua primeira edição no ano de 2016 e de acordo com técnico da Emater de Cacoal/RO, Wesley Gama, desde a primeira edição, a qualidade encontrada na bebida extraída dos grãos selecionados surpreenderam os especialistas durante a etapa de degustação. Por se tratar de um café considerado inferior ao do tipo arábica na qualidade da bebida, o café robusta produzido no estado têm surpreendido por apresentar aromas e nuances de boa qualidade quando avaliado por especialistas de várias partes do mundo.

O concurso conta com a participação de vários cafeicultores espalhados por todo o estado. Os principais requisitos/etapas, de acordo com o regulamento do concurso disponibilizado pela EMATER-RO, para a participação no concurso são as seguintes:

Se inscrever em um dos escritórios da EMATER-RO em algum município do estado, levando uma amostra do lote selecionado para o concurso, com o volume de três litros de café pilado;

Manter disponível em sua propriedade um lote contendo no mínimo cinco sacas de $60 \mathrm{~kg}$ de café canéfora pilado, que tenha as mesmas características da amostra que foi entregue no dia da inscrição;

Após a avaliação inicial das amostras, os 30 finalistas são submetidos a uma auditoria, onde a comissão organizadora coleta uma nova amostra de café dos respectivos lotes separados para o concurso nas propriedades e uma segunda análise é realizada para comprovar a compatibilidade das amostras com o lote.

Todas as amostras selecionadas após a auditoria são submetidas a uma análise física (determinação de umidade, que devem estar entre 11\% e 13\% e avaliação de defeitos físicos que não pode passar da classificação superior ao tipo 8 - 360 defeitos) e as que não estiverem de acordo com os requisitos estipulados serão desclassificadas. Outras características classificatórias analisadas são: secagem e cor, uniformidade e tamanho do grão.

As amostras classificadas fisicamente são submetidas a análise de qualidade da bebida por profissionais com formação específica (Q-Grader) e com experiência em degustação de café canéfora. Dez principais atributos são levados em consideração, com base no Protocolo de Degustação de Robustas Finos da Organização Internacional do Café: fragrância/aroma, sabor, retrogosto, relação salinidade/acidez, relação amargor/doçura, sensação na boca, equilíbrio, uniformidade, limpeza e conjunto.

Os três produtores que, após todas as análises, apresentarem as maiores pontuações referente a qualidade de bebida das amostras inscritas são considerados os vencedores do ConCafé.

\section{METODOLOGIA}

A pesquisa realizada é classificada como uma pesquisa descritiva com abordagem qualitativa. Neste tipo de pesquisa procura-se retratar as características do objeto estudado, fornecendo com precisão os fatos, onde se coleta informações, bibliográficas ou não, e analisa-se as variáveis envolvidas. 0 método utilizado na pesquisa foi o método dedutivo. 
O método dedutivo, de acordo com a acepção clássica, é o método que parte do geral e, a seguir, desce ao particular. Parte de princípios reconhecidos como verdadeiros e indiscutíveis e possibilita chegar a conclusões de maneira puramente formal, isto é, em virtude unicamente de sua lógica (GIL, 2008).

Na primeira etapa da pesquisa foi realizado um levantamento bibliográfico dos principais materiais sobre o tema em questão (livros, artigos, teses e reportagens). A segunda etapa constituiu de uma entrevista semi-estruturada com um técnico da EMATER de Cacoal/RO a fim de levantar informações sobre o concurso e os participantes e, posteriormente, uma entrevista semi-estruturada, com 20 perguntas abertas, realizada com os três vencedores do ConCafé dos anos de 2016, 2017 e 2018. Na terceira etapa foi feita a compilação dos dados para análise, em conjunto com o cálculo por média aritmética simples das pontuações tanto dos três primeiros colocados quanto de todos os classificados das três edições do concurso, para então gerar os resultados de acordo com os objetivos em questão. É importante destacar que a pesquisa em questão possui caráter ético, portanto nenhuma informação (exceto as autorizadas) foram divulgadas.

\subsection{CARACTERIZAÇÃo}

O estudo tem como foco parte da cadeia básica do café, onde se baseia principalmente nas etapas de plantio, colheita e secagem, como ilustrado na figura 1.

Figura 1 - Cadeia produtiva do café.

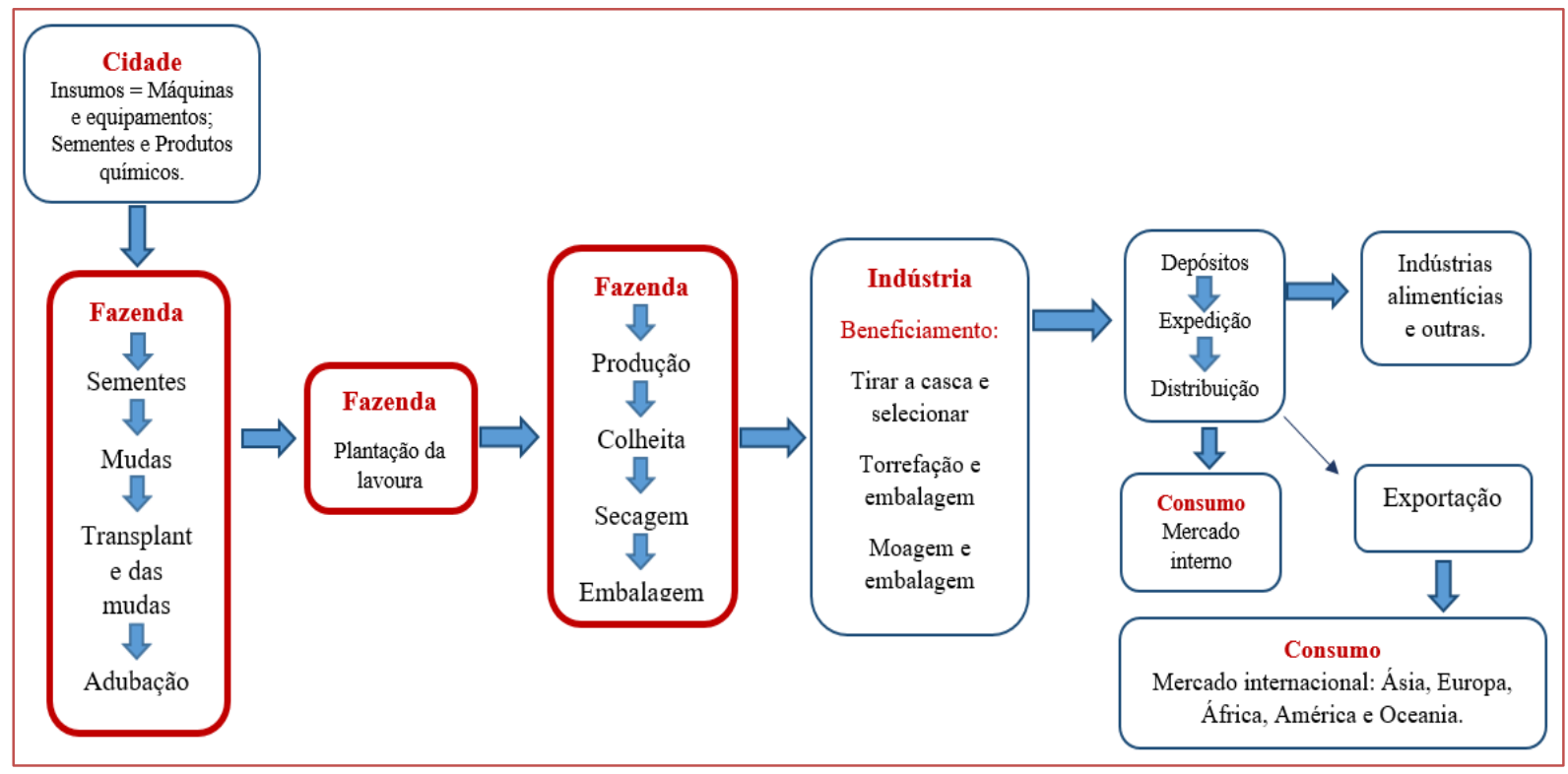

Fonte: Calegari (2017).

Os campos destacados em borda vermelha na figura 1, esquematizam o processo produtivo dos participantes do ConCafé, que atuam apenas em parte da cadeia produtiva total do café.

A pesquisa foi realizada com 3 (três) produtores de café que venceram as três edições do concurso ConCafé, o ganhador da primeira edição, no ano de 2016, foi o produtor Arneli Sergio Kalk, de 41 anos, e no decorrer do texto será chamado de Cafeicultor 1. Sua propriedade está localizada na Linha Figueira quilômetro 8, lote 85 E, Gleba 08, Zona Rural, município de Cacoal/RO.

0 ganhador da segunda edição, no ano de 2017, foi o meeiro do produtor Arneli Sergio Kalk, Tiago Moraes Duarte, de 27 anos, e no decorrer do texto será chamado de Cafeicultor 2, sendo a mesma lavoura do ano anterior.

$03^{\circ}$ Concafé, realizado no ano de 2018, teve como vencedor o Dione Mendes Bento de 25 anos, e será chamado de Cafeicultor 3 no decorrer do texto. Sua propriedade fica localizada na zona rural da cidade de Cacoal/RO, precisamente na linha 10 , lote 29 , gleba 10. 


\section{RESULTADOS}

As pontuações obtidas pelos três melhores colocados dos três anos de concurso podem ser observadas no gráfico 1.

Gráfico 1 - Notas dos três primeiros colocados nos anos de 2016, 2017 e 2018 do ConCafé.

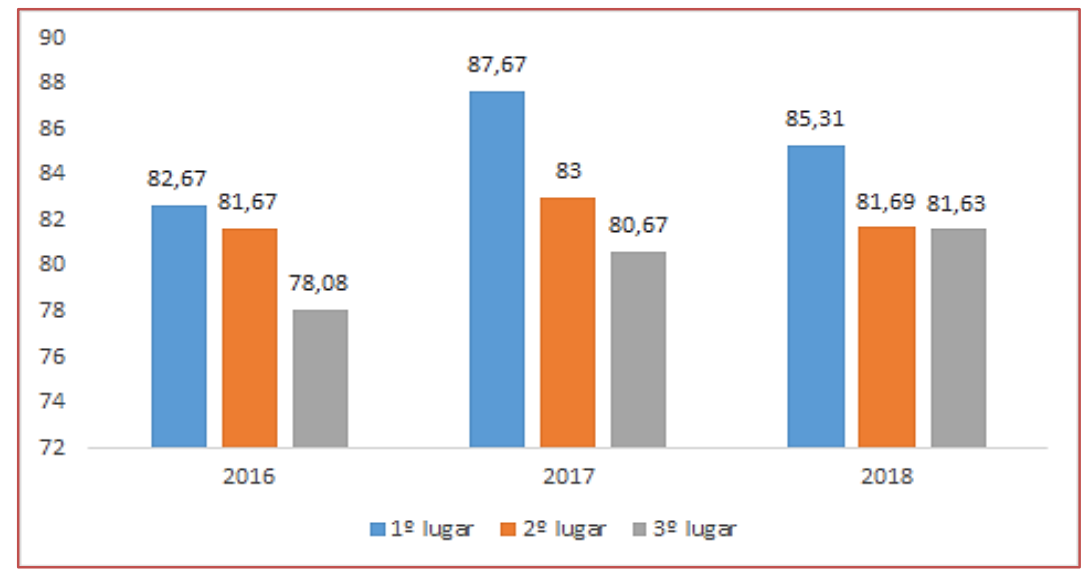

Fonte: Autores (2018).

Pela análise do gráfico 1 podemos dizer que os cafés de 2017 foram os que melhor pontuaram, com variação positiva de 5,70\%, 1,60\% e 3,21\% entre os primeiros, segundos e terceiros colocados, respectivamente, entre as edições de 2016 e 2017, já em comparação entre as edições de 2017 e 2018 , o decréscimo foi de 2,77\%,1,60\% e 1,18\%, respectivamente.

Analisando as médias das notas de todos os participantes do ConCafé temos essa evolução melhor evidenciada, sendo a média de 201673 pontos, seguida da média 74,67 em 2017 e a de 2018, 76,92. Essa melhora nas avaliações obtidas pode ser atribuída ao impacto causado pelo primeiro concurso aos cafeicultores da região, que percebendo a valorização que o café de qualidade pode atingir, em conjunto com os incentivos de órgãos como a EMATER e SEAGRI, se sentiram mais motivados a investir em práticas que proporcionem uma produção com alto padrão de qualidade, além do tipo de clone selecionado, que resultam em diferentes qualidades de bebidas.

\subsection{PRÁTICAS DE QUALIDADE EXERCIDAS PELOS GANHADORES DO CONCAFÉ}

No ano de 2016 e 2017, por se tratar da mesma lavoura e em entrevista com os cafeicultores 1 e 2 as práticas aplicadas para ambas as edições do concurso foram as mesmas, portanto a comparação das práticas de qualidade acontecerá entre a lavoura do cafeicultor 1 e $2 \mathrm{com}$ a do cafeicultor 3 .

A propriedade do cafeicultor 1 conta com 15,5 alqueires no total e 12 hectares de lavoura de café, já o cafeicultor 3 possui uma propriedade de 5 alqueires e meio, sendo 8 hectares de de café plantado.

Quando perguntados a respeito do tempo em que produzem café, ambos os cafeicultores relataram que desde que eram crianças já tinham contato com a produção do café e outras lavouras, estando no ramo agroindustrial, na agricultura familiar e na produção de café há muitos anos. Na propriedade do cafeicultor 1 é produzido exclusivamente café e cultivo de mudas em viveiros, onde o próprio cafeicultor cultiva mudas de café para o uso pessoal e comercial, por meio de clonagem, criando plantas mais resistentes a partir de suas melhores matrizes. Este produtor é pioneiro nas práticas de melhoramento genético dos cafés no estado, sendo reconhecido como o primeiro produtor a ter um jardim clonal em Rondônia, no ano de 2007. O cafeicultor 3 possui uma pequena plantação de milho, além da lavoura de café, porém ressaltou que em breve pretende se dedicar totalmente a produção de café. Suas mudas são adquiridas no município de Alto Alegre dos Parecis e também do viveiro do cafeicultor 1.

A motivação de ambos os produtores para a participação do concurso veio por meio do incentivo da EMATER, para que o café produzido por eles ganhasse visibilidade e valor agregado. Para o cafeicultor 1 , café de qualidade é um tipo de mercado que muitos produtores ainda não acreditam, mas que existem 
aqueles que confiam no potencial do mercado e reconhecem o valor do café, e pagam pelo trabalho dos produtores, pois para conseguir atingir uma boa qualidade é necessário a realização de práticas diferenciadas dos produtores convencionais, como na maturação do grão e na sua secagem, os quais acarretam maiores custos do que na produção de cafés comuns. Para o cafeicultor 3 a qualidade do café representa reconhecimento e valorização do seu produto, é como conseguir proporcionar um produto bom para a mesa dos brasileiros.

Em relação aos cuidados com a lavoura de café do produtor 1, se iniciam na seleção de bons clones para a criação das mudas, onde é essencial para se obter uma boa qualidade no café. Após a seleção do clone é realizada a preparação do solo que consiste em fazer análises laboratoriais das características do solo, e realizar as correções necessárias seguido pela adubação. 0 produtor contou que os adubos que são utilizados em sua propriedade são em sua maioria de origem orgânica, como a cama-de-frango (tipo de compostagem formada por casca de arroz, sabugo de milho triturado, serragem grossa de madeira ou capim picado, dejetos, penas e sobras de ração do sistema de criação de frangos (FERREIRA JUNIOR, 2011). 0 produtor destaca que não aplica o uso de agroquímicos em sua lavoura e trabalha sempre de maneira preventiva para não precisar de intervenção química, como defensivos químicos, por exemplo. Com o solo preparado e devidamente adubado é realizado o plantio das mudas. A ocorre de maneira natural na lavoura do cafeicultor, ou seja, por meio das chuvas. 0 auge de produtividade das suas plantas acontecem após três anos do plantio e duram cerca de um ano. A partir do quinto ano a planta começa a sofrer o processo de desgaste natural, onde acontece a queda da produtividade, sendo necessário realização de podas para que haja uma restauração da planta, que consiste, de acordo com cafeicultor 1, na seleção dos brotos na parte posterior da planta e na retirada das hastes, chamada de "poda pulmão".

A colheita é realizada de forma manual, na lavoura do cafeicultor 1 , ocorrendo somente quando a fruta apresentar coloração avermelhada, o termo utilizado no meio cafeeiro é "cereja", que é quando a maior parte dos grãos estão maduros. Por possuir mais de uma variedade de clone em sua propriedade, a colheita é feita separadamente, para que não haja uma mistura dos grãos e ocasione alterações indesejadas na bebida produzida. Após a colheita o café passa pelo processo de secagem, realizado em terreiro suspenso pelo produtor, logo após esse processo os grãos são ensacados e são encaminhados para receber o processo de torra.

As práticas realizadas para qualidade da produção do cafeicultor 3, vão desde o cuidado com solo, até a secagem do grão, seguindo a linha de cuidados práticos para cultivo de café. Na propriedade deste produtor, são realizadas análise do solo, antes da plantação das mudas, para saber a dosagem e que tipo de correção de minerais se devem aplicar, geralmente são usados adubos orgânicos a base de cama de frango e adubação química. Na propriedade também são realizadas podas quando as plantas ainda estão pequenas, para ter uma maior quantidade de brotos e também podas nas plantas já adultas após colheitas e o auge de sua plantação ocorre quando as plantas atingem em torno de 2 a 3 anos de idade. A propriedade também conta com um sistema de irrigação que são feitos através dos métodos conhecidos como aspersão, outorga e manejo de água. A colheita do café é realizada a mão pelos próprios membros da família, visto que a produção é caracterizada como familiar, onde está colheita é realizada quando o grão atinge a característica de cereja (maduro) ou pelo menos $80 \%$ deles estão neste estágio, sendo feita esta colheita de uma só vez. A secagem que é um dos principais pontos para se garantir a qualidade do grão é realizada em estufa de lajotas, forrado com areia. Para prevenção de pragas são utilizados defensivos.

Aplicando corretamente todos esses processos citados anteriormente a colheita realizada pelo cafeicultor 3 chega a ser de 140 sacas por hectare, onde as plantas são chamadas clones do tipo robusta.

A lavoura do cafeicultor 1 e 2 também é de robusta e possui uma produtividade mais baixa que a do cafeicultor 3, atingindo cerca de 94 sacas de café por hectare, isso se dá, principalmente, pelo fato da lavoura não possuir irrigação mecanizada, dependendo totalmente das chuvas. É pertinente ressaltar, portanto, que a produtividade não está diretamente ligada à qualidade, caso contrário os cafés da lavoura dos cafeicultores 1 e 2 não estariam entre os melhores de Rondônia.

As figuras 2 e 3 mostram pés de café das lavouras dos cafeicultores 1, 2 e 3, ambas em ponto de colheita. 




Fonte: Emater (2017).

Figura 3 - Lavoura do ganhador do concafé 2018.

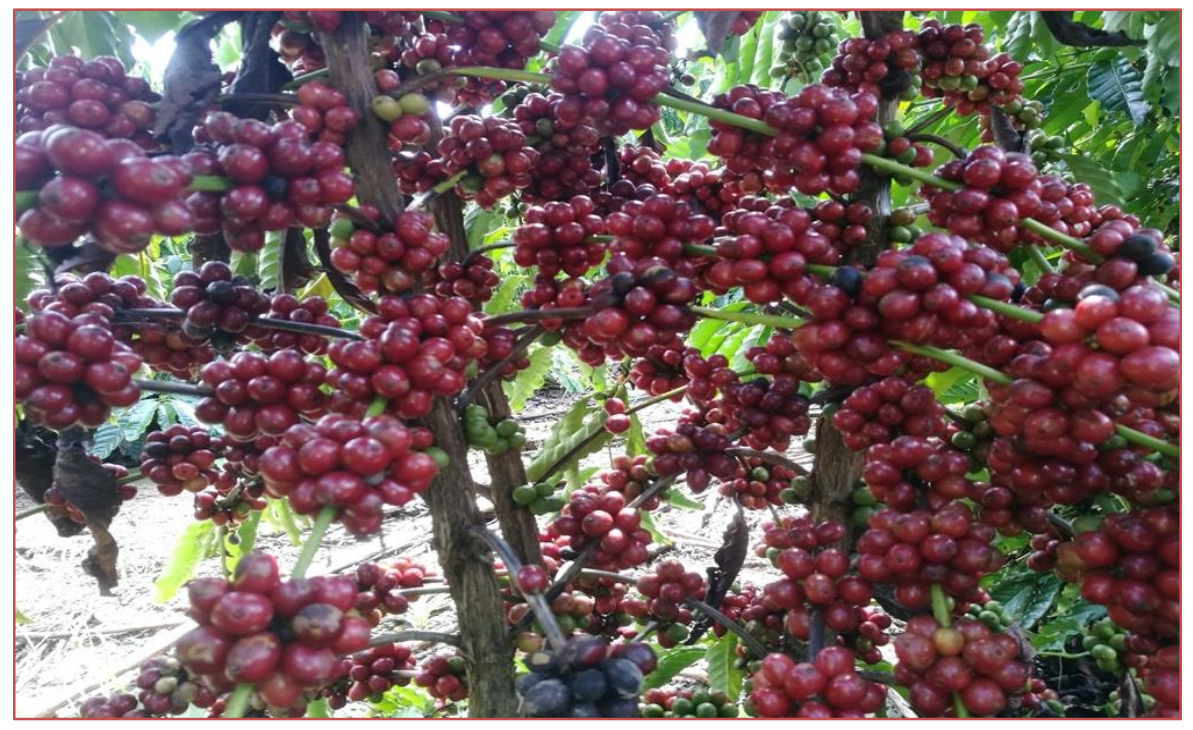

Fonte: Emater (2018).

O café levado ao concurso de 2017 foi da mesma lavoura do ano de 2016, porém o café selecionado foi o clone 80, que possui características genéticas diferentes do clone 41 que foi o clone usado pelo cafeicultor 1, em 2016. O tipo de clone afeta diretamente na bebida extraída, então essa diferença de clones proporcionou uma outra qualidade de bebida, evidenciada na nota alta recebida pelo cafeicultor 2.

Para se obter um café de boa qualidade é necessário a realização de todas etapas básicas da produção de café, quando ocorre quebra de uma dessas etapas, acontece a perda de alguma qualidade do grão. Analisando os três ganhadores do primeiro lugar do concurso é possível perceber uma certa similaridade no cultivo de suas plantações, onde os cuidados básicos como: análise e adubação do solo, escolha da muda, poda, colheita e secagem são praticamente as mesmas, com alguns detalhes diferentes. Para melhor entendimento, no quadro 1 é feito uma análise das práticas que os ganhadores realizam em suas propriedades: 
Quadro 1 - Análise das práticas realizadas pelos ganhadores conCafé nos anos de 2016 a 2018.

\begin{tabular}{|c|c|c|c|c|}
\hline $\mathrm{p}$ & Cafeicultor 1 & Cafeicultor 2 & Cafeicultor 3 & Frequência \\
\hline Análise do solo & $\mathrm{x}$ & $\mathrm{x}$ & $\mathrm{x}$ & $100 \%$ \\
\hline Adubação orgânica & $\mathrm{x}$ & $\mathrm{x}$ & $\mathrm{x}$ & $100 \%$ \\
\hline Adubação química & - & - & $\mathrm{x}$ & $33 \%$ \\
\hline Produção das próprias mudas & $\mathrm{x}$ & $\mathrm{x}$ & - & $66 \%$ \\
\hline Seleção de mudas & $\mathrm{x}$ & $\mathrm{x}$ & $\mathrm{x}$ & $100 \%$ \\
\hline Irrigação por aspersão & - & - & $\mathrm{x}$ & $33 \%$ \\
\hline Colheita Manual & $\mathrm{x}$ & $\mathrm{x}$ & $\mathrm{x}$ & $100 \%$ \\
\hline $\begin{array}{l}\text { Poda para brotação de novos } \\
\text { galhos }\end{array}$ & $\mathrm{x}$ & $\mathrm{x}$ & $\mathrm{x}$ & $100 \%$ \\
\hline Secagem em estufa & - & - & $\mathrm{x}$ & $33 \%$ \\
\hline Secagem em terreiro suspenso & $\mathrm{x}$ & $\mathrm{x}$ & - & $66 \%$ \\
\hline Beneficiamento & $\mathrm{x}$ & $\mathrm{x}$ & - & $66 \%$ \\
\hline
\end{tabular}

Fonte: Autores, 2018.

No quadro 1 podemos fazer um comparativo do que os três cafeicultores realizam em suas propriedades. $\mathrm{Na}$ plantação dos cafeicultores 1 e 2, a adubação do solo é feita somente com adubo orgânico, especialmente cama de frango, outro detalhe a ser notado é que as mudas são feitas pelo próprio produtor ou seja além de produtor é também viveirista, onde a seleção de mudas é realizada pelo produtor em sua propriedade (lembrando que a plantação do cafeicultor 1 e 2 é a mesma), diferentemente do cafeicultor 3 onde a adubação é realizada por adubação orgânica (cama de frango) e adubação química ( de acordo com a necessidade do solo) e suas mudas são compradas de viveiros. Outra diferença nas práticas dos ganhadores está na irrigação, onde somente o cafeicultor 3 utiliza, sendo que na propriedade dos cafeicultores 1 e 2 a irrigação da plantação é feita somente quando chove. Na fase de secagem também existe diferença entre os produtores, onde cafeicultores 1 e 2 a realização da secagem é em um secador suspenso e o do cafeicultor 3 é realizado em uma estufa de lajotas. A seguir temos as figuras 4 e 5 de forma a melhor visualizar como e onde é realizada a secagem dos produtores: 
Figura 4 - Secador dos ganhadores do concafé 2016 e 2017.



Fonte: Emater (2017).

Figura 5 - Secador do ganhador do concafé 2018.

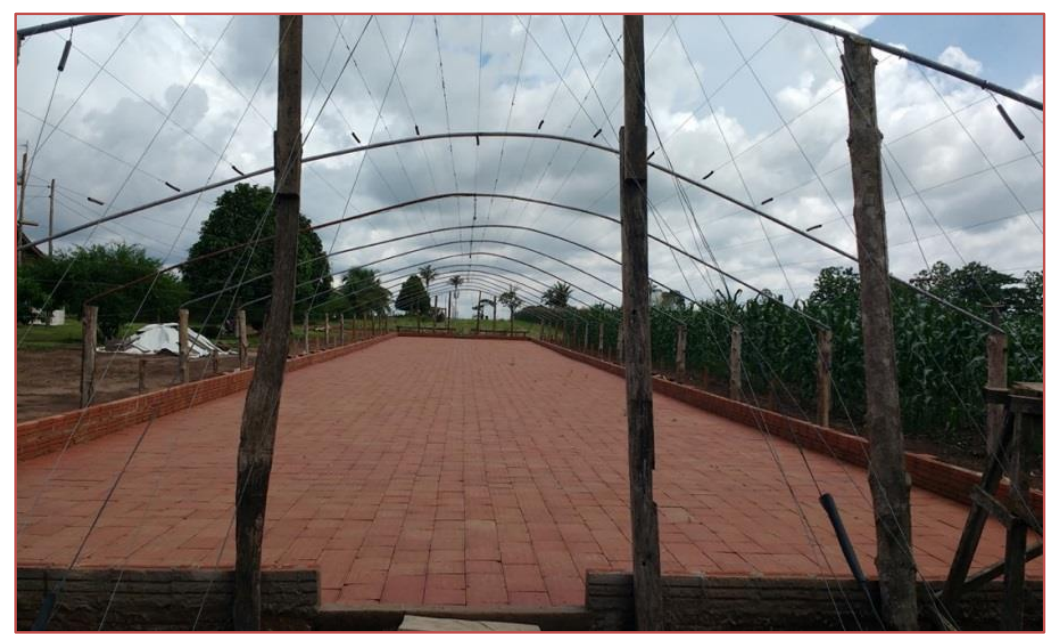

Fonte: Autores (2018).

Dessas diferenças citadas anteriormente podemos destacar que as principais são a irrigação e adubação. A irrigação pode afetar diretamente no sabor da bebida produzida, de forma que o café que recebe irrigação somente da chuva, e havendo uma evolução do seu ciclo natural onde também não há uma interrupção no seu processo de desenvolvimento, pode apresentar uma maior apuração em seu sabor, devido a maior concentração de açúcares, já a plantação que possui uma irrigação mecânica, há uma grande necessidade dessa irrigação ser feita da forma correta e nos períodos corretos, se porventura for feita errada, pode danificar a qualidade do grão e, posteriormente, da bebida.

A fase de adubação é onde a planta recebe seus nutrientes, no caso onde há uma a dubação mais orgânica a planta se desenvolve de forma mais saudável do aquela que recebe adubação química.

Como foi citado anteriormente todos os três vencedores realizam uma série de práticas de forma padronizada para garantir a qualidade do café, quando há a realização de práticas padrão ou procedimentos padrão é a realização de um POP (práticas de operação padrão), com isso é possível afirmar que os cafeicultores aplicam um POP mesmo que de forma intuitiva. 


\subsection{Mapeamento da Produção de Café com Práticas de Qualidade em Rondônia}

Com o resultado das três edições do concurso e todos os cafeicultores do estado que participaram e foram avaliados, foi possível mapear os municípios do estado em que ocorrem práticas de qualidade no cultivo de café. A figura 6 traz este mapeamento.

Figura 6 - Mapa dos municípios de Rondônia que realizam práticas de qualidade na produção de café.



Fonte: Autores (2018).

Os pontos em vermelho representam a quantidade de vezes que os municípios tiveram representantes no ConCafé. É importante destacar a região Centro-Leste (figura 7) do estado, composta pelos municípios como Cacoal, Espigão d'Oeste, Alto Alegre dos Parecis, Alvorada D’Oeste, Alta Floresta, e outros, de onde a cultura do café se desenvolve melhor devido a diversas condições, como o clima e solo. Nesta região há uma concentração de cafeicultores empenhados em produzir cafés com uma qualidade superior à produção convencional. 
Figura 7 - Região Centro-Leste do estado.

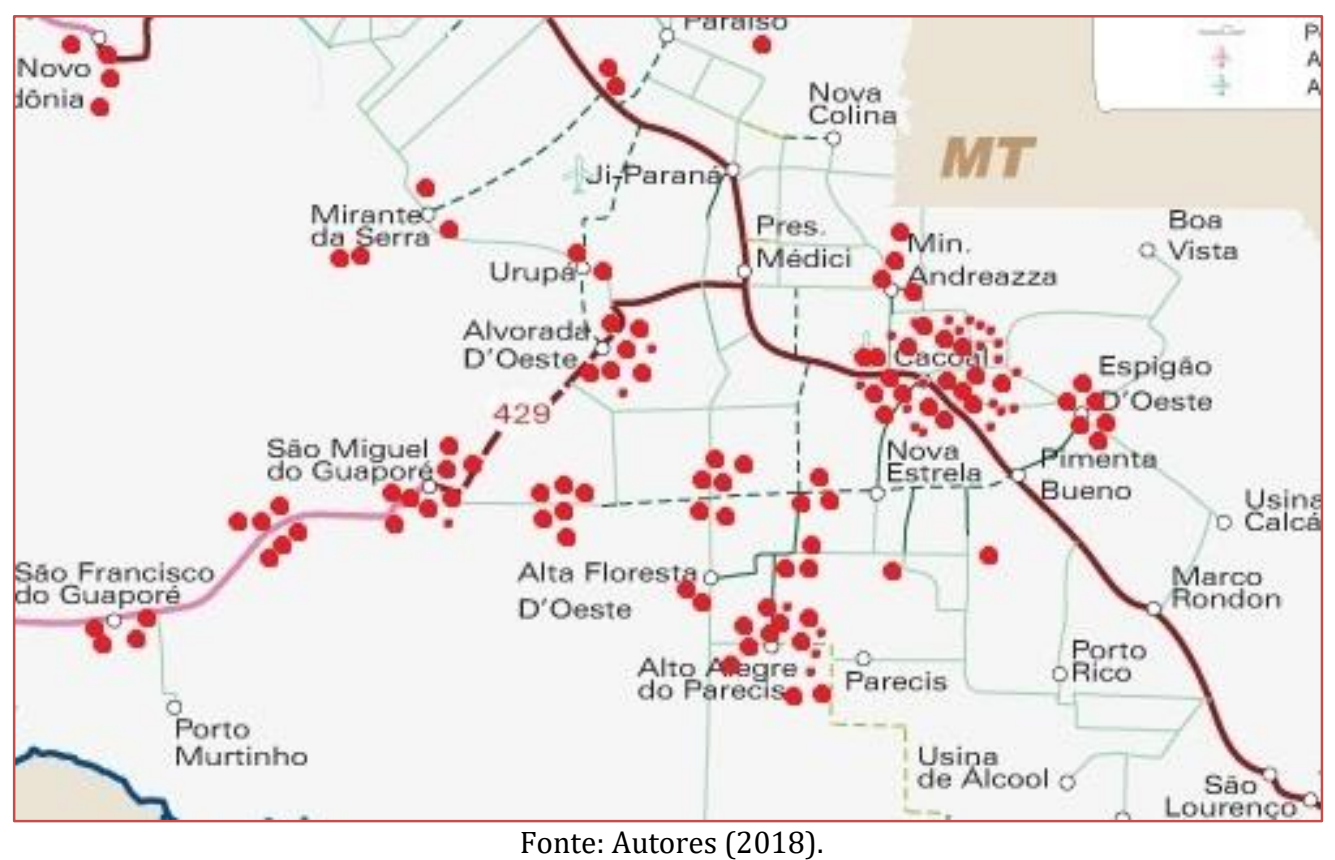

O município de Cacoal foi o que mais forneceu produtores de café para as três edições do concurso, cerca de 35 participantes avaliados nos três anos de ConCafé.

No ano de 2017 e 2018, os três ganhadores da edição do ConCafé, participaram da Semana Internacional do Café, realizada em Minas Gerais. No evento ocorre a premiação Coffee of The Year, onde são escolhidos os melhores cafés do Brasil, separados em duas categorias: cafés do tipo arábica e cafés do tipo conilon. 0 cafeicultor 2, em 2017, foi escolhido como segundo melhor café da categoria conilon, provando então a qualidade da bebida produzida pela lavoura do cafeicultor 1. Além dele, o produtor André Kalk, irmão do cafeicultor 1, levou o terceiro lugar na disputa, repercutindo ainda mais a qualidade do café rondoniense. Já na edição de 2018, o cafeicultor 3, ficou na 4 a posição do concurso nacional. Estes resultados consolidam o estado de Rondônia entre os grandes produtores de café do país.

\section{CONSIDERAÇõES FINAIS}

Por meio do estudo em questão foi possível perceber a importância das práticas de qualidades exercidas na produção de café do estado de Rondônia, evidenciadas no ConCafé. 0 concurso foi uma forma encontrada pelo estado para incentivar a produção de café, e também valorizar os cafés produzidos de maneira mais qualificada.

Por se tratar de agricultura familiar, o volume produtivo atingido pelos cafeicultores em questão é baixo, tendo em vista que todas as etapas realizadas no cultivo do café são realizadas de maneira manual e com poucas pessoas no processo. Nas duas propriedades estudadas foi possível perceber a renovação da geração familiar, onde os cafeicultores têm idades relativamente baixas (41, 27 e 25, respectivamente) e estão dando continuidade às atividades produtivas dos pais.

Um ponto percebido foi a força do município de Cacoal/RO na produção do estado, sendo o município que mais forneceu participantes ao ConCafé, em todas as edições. Em conjunto com o fato dos vencedores dos três anos do concurso ConCafé e os dois vencedores do Coffee of The Year de 2017 exercerem suas atividades no município.

Outro aspecto evidenciado durante a pesquisa foi a falta de reconhecimento do café com maior excelência pelas empresas e compradores dentro do estado. Os produtores entrevistados ressaltaram a dificuldade de serem remunerados de maneira adequada pelos cafés que produzem, cafés estes que necessitam de um maior investimento e atenção na sua produção.

Os cafés premiados no concurso nacional em 2017, segundo os produtores, receberam propostas de exportações para outros países por grandes empresas, porém a quantidade de sacas solicitada por essas 
empresas é muito alta, e os produtores não conseguem atingi-la com suas lavouras. Sendo assim, cabe ao estado investir nesses produtores, ou promover ações para chamar a atenção de outros produtores para a importância das práticas de qualidade em suas lavouras. Uma saída para conseguir a demanda solicitada poderia ser a criação de cooperativas em que as práticas realizadas por todos os cooperados fossem semelhantes e garantisse a qualidade dos cafés para possível exportação. Projetando assim, o café do estado de Rondônia mundialmente.

\section{REFERÊNCIAS}

[1] ASSOCIAÇÃO BRASILEIRA DA INDÚSTRIA DE CAFÉ. Concurso Nacional ABIC de Qualidade do Café. Disponível em: <http://abic.com.br/>. Acesso em: 11 out. 2018.

[2] BATALHA, M. Gestão Agroindustrial: GEPAI: Grupo de estudos e pesquisas agroindustriais. 3 ed. São Paulo: Atlas, 2011.

[3] BRASIL. Instrução Normativa no 8, de 11 de junho de 2003. MINISTÉRIO DA AGRICULTURA, PECUÁRIA E ABASTECIMENTO - MAPA. 2003. Disponível em:

<http://www.sapc.embrapa.br/arquivos/consorcio/legislacao/Instrucao_Normativa_n_8.pdf>. Acesso em: 30 out. 2018.

[4] CALEGARI, L. M. - Os setores da economia e as cadeias produtivas, 2017. Disponível em: <https://luizcalegari.com/index.php/6-ano/2-semestre/298-aprendizagem-5-os-setores-da-economia-e-as-cadeiasprodutivas>. Acesso: 05 nov. 2018.

[5] CARVALHO, M. PALADINI, E. Gestão da qualidade: teorias e casos. 2 ed. Rio de Janeiro: Elsevier: ABEPRO, 2012.

[6] COLENGHI, V. M. O\&M e Qualidade Total: uma integração perfeita. Rio de Janeiro: Qualitymark. 1997.

[7] Delgado, Guilherme Costa. Bergamasco, Sonia Maria Pessoa Pereira (orgs.) Agricultura familiar brasileira: desafios e perspectivas de futuro. Brasília: Ministério do Desenvolvimento Agrário, 2017.

[8] EMBRAPA. Agroindústria. Disponível em: <https://www.embrapa.br/grandes-contribuicoes-para-aagricultura-brasileira/agroindustria>. Acesso em: 10 de out. 2018.

[9] EMBRAPA. Produção De Mudas Clonais De Cafeeiros. Direção de Renata Silva. 2014. (8 min.), son., color. Disponível em: <https://www.youtube.com/watch?v=ncGxz5_ulNE>. Acesso em: 30 out. 2018.

[10] ENTIDADE AUTÁRQUICA DE ASSISTÊNCIA TÉCNICA E EXTENSÃO RURAL DO ESTADO DE RONDÔNIA EMATER/RO. Concafé. Disponível em: <http://www.emater.ro.gov.br/ematerro/>. Acesso em: 13 out. 2018.

[11] FERREIRA JUNIOR, R. Cama de frango vira adubo. Disponível em:

<http://revistagloborural.globo.com/Revista/Common/0„EMI246995-18289,00-

CAMA+DE+FRANGO+VIRA+ADUBO.html>. Acesso em: 29 out. 2018.

[12] FUNDAÇÃO PROCAFÉ. Clonagem. Disponível em:

<http://fundacaoprocafe.com.br/laboratorio/biotecnologia/clonagem>. Acesso em: 30 out. 2018.

[13] GIL, A. C. Métodos e técnicas de pesquisa social. 6. ed. São Paulo: Atlas, 2008.

[14] GOVERNO DO BRASIL. Rondônia é o quinto estado que mais produz café em todo o País. Disponível em: <http://www.brasil.gov.br/noticias/economia-e-financas/2018/06/rondonia-e-o-quinto-estado-que-mais-produzcafe-em-todo-o-pais>. Acesso em: 13 out. 2018.

[15] MINISTÉRIO DA AGRICULTURA, PECUÁRIA E ABASTECIMENTO - MAPA. Café no Brasil 2017. Disponível em: <http://www.agricultura.gov.br/assuntos/politica-agricola/cafe/cafeicultura-brasileira>. Acesso em: 27 out. 2018.

[16] MUNDO EDUCAÇÃO. Economia Cafeeira. Disponível em:

<https://mundoeducacao.bol.uol.com.br/historiadobrasil/economia-cafeeira.ht>. Acesso em: 26 out. 2018.

[17] NASSER, P. Café do Brasil: Rondônia. Disponível em: <<http://www.mexidodeideias.com.br/industria/cafedo-brasil-rondonia/>. Acesso em: 13 out. 2018.

[18] PALADINI, E. P. Gestão da Qualidade: teoria e prática. 2 ed. São Paulo: Atlas, 2010.

[19] Portal do Governo do Estado de Rondônia. Soja e café fortalecem economia de Rondônia com sustentabilidade 2015. 2009. Disponível em: <http://www.rondonia.ro.gov.br/soja-e-cafe-fortalecem-a-economia-derondonia-com-sustentabilidade/>. Acesso em: 10 de out. 2018.

[20] PORTAL EDUCAÇÃO. Procedimentos Padrão de Higiene Operacional (PPHO) e Procedimentos Operacionais Padronizados (POP). Disponível em:

<https://www.portaleducacao.com.br/conteudo/artigos/nutricao/procedimentos-padrao-de-higiene-operacionalppho-e-procedimentos-operacionais-padronizados-pop/45869>. Acesso em: 10 de out. 2018. 
[21] REVISTA CAFEICULTURA. 2011. Disponível em: <http://revistacafeicultura.com.br/?mat=40384>. Acesso em: 10 de out. 2018.

[22] REVISTA CAFÉS DE RONDÔNIA: Aroma, Sabor e Origem. Rondônia: [s.l], v. 3, 2018. Anual.

[23] REVISTA RONDONIAGORA. Produtor de Cacoal vence o concurso de qualidade do café em Rondônia 2018. Disponível em: <https://www.rondoniagora.com/agronegocio/produtor-de-cacoal-vence-o-concurso-de-qualidadedo-cafe-em-rondonia>. Acesso em: 25 out. 2018.

[24] RIBEIRO, A. R. ANÁLISE, 2005. Revista das Faculdades de Tecnologia e de Ciências Econômicas, Contábeis e de Administração de Empresas Padre Anchieta . Jundiaí - SP: Sociedade Padre Anchieta de Ensino. Disponível em: $<$ https://s3.amazonaws.com/academia.edu.documents/28502438/analise11.pdf?AWSAccessKeyId=AKIAIWOWYYGZ 2Y53UL3A\&Expires=1540612954\&Signature=W5kA6G2ALhTA0go28af8HsFwNFs\%3D\&response-contentdisposition=inline\%3B\%20filename\%3DUMA_ANALISE_DA_OMG_MODEL_DRIVEN_ARCHITEC.pdf\#page=23>. Acesso em: 26 out. 2018.

[25] ROBLES, J. A. BONELLI, V. Gestão da Qualidade e do meio ambiente: enfoque econômico, financeiro e patrimonial. 1 ed. São Paulo: Atlas, 2008.

[26] RONCHI, C. P. A origem do café café conilon. Trecho do Curso Online Agripoint. Disponível em: <https://www.cafepoint.com.br/noticias/giro-de-noticias/a-origem-do-cafe-conilon-56271n.aspx>. Acesso em 28 de out. de 2018.

[27] SEMANA INTERNACIONAL DO CAFÉ. Regulamento Resumido Do Prêmio "Coffee Of The Year Brasil 2018". PDF. Disponível em: <http://semanainternacionaldocafe.com.br/br/wp-

content/uploads/2018/09/Regulamento_Resumido_Coffee-of-the-Year-2018.pdf>. Acesso em: 25 out. 2018. 


\section{Capítulo 2}

Proposta de melhorias no controle de estoque utilizando a ferramenta MASP em uma fábrica de descartáveis

\section{Marcone Freitas dos Reis \\ Barbara Stephany Serra Litter \\ Marcos dos Santos \\ Angélica Rodrigues de Lima \\ Alexandre Camacho da Paixão}

Resumo: Atualmente as empresas buscam a otimização de seus processos na gestão de estoque ou até mesmo uma reengenharia, para encontrar métodos, técnicas, sistemas e filosofias de gestão empresarial, que permitam às organizações alcançar melhores níveis de desempenho, especialmente no que diz respeito ao nível de serviço ao cliente e à redução de custos. Por esta razão, desenvolveu-se o presente estudo com o objetivo de propor melhorias nos processos de controle de estoque em uma fábrica de descartáveis localizada no Rio de Janeiro utilizando a ferramenta MASP (Métodos de Análise e Solução de Problemas). Com a aplicação do MASP foi possível identificar e definir claramente o problema e sua relevância, de forma que ele pudesse ser analisado, e suas causas principais e fundamentais identificadas, sendo assim, foi possível traçar um plano de ação para solucionar as causas e alcançar melhorias no ambiente organizacional.

Palavras chave: Controle de estoque, MASP, Fábrica de descartáveis. 


\section{INTRODUÇÃO}

A gestão de estoque é importante para a empresa permanecer competitiva no mercado, visto que influencia diretamente na rentabilidade da mesma, pois absorve um capital que poderia estar sendo investido de outras maneiras. Para organizações de pequeno porte, por exemplo, acaba sendo um desafio, porque absorve grande parte de seus orçamentos. Assim, os estoques devem ser muito bem planejados, implementados e controlados. (PEREIRA et al., 2015)

Agregando valores da qualidade à gestão de estoque, afirma-se que a satisfação das necessidades dos clientes deve ser a principal meta para os trabalhadores. Isso requer a atitude de colocar o cliente em primeiro lugar e de acreditar que esse princípio é o objetivo de trabalho de cada um (FITZSIMMONS; FITZSIMMONS, 2014).

Neste estudo serão abordadas as etapas de identificação, observação, análise e plano de ação com o objetivo de analisar as não conformidades na gestão de estoques de uma indústria de descartáveis e propor melhorias.

Diante da necessidade de identificar e tratar desperdícios do processo, as vezes desconhecidos, minimizar rejeitos, garantir um controle do processo para utilização eficiente da linha produtiva, e reduzir o lead time foi decidido utilizar a ferramenta MASP (Métodos de Análise e Solução de Problemas) para analisar os processos envolvidos na gestão de estoque da indústria estudada, afim de identificar as não conformidades e propor melhorias.

\section{PROBLEMA}

Em um mix de mais de 500 produtos disponíveis para venda, observa-se que existe uma discrepância entre o estoque real e o informado no sistema. A falta de produtos traz consequências negativas para o negócio. Obriga a empresa a ter custos adicionais como horas extras na produção para repor com urgência os itens faltantes. As compras urgentes custam mais caro, pois os transportes tornam-se urgentes, utilizando-se até mesmo do frete dedicado (transporte exclusivo) ou aéreo para redução do tempo de entrega. Aumenta-se o custo dos insumos e a empresa perde vendas ou pagar multas por atraso, perdendo clientes.

Confeccionou-se um mapa mental, Figura 1 a seguir, a fim de facilitar a visualização do problema em questão.

Figura 1 - Mapa mental do estudo de caso

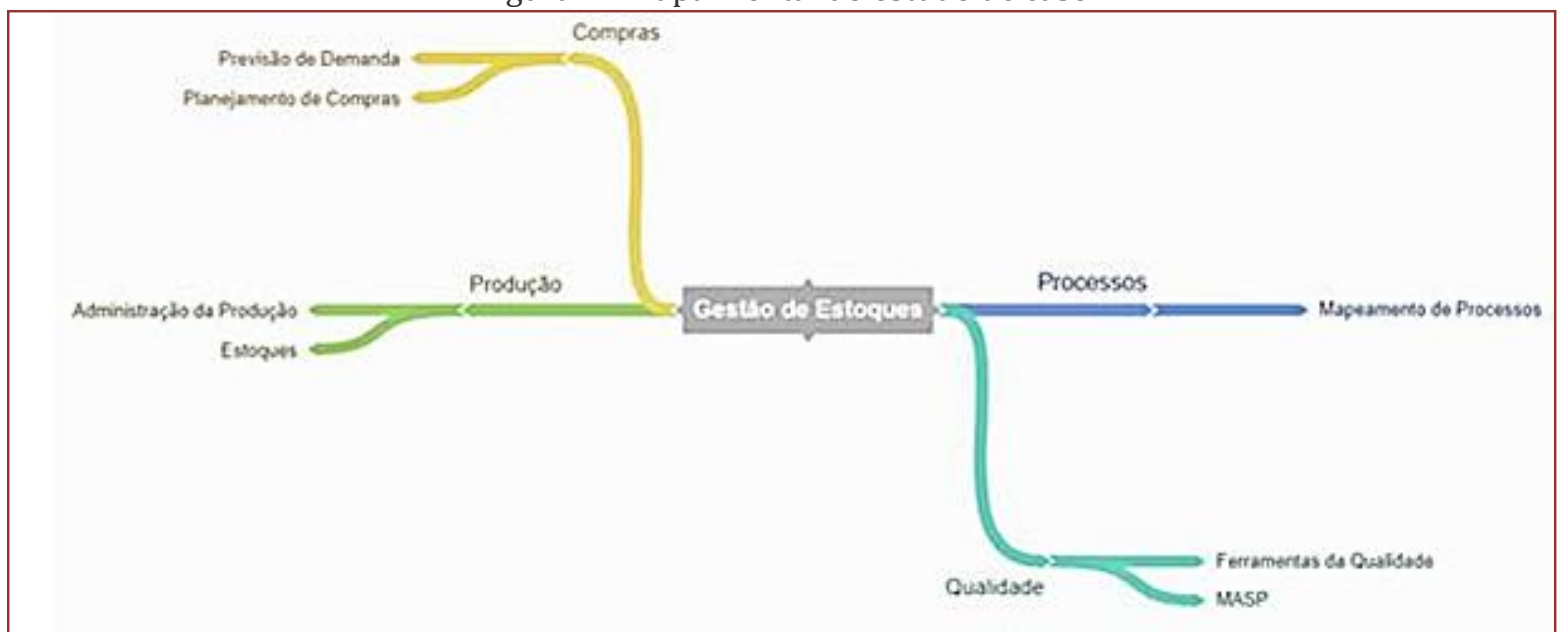

Fonte: Autores (2018)

\section{FUNDAMENTAÇÃO TEÓRICA}

\subsection{GESTÃO DE COMPRAS}

Para Novaes (2007), o planejamento do processo de distribuição depende da antevisão da forma como a demanda dos produtos vai evoluir no futuro. Precisa-se programar as encomendas de matéria-prima e de componentes necessários à fabricação de seus produtos. É necessário também prever a mão de obra 
necessária, instalações fixas, depósitos, recursos financeiros e um sem-número de variáveis que exigem tempo para serem concretizadas. Dessa forma, projeções da demanda bem elaboradas e robustas podem significar ganhos competitivos, econômicos e financeiros para a empresa e para a cadeia de suprimento em que ela se insere.

Uma gestão de compras e vendas de produtos acabados baseada em métodos de previsão de demanda proporciona diminuição do lote econômico de compra e estoques de segurança correlacionados a demanda real, evitando assim estoques excessivos e perdas por obsolescência, que acarretam em perda de dinheiro e custos totais elevados. (REIS et al., 2015)

\subsection{GESTÃO POR PROCESSOS}

Segundo Aguiar et al. (2016), o mapeamento de processos é uma ferramenta com objetivo de aperfeiçoar os processos existentes ou de implantar uma nova estrutura voltada para processos, assim é uma técnica utilizada por empresas para entender de forma clara e simples como uma unidade de negócio está operando, representando cada passo de operação dessa unidade em termos de entradas, saídas e ações, Figura 2 a seguir.

Figura 2 - Qualquer produção envolve os processos input - transformação - output



Fonte: Adaptado de SLACK; CHAMBERS; JOHNSTON (2009)

\subsubsection{BPM (BUSINESS PROCESS MANAGEMENT) E BPMN (BUSINESS PROCESS MODELING NOTATION)}

De acordo com BPM CBOK (2013) o BPM constitui um conjunto de capacidades de negócio para identificar, desenhar, executar, documentar, medir, monitorar, controlar e melhorar processos de negócio, automatizados ou não, para alcançar resultados consistentes e alinhados com os objetivos estratégicos da organização. Envolve uma continuidade, um ciclo feedback sem fim para assegurar que os processos de negócio estejam alinhados com a estratégia organizacional e ao foco do cliente.

Brasil (2013) diz que, a BPMN é uma notação gráfica que descreve as atividades do processo de forma lógica, apresentando as interações entre os envolvidos, bem como as informações essenciais para análise, simulação e execução dos processos. As principais vantagens da Business Process Model and Notation (BPMN), segundo Campos e André (2014), são: Facilidade de entendimento por parte da equipe, possui padrão aberto, padronização e disponibilização pelo Object Management Group (OMG).

\subsection{GESTÃO DA QUALIDADE: CONCEITO E FERRAMENTAS}

A gestão da qualidade não é uma atividade isolada, ela é parte da gestão total. Ela organiza, controla e orienta os recursos de uma organização para atingir os objetivos da qualidade desdobrados em função de uma política da qualidade estabelecida e implementada. (REIS et al., 2017)

Segundo Reis et al. (2017), as ferramentas de qualidade são técnicas que se podem utilizar com a finalidade de definir, mensurar, analisar e propor soluções para problemas que eventualmente são encontrados e interferem no bom desempenho dos processos de trabalho. 
No Quadro 1 a seguir, são apresentadas as sete ferramentas e suas funcionalidades.

Quadro 1 - Sete ferramentas da qualidade

\begin{tabular}{|c|c|c|}
\hline FERRAMENTAS & O QUE É & PARA QUE UTILIZAR \\
\hline $\begin{array}{l}\text { FOLHA DE } \\
\text { VERIFICAÇĀO }\end{array}$ & Planilha para a coleta de dados & $\begin{array}{l}\text { Para facilitar a coleta de } \\
\text { dados pertinentes a um } \\
\text { problema }\end{array}$ \\
\hline $\begin{array}{l}\text { DIAGRAMA DE } \\
\text { PARETO }\end{array}$ & $\begin{array}{l}\text { Diagrama de barraque ordena as } \\
\text { ocorréncias do maior para o menor }\end{array}$ & $\begin{array}{l}\text { Priorizar os poucos, mas } \\
\text { vitais. }\end{array}$ \\
\hline $\begin{array}{l}\text { DIAGRAMA DE CAUSA } \\
\text { E EFEITO }\end{array}$ & $\begin{array}{l}\text { Estrutura do método que expressa, } \\
\text { de modo simples e fácil, a série de } \\
\text { causa de um efeito (problema) }\end{array}$ & $\begin{array}{l}\text { Ampliar a quantidade de } \\
\text { causas potenciais a serem } \\
\text { analisadas }\end{array}$ \\
\hline $\begin{array}{l}\text { DIGRAMA DE } \\
\text { DISPERSÄO }\end{array}$ & $\begin{array}{l}\text { Gráfico cartesiano que representa } \\
\text { a relação entre duas variáveis }\end{array}$ & $\begin{array}{l}\text { Verificar a correlação entre } \\
\text { duas variăveis }\end{array}$ \\
\hline HISTOGRAMA & $\begin{array}{l}\text { Diagrama de barra que representa } \\
\text { a distribuição da ferramenta de } \\
\text { uma população }\end{array}$ & $\begin{array}{l}\text { Verificar o comportamento } \\
\text { de um processo em relação à } \\
\text { especificação }\end{array}$ \\
\hline FLUXOGRAMA & $\begin{array}{l}\text { São fluxos que permite a visão } \\
\text { global do processo por onde passa } \\
\text { o produto }\end{array}$ & $\begin{array}{l}\text { Estabelecer os limites e } \\
\text { conhecer as atividades }\end{array}$ \\
\hline $\begin{array}{l}\text { GRÁFICO DE } \\
\text { CONTROLE }\end{array}$ & $\begin{array}{l}\text { Gráfico com limite de controle que } \\
\text { permite o monitoramento dos } \\
\text { processos }\end{array}$ & $\begin{array}{l}\text { Verificar se o processo está } \\
\text { sob controle }\end{array}$ \\
\hline
\end{tabular}

Fonte: ORTIZ et al. (2002)

\subsubsection{MASP (MÉTODOS DE ANÁLISE E SOLUÇÃO DE PROBLEMAS)}

Campos (2013) propõe 08 etapas de implementação do MASP: (1) identificação - definir o problema, levantando históricos e consequências; (2) observação - investigar as características do problema com uma visão ampla, dividindo-o em partes menores; (3) análise - descobrir as causas fundamentais do problema; (4) plano de ação - conceber um plano para bloquear as causas fundamentais; (5) execução bloquear as causas, a fim de impossibilitar o seu reaparecimento; (6) verificação - verificar se o bloqueio realizado foi realmente efetivo; (7) padronização - evitar o reaparecimento do problema; (8) conclusão recapitular o processo de aplicação, registrando-o para aproveitamento em trabalhos futuros.

O Quadro 2 a seguir, apresenta as ferramentas sugeridas em cada fase do MASP. (MORAIS et al, 2017)

Quadro 2 - Ferramentas da qualidade usadas no MASP

\begin{tabular}{|l|l|}
\hline \multicolumn{1}{|c|}{ Etapas do MASP } & \multicolumn{1}{|c|}{ FERRAMIENTAS } \\
\hline 1.Identificaçào do problema & $\begin{array}{l}\text { Brainstorming, Entrevistas, Diagrama de Pareto, Gráfico de } \\
\text { controle }\end{array}$ \\
\hline 2. Observação do problema & Fluxograma, Anälise de Pareto, folha de verifieação \\
\hline 3. Análise do problema & $\begin{array}{l}\text { Braistorming, Diagrama de Ishikawa, Diagrama de Dispersão, } 5 \\
\text { porqués }\end{array}$ \\
\hline 4. Plano de Ação & 5W2H \\
\hline 5. Ação & 5W2H \\
\hline 6. Verificação & Diagrama de Pareto, Gráfico de Controle \\
\hline 7. Padronização & 5 W2H \\
\hline \$. Conclusão & - \\
\hline
\end{tabular}

Fonte: Adaptado de MORAIS et al. (2017)

\section{PROPOSTA DE SOLUÇÃO}

\subsection{A EMPRESA}

O estudo de caso foi realizado em uma indústria de descartáveis, localizada no Rio de Janeiro, que está há 25 anos no mercado. É uma empresa focada, principalmente, no atendimento a rede de mercados e supermercados, que não disponibilizam espaço para estoque dos produtos ofertados, somente a área de venda, ou seja, o que fica exposto ao consumidor. 


\subsection{ETAPAS DO MASP}

\subsubsection{IDENTIFICAÇÃO DO PROBLEMA}

Realizou-se o levantamento dos principais produtos comercializados no ano de 2017, e através de gráfico de Pareto, conforme apresentado no Gráfico 1 a seguir, as seis classes de produtos mais vendidas.

Gráfico 1 - Principais produtos comercializados no ano de 2017

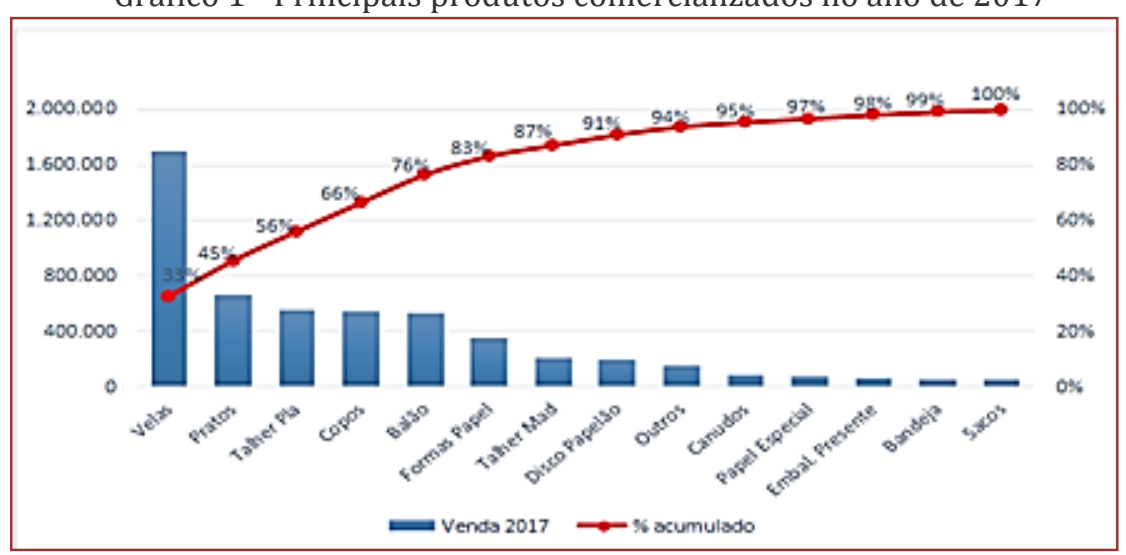

Fonte: Autores (2018)

Para proporcionar evidências objetivas da importância do problema escolhido, foi elaborada uma lista de verificação e aplicada às seis classes de produtos, em todos os pedidos de vendas de 2017. A finalidade dessa lista foi coletar os dados referentes a quantidade de produtos de cada classe, que deixou de ser enviado aos clientes por não ter o produto em estoque, e o valor que a empresa deixou de faturar com essas faltas. A Tabela 1 a seguir apresenta o resumo dos dados coletados com a lista de verificação, na classe "Copos".

Tabela 1 - Resumo dos dados coletados com a lista de verificação da classe "Copos"

\begin{tabular}{|cccl|}
\hline \multicolumn{4}{|c|}{ Produto: COPO CAFE 50ML 50X50 UND } \\
\hline Cliente & Data do Pedido & Quantidade & Valor Total \\
\hline A & $04 / 03 / 2016$ & 1 & RS 66,00 \\
B & $30 / 03 / 2016$ & 2 & RS 132,00 \\
C & $24 / 03 / 2016$ & 1 & RS 66,00 \\
D & $19 / 09 / 2016$ & 1 & RS 79,75 \\
\hline TOTAL DO PRODUTO & & 5 & RS 343,75 \\
\hline TOTAL DA CLASSE & & 609 & RS 56987,58 \\
\hline
\end{tabular}

Fonte: Autores (2018)

Na Tabela 2 a seguir, é possível ver o total das quantidades de produtos e respectivos valores que deixaram de ser faturados, por classe, no ano de 2017.

Tabela 2 - Quantidade de produtos X Valor de faturamento perdido em 2017

\begin{tabular}{|lcc|}
\hline \multicolumn{1}{|c|}{ Classe } & Quantidade de produtos & Valor \\
\hline Balão & 2232 & RS 13.803,58 \\
Copos & 609 & RS 56.987,58 \\
Talheres Plásticos & 378 & RS 23.558,28 \\
Pratos & 1386 & RS $61.435,66$ \\
Velas & 2794 & RS 47.678,78 \\
Formas de Papel & 3616 & RS 98.429,19 \\
\hline Total Pacotes & 11015 & RS 301.893,07 \\
\hline
\end{tabular}

Fonte: Autores (2018) 
0 resultado apurado com a aplicação das folhas de verificação pode ser visto no Gráfico 2 a seguir, com o comparativo do faturamento real e o faturamento ideal (sem faltas de produtos).

Gráfico 2 - Faturamento Real X Faturamento Ideal do ano de 2017

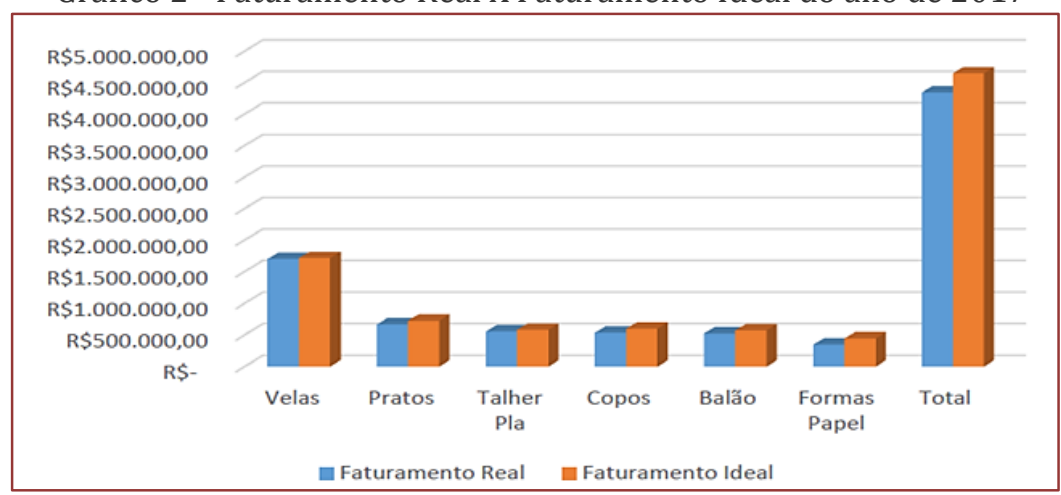

Fonte: Autores (2018)

A falta de produtos ocasionou uma perda de $\mathrm{R} \$ 301.893,07$ representando $6,95 \%$ do faturamento total da empresa no ano de 2017.

\subsubsection{OBSERVAÇÃO DO PROBLEMA}

Para esta fase de observação do problema, foi definido a lista de entrevistados, planejadas as entrevistas, realizando coletas de dados para a estruturação do mapeamento do processo, com o objetivo de levantar informações, sobre:

- Tipos de documentos utilizados no processo;

- Tipos de sistemas utilizados;

- Tipos de equipamentos e ferramentas;

- Os responsáveis pela atividade;

- As áreas que controlam e acompanham o abastecimento;

- $\quad$ Procedimentos que regulam a atividade;

- Melhorias e dificuldades encontradas.

a) Setor de compras - Atualmente não existe padronização ou planejamento no setor de compras. A colaboradora que envia os pedidos aos fornecedores é a mesma que atende aos principais clientes. Não existe comunicação entre o setor de produção e compras. A compradora não faz nenhum tipo de análise de previsão de demanda, no fim de estoque e compra uma quantidade que acha que conseguirá vender.

Não são realizadas cotações ou avaliações de fornecedores. Não existe um cadastro de fornecedores;

b) Recebimento de mercadorias - Não existe definição ou treinamento para este setor. Os pedidos de fornecedores não recebem nenhum tipo de conferência, seja ela de preços de produtos, prazo de pagamento, qualidade ou data de entrega. A transportadora entrega a nota fiscal a recepcionista que a transfere ao encarregado, e este recebe a mercadoria pela nota, conferindo apenas se os produtos e quantidades recebidas são os mesmos que constam na nota fiscal;

c) Produção - Não existe planejamento no setor de produção. Para saber os produtos que devem ser produzidos, a colaboradora responsável pede ao ajudante que verifique, nas estantes do estoque, os produtos que estão zerados ou acabando. Em seguida, com a lista em mãos, esta verifica se tem a matéria prima disponível para industrialização. Caso tenha, ela passa para uma das auxiliares produzir, caso não tenha, o produto fica em falta e a informação não é passada para a compradora. Os produtos utilizados no 
processo de produção não são baixados no sistema de estoque de imediato assim como a entrada dos produtos produzidos, o processo é feito manualmente no fim do dia de trabalho.

A equipe de trabalho da produção é composta por oito colaboradores, contando com a responsável da produção.

\subsubsection{ANÁLISE DO PROBLEMA}

\subsubsection{MAPEAMENTO DO PROCESSO}

O mapeamento do processo foi realizado com levantamentos de dados obtidos através de acompanhamento da execução das atividades e entrevistas com os operadores dos setores envolvidos, que são: Compras, Recebimento de mercadorias e Produção. 0 mapeamento do processo atual é apresentado na Figura 3 a seguir.

Figura 3 - Mapeamento do processo atual

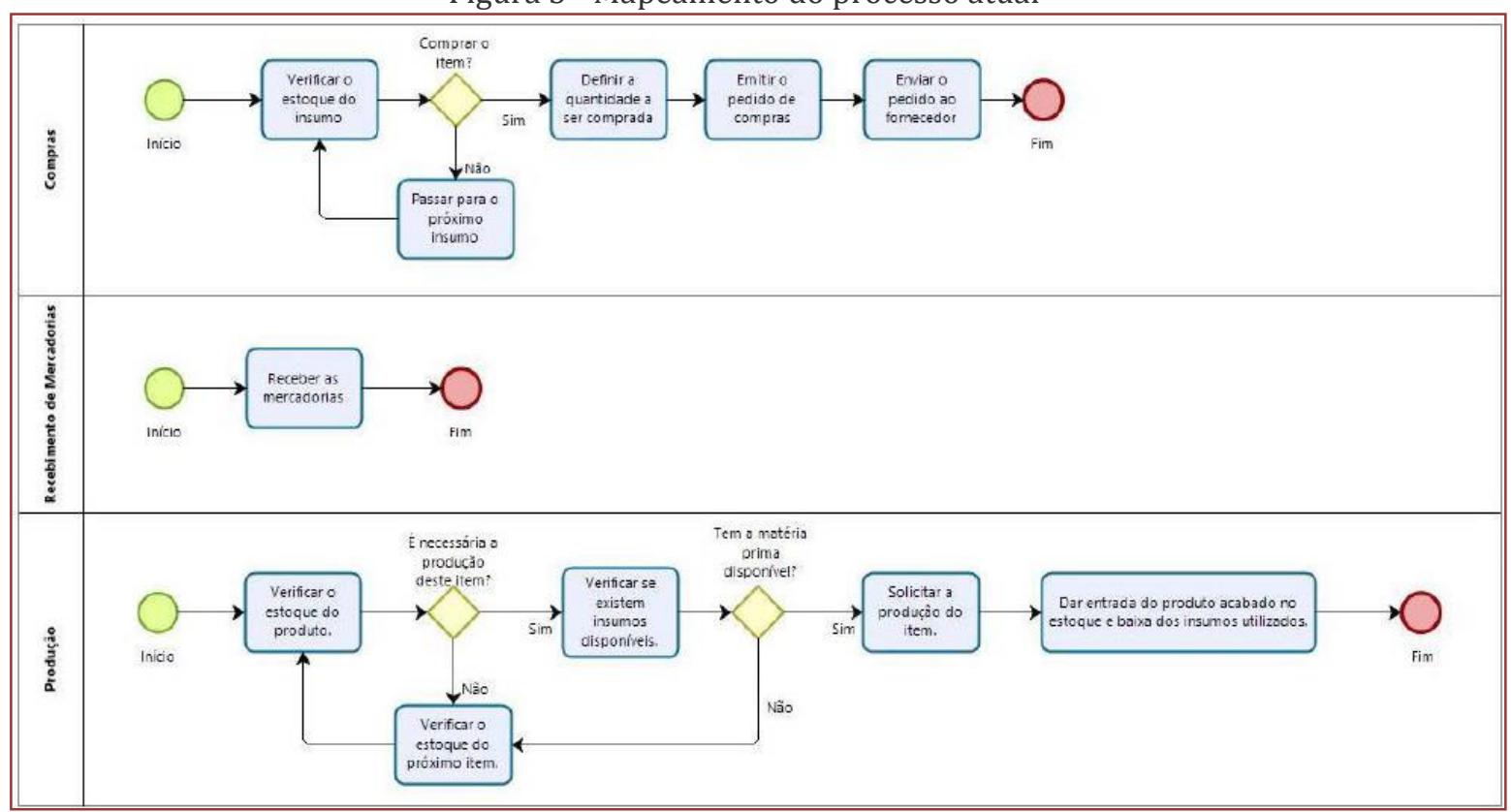

Fonte: Autores (2018)

A partir do detalhamento de todas as atividades dos processos por setor, apresentados posteriormente, as propostas de melhorias poderão ser apresentadas.

a) Setor de compras - Foi realizado análise do processo atual, e identificadas as falhas.

1. Verificar o estoque de materiais

Responsável: Compradora.

Atividade: A compradora acessa o sistema e verifica a quantidade do estoque acabado dos insumos para verificar o que está zerado ou acabando.

Falhas: Não existe uma análise quanto à previsão da demanda. Dessa forma nunca será correta a avaliação do que realmente está acabando visto que isso pode variar bastante conforme a saída dos produtos. 0 estoque zerado significa que o cliente não poderá ser atendido ou o lead time será grande caso tenha que esperar o produto chegar e ser produzido.

2. Definir os itens que devem ser comprados.

Responsável: Compradora.

Atividade: A compradora, após verificar o que está zerado ou acabando, define os itens que devem ser comprados.

Falhas: Não existe uma análise quanto à previsão da demanda. Dessa forma nunca será correta a avaliação 
do que realmente está acabando visto que isso pode variar bastante conforme a saída dos produtos. 0 estoque zerado significa que o cliente não poderá ser atendido ou o lead time será grande caso tenha que esperar o produto chegar e ser produzido.

3. Emitir a ordem de compra

Responsável: Compradora.

Atividade: A compradora utiliza o talão de pedidos de venda da empresa para escrever manualmente o que vai solicitar ao fornecedor.

Falhas: 0 pedido não possui preço, prazo de pagamento, data de entrega, impostos agregados e outras informações essenciais em um pedido que deva ser verificado no momento do recebimento. Não existe padrão para a ordem de compras. Podendo ocasionar graves erros de recebimento e consequentes faltas de produtos.

4. Enviar o pedido ao fornecedor.

Responsável: Compradora.

Atividade: A compradora passa o pedido de compras para o fornecedor pelo telefone.

Falhas: Não existe registro do que foi pedido, podendo causar erros de fornecimento e consequentemente envios de material divergentes com o solicitado.

b) Setor de recebimento de mercadorias - Foi realizado análise do processo atual, e identificadas as falhas.

1. Receber as mercadorias.

Responsável: Encarregado.

Atividade: 0 encarregado começa a receber as mercadorias e confere os produtos e suas quantidades conforme a nota fiscal.

Falhas: Os materiais recebidos pelo setor de recebimento não são verificados para se certificar que os itens correspondem aos solicitados no pedido de compras, suas quantidades, preços, prazo e qualidade.

c) Setor de produção - Foi realizado análise do processo atual, e identificadas as falhas.

1. Verificar o que é necessário produzir.

Responsável: Chefe da produção.

Atividade: A chefe da produção solicita ao ajudante que verifique nas estantes do estoque quais produtos estão zerados ou acabando.

Falhas: Essa verificação deve ser feita com antecedência para que o cliente não deixe de ser atendido por falta do produto e deve ser facilmente identificada através do sistema informatizado.

2. Verificar se tem matéria prima disponível para produção dos produtos definidos como necessários.

Responsável: Chefe da produção.

Atividade: A chefe da produção solicita ao ajudante que verifique se tem a matéria prima disponível para a produção.

Falhas: Essa verificação deve ser feita com antecedência, conforme a necessidade da produção. Deve ser facilmente identificada através do sistema informatizado.

3. Solicitar a produção dos itens que tem a matéria prima disponível.

Responsável: Chefe da produção.

Atividade: A chefe da produção solicita as auxiliares, verbalmente, a produção dos itens necessários.

Falhas: Não existe registro de trabalho e documento indicando o que deve ser produzido e como deve ser produzido. Não existe conferência do que foi produzido.

4. Dar entrada, no sistema, nos produtos fabricados e baixa na matéria prima que foi utilizada.

Responsável: Chefe da produção. 
Atividade: A chefe da produção dá entrada, manualmente, no sistema, dos produtos que foram produzidos e baixa das matérias primas que foram utilizadas.

Falhas: Esse processo não deveria ser manual, visto que pode ocasionar erros de quantidade de estoque.

\subsubsection{PLANO DE AÇÃO}

De acordo com Mello et al., (2016), a ferramenta 5W2H, Quadro 2, objetiva realizar um checklist para tornar claro o resultado que se pretende alcançar realizando perguntas que permitirão, através das respostas, obter um planejamento geral para tomada de decisão quanto às ações que devem ser realizadas.

\begin{tabular}{|l|l|l|l|}
\hline \multicolumn{3}{|c}{ Quadro 2 - Método 5W2H } \\
\hline \multirow{3}{*}{$5 \mathbf{W}$} & & \multicolumn{2}{c|}{ Método dos 5W2H } \\
\cline { 2 - 4 } & What & O Que? & Que ação será executada? \\
\cline { 2 - 4 } & Who & Quem? & Quem irá executar/participar da ação? \\
\cline { 2 - 4 } & Where & Onde? & Onde será executada a ação? \\
\cline { 2 - 4 } & When & Quando? & Quando a ação será executada? \\
\cline { 2 - 4 } & Why & Por Quê? & Por que a ação será executada? \\
\hline \multirow{2}{*}{$2 \mathbf{H}$} & How & Como? & Como será executada a ação? \\
\cline { 2 - 4 } & How much & Quanto custa? & Quanto custa para executa a ação? \\
\hline
\end{tabular}

\subsubsection{COMPRAS}

O objetivo é estabelecer a sistemática para aquisição de produtos ou serviços. Assegurar que os fornecedores sejam avaliados de acordo com as necessidades de aquisição de insumos, e manter um estoque necessário para atender ao planejamento de produção. Definir os critérios de recebimento e inspeção de todos os insumos produtivos que fazem parte dos produtos da empresa. Assegurar a qualidade da matéria-prima, embalagens, rótulos, folhetos e etiquetas utilizadas visando a isonomia do produto final. Na Figura 4 a seguir, é apresentado o plano de ação.

Figura 4 - Plano de ação do setor de compras

\begin{tabular}{|c|c|c|c|c|c|c|c|}
\hline $\begin{array}{c}\text { Oogue } \\
\text { Emitir a } \\
\text { ordem de } \\
\text { compras }\end{array}$ & $\begin{array}{c}\text { Fomulário: } \\
\text { Pedido de } \\
\text { Compras }\end{array}$ & $\begin{array}{c}\text { Coordenador } \\
\text { de Produção }\end{array}$ & $\begin{array}{c}\text { Sempre que } \\
\text { necessária a } \\
\text { aquisição do } \\
\text { produto }\end{array}$ & $\begin{array}{c}\text { Sistema da } \\
\text { Empresa }\end{array}$ & $\begin{array}{c}\text { Para manter } \\
\text { estoque } \\
\text { estratégico }\end{array}$ & $\begin{array}{c}\text { Não haverá } \\
\text { custos para } \\
\text { este }\end{array}$ \\
\hline $\begin{array}{c}\text { Avaliar os } \\
\text { fornecedores }\end{array}$ & $\begin{array}{c}\text { Formulário: } \\
\text { Avaliação de } \\
\text { Fomecedores }\end{array}$ & $\begin{array}{c}\text { Coordenador } \\
\text { de Produção }\end{array}$ & $\begin{array}{c}\text { Sempre que } \\
\text { receber um } \\
\text { pedido }\end{array}$ & $\begin{array}{c}\text { Sistema da } \\
\text { Empresa }\end{array}$ & $\begin{array}{c}\text { Para manter } \\
\text { a qualidade } \\
\text { dos produtos }\end{array}$ & $\begin{array}{c}\text { Não haverá } \\
\text { custo para } \\
\text { este }\end{array}$ \\
\hline
\end{tabular}

Fonte: Autores (2018)

- Emissão do pedido de compras:

Caberá ao coordenador de produção manter as informações de suprimentos atualizadas de forma a construir um estoque estratégico na cadeia de suprimentos. Essa atualização deverá ser mantida para que os processos posteriores sejam executados de forma padronizada e ausente de gargalos.

A solicitação para aquisição de insumos será feita através do preenchimento do formulário desenvolvido para esta finalidade chamado de Pedido de Compras, apresentado na Figura 5 a seguir. Este descreve claramente o produto a ser adquirido e todas as informações mínimas necessárias. 
Figura 5 - Formulário do pedido de compras

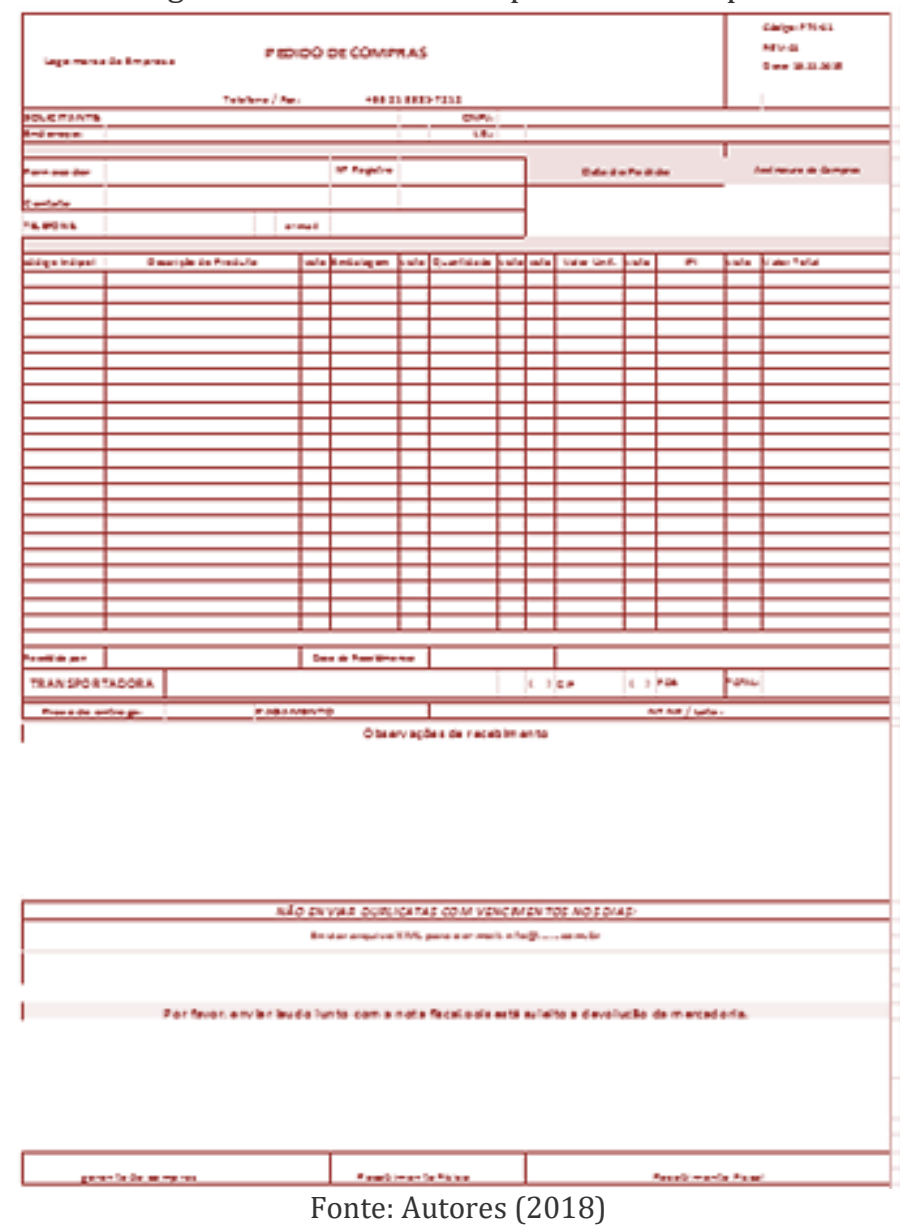

- $\quad$ Avaliação de fornecedores:

Após o recebimento da mercadoria, o fornecedor será avaliado, através do formulário de avaliação de fornecedores apresentado na Figura 6 a seguir, em todo pedido recebido e classificado conforme o percentual de adequação obtido no mês.

No caso de fornecedores reprovados por falhas de recebimento, quantidades e qualidade deverão ser formalizadas as possibilidades de adequação junto ao fornecedor e realizar verificações de qualidade caso o fornecedor queira manter a parceria com a empresa. 
Figura 6 - Formulário de avaliação de fornecedores



Fonte: Autores (2018)

\subsubsection{RECEBIMENTO DE MATERIAIS}

O objetivo é seguir todos os processos desenvolvidos para realização de recebimento de insumos e assegurar que este processo seja executado sob condições controladas, a fim de garantir que o produto que está sendo recebido esteja conforme solicitado. Na Figura 7 a seguir, é apresentado o plano de ação.

Figura 7 - Plano de ação do setor de recebimento de materiais

\begin{tabular}{|c|c|c|c|c|c|c|}
\hline O que & Como & Quem & Ouando & Onde & Por que & Quanto \\
\hline $\begin{array}{c}\text { Conferência } \\
\text { Fisc-al }\end{array}$ & $\begin{array}{l}\text { Formulário: } \\
\text { Pedido de } \\
\text { Compras }\end{array}$ & Recepção & $\begin{array}{l}\text { Sempre que } \\
\text { chegar } \\
\text { material de } \\
\text { formecedor }\end{array}$ & $\begin{array}{c}\mathrm{Na} \\
\text { Recepção da } \\
\text { Empresa }\end{array}$ & $\begin{array}{l}\text { Para validar } \\
\text { as } \\
\text { informações } \\
\text { da nota } \\
\text { fiscal em } \\
\text { relação ao } \\
\text { pedido. }\end{array}$ & $\begin{array}{c}\text { Não haverá } \\
\text { custos para } \\
\text { este } \\
\text { procedimento }\end{array}$ \\
\hline $\begin{array}{c}\text { Recebimento } \\
\text { Fisico }\end{array}$ & $\begin{array}{l}\text { Formulário: } \\
\text { Pedido de } \\
\text { Compras }\end{array}$ & $\begin{array}{l}\text { Coordenador } \\
\text { da } \\
\text { Expedição }\end{array}$ & $\begin{array}{l}\text { Sempre que } \\
\text { receber um } \\
\text { pedido }\end{array}$ & $\begin{array}{l}\text { No setor de } \\
\text { descarga de } \\
\text { Material }\end{array}$ & $\begin{array}{l}\text { Para atestar } \\
\text { a quantidade } \\
\text { e qualidade } \\
\text { do material } \\
\text { recebido. }\end{array}$ & $\begin{array}{l}\text { Não haverá } \\
\text { custo para } \\
\text { este } \\
\text { procedimento }\end{array}$ \\
\hline
\end{tabular}

Fonte: Autora (2018)

\section{- Conferência fiscal:}

A primeira etapa desse procedimento é a conferência fiscal, momento em que são verificadas todas as informações dos produtos para garantir que a nota fiscal esteja conforme as especificações da ordem de compras e registra o número da nota fiscal.

Caso as informações de produtos a serem recebidos estiverem divergentes das solicitadas, o setor de compras deve ser acionado para tratar a ocorrência e definir a decisão a ser tomada, seja de receber ou não o material. 
Recebimento físico:

A etapa seguinte é o recebimento físico do material. Compete ao Setor de Expedição, o recebimento de todos os materiais.

Os materiais a serem recebidos devem ser avaliados com critérios pré-definidos para que os produtos não estejam em desacordo com os critérios de segurança e padrão do produto. Abrir 2\% da mercadoria recebida, fazer análise visual e comparar com as amostras disponíveis no show room situado na empresa.

Feito o recebimento definitivo, o setor responsável registra a aprovação no formulário, no campo Registro de Recebimento e atestar a Nota Fiscal.

\subsubsection{PRODUÇÃO}

O objetivo é desenvolver todos os processos necessários para a realização de seus produtos e assegurar que estes processos sejam executados sob condições controladas. Na Figura 8 a seguir, é apresentado o plano de ação da produção.

Figura 8 - Plano de ação

\begin{tabular}{|c|c|c|c|c|c|c|}
\hline O que & Como & Quem & Quando & Onde & Por que & Quanto \\
\hline $\begin{array}{l}\text { Elaborar o } \\
\text { planejamento } \\
\text { de Produção }\end{array}$ & $\begin{array}{l}\text { - Previsão de } \\
\text { Demanda } \\
\text { - Verificação } \\
\text { do estoque } \\
\text { atual }\end{array}$ & $\begin{array}{l}\text { Coordenador } \\
\text { de Produção }\end{array}$ & Semanalmente & $\begin{array}{l}\text { Sistema } \\
\text { da } \\
\text { Empresa }\end{array}$ & $\begin{array}{c}\text { Para manter } \\
\text { o estoque de } \\
\text { produtos } \\
\text { necessários. }\end{array}$ & $\begin{array}{c}\text { Não haverá } \\
\text { custos para } \\
\text { este } \\
\text { procedimento }\end{array}$ \\
\hline $\begin{array}{l}\text { Emitir a ordem } \\
\text { de produção }\end{array}$ & $\begin{array}{l}\text { Formulário: } \\
\text { Ordem de } \\
\text { Produção }\end{array}$ & $\begin{array}{l}\text { Coordenador } \\
\text { da Expedição }\end{array}$ & $\begin{array}{l}\text { Sempre que } \\
\text { necessário. }\end{array}$ & $\begin{array}{l}\text { Sistema } \\
\text { da } \\
\text { Empresa }\end{array}$ & $\begin{array}{l}\text { Para liberar } \\
\text { a produção } \\
\text { dos produto } \\
\text { necessários. }\end{array}$ & $\begin{array}{l}\text { Não haverá } \\
\text { custo para } \\
\text { este } \\
\text { procedimento }\end{array}$ \\
\hline $\begin{array}{l}\text { Monitoramento } \\
\text { do Produto }\end{array}$ & $\begin{array}{l}\text { Formulário: } \\
\text { Monitoramento } \\
\text { do Produto }\end{array}$ & Operadores & $\begin{array}{l}\text { Durante todo } \\
\text { o processo de } \\
\text { produção }\end{array}$ & $\begin{array}{l}\text { No setor } \\
\text { de } \\
\text { produção } \\
\text { da } \\
\text { empresa }\end{array}$ & $\begin{array}{l}\text { Para manter } \\
\text { a qualidade } \\
\text { do produto }\end{array}$ & $\begin{array}{l}\text { Não haverá } \\
\text { custo para } \\
\text { este } \\
\text { procedimento }\end{array}$ \\
\hline $\begin{array}{l}\text { Aprovação dos } \\
\text { produtos }\end{array}$ & $\begin{array}{l}\text { Formulário: } \\
\text { Ordem de } \\
\text { Produção }\end{array}$ & $\begin{array}{l}\text { Encarregada } \\
\text { da produção }\end{array}$ & $\begin{array}{l}\text { Ao término da } \\
\text { execução das } \\
\text { atividades da } \\
\text { ordem. }\end{array}$ & $\begin{array}{l}\text { No setor } \\
\text { de } \\
\text { Produção } \\
\text { da } \\
\text { empresa. }\end{array}$ & $\begin{array}{l}\text { Para atestar } \\
\text { a qualidade } \\
\text { do produto. }\end{array}$ & $\begin{array}{l}\text { Não haverá } \\
\text { custo para } \\
\text { este } \\
\text { procedimento }\end{array}$ \\
\hline $\begin{array}{l}\text { Inventário do } \\
\text { estoque }\end{array}$ & $\begin{array}{l}\text { Contagem do } \\
\text { estoque }\end{array}$ & $\begin{array}{c}\text { Encarregada } \\
\text { de Produção } \\
\text { e } \\
\text { colaboradores }\end{array}$ & Mensalmente & $\begin{array}{c}\mathrm{Na} \\
\text { empresa }\end{array}$ & $\begin{array}{c}\text { Para manter } \\
\text { a } \\
\text { acuracidade } \\
\text { do estoque }\end{array}$ & $\begin{array}{c}\text { Não haverá } \\
\text { custos para } \\
\text { este } \\
\text { procedimento }\end{array}$ \\
\hline $\begin{array}{l}\text { Treinamento e } \\
\text { Capacitação }\end{array}$ & $\begin{array}{c}\text { Palestras, } \\
\text { vídeos e fichas } \\
\text { técnicas. }\end{array}$ & $\begin{array}{l}\text { Encarregada } \\
\text { da Produção }\end{array}$ & $\begin{array}{c}\text { Toda } \\
\text { contratação e } \\
\text { a cada } 3 \\
\text { meses }\end{array}$ & $\begin{array}{l}\text { No setor } \\
\text { de } \\
\text { produção }\end{array}$ & $\begin{array}{l}\text { Para manter } \\
\text { a } \\
\text { equivalência } \\
\text { dos } \\
\text { processos. }\end{array}$ & $\begin{array}{c}\text { Não haverá } \\
\text { custos para } \\
\text { este } \\
\text { procedimento }\end{array}$ \\
\hline
\end{tabular}

Fonte: Autores (2018)

\section{- Planejamento da produção:}

A base de planejamento de produção deve estar relacionada aos seguintes critérios: acompanhamento do estoque atual e previsão de demanda.

Com base nas definições de demanda e relação de estoque, o coordenador de produção consegue definir o planejamento de produção, com a especificação de produção diária. 0 gestor da área deve considerar nesta especificação de produção a disponibilidade de máquinas, insumos e operacional a serem manufaturados.

Os operadores devem ser orientados a seguir rigorosamente as orientações técnicas para o respectivo produto, contidas na ficha técnica, Figura 9 a seguir. 
Figura 9 - Modelo de Ficha Técnica



Fonte: Autores (2018)

\section{- Ordem de produção:}

Com o planejamento de produção definido, as ordens de produção podem ser emitidas. Na nova OP, além do número da ordem de produção que será o número do lote do produto, constam o lote dos insumos que serão utilizados e suas respectivas quantidades, além da data e hora de início e fim das operações, e operador responsável por cada etapa da produção.

- Monitoramento do produto:

Em todo o processo deve ser realizado o monitoramento do produto, onde devem ser verificadas as referências, respectivos códigos de barras, número do lote, data de fabricação e validade dos produtos ao serem embalados, assim como, a existência de partes cortantes, pontiagudas, defeitos visuais, deformações ou qualquer intempérie que possa ser considerada como fora dos padrões de qualidade. Os operadores devem conferir de forma amostral a cada lote de produto. Deverão ser respeitadas as quantidades e a embalagem do produto.

- Aprovação do produto:

A última etapa se trata da aprovação do produto, momento em que se deve confirmar as quantidades por caixa, verificar se a referência (código para comercialização EAN) assinalada no lado externo da caixa e o lote correspondem ao produto embalado. Datar e identificar o colaborador responsável pela embalagem final.

O Produto Final será encaminhado ao estoque quando a Ordem de Produção for encerrada totalmente, e para sua preservação, deve ser colocado numa área pré-determinada, em pallets ou prateleiras, demarcada com sua referência e deve respeitar o limite de empilhamento máximo permitido.

A coordenadora de produção encerrará o processo utilizando um sistema informatizado cujas entradas de produtos acabados serão alimentadas pela baixa das Ordens de Produção. 


\section{CONSIDERAÇÕES FINAIS}

0 presente trabalho conseguiu atingir o seu objetivo geral de propor melhorias para a gestão de estoque, utilizando o MASP como ferramenta. Através dos quatro primeiros passos da ferramenta aplicados, foi possível identificar e definir claramente o problema e sua relevância, dessa forma ele pôde ser analisado e as não conformidades dos processos, identificadas. Sendo assim, foi possível traçar um plano de ação para solucionar as causas e alcançar melhorias no ambiente organizacional para a obtenção de resultados otimizados.

A falta de produtos, que é constante na empresa, tende a ser resolvida com a aplicação da proposta deste trabalho, visto que, com a execução do planejamento da produção interligado com a compra da matéria prima necessária e com seu devido recebimento, a empresa terá condições de manter o estoque estratégico que necessita para atender integralmente os pedidos de seus clientes e com o lead time almejado.

\section{REFERÊNCIAS}

[1] Aguiar, Wellington Sousa et. al. Avaliação de softwares livres de BPMN para mapeamento de processos. Rio de Janeiro: Inovarse - XII congresso nacional de excelência em gestão \& III Inovarse, 2016.

[2] Bpm Cbok - Guia para o Gerenciamento de Processos de Negócio. Corpo Comum do Conhecimento - Abpmp Bpm Cbok. V3. Association of Business Process Management Professionals, 2013.

[3] Brasil. Ministério Público Federal. Manual de Gestão por Processos. Secretaria Jurídica e de Documentação, Escritório de Processos Organizacionais do MPF. Brasília: MPF/PGR, 2013.

[4] Campos, André L. N. Modelagem de processos com BPMN. 2.ed. Rio de Janeiro: Brasport, 2014.

[5] Castro, A. D. J, Pinheiro, A, Yovanka Pérez Ginoris, Y. P. (2011). Aplicação do Método de Soluções de Problemas (PDCA) em um sistema de tratamento de efluentes de indústria frigorífica de aves. Revista Ambiente \& Água - An Interdisciplinary Journal of Applied Science, 6(3). http://dx.doi.org/10.4136/ambi-agua.743.

[6] Fitzsimmons, James A.; Fitzsimmons, Mona J.. Administração de Serviços: Operações, estratégia e tecnologia da informação. 7. ed. São Paulo: Amgh, 2014.

[7] Morais, Márcia Gomes de et al. A Gestão da Qualidade na Prestação de Serviços: Um estudo de caso em um restaurante localizado em São Luiz - MA. In: XXXVII Encontro Nacional de Engenharia de Produção, 37., 2017, Joinville. A Engenharia de Produção e as novas tecnologias produtivas: indústria 4.0, manufatura aditiva e outras abordagens avançadas de produção. Joinville: Enegep, 2017.

[8] Novaes, Antônio Galvão. Logística e gerenciamento da cadeia de distribuição: estratégia, operação e avaliação. 3. ed. Rio de Janeiro: Elsevier, 2007.

[9] Ortiz, Paulo e Pierri, Suzana. Modelos de Gestão da Qualidade 2. Senai: Universidade Federal do Paraná, Curitiba, 2002.

[10] Pereira, Barbara Moreto et al., Gestão de estoque: Um estudo de caso em uma empresa de pequeno porte de Jaguaré. In: XXXV Encontro Nacional de Engenharia de Produção, 2015, Fortaleza. Fortaleza: Enegep, 2015.

[11] Reis, João Gilberto Mendes dos et al. Previsão de demanda no mercado no varejo: Um estudo de caso em um comércio de baterias automotivas. In: Sadsj, 1., 2015, São Paulo. South American Development Society Journal. São Paulo: Sadsj, 2015.

[12] Reis, Marcone Freitas dos et al. Aplicação de ferramentas da qualidade no processo de fabricação de painéis elétricos. In: XI Eepa, 11., 2017, Paraná. Empreendedorismo e Sustentabilidade: Contribuição da Engenharia de Produção. Paraná: Eepa, 2017.

[13] Reis, Marcone Freitas dos et al. Gerenciamento de Qualidade no Projeto de Implantação do Sistema de Gestão de Metas em uma Empresa de Telecom. In: XI Eepa, 11., 2017, Paraná. Empreendedorismo e Sustentabilidade: Contribuição da Engenharia de Produção. Paraná: Eepa, 2017.

[14] Sebrae. Ferramenta 5W2H. Disponível em: < http://www.tre-ma.jus.br/qualidade/cursos/5w_2h.pdf>. Acesso em: 14 Jul.2018.

[15] Slack, Nigel; Chambers, Stuart; Johnston, Robert. Administração da Produção. 3. ed. São Paulo: Atlas, 2009. 


\section{Capítulo 3}

Descrição do Controle Estatístico de Processos (CEP) implantado nas indústrias de autopeças

\section{Fabiano Rodrigues Soriano}

Pedro Carlos Oprime

Fabiane Leticia Lizarelli

Resumo: O Controle Estatístico de Processo (CEP) corresponde a um conjunto de ferramentas estatísticas com o objetivo de evidenciar e minimizar as causas de variação nos produtos e processo, sendo este seu principal benefício. Apesar dos diversos casos de sucesso na sua aplicação, algumas organizações fracassam, pois não administram corretamente os Fatores que são Críticos para o Sucesso de sua implantação (FCS). 0 objetivo deste trabalho e descrever quais são as principais ferramentas, benefícios e quais FCS são considerados pelas empresas de autopeças certificadas na ISO/TS 169490. Para este Survey foram selecionadas 35 empresas. Seus resultados indicam que as empresas utilizam predominantemente as ferramentas básicas para a condução de suas atividades, os benefícios percebidos pela aplicação do CEP são consistentes com a literatura, porem poderia ser mais intenso à medida que lidam corretamente com o FCS.

Palavras-chave: Controle estatístico de Processo; implantação; indústria de autopeças 


\section{INTRODUÇÃO}

O Controle Estatístico de Processo (CEP) corresponde a um conjunto de ferramentas e técnicas estatísticas voltadas para a melhoria dos padrões da qualidade de produtos e serviços. Sua aplicação nos programas de qualidade das empresas busca estabelecer a estabilidade e o domínio estatístico nos processos produtivos para que estes trabalhem dentro de uma faixa aceitável de variação, porem objetivando melhorias nos índices de variabilidade (LIM, et. al. 2017, Putri e Yusof, 2009).

Apesar de ser reconhecido pelas indústrias como um aliado na melhoria da qualidade, fazer parte dos Sistemas da Qualidade ISO 9000 e ISO/TS 16949, contar com uma literatura ampla e diversificada sobre o assunto, apresentar diversos casos de sucesso na aplicação deste conjunto ferramentas, ainda há diversos relatos de fracasso e aplicação limitada do potencial do CEP nas empresas de todos os segmentos de atividade econômica (Rohani; Yusof; Mohamad, 2010; Soriano; Oprime; Lizarelli, 2017).

O objetivo deste trabalho e descrever quais são as principais ferramentas, benefícios e quais FCS são considerados pelas empresas de autopeças certificadas na ISO/TS 16949. Estas empresas foram selecionadas como objeto de estudo devido a exigências contratuais de aplicação entre clientes e fornecedores e maturidade na sua aplicação, servindo de parâmetro positivo para empresas de todos os setores que desejam implantar o CEP.

Poucos trabalhos foram encontrados que confrontam a percepção dos responsáveis pelo CEP versus as recomendações da literatura, em especial no contexto nacional. De maneira complementar Rohani; Yusof; Mohamad (2010) recomendam a descrição das praticas do CEP em diferentes contextos culturais e tecnológicos.

\section{REVISÃO DE LITERATURA}

O CEP consiste em um conjunto de ferramentas estatísticas com objetivo de identificar, monitorar e reduzir as causas de variabilidade no processo produtivo amplamente utilizado no desenvolvimento de projetos de melhoria e para evidenciar o domínio sob as características da qualidade desejadas pelos clientes (Soriano; Oprime; Lizarelli, 2017).

As cartas de controle e planos de inspeção constituem as principais ferramentas do CEP e possibilitam monitorar o desempenho do processo, e seu uso adequado facilita a tomada de decisão de intervir no processo produtivo, melhorando assim a eficiência das ações (Ahmadan et.al., 2012; LIM, et. al. 2017).

\subsection{BENEFÍCIOS DA APLICAÇÃO DO CEP}

A utilização correta das cartas de controle possibilita identificar as causas de variação no processo em especial as mais representativas e as quais podem se estabelecer relação direta. A redução da variabilidade possibilita uma redução substancial na quantidade de defeitos e consequentemente aumento da produtividade (Montgomery, 2014; Oakland, 2008; LIM, et. al. 2017).

De maneira secundária, é importante destacar que a aplicação eficiente do CEP apresenta os seguintes benefícios: Sua aplicação eficiente aumenta substancialmente a satisfação dos clientes, pois menos produtos defeituosos serão entregues aos clientes além de características de qualidade desejadas são mais facilmente alcançadas (Rohani; Yusof; Mohamad, 2010).

O treinamento nestas ferramentas aprimora a capacidade de estudo de problema para a equipe além de contribuí para o aprimoramento técnico das pessoas e motivá-las em suas ações pela busca da qualidade e satisfação dos clientes (Rohani; Yusof; Mohamad, 2010).

Finalmente, a redução da variabilidade possibilita uma melhora à velocidade de entrega do produto uma vez que menos itens serão perdidos durante o processo produtivo, além de uma redução substancial na necessidade de realizar inspeções de qualidade (Montgomery, 2014; Oakland, 2008; LIM, et. al. 2017).

Neste trabalho foram selecionados para serem descrito os seguintes benefícios com a implantação do CEP: satisfação dos clientes; capacidade de estudo de problema; imagem da empresa; influencia nas abordagens de melhoria, redução da variabilidade, decisão sobre a compra de equipamento, velocidade de entrega do produto, retorno financeiro; ganhos de produtividade, Motivação dos colaboradores, aprimoramento técnico das pessoas e desempenho de campo dos produtos. 


\subsection{CARTAS DE CONTROLE COMO FERRAMENTAS DA MELHORIA DA QUALIDADE}

Montgomery (2014) apresenta as principais cartas de controle e sob quais situações devem ser aplicadas no CEP. Basicamente, as cartas de controle dividem-se em dois grandes grupos sendo as cartas por atributo e variáveis. As seguintes cartas de controle são identificadas na literatura para controle de atributos p, np, c, u e para variáveis X/R, X/S. (Montgomery, 2014; Oakland, 2008).

Encontram-se, ainda na literatura, aplicações das cartas: Gráfico de Controle de Soma Acumulada (CUSUM), Gráfico de Controle de Médias Móveis Exponencialmente Ponderadas (EWMA), além da aplicação combinada das anteriores (CUSUM/ EWMA).

A carta para variáveis individual de Shewart, ainda aplicada intensivamente na indústria, é precursora das cartas de controle para variáveis (Montgomery, 2014;; Oakland, 2008).

Outros grupos de carta de controle tais como as não-paramétricas, pequenos lotes e multivariadas ainda são objeto de estudo pela academia e sua aplicação prática industrial é pouco discutida na literatura (Montgomery, 2014; Oakland, 2008).

Além da implantação das cartas de controle, há outras ferramentas que devem ser aplicadas em conjunto para viabilizar o correto plano de ação. Assim, sua implantação está relacionada à correta mensuração do sistema de medição Repetibilidade \& Reprodutibilidade (GR\&R), e a análise dos índices referenciais de desempenho e capacidade do sistema produtivo (Montgomery, 2014; Oakland, 2008).

Para a condução deste trabalho as seguintes ferramentas foram selecionadas para descrição de seu uso pelas indústrias de autopeças: carta de controle por atributo; carta de controle por variáveis, gráfico de controle de soma acumulada, gráfico de controle de médias móveis exponencialmente ponderadas (EWMA), gráficos de controle multivariados; gráfico de controle individual de Shewhart, gráfico de controle para pequenos lotes; estudo de capacidade do processo e análise do sistema de medição.

\subsection{CONTROLE DA QUALIDADE POR INSPEÇÃO}

Apesar de a eficiência relativa das cartas de controle na identificação das tendências de falhas potenciais serem superior àquela apresentada pelos métodos de inspeção, estes últimos ainda fazem parte dos manuais de qualidade dos fornecedores da indústria automobilística como forma de controlar a qualidade no recebimento de matérias-primas e de ratificar a eficiência dos processos e do produto final (Rohani;YUSOF; Mohamad, 2010; Putri e YUSOF, 2009).

Inspecionar $100 \%$ dos produtos não garante a qualidade na entrega do produto final, pois além de representar um elevado custo para o fabricante, inviabiliza em muitos casos sua realização. Todas as ferramentas de inspeção selecionadas neste trabalho estão propensas à ocorrência de dois tipos de erro, definidas pela literatura como sendo tipo I e tipo II em razão da quantidade de amostras utilizadas (Wetherill, 1977; Oakland, 2008; Montgomery, 2014).

No intuito de minimizar os efeitos do custo e maximizar a eficiência na detecção das falhas, a literatura apresenta diferentes formas de inspecionar a qualidade dos produtos, dentre as quais se destacam as ferramentas de amostragem de aceitação lote à lote, Contínua e Skip-Lot.

\subsection{FATORES CRÍTICOS DE SUCESSO PARA A IMPLANTAÇÃO DO CEP}

A literatura enfatiza como um FCS que sem o comprometimento da alta administração as iniciativas do CEP não se estabelecem uma estrutura necessária para uma condução eficiente das atividades e assim os recursos para o desenvolvimento das atividades deixam de estar disponível. Com um recurso significativo a literatura recomenda a aquisição de programas computacionais para a realização das atividades (Montgomery, 2014; LIM, et. al. 2017).

A literatura ainda recomenda o treinamento e a reciclagem dos conceitos para os envolvidos com o as atividades do CEP principalmente no local de realização das atividades de maneira constante. Essa prática auxilia na visualização de oportunidades práticas de aplicação das técnicas. É recomendado pela literatura que exista a figura de um facilitador. Esse facilitador deve ser treinado nas diversas ferramentas e dar suporte para o nível operacional no desenvolvimento de suas atividades (Toledo; Lizarelli; Santana-JR, 2017; Montgmery, 2017). 
Para este trabalho os seguintes FCS foram selecionados para estudo: analise do sistema de medição, aplicação correta das ferramentas, apoio da alta administração, seleção das características critica da qualidade para a aplicação do CEP, projeto piloto, utilização de programas computacionais e condução dos treinamentos.

\section{MÉTODO DE PESQUISA}

Para atingir o objetivo proposto, é necessário organizar e analisar a opinião dos especialistas na implantação e gestão do CEP na indústria brasileira de autopeças. A estrutura conceitual deste trabalho foi estabelecida por meio de uma revisão da literatura, na qual se buscou, nas principais obras da literatura disponível e atual, identificar os benefícios, FCS e ferramentas associadas ao CEP. Este questionário foi validado conceitualmente e tecnicamente por 05 empresas.

As variáveis de pesquisa selecionadas como benefícios do CEP estão apresentados na tabela 01 na forma de afirmações com as quais os respondentes deveriam expressar sua concordância por meio de uma escala likert de 05 pontos.

Tabela 01 Benefícios da aplicação do CEP

\begin{tabular}{|l|l|}
\hline R1 & Aumenta substancialmente a satisfação dos clientes \\
\hline R2 & Aprimora a capacidade de estudo de problema \\
\hline R3 & Melhoria na imagem da empresa \\
\hline R4 & É parte importante do TPM \\
\hline R5 & É parte importante do Lean Manufacture \\
\hline R6 & Contribui para a redução da variabilidade do processo \\
\hline R7 & Contribui para decisão sobre a compra de equipamento \\
\hline R8 & Melhora a velocidade de entrega do produto \\
\hline R9 & Traz o retorno financeiro esperado \\
\hline R10 & É parte importante do sistema de gestão da qualidade ISO \\
\hline R11 & Reduz de defeitos e ganhos de produtividade \\
\hline R12 & Motiva os colaboradores envolvidos em suas ações \\
\hline R13 & Contribuí para o aprimoramento técnico das pessoas \\
\hline R14 & Contribuí para o desempenho de campo dos produtos \\
\hline R15 & Contribuí para o sucesso das abordagens de melhoria Seis Sigma \\
\hline
\end{tabular}

As principais ferramentas do CEP selecionados neste trabalho estão representadas na tabela 02 . Neste caso, os respondentes deveriam indicar por meio de uma escala likert de 04 pontos a intensidade de aplicação das ferramentas selecionadas.

Tabela 02 Principais Cartas de controle e técnicas de amostragem

\begin{tabular}{|c|l|}
\hline F1 & Carta de controle por atributo (p, np, c, u) \\
\hline F2 & Carta de controle por variáveis (X/R, X/S) \\
\hline F3 & Gráfico de controle de soma acumulada (CUSUM) \\
\hline F4 & Gráfico de controle de médias móveis exponencialmente ponderadas (EWMA) \\
\hline F5 & Gráficos de controle multivariados \\
\hline F6 & Gráfico de controle individual de Shewhart \\
\hline F7 & Gráfico de controle pequenos lotes \\
\hline F8 & Estudo de capacidade do processo (Cp, Cpk, Pp, Ppk) \\
\hline F9 & Análise do sistema de medição Repetibilidade \& Reprodutibilidade (GR\&R) \\
\hline F10 & Amostragem por aceitação lote a lote \\
\hline F11 & Amostragem contínua \\
\hline F12 & Plano de amostragem Skip-Lot \\
\hline
\end{tabular}

Fonte: Oakland, 2008; Montgomery, 2014; Wetherill, 1977. 
Na tabela 03 estão os FCS selecionados neste trabalho. Em relação às afirmações os entrevistados deveriam informar de maneira subjetiva a frequência com que realiza as atividades do CEP utilizando uma escala likert de 05 pontos. Fonte: próprio autor

Tabela 03 Fatores críticos de sucesso

\begin{tabular}{|c|c|c|}
\hline $\begin{array}{l}\text { Analise do Sistema } \\
\text { de Medição }\end{array}$ & Q41 & Análise de (R \& R) são realizadas antes de iniciar as atividades do CEP \\
\hline \multirow{4}{*}{ Aplicação } & Q36 & As causas especiais são identificadas e removidas imediatamente. \\
\hline & Q46 & $\begin{array}{l}\text { São observados todos os pressupostos estatísticos (tamanho amostral, } \\
\text { normalidade, dentre outros) no uso das cartas de controle. }\end{array}$ \\
\hline & Q47 & Os limites de controle são revisados periodicamente \\
\hline & Q48 & São calculados os índices de estabilidade do processo \\
\hline \multirow{3}{*}{ Apoio } & Q29 & $\begin{array}{l}\text { A alta administração monitora o cumprimento de metas para o desempenho } \\
\text { de qualidade. }\end{array}$ \\
\hline & Q40 & Existe suporte gerencial na condução de ações de melhoria. \\
\hline & Q42 & A alta administração cria uma estrutura de suporte para o CEP \\
\hline \multirow{3}{*}{$\begin{array}{c}\text { Característica } \\
\text { Critica }\end{array}$} & Q38 & As cartas de controle são aplicadas somente em características críticas. \\
\hline & Q39 & $\begin{array}{l}\text { É o cliente que decide sobre qual parâmetro do produto / processo deve ser } \\
\text { monitorado. }\end{array}$ \\
\hline & Q43 & Todos os processos/características críticas são controlados pelo CEP \\
\hline Piloto & Q49 & $\begin{array}{l}\text { Os processos produtivos são selecionadas corretamente para a implantação } \\
\text { do CEP. }\end{array}$ \\
\hline Software & Q37 & São utilizados pacotes computacionais na condução das atividades do CEP \\
\hline \multirow{3}{*}{ Treinamento } & Q32 & $\begin{array}{l}\text { Treinamentos básicos em CEP são ministrados aos trabalhadores } \\
\text { diretamente ligados a produção }\end{array}$ \\
\hline & Q33 & $\begin{array}{l}\text { Os conhecimentos adquiridos sobre CEP nos treinamentos são aplicados } \\
\text { imediatamente após sua realização. }\end{array}$ \\
\hline & Q34 & $\begin{array}{l}\text { Cursos de aperfeiçoamento na aplicação de ferramentas CEP são realizados } \\
\text { regularmente. }\end{array}$ \\
\hline
\end{tabular}

Fontes: Rohani;YUSOF; Mohamad, 2010; Soriano et. al. 2017; LIM, et. al. 2017

Ao todo, 98 dessas empresas concordaram em participar da pesquisa, resultando em 43 questionários respondidos. Destes questionários, 08 foram removidos devido ao respondente ter uma experiência $<01$ ano à frente da gestão do CEP, não ter certificação atualizada na norma ISO TS 16949 e não ter CEP ativo. A tabela 04 apresenta a experiência dos respondentes na condução na gestão do CEP.

Tabela 04 Experiência dos respondentes na condução na gestão do CEP

\begin{tabular}{|c|c|c|c|c|}
\hline $\begin{array}{c}\text { Anos de } \\
\text { experiência }\end{array}$ & Contagem & $\begin{array}{l}\text { Contagem } \\
\text { acumulada }\end{array}$ & Percentual & $\begin{array}{c}\text { Percentual } \\
\text { Acumulativo }\end{array}$ \\
\hline 1 & 1 & 1 & 2,86 & 2,86 \\
\hline 2 & 4 & 5 & 11,43 & 14,29 \\
\hline 3 & 2 & 7 & 5,71 & 20,00 \\
\hline 4 & 2 & 9 & 5,71 & 25,71 \\
\hline 5 & 1 & 10 & 2,86 & 28,57 \\
\hline 7 & 3 & 13 & 8,57 & 37,14 \\
\hline$>10$ & 22 & 35 & 62,86 & 100,00 \\
\hline Dados perdidos & 0 & 35 & 0,00 & 100,00 \\
\hline
\end{tabular}

Os 35 questionários selecionados passaram por validação estatística por meio da medida do alpha de Cronbach, os quais resultaram em valores $>0,6$, recomendados pela literatura para pesquisas deste tipo (Forza, 2002) para a condução das análises. A tabela 05 apresenta os resultados encontrados. 
Tabela 05 validação estatística dos constructos de pesquisa

\begin{tabular}{|c|l|c|}
\hline \multirow{4}{*}{ Coleta de dados } & População Identificada & 176 \\
\cline { 2 - 3 } & Questionários enviados & 98 \\
\cline { 2 - 3 } & Questionários respondidos & 43 \\
\cline { 2 - 3 } & Questionários utilizados & 35 \\
\hline \multirow{3}{*}{ Alfa de Cronbach. } & Resultados & 0,89 \\
\cline { 2 - 3 } & Ferramentas & 0,81 \\
\cline { 2 - 3 } & Fatores Críticos de sucesso FCS & 0,84 \\
\hline
\end{tabular}

Fonte: próprio autor

\section{ACHADOS DO SURVEY}

Nos itens a seguir, são descritas as análises realizadas nos questionários válidos, e os dados explicitam as características do CEP nas empresas estudadas. 0 primeiro tópico à ser apresentado trata das ferramentas utilizadas pelas empresas estudadas.

\subsection{FERRAMENTAS UTILIZADAS NO CEP DAS EMPRESAS ESTUDADAS}

A tabela 06 mostra a intensidade com que as principais cartas de controle e técnicas de inspeção são utilizadas pelas empresas nas quais os entrevistados gerenciam o CEP, sendo possível observar as tendências de respostas.

Tabela 06 Percentual de utilização das técnicas estatísticas estudadas

1-Raramente usada 2 2-Pouco aplicada 3-Aplicada $\quad$ 4-Bastante aplicada 5-Intensivamente aplicada

\begin{tabular}{|c|c|c|c|c|c|}
\hline F1 & 31,43 & 28,57 & 31,43 & 2,86 & 5,71 \\
\hline F2 & 8,57 & 14,29 & 34,29 & 17,14 & 25,71 \\
\hline F3 & 60,00 & 11,43 & 14,29 & 8,57 & 5,71 \\
\hline F4 & 54,29 & 17,14 & 20,00 & 5,71 & 2,86 \\
\hline F5 & 40,00 & 31,43 & 8,57 & 14,29 & 5,71 \\
\hline F6 & 45,71 & 37,14 & 8,57 & 5,71 & 5,71 \\
\hline F7 & 37,14 & 25,71 & 20,00 & 11,43 & 42,86 \\
\hline F8 & & 5,71 & 31,43 & 20,00 & 40,00 \\
\hline F9 & 2,86 & 5,71 & 25,71 & 25,71 & 25,71 \\
\hline F10 & 17,14 & 11,43 & 31,43 & 14,29 & 22,86 \\
\hline F11 & 17,14 & 8,57 & 25,71 & 25,71 & 22,86 \\
\hline F12 & 14,29 & 28,57 & 20,00 & 14,29 & \\
\hline
\end{tabular}

Fonte: Próprio autor

Observa-se nesta tabela o uso intensivo das cartas de controle por variáveis, bem como o uso da análise da capacidade de processo $(\mathrm{Cp} / \mathrm{Cpk})$ e da análise do sistema de medição. Fator coerente, pois o método de aplicação das cartas de controle presume que o sistema de medição seja adequado, e o indicador do desempenho do processo em termos de qualidade é avaliado pelos índices de capacidade.

É possível observar que as empresas pesquisadas fazem uso de técnicas de amostragem para controlar as características de qualidade dos itens produzidos, o que contrasta com literatura da área, que incentiva a adoção de técnicas para controle de processo ao invés das inspeções.

As cartas de controle para atributo são menos aplicadas, se comparadas às cartas de controle por variáveis. De maneira geral, no contexto da indústria de autopeças, as características dos produtos podem, em sua maioria, ser avaliadas na forma de variáveis. As cartas de controle CUSUM, EWMA, Multivariadas e Pequenos Lotes, embora amplamente discutidas na literatura, são pouco utilizadas nas empresas. 
As empresas pesquisadas não utilizam as cartas de controle individual de Shewhart, a aplicação destas técnicas está relacionada a um grande número amostral. Foi possível observar nos resultados que as técnicas de amostragem por aceitação lote a lote, contínua e Skip-Lot não apresentam um padrão consistente de aplicação.

Dando sequencia à analise dos dados, o tópico seguinte apresenta os principais benefícios gerados pela utilização das ferramentas do CEP nas empresas estudadas.

\subsection{BENEFÍCIOS PERCEBIDOS PELAS EMPRESAS ESTUDADAS EM RELAÇÃO À IMPLANTAÇÃO DO CEP}

A tabela 07 apresenta os resultados referentes aos benefícios percebidos pelos entrevistados referentes à aplicação do CEP nas empresas participantes da pesquisa.

Tabela 07 Percepção dos benefícios do CEP em percentual

\begin{tabular}{|c|c|c|c|c|c|}
\multicolumn{1}{|c|}{ 1-Impacta negativamente } & 2-Não impacta & 3-Indiferente & \multicolumn{1}{l|}{ 4-Impactante } & 5-Impacto muito alto \\
\hline R01 & & 2,86 & 5,71 & 54,29 & 37,14 \\
\hline R02 & & & 5,71 & 60 & 34,29 \\
\hline R03 & & 5,71 & 34,29 & 40 & 20 \\
\hline R04 & & 5,71 & 25,71 & 51,43 & 17,1 \\
\hline R05 & & 2,86 & 22,86 & 62,86 & 11,43 \\
\hline R06 & & 5,71 & 2,86 & 34,29 & 57,14 \\
\hline R07 & & 2,86 & 17,14 & 57,14 & 22,86 \\
\hline R08 & & 8,57 & 40 & 40 & 11,43 \\
\hline R09 & & 5,71 & 22,86 & 57,14 & 14,29 \\
\hline R10 & & 2,86 & 17,14 & 54,29 & 25,71 \\
\hline R11 & 2,86 & 5,71 & 20 & 48,57 & 22,86 \\
\hline R12 & 8,57 & 8,57 & 45,71 & 34,29 & 2,86 \\
\hline R13 & 2,86 & 2,86 & 14,29 & 71,43 & 8,57 \\
\hline R14 & 2,86 & 5,71 & 11,43 & 62,86 & 17,14 \\
\hline R15 & 2,86 & 5,71 & 14,29 & 60 & 17,14 \\
\hline
\end{tabular}

Fonte: Próprio autor

Observando os resultados apresentados na tabela 07 é possível inferir que para um percentual pequeno dos entrevistados, não são percebidos impactos positivos na redução de defeitos, ganhos de produtividade, satisfação dos clientes, motivação dos envolvidos, melhoria no desempenho em campo dos produtos, melhoria na imagem da organização e que o CEP pode auxiliar no sucesso dos programas de melhoria.

O CEP apresenta um papel importante também na implantação de outras abordagens e melhorias e sistemas da qualidade, pois auxilia na compreensão das necessidades e relações entre os processos produtivos. Para os gestores, o principal resultado da implantação do CEP consiste na identificação e redução da variabilidade do processo produtivo.

No entanto, observa-se que o mesmo não impacta na motivação das pessoas, e isso pode ser atribuído ao fato de as cartas de controle ser consideradas como uma atividade extra para o nível operacional. Observando o CEP, é possível ressaltar sua contribuição para o desempenho de campo dos produtos, redução da variabilidade do processo, compra de equipamento, e velocidade de entrega do produto.

Os benefícios da aplicação do CEP estão diretamente relacionados à maneira pela qual a empresa utilizou para organizar suas atividades. Neste sentido, o próximo tópico apresenta uma descrição da importância percebida pelos gestores do CEP nas empresas estudadas relacionadas aos FCS. 


\subsection{FATORES CRÍTICOS DE SUCESSO (FCS) OBSERVADO PELAS EMPRESAS ESTUDADAS}

Os resultados apresentados na tabela 08 demonstram a constância com o que a empresa realiza as atividades relacionadas em percentual. Assim seus resultados evidenciam se a empresa lida corretamente com os FCS na condução das atividades do CEP.

Tabela 08 Percentual de observação dos FCS nas atividades do CEP

\begin{tabular}{|l|c|c|c|c|c|}
\hline \multicolumn{2}{|c|}{$\begin{array}{c}\text { 1-Nunca é } \\
\text { realizado }\end{array}$} & $\begin{array}{c}\text { 2-É pouco } \\
\text { realizado }\end{array}$ & $\begin{array}{c}\text { 3-Constantemente } \\
\text { realizado }\end{array}$ & $\begin{array}{c}\text { 4-Intensamente } \\
\text { realizado }\end{array}$ & $\begin{array}{c}\text { 5-Realizado sem } \\
\text { exceção }\end{array}$ \\
\hline C01 & & & 22,86 & 31,43 & 45,71 \\
\hline C02 & & & 8,58 & 31,42 & 60,00 \\
\hline C03 & & & 2,86 & 54,28 & 42,86 \\
\hline C04 & & 5,71 & 8,57 & 45,72 & 40,00 \\
\hline C05 & & 2,86 & 2,86 & 37,14 & 57,14 \\
\hline C06 & & & 5,71 & 42,86 & 51,43 \\
\hline C07 & & & 8,57 & 34,29 & 57,14 \\
\hline C08 & & 2,85 & 14,29 & 51,43 & 31,43 \\
\hline C09 & 2,86 & & 40,00 & 31,43 & 25,71 \\
\hline C10 & 2,86 & 11,43 & 37,14 & 40,00 & 28,57 \\
\hline C11 & 8,57 & 8,57 & 11,43 & 42,86 & 31,43 \\
\hline C12 & & & 14,29 & 54,29 & 31,43 \\
\hline C13 & & & 34,29 & 34,29 & 60,00 \\
\hline C14 & & 2,86 & 2,86 & 34,29 & 40,00 \\
\hline C15 & & & 8,57 & 51,43 & 28,57 \\
\hline C16 & & & 11,43 & 60,00 & \\
\hline
\end{tabular}

Na tabela 08 é possível observar que os entrevistados indicaram que a análise do sistema de medição, por meio de uma análise de (R\&R) são realizadas constantemente demonstrando a necessidade de separar a variação pertencente ao processo produtivo, produto e sistema de medição.

Em sua maioria os entrevistados determinam os índices de capacidade e desempenho do processo e procuram identificar e remover as causas de variação no processo produtivo tornando o processo mais estatisticamente estável. Os respondentes observam os principais pressupostos estatísticos tais como: tamanho amostral, normalidade, dentre outros para a aplicação das cartas de controle. Os limites de controle não são revisados periodicamente apenas para um pequeno grupo de entrevistados. Isso pode levar à indicadores de desempenho de processo equivocados.

Em relação à alta administração criar uma estrutura de suporte para o CEP observa-se que alguns gestores gostariam de possuir maiores recursos para a realização de suas atividades. Contudo, em sua maioria os gestores estão satisfeitos com os investimentos na estrutura de trabalho do CEP.

A literatura estudada recomenda que as cartas de controle sejam aplicadas somente em características críticas, funcionais e de segurança dos produtos e processos. Existem alguns casos nos quais os responsáveis pelo CEP não concordam com essa prática o que pode levar a um excesso de cartas de controle.

Os resultados indicam que o cliente na maioria dos casos decide sobre qual parâmetro do produto / processo deve ser monitorado. Essas práticas estão bem estruturadas na relação com o fornecedor da indústria de autopeças. Neste caso, existe uma comunicação entre as partes de quais características que deve ser controlado para a satisfação dos requisitos do produto.

Para uma parcela significativa dos entrevistados nem todos os processos/características críticas são controladas pelo CEP. Nesta situação, existem características criticas para a qualidade que não são monitoradas o que pode gerar problemas significativos para o desempenho do produto final.

Em sua maioria os processos produtivos nos quais se objetiva a implantação das cartas de controle são selecionadas corretamente, pois se aplicados incorretamente podem comprometer as atividade de sustentação do CEP. 
Para uma parcela significativa dos entrevistados não são utilizados pacotes computacionais na condução das atividades do CEP em parte isso pode ser atribuído à aplicação de formulários impressos nos quais os operadores realizam o registro de suas ações, de maneira mais rápida e prática.

Em sua maioria e segundo os entrevistados, treinamentos básicos em CEP são ministrados regularmente aos trabalhadores diretamente ligados a produção e que estes são aplicados imediatamente após sua realização. Está prática está prevista na literatura como importante, pois o CEP é um conjunto de ferramentas direcionadas ao nível operacional.

\section{CONCLUSÃO}

Do ponto de vista da aplicação das ferramentas, foram selecionadas as mais recorrentes na literatura para controle da qualidade. Em parte isso pode ser explicado pelas características do setor predominantemente trabalhar com o controle de variáveis. Contudo, um estudo aprofundado sobre esses assunto pode investigar se os gestores tem conhecimento necessário que viabilizam a aplicação de outras ferramentas ou se neste setor tais atividades são pouco necessárias.

Em relação aos benefícios da aplicação do CEP estes estão diretamente relacionados à condução das atividades. De maneira geral é possível concluir que os benefícios principais observados pelos gestores derivam da redução da variabilidade. Uma das principais razões para isso está na exigência do setor de automotivo pelas exigências contratuais e organização do setor.

A implantação do CEP leva em consideração as caraterísticas criticas solicitações de cliente. Já os treinamentos estes estão alinhados ao recomendado pela literatura, pois esses são direcionados aos operadores realizados constantemente e seus conceitos são aplicados logo após sua realização. Os resultados deste trabalho demonstram que a condução das atividades pelas estudadas está alinhada à literatura.

\section{REFERENCIAS}

[1] Ahmadan, M.F; Zakuan. N.; Jusoh, A.; Takalac, J. Relationship of TQM and business performance with mediators of SPC, lean production and TPM. Procedia-Social and Behavioral Sciences, v. 65, p. 186-191, 2012.

[2] Forza, C. Survey research in operations management: a process-based perspective. International Journal of Operations \& Production Management, v. 22, n. 2, p. 152-194, 2002.

[3] Lim, S.A.; Antony, J.; HE, Z.; Arshed, N. Critical observations on the statistical process control implementation in the UK food industry. International Journal of Quality \& Reliability Management, v. 34, n. 5, p. 684-700, 2017.

[4] Lizarelli, F. L.; Bessi, N.C.; Oprime, P.C.; Amaral R. M.; Chakraborti, S. A bibliometric analysis of 50 years of worldwide research on statistical process control. Gestão \& Produção, v. 23, n. 4, p. 853-870, 2016.

[5] Montgomery, D. C. Introdução ao controle estatístico da qualidade. 4 ed. Rio de Janeiro: LTC, 2014. 513p

[6] Oakland, J. S. Statistical Process Control. Routledge, 2008.

[7] Putri, N. T.; Yusof, S. M. Critical success factors for implementing quality engineering tools and techniques in malaysian's and indonesian's automotive industries: An Exploratory Study. In: Proceedings of the International MultiConference of Engineers and Computer Scientists. 2009. p. 18-20.

[8] Rahman, M. N. A.; Zain, R. M.; Alias, A. M.; Nopiah, Z. M. Statistical process control: Best practices in small and medium enterprises. Maejo International Journal of Science and Technology, v. 9, n. 2, p. 193-208, 2015.

[9] Rohani, J.M.; Yusof, S.M.; Mohamad, I. The Development of a Survey Instrument for Measuring a Relationship Between Statistical Process Control Success Factors and Performance. Jurnal Mekanikal, n. 30, p. 1-16, 2010.

[10] Soriano, F. R.; Oprime, P. C.; Lizarelli, F. L. Impact analysis of critical success factors on the benefits from statistical process control implementation. Production, v. 27, 2017.

[11] Toledo, J. C.; Lizarelli, F. L.; Santana-JR. M. Success factors in the implementation of statistical process control: action research in a chemical plant. Production, v. 27, 2017.

[12] Wetherill, G. B.Sampling inspection and quality control. Springer, 1977. 


\section{Capítulo 4}

\section{O impacto do facelift no contexto de P\&D com ênfase em qualidade total}

\section{Felipe Ferreira Sereno \\ Francisco Ignácio Giocondo Cesar}

Resumo: Devido à grande concorrência entre os produtos de consumo tornou-se necessário uma atualização constante da qualidade dos produtos sem alterações funcionais, devido a isso a utilização da técnica de face lift está cada vez mais presente nos setores pesquisa e desenvolvimento (P\&D). Este artigo tem por finalidade avaliar as estratégias desta nova técnica de atualização de produto o face lift que está se tornando cada vez mais usual nos setores de P\&D de produtos, e como está analise será construída com ênfase nos processos de Qualidade Total (QT). A partir de uma pesquisa bibliográfica exploratória, se busca identificar produtos que passaram por face lift e se mantiveram ao longo do tempo no mercado. Identificar a partir desta pesquisa, o quanto a técnica do face lift está sendo utilizada e como ela influência positivamente na qualidade do produto e na sua permanência no mercado, dessa forma buscando manter o cliente sempre satisfeito. Por este motivo a ênfase na QT.

Palavras chave: Desenvolvimento de Produto; Face lift; P\&D; Qualidade Total. 


\section{INTRODUÇÃO}

O face lift vem se tornando cada vez mais relevante para a atualização de produtos, devido as alterações estéticas realizadas sem que ocorra alterações estruturais onerosas. Sua principal utilização é na indústria automotiva, pois geralmente na parte externa do veículo são realizadas melhorias nos faróis, grades, acabamento de peças, para-choques, entre outras possíveis. Isto ocorre devido ao crescimento da concorrência e melhorias continuas que são necessárias devido ao "feedback" constante dos consumidores.

A importância do face lift é abordada por Sami em seu estudo sobre o rastreamento visual em projetos, e definindo como uma possibilidade de envolver novas mensagens na aparência do produto, ou seja, as melhorias serão realizadas para se obter mais atenção ao produto pelo cliente (KUKKONEN, 2005, p.7).

Novas tecnologias são implantadas em diversas áreas dentro do processo como robôs, impressoras 3D, inteligência artificial entre outros e na qualidade, estes progressos não poderiam ser diferentes, com isso a Qualidade Total (QT) se torna necessária em todos os processos trazendo melhorias dentro da empresa, e fora da empresa, com o "feedback" do cliente. A QT reflete um exemplo desta busca continua para a melhoria, pois o face lift se torna relevante no contexto das empresas atuais, com isso este artigo estuda os seus impactos.

Todo produto carrega uma identidade própria e de sua marca, desta maneira o face lift também colabora em detalhes visuais afim de destacar-se dos concorrentes e de produtos similares (KUKKONEN, 2005, p.7). Devido a isto, busca-se com o face lift estabelecer um equilíbrio entre rendimento, qualidade, funcionalidade, baixos custos de construção, operação e manutenção do projeto, ou seja, obter maiores lucros com menores investimentos. Estas estratégias de equilíbrio são os principais objetivos da engenharia de valor pelo qual está em evolução juntamente com a QT (MIZUNO, 2010, p.40).

A indústria automotiva utiliza deste método projetual por conta dos baixos custos e principalmente pelo menor impacto no processo existente, porém, a qualidade destes carros que passaram por face lift devem ser melhoradas por todos os envolvidos no processo produtivo gerando a necessidade da qualidade total. $\mathrm{O}$ artigo pretende exibir como são trazidas estas melhorias e como a indústria lida com elas, utilizando das ferramentas da qualidade como avaliação durante o processo.

A qualidade total envolvida no P\&D durante o face lift de produto gera impactos, este artigo pretende compreender por meio de pesquisa bibliográfica como o desenvolvimento de pequenas mudanças estéticas tem influência no processo produtivo e quanto são positivas essas melhorias na qualidade, durante todo o processo.

Mostrar como o face lift é utilizado na área automotiva, seus impactos na produção e como está sendo abordado esta melhoria perante os conceitos da Qualidade Total.

No próximo capítulo será abordado o referencial teórico que irão dar suporte a pesquisa aqui desenvolvida. No capítulo 3 serão descritos o método e a metodologia adotada para o desenvolvimento deste trabalho. No capítulo 4, aborda P\&D em suas várias etapas com ênfase na qualidade total dentro do setor automotivo. Capítulo 5 explora os principais conceitos e problemáticas envolvendo a inovação por meio do face lift e as análises desenvolvidas pela qualidade. Capítulo 6 análises da utilização do conceito face lift no segmento automotivo.

\section{REFERENCIAL TEÓRICO}

\subsection{QUALIDADE TOTAL}

O princípio da Qualidade Total é fornecer eficácia genuína, o controle deve começar com o design do produto e terminar somente quando o produto tiver sido colocado nas mãos de um cliente que permanece satisfeito pelo produto que recebeu (LOCKAMY, 1995, p.73).

A Qualidade Total será composta pela cooperação mútua de todos em uma organização e processos de negócios associados para produzir produtos e serviços que atendam e, esperamos, excedam as necessidades e expectativas dos clientes. Desta forma a qualidade se torna uma filosofia e um conjunto de princípios orientadores para gerenciar uma empresa (REES et al,2001, p.1).

Os princípios da Qualidade Total estão embaçados na orientação para o clientes (compreender os desejos e necessidades dos clientes de hoje e antecipar os desejos e necessidades futuros do cliente), compromisso de liderança, melhoria e aprendizado contínuos (identificação de benchmarks de práticas excelentes e a 
instilação de um senso de propriedade do processo pelo funcionário), cooperação e desenvolvimento de parcerias e responsabilidade social (MOCCIA S.,2016, p.222)

\subsection{PESQUISA E DESENVOLVIMENTO}

O pesquisa e desenvolvimento (P\&D) são realizados os primeiros estudos e se inicia os parâmetros projetuais, a partir dos dados coletados pela gestão da qualidade (QM) gerando oportunidades para aplicar princípios e técnicas de QM e P\&D em suas atividades inovadoras, onde as oportunidades permitem detectar a demanda dos clientes (KIM et al, 2012, p.297).

Com a visão do produto é possível mudar a atitude da equipe de projetos, frente ao desafio do desenvolvimento de um produto inovador, pois baseado na especificação de requisitos do consumidor (início do projeto), é substituído pela busca em satisfazer a determinadas necessidades emocionais do consumidor (FERREIRA JUNIOR et al, 2011, p. 63). Dentro da pesquisa e desenvolvimento pode-se considerar os feelings dos consumidores; sugerindo tendências; proporcionando respostas rápidas e apropriadas a cada tipo de consumidor ou nicho; coletando e atualizando dados dos clientes com maior frequência, orientando a equipe de desenvolvimento sobre quais características priorizar em um produto (FERREIRA JUNIOR et al, 2011, p. 67).

Com a integração de valores emocionais em produtos estes se tornam independentes, ou seja, refletindo um estilo de vida individual do consumidor. Além disso, se o cliente tiver a escolha entre produtos de diferentes fabricantes, que são equivalentes em preço e desempenho, uma decisão de compra pode ser tomada pelo apelo estético (SCHÜTTE, S., 2005, p. 2).

\subsection{PRINCIPAIS CONCEITOS DO FACELIFT}

O face lift pode ser uma maneira de se obter inovação em curto ou a longo prazo, por meio da constante evolução dos valores e da cultura. Está presente em diversos mercados, por exemplo, eletrodomésticos, roupas, objetos de decoração, mobília, automotivo, etc. A estética representa a imagem, o estilo e o valor principal do produto, por isso a preocupação dos fabricantes de automóveis para o seu design e face lift (CHANG et al,2013, p. 143).

Os custos de qualidade são os indicadores de desempenho da qualidade aprimorada de projeto e qualidade de conformidade, com isso o face lift pode ser expresso como termo de valor ao produto, onde os benefícios da melhoria incluem maior qualidade do produto e redução de custos de falha (SETIJONO D., 2008, p. 292).

Com a avaliação dos clientes é constatado o valor das melhorias de qualidade, onde se assume que a função é positiva e crescente, significando que quando o valor das melhorias de qualidade aumenta, a mudança relativa no valor percebido pelo cliente também sobe, isto ocorre com as possíveis alterações estéticas (SETIJONO D., 2008, p. 309).

\section{MÉTODO \& METODOLOGIA}

\subsection{MÉTODO}

A pesquisa foi realizada a partir de informações referentes aos autores da engenharia, principalmente sobre estudos da área da qualidade e por meio de pesquisa exploratória em exemplares de revistas do setor automotivo.

\subsection{METODOLOGIA}

O artigo foi construído fazendo uma pesquisa bibliográfica exploratória, tomando como base de dados os livros, artigos e revistas da área da qualidade para o conhecimento dos temas tratados e para o melhor direcionamento do estudo. A metodologia foi estabelecida por meio de pesquisas exploratórias em artigos publicados entre os anos de 1995 a 2018 e exemplares da revista Quatro Rodas (editora Abril) a partir de setembro de 2018 a maio de 2019.Para o agrupamento e segregação dos dados coletados foi realizado uma análise dos conceitos tratados pelo autor e base de pesquisa do estudo em análise. 


\section{PESQUISA}

\subsection{P\&D E A QUALIDADE TOTAL NO DESIGN AUTOMOTIVO}

$\mathrm{Na}$ área de pesquisa e desenvolvimento (P\&D) são lançados diversos desafios para a melhoria dos produtos, por meio de inovações, revisões, adequações e pelo face lift o qual o artigo se propõem a estudar e analisar. No P\&D são realizados estudos empíricos a partir dos dados coletados pela gestão da qualidade (QM) gerando oportunidades para aplicar princípios e técnicas de QM e P\&D em suas atividades inovadoras, onde as oportunidades permitem detectar eficientemente a demanda dos clientes. Vale destacar o trabalho da QM, com efeito, esta traz ao P\&D as necessidades dos clientes, as minimizações de atividades sem valor e redução do tempo e dos custos de desenvolvimento de novos produtos (KIM et al, 2012, p.297).

O princípio da Qualidade Total é fornecer eficácia genuína, o controle deve começar com o design do produto e terminar somente quando o produto tiver sido colocado nas mãos de um cliente que permanece satisfeito. Com isso a qualidade tem papel importante durante a concepção do produto e se estende ao longo de todo o seu ciclo de vida, por isso, são necessários alguns mecanismos que permitam que as empresas integrem a QT em todas as suas atividades (LOCKAMY, 1995, p.73).

A chamada "implantação de qualidade" traz a voz do cliente para o processo de design, garantindo a qualidade de design e produção, ou seja, identificando alvos de design e especificações de produtos e peças, que são consistentes com os requisitos desejados (LOCKAMY, 1995, p.74).

Para que o P\&D consiga atingir suas metas junto a qualidade são sugeridas algumas fases durante o processo são estes: 1 - Planejamento de conceito de produto - começa com pesquisa de mercado e de consumidor, levando a um plano de produto onde são discutidas as ideias, esboços, modelos conceituais e planos de marketing. 2 - Design do produto, leva os conceitos do produto e desenvolve especificações de produtos e componentes, nesta fase são construídos e testados os protótipos. 3 - Os processos de fabricação, execuções piloto para os processos de produção e ferramentas são feitas para determinar os níveis de fabricação e os padrões de produção do produto. 4- Produção - Uma vez resolvidos os problemas das fases anteriores o produto entrará em produção, alcançando o cliente. A partir disso, o feedback do cliente serve como insumo para as próximas gerações de produtos (LOCKAMY, 1995, p.75).

$\mathrm{O}$ design de produto visa aumentar a qualidade do projeto e garantir a manufatura, desta forma, a qualidade do design leva à padronização de componentes, à simplificação de projetos e à incorporação das necessidades dos clientes nos processos de projeto. Com isso, as organizações devem encorajar a comunicação constante entre clientes, engenheiros e fabricantes durante o P\&D. Segundo Kim 2012 um design eficiente é caracterizado por menos componentes padronizados permitindo uma redução nas mudanças desnecessárias, evitando problemas com a qualidade e minimizando as taxas de falha (KIM et al, 2012, p.299).

\section{FACE LIFT COMO RECURSO DE INOVAÇÃO}

O design tem importância dentro do cenário industrial e mercadológico como uma ferramenta para se inovar ou atualizar produtos. Na indústria automotiva o design trabalha com o chamado face lift que são atualizações realizadas em uma plataforma de veículo geralmente no meio do ciclo do produto.

A inovação no mercado é dividida em incremental e radical por considerar as características de nível de mudança (menor x maior), cliente-alvo ou mercado (existente x novo) e o nível de risco (baixo x alto). A inovação incremental refere-se a pequenas alterações em termos de design, função, preço, quantidade e características para atender às necessidades dos clientes existentes e a inovação radical é definida como a adoção de novas tecnologias para criar uma demanda. A inovação de produto refere-se as mudanças de produtos ou serviços, ou seja, a inovação de processo é definida como as mudanças no método de produção ou serviços. A inovação radical de produtos se torna a introdução de produtos (ou serviços) que incorporam tecnologias diferentes daquelas utilizadas, enquanto a inovação incremental de produto se refere à inovação relacionada ao fornecimento de novos recursos, melhorias ou benefícios para a tecnologia existente no mercado existente (KIM et al, 2012, p.297).

Com isso é possível notar que se torna cada vez mais importante manter o produto dentro dos parâmetros da inovação, porém de maneira sucinta em relação aos custos. 0 face lift pode ser uma maneira de se obter isto em curto ou a longo prazo, por meio da conste evolução dos valores e da cultura, fazendo com que principalmente o design automotivo esteja em constantes mudanças e melhorias. Pois é na estética que se representa a imagem, o estilo e o valor principal do produto, portanto o carro sempre foi a principal 
preocupação dos fabricantes de automóveis para o seu programa de face lift. De acordo com o estudo realizado por Chang a aparência frontal dos carros é a principal área de interesse dos consumidores no momento em que eles olham para um carro, até mesmo sem o logotipo anexado, ou seja, são amplamente utilizados na análise do gosto ou não de uma aparência. 0 desejo subconsciente do consumidor após a primeira impressão mostra que o frontal do carro cumpriu o seu papel, mas comprar o carro é um comportamento do consumidor para atender às suas próprias necessidades gerando outras analises como economia, mecânica, valores de seguro, garantia, etc.(CHANG et al,2013, p. 143).

O Kansei Engineering foi o método utilizado no estudo sobre o frontal dos carros, sua utilização se torna necessária para explorar os fatores humanos, focado no lado psicológico do cliente, porém, na prática é usado principalmente no design de produtos orientando para o consumidor (CHANG et al,2013, p. 143).

Vale destacar que um produto age como um meio de transporte de mensagens. Por consequência estas mensagens são transmitidas pela estética não se limitando apenas ao sentido visual de beleza, mas também carrega muitos significados, tais como: julgamento de valor, etc. a indústria automotiva atingiu um estágio maduro, e existem vários tipos de modelos de carros disponíveis, gerando suas próprias ênfases na imagem, o que poderia trazer sentimentos diferentes para as pessoas (CHANG et al,2013, p. 143).

Para se obter os melhores resultados com o produto, precisamos manter a qualidade de todo o processo ocorrendo de maneira orgânica. Por este motivo o conceito de QFD (Quality Function Deployment) ajuda as empresas a identificarem os requisitos reais dos clientes e traduz esses requisitos em recursos do produto, especificações de engenharia e, finalmente, detalhes durante a produção. 0 produto poderá ser fabricado para satisfazer o cliente, caracterizando processo integrador que vincula as necessidades do cliente, os requisitos de projeto e peças, o planejamento do processo e as especificações de fabricação durante o desenvolvimento do produto (LOCKAMY, 1995, p.74).

Os benefícios deste conceito são: melhor satisfação do cliente resultante da melhoria da qualidade do design, prazos de entrega mais curtos devido a mudanças de engenharia menores e anteriores, melhores ligações entre várias etapas de projeto e fabricação, redução do número de componentes do produto e por fim um ambiente de trabalho melhorado através da integração horizontal de funções (LOCKAMY, 1995, p.75).

As informações do cliente no QFD são essenciais para a integração do TQM (Total Quality Management) focado no cliente em atividades de desenvolvimento de novos produtos, dessa forma é possível utilizar essas informações como uma entrada durante o processo. Os dados secundários (de relatórios privados ou dados de garantia) devem servir apenas para confirmar as informações do cliente e não para substituí-las. Essas fontes de dados secundárias só podem fornecer informações sobre pontos de insatisfação do cliente no passado, não sobre o que os clientes desejam nos produtos futuros (LOCKAMY, 1995, p.81).

Se obtém as informações do cliente por meio de pesquisas de mercado e estudos de segmentação de mercado como pontos de partida para identificar as necessidades do cliente. Sendo detalhado os estudos por meio de questões críticas. Um exemplo disso é a Toyota que usa essa abordagem no Japão, possuindo seus próprios canais de distribuição no Japão, ela empresta seus funcionários do canal de distribuição apropriado para as equipes de desenvolvimento de produtos. Esses membros da equipe do canal, por meio de seu foco no cliente, sabem muito sobre as necessidades e atitudes do cliente, influenciando não apenas em previsões de demanda, mas também nas características da próxima geração de automóveis da marca (LOCKAMY, 1995, p.81).

Para o êxito do QFD se requer dados e informações sobre as necessidades do cliente. Nos casos em que a empresa não possui um bom banco de dados de clientes, pode ser necessário criar um sistema de informações separado para a implementação do QFD. A pesquisa com clientes baseada em entrevistas com clientes em primeira mão, análises de mercado, psicologia do consumidor, etc. é essencial para melhorar os designs dos produtos (LOCKAMY, 1995, p.82).

\subsection{O FACE LIFT NO SEGMENTO AUTOMOTIVO}

No passado, muitos fabricantes de automóveis estavam priorizando o design do corpo, mas agora eles estão dando mais atenção à aparência frontal do carro, especialmente ao logotipo. 0 logotipo do carro costumava ser pequeno e muitas vezes era colocado em posição discreta. Agora é feito maior e integrado com a grade. 0 design também tende a usar expressões humanas, com os faróis simulando olhos humanos alegres ou viciosos e grade simulando o nariz humano como exemplos. Portanto, o design da expressão 
frontal de um carro será uma das preocupações do consumidor no futuro, por isso influenciará diretamente a imagem geral e o desempenho de vendas (CHANG et al,2013, p. 146).

Atualmente a maioria das empresas aplica uma série de métricas para avaliar o desempenho dos produtos que produzem, durante e após a fase de P\&D, para tomar decisões consistentes. Existem diversos métodos para avaliar o design do produto por meio de usabilidade, vendas, lucro, facilidade de fabricação e assim por diante, porém as influências de vários atributos afetam. Parece haver uma falta de métodos adequados para medir a aparência, o design visível e seu efeito na preferência de produto dos clientes. Com isso, as decisões de design são geralmente fundamentadas puramente em opiniões subjetivas (KUKKONEN, 2005, p.1).

Por conta disso, foi realizada uma pesquisa exploratória nos exemplares da revista Quatro Rodas (editora Abril) a partir de setembro de 2018 a maio de 2019, com isso foi possível trazer alguns pontos importantes sobre o design automotivo e sobre o face lift. Com o apoio do Editor Paulo Campo Grande foi realizada uma entrevista sobre o face lift na indústria automotiva brasileira, com isso a pesquisa teve melhores informações e uma construção da real relevância entre o P\&D e a qualidade total no design automotivo.

Abaixo estão os resultados obtidos a partir da pesquisa nos exemplares da revista Quatro Rodas e da entrevista realizada em 20/05/2019 das $17 \mathrm{~h} 00$ até as 18h00. Também foram adicionados aos resultados as principais definições sobre a ênfase em QT estes resultantes da pesquisa nos artigos sobre o assunto.

1. De acordo com suas experiências no meio automotivo. Como avalia a realização do face lift na indústria?

O face lift é uma atualização de produtos que na maioria das vezes ocorre no meio do ciclo de vida do carro, dessa forma um carro tem 6 anos de vida sendo no 3 ano a realização do face lift. Atualmente o face lift não traz apenas mudanças estéticas, mas envolve melhorias na parte técnica e novas tecnologias, exemplos disso são os "redesign" de faróis, lanternas, para-choques, grandes frontais, melhorias técnicas nos faróis como troca das lentes e também os sistemas de multimidias.

As novas plataformas desenvolvidas pelas montadoras têm colaborado para as melhorias mecânicas e estéticas durante o ciclo do carro, fazendo com que o carro evolua em pouco tempo. As plataformas modulares trazem essa flexibilidade aos carros sendo mais ágil a melhoria. Existem montadoras com maiores ciclos de produto, como por exemplo a Mercedes-Bens com a durabilidade de plataforma por 10 anos. Vale ressaltar que o face lift funciona muito bem quando a equipe de vendas das marcas precisa vender mais carros, porém tem menos recursos para atualiza-los perante aos concorrentes.

\section{Existe algum carro que tenha se destacado positivamente pelo(os) o face lift realizado?}

O face lift é uma oportunidade ao produto devido as melhorias, as alterações podem ser de renovação e melhoria para o carro. Exemplos positivos no mercado seriam os carros:

GM Cobalt - nova lanterna mais fina - simetria com os vincos do capo e com os vincos laterais; nova grade e novo para-choque frontal. Essas melhorias trouxeram características mais agressivas e mais bem distribuídas na frente do carro.

Figura 1 - GM Cobalt 2012

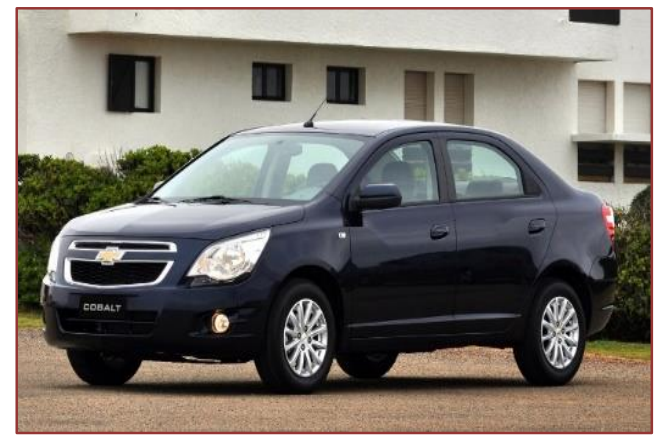

Fonte: All The Cars (2011). 
Figura 2 - GM Cobalt 2017

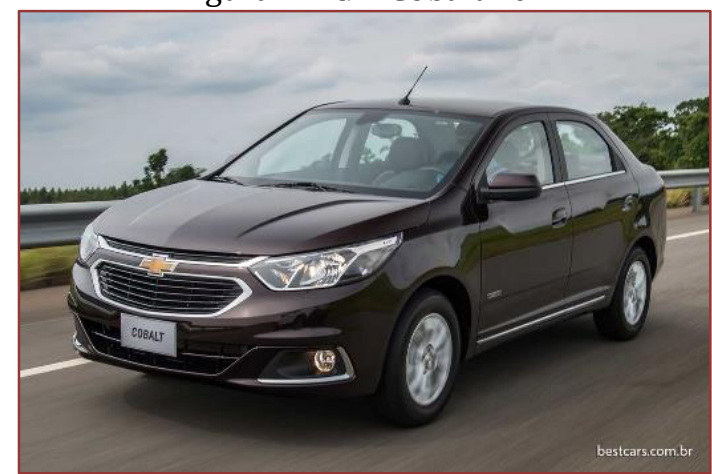

Fonte: Best Cars (2019).

\section{Existe algum carro que tenha se destacado negativamente pelo(os) o face lift realizado?}

O face lift é uma oportunidade do produto devido as melhorias, porém deve-se tomar cuidados com as previsões de estilo pelo qual as alterações podem ser preocupantes para o carro. Exemplos negativos no mercado seriam os carros:

Fiat Marea - aproveitamento da lanterna do Lancia Lypra para a realização de uma falsa atualização do carro.

Figura 3 - Fiat Marea 1999

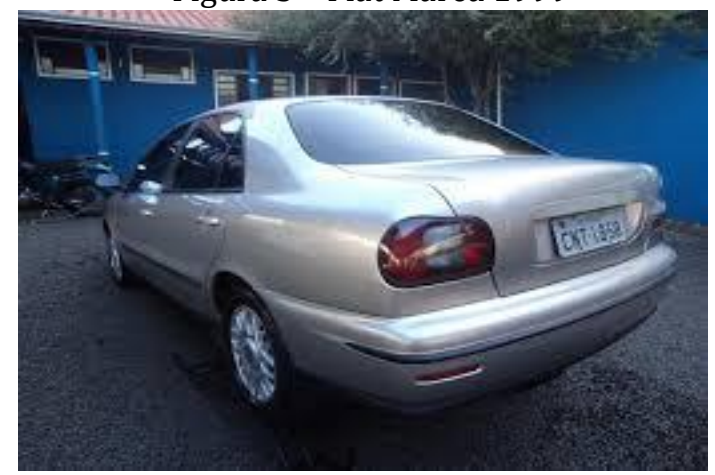

Fonte: Carro Piracicaba (2019).

Figura 4 - Fiat Marea 2006



Fonte: Noticias Automotivas (2018).

Em sua opinião o face lift tem influenciado o mercado a ter os "mesmos" carros sempre?

Não estamos tendo no mercado os "mesmos" carros, pois tudo depende da "escola" em que o carro foi projetado. Ou seja, existem diversas influencias durante o processo de atualização de acordo com as tendências do mercado (marketing desejado). Paulo afirma que a ideia em todos os casos de face lift é melhorar o carro. Os carros são projetados respeitando o "DNA" da marca, ou seja, seguem guias estéticos e principalmente técnicos dos fabricantes. 
4. O senhor acredita que a renovação de modelos seja a melhor opção na ótica mercadológica atualmente?

Em quanto for possível manter o carro renovado o face lift é uma saída para as reduções de projetos no Brasil e no mundo, dependendo apenas da prospecção da empresa. Todos os esforços são para aumentar as vendas em curto prazo.

Alguns feedbacks devem ser desconsiderados devido a alguns riscos, dessa forma o consumidor quer uma melhoria no carro, porém não paga pelo produto. Por exemplo disso são os carros "off-road" que são mais caros para se vender um produto "fora da cidade", porem na realidade é o mesmo carro com algumas implementações estéticas. Os atributos físicos e visuais claros nos quais um designer pode trabalhar para obter a impressão desejada no carro. A usabilidade aparente refere-se à usabilidade percebida e esperada em relação à experiência real de usar o produto, ou seja, nem sempre o que se espera do produto é usual (KUKKONEN, 2005, p.2).

Figura 5 - Fiat Argo Trekking

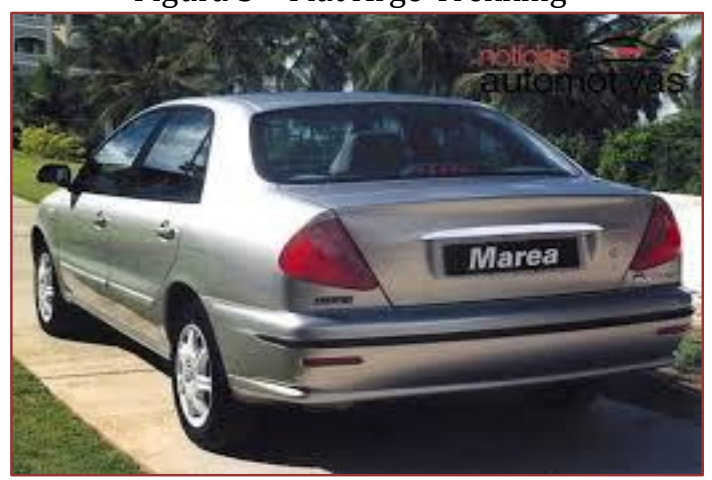

Fonte: Revista Quatro Rodas (2019).

\section{ANÁLISE DE RESULTADOS}

Pode-se traçar dois resultados importantes com esta pesquisa. Com este estudo foi possível perceber o quanto o face lift presente em diversos mercados, por exemplo, eletrodomésticos, roupas, objetos de decoração, mobília e principalmente no setor automotivo.

A partir desta analise foram construídos os resultados sobre o face lift no principal setor utilizado, o automotivo. Pode-se concluir que a qualidade é de extrema importância durante os processos de face lift, pois este setor da indústria já realiza a Qualidade Total fornecendo o controle do design até o produto nas mãos dos clientes.

\section{CONSIDERAÇõES FINAIS}

O face lift é uma ferramenta de inovação em qualquer área utilizada, pois se torna uma oportunidade de o produto ter melhorias continuas gerando uma longevidade do produto e da marca. Estes parâmetros da inovação se transformam em uma maneira de atualização com redução dos custos industriais.

Conhecendo o mercado em que o face lift for utilizado, podemos detectar que a inovação pode ser a "chave" do negócio, pois esta refere-se a novas aplicações de conhecimento, ideias, métodos e habilidades que podem gerar capacidades únicas e alavancar a competitividade de uma empresa (KIM et al, 2012, p.296). Tornou-se importante conhecer cada vez mais o cliente e suas necessidades gerando os sistemas de informações gerenciais que fornecem dados sobre os custos de qualidade e satisfação do cliente. Os setores de marketing e engenharia usam a filosofia do QFD e TQM para ajudar a projetar e entregar um produto de qualidade aos seus clientes (LOCKAMY, 1995, p.76).

Dessa forma as informações em primeira mão sobre o cliente são essenciais para integrar a verdadeira "voz do cliente" aos produtos, utilizando do face lift. Medidas de desempenho baseadas em QFD devem ser adotadas para fornecer um meio de motivação, feedback de desempenho e recompensas para equipes de QFD. 0 face lift é uma oportunidade ao produto devido as alterações que podem ser de renovação e melhoria no setor automotivo, assim o QFD integra TQM a novos produtos resultando em vantagens estratégicas de mercado devido à maior satisfação do cliente (LOCKAMY, 1995, p.83). 
0 artigo mostrou o quanto a técnica do face lift está sendo utilizada e como ela influência positivamente na qualidade do produto, dessa forma mantendo o cliente sempre satisfeito por meio da Qualidade Total fornecendo o controle do produto e do processo.

\section{REFERÊNCIAS}

[1] All The Cars. Chevrolet Cobalt 2012 Brasil (2011). Disponível em:

https://allthecars.files.wordpress.com/2011/11/chevrolet-cobalt-2012-brasil-011.jpg. Acessado em 20 de maio de 2019.

[2] Best Cars. Chevrolet Cobalt modelo 2017 (2019). Disponível em:

http://bestcars.uol.com.br/bc/participe/opinioes-proprietarios/teste-do-leitor-chevrolet/chevrolet-cobalt/. Acessado em 20 de maio de 2019.

[3] Carro Piracicaba. Fiat Marea 1999 (2019). Disponível em:

https://carropiracicaba.com.br/veiculos/1655613-fiat-marea-elx-2.0-20v-1999.html. Acessado em 20 de maio de 2019.

[4] Chang Y. M.; Chu C.; MA M. (2013). Exploring the Visual Cognitive Features on the Design of Car Based on the Theory of Eye-Tracking Technology. Southern Taiwan University of Science and Technology and National Cheng Kung University.

[5] Ferreira Junior, Lucelindo Dias; BENASSI, João Luís Guilherme; AMARAL, Daniel Capaldo. Kansei engineering na gestão ágil de projetos de novos produtos: potencialidades e desafios. Anais.. Bauru, SP: [s.n.], 2010.

[6] Kim, D. Y.; Kumar, V.; Kumar, U. (2012). Relationship between quality management practices na innovation. Journal of Operations Management, n. 20, 295-315.

[7] kukkonen, S. (2005). Exploring eye tracking in design evaluation. University of Art and Design Helsinki, Finland.

[8] Lockamy, A.; Khurana, A. (1995). Quality function deployment: total quality management for new product design. International Journal of Quality \& Reliability Management, Vol. 12 Iss 6 pp. 73 - 84.

[9] Mizuno, C. S. (2010). Aperfeiçoamento de um produto através do estudo de sua confiabilidade como um fator de valor. Escola Politécnica da Universidade de São Paulo.

[10] Moccia, S. (2016). The role of value and virtues in TQM; an overview of literature. The TQM Journal, v. 28 , n. 2.

[11] Noticias Automotivas. Fiat Marea: história, versões, modelos, motores e a má fama (2018). Disponível em: https://www.noticiasautomotivas.com.br/fiat-marea/. Acessado em 20 de maio de 2019.

[12] Rees, C. J.; Doran, E. (2001). Employee selection in a total quality management context: taking a hard look at a soft issue. Total Quality Managemen, vo. 12, no. 7 \& 8. P. 855-860.

[13] Revista Quatro Rodas. Fiat Argo Trekking usa fantasia aventureira discreta por R 58.990 (2019). Disponível em: https://abrilquatrorodas.files.wordpress.com/2019/04/imagem1.jpg?quality=70\&strip=info \&w=1024. Acessado em 20 de maio de 2019.

[14] Schütte, S. (2005). Engineering emotional values in product design - Kansei engineering in development. Linköping, Sweden: Linköping University.

[15] Setijono, D.; Dahlgaard, J. J. (2008). The value of quality improvements. International Journal of Quality \& Reliability Management, Vol. 25 Iss 3 pp. 292 - 312

[16] Agradecimento: Agradecemos o apoio das seguintes indstituiçãos: Faculdade de Ciências Aplicadas (FCA) Unicamp; ao Instituto Federal de Educação, Ciências e Tecnologia de São Paulo - Câmpus Piracicaba. 


\section{Capítulo 5}

A utilização de ferramentas de gestão de tempo em Projetos WEB: Um estudo de caso em ambiente Website Multi-Idioma

\section{Raul César do Carmo Matos}

Jefferson de Souza Pinto

Aelso Rocha Brito

Carlos Roberto Dantas

Resumo: A gestão do tempo em projetos possui papel cada vez mais importante nas organizações, uma vez que contribui diretamente para o sucesso do projeto, bem como na qualidade do produto final e na satisfação do cliente. Dessa maneira, este trabalho tem como objetivo analisar e discutir como as ferramentas de gestão do tempo, em especial o método da corrente crítica, podem auxiliar no gerenciamento do tempo em projetos de aplicações web. 0 método utilizado tem como base a pesquisa bibliográfica com abordagem exploratória com o estudo de caso para demonstrar sua aplicabilidade, utilizando-se para tal um projeto de website multi-idioma realizado na empresa estudada. Os resultados obtidos foram satisfatórios, uma vez que foi possível afirmar que a aplicação da corrente crítica impactou de forma positiva o gerenciamento do projeto estudado, definindo atividades e reduzindo seus tempos de duração e as probabilidades de atrasos.

Palavras-chave: Gestão de projetos; gestão do tempo; teoria das restrições; corrente crítica. 


\section{INTRODUÇÃO}

O desenvolvimento de projetos está presente nas organizações em vários sentidos, como para o desenvolvimento de produtos, serviços, tecnologias, resoluções de problemas, mudanças entre outros, sendo uma sequência de atividades programadas, com compromisso de fornecer um resultado que produz mudança (Maximiano, 2014).

Para que um projeto seja entregue com sucesso é necessário que seu gerenciamento seja efetivo (Munns e Bjeirm, 1996; Duarte et al., 2012). De acordo com Maximiano (2014), existem três medidas imediatas de avaliação de sucesso de um projeto, sendo elas a entrega do resultado singular, ou produto, o atendimento no prazo e do custo programados.

No cenário empresarial, em um ambiente competitivo, as organizações vêm buscando cada vez mais aperfeiçoar seus processos, minimizar seus custos e otimizar sua produtividade (Barcaui e Quelhas, 2004), visando a manutenção e o ganho de mercado.

Dessa forma, o gerenciamento de projetos tem recebido a atenção de pesquisadores e profissionais, uma vez que possui um papel cada vez mais importante nas organizações (Silva, Rodrigues e Lacerda, 2012, p. 1), em especial na área de gerenciamento de tempo, que é um ponto crítico em empresas de qualquer setor. Os atrasos na entrega de produtos ou serviços, bem como a sobrecarga dos colaboradores, podem ocasionar na maioria das vezes perdas financeiras, insatisfação dos clientes/funcionários, perda de qualidade e causar sérias consequências mercadológicas para um produto ou serviço.

Neste sentido, o método da Corrente Crítica (CCPM - Critical Chain Project Management), baseada na Teoria das Restrições (TOC, Theory of Constraints), do físico israelense Eliyahu Goldratt, em seu livro The Goal, de 1984, busca aprimorar as estimativas de tempo do projeto, visando a entrega no prazo e no orçamento planejados, eliminando os efeitos negativos da incerteza sobre o processo de execução do projeto, adicionando segurança às tarefas e garantindo que o projeto seja bem executado mesmo em um ambiente dinâmico (LUIZ et al., 2015, p.3). A partir do cenário, o trabalho tem objetivo analisar e discutir como a utilização da CCPM pode auxiliar no gerenciamento do tempo em projetos de web.

\section{FUNDAMENTAÇÃO TEÓRICA}

\subsection{GERENCIAMENTO DE TEMPO EM PROJETOS}

O Gerenciamento de Tempo do projeto descreve os processos que asseguram o término do projeto no prazo previsto, sendo, de acordo com o PMI (2019), dividido em: definição das atividades; sequenciamento e estimativa da duração das atividades; identificação dos recursos necessários e seu custo; elaboração do cronograma do projeto; e elaboração do orçamento do projeto (Maximiano, 2014, p.87). De acordo com o Guia PMBOK (PMI, 2019), com relação ao cronograma, os processos de Gerenciamento do Cronograma do Projeto divididos em: (1) Planejar o gerenciamento do cronograma; (2) Definir as atividades; (3) Sequenciar as atividades; (4) Estimar as durações das atividades; (5) Desenvolver o cronograma; e (6) Controlar o cronograma.

0 gerenciamento do tempo está interligado com o orçamento do projeto, uma vez que à medida que o projeto tem mais recursos o prazo diminui e vice-versa. Para que o gerenciamento do tempo seja efetivo, diversas ferramentas foram desenvolvidas ao longo do tempo e são utilizadas para que o sucesso almejado para o projeto seja alcançado e perdas de recursos e de prazos sejam mitigadas, entre elas a CCPM.

\subsection{TEORIA DAS RESTRIÇÕES}

Uma restrição pode ser qualquer coisa que impeça um sistema de atingir um desempenho maior com relação à sua meta (Goldratt, 1998; Csillag e Corbett, 1998). Essas restrições podem ser classificadas como restrições internas e restrições externas (de mercado) e para gerir a performance do sistema a restrição deve ser identificada e administrada corretamente (Goldratt e Cox, 2002).

Essas restrições são tratadas por meio do chamado "Processo de Pensamento" (Thinking Process), onde são respondidas as seguintes perguntas: 0 que mudar? Como provocar a mudança? Mudar para que? (Goldratt, 2004; Barcaui e Quelhas, 2004; Lacerda, Cassel e Rodrigues, 2010). 
A partir das respostas às perguntas anteriores chega-se a uma série de sintomas os quais apontam para o problema principal chamado de Core Conflict, que é inevitavelmente um conflito não resolvido (Goldratt, 2004). Ao identificar o conflito principal, sua restrição é também identificada e estratégias para a melhoria de desempenho traçadas, sendo, de acordo com a teoria, propostos cinco passos para aumentar o desempenho de um sistema. São eles: (1) Identificar a restrição; (2) Explorar a restrição; (3) Subordinar tudo e todos à restrição; (4) Elevar a restrição; (5) Não permita que a sua inércia seja a restrição do sistema, volte ao primeiro passo.

\subsection{MÉTODO DA CORRENTE CRÍTICA}

A aplicação da teoria das restrições no gerenciamento de projetos é denominada Método da Corrente Crítica (Goldratt, 1998; Barcaui e Quelhas, 2004; Nazareth, Mello e Chakour, 2015). 0 método da Corrente Crítica ou CCPM apresenta-se como uma alternativa ao caminho crítico, tendo como premissa a observação do projeto como um todo e não somente suas atividades individuais e propõe que as atividades sejam iniciadas no tempo mais tarde (late start), tenham sua duração com o tempo de maior probabilidade e que as seguranças de tempo não sejam inseridas nas atividades individualmente (Leach, 1999; Lechler, Ronen e Stohr, 2005; Silva, Rodrigues e Lacerda 2012).

De acordo com PMI (2019), o caminho crítico é aquele com menor folga em todo o caminho da rede, ou seja, o maior caminho de duração de atividades em um projeto, consequentemente, o caminho crítico define o tempo de duração de um projeto e, logo, pode ser considerado como sua maior restrição (Barcaui e Quelhas, 2004). Outras podem ser as restrições em um projeto, como quantidade de trabalho, conjunto de recursos, entre outros.

Uma das aplicações da CCPM é a programação de um projeto único, de maneira a reduzir a duração do projeto e simplificar o seu controle. Uma das premissas da CCPM é a de que uma adequada gestão do tempo permite a redução de custos e a otimização dos recursos (Lechler, Ronen e Stohr, 2005; LUIZ et al., 2015).

As incertezas inerentes aos projetos são a principal fonte de problemas em seu gerenciamento e se originam das dificuldades e obstáculos de difícil previsão no início que, desconhecidas e imensuráveis em tal momento, passam a ser um problema para seu planejamento, especificamente nas estimativas de duração de atividades. Para compensar as incertezas, as estimativas dos tempos das atividades são inflacionadas, adicionando segurança (Goldratt, 1998; Silva, Rodrigues e Lacerda, 2012).

Apesar dos prazos adicionais de segurança inseridos em cada atividade, durante sua execução muitas acabam atrasando, comprometendo as atividades seguintes e contribuindo para o fracasso do projeto (Leach, 1999). Algumas razões para atrasos na execução das tarefas do projeto estão relacionadas às questões comportamentais. Mesmo que existam margens para a proteção de tempo para as incertezas, o comportamento humano necessita ser levado em consideração nos aspectos que influenciam seus prazos, conforme Quadro 1.

Com base nos problemas apresentados, a CCPM propõe uma redução de 50\% na estimativa de tempo de cada tarefa, inserindo-se parte do tempo removido em buffers (pulmões) ao final de cada caminho da rede (Barcaui e Quelhas, 2004; Luiz et al., 2015), sendo que a duração do pulmão deverá ser a metade da duração da Corrente Crítica (Silva, Rodrigues e Lacerda, 2012).

Os pulmões são classificados em: a) Pulmão de Projeto (Project Buffer); b) Pulmão de Convergência (Feeding Buffer) e; c) Pulmão de Recurso (Resource Buffer). o Pulmão de Projeto é a proteção de tempo utilizada no final da rede; o Pulmão de Convergência é a proteção utilizada em caminhos não críticos, com vistas a proteger Corrente Crítica de atrasos que possam ocorrer em uma corrente não-crítica; e o Pulmão de Recurso que tem objetivo de garantir que o recurso necessário estará disponível no início de sua atividade (Silva, Rodrigues e Lacerda, 2012, Luiz et al., 2015). 
Quadro 1 - Influências do comportamento humano nos projetos.

1. Síndrome do Estudante: "É característico da natureza humana esperar que uma tarefa fique realmente urgente para realizá-la" (Barcaui e Quelhas, 2004, p.8). Esse mecanismo de defesa natural se refere ao adiamento até um último momento para a execução da tarefa, (Lechler, Ronen e Stohr, 2005), gerando aumento do stress e da pressão sobre o recurso (Smith, 2010). Ter mais tempo só deixa o prazo de início mais tardio (Assunção, 2018). 2. Lei de Parkinson: "0 trabalho se expande para preencher todo o tempo disponível" (Barcaui e Quelhas, 2004, p.8). Mesmo que uma tarefa seja ou possa ser completada antes do prazo, o recurso utiliza todo o tempo para realizá-la (Lechler, Ronen e Stohr, 2005).

3. Multitarefa nociva: Ocorre quando o recurso é requisitado a realizar várias tarefas ao mesmo tempo, seja no mesmo projeto ou em projetos diferentes, causando assim a perda de tempo na troca entre as atividades. A falta de prioridades ou o conhecimento claro dos prazos do projeto levam a ocorrência deste fato (Nazareth, Mello e Chakour, 2015).

Fonte: Elaborado pelos autores (2019).

Especificamente para gerenciamento de multiprojetos, a CCPM propõe o pulmão de programação (Scheduling Buffer), que se utiliza da mesma programação em ambientes de projeto único, controlando-se a entrada de novos projetos a fim de evitar o compartilhamento de recursos e que o atraso em um projeto afetem outros projetos (Luiz et al., 2015), e o pulmão de capacidade (Capacity Buffer), a fim de se "evitar possíveis atrasos causados por flutuações entre projetos" (Barcaui e Quelhas, 2004, p.18) "Pulmões aparecem como tarefas no plano de projeto, mas não há trabalho destinado a eles" (Luiz et al., 2015, p. 4).

No Quadro 2 são apresentados os 3 passos para criação de um diagrama de rede baseado em CCPM, conforme Barcaui e Quelhas (2004).

Quadro 2 - Passos para criação de um diagrama de rede.

1. Criar a rede: É criado um diagrama de rede de forma tradicional, onde são listadas as atividades e caminhos, duração de cada atividade e recursos associados. 0 primeiro passo é utilizar o tempo médio de duração para cada atividade. 0 próximo passo é reduzir pela metade todos os tempos das atividades e utilizar o late start (tempo de início mais tarde).

2. Identificar a Corrente Crítica: Após a criação da rede, a próxima etapa é a eliminação da contenção de recursos para facilitar a identificação da Corrente Crítica, considerando-se além do tempo as dependências entre atividades e recursos.

3. Proteger a Corrente Crítica: Após a identificação da Corrente Crítica, é inserido um pulmão de projeto ao final da Corrente Crítica, correspondente a $50 \%$ do tempo total retirado de cada tarefa. São também inseridos também os pulmões de convergência em cada caminho não crítico. Fonte: Barcaui e Quelhas (2004).

De acordo com Barcaui e Quelhas (2004), os pulmões são utilizados pela CCPM, em especial o Pulmão de Projeto, para se gerenciar e medir o progresso de um projeto e sua perspectiva de entrega no prazo. 0 gerenciamento é feito dividindo-se os buffers conforme a Figura 1, onde cada nível representa $1 / 3$ do tempo calculado ao buffer.

Figura 1 - Exemplo de Gerenciamento de Buffers.

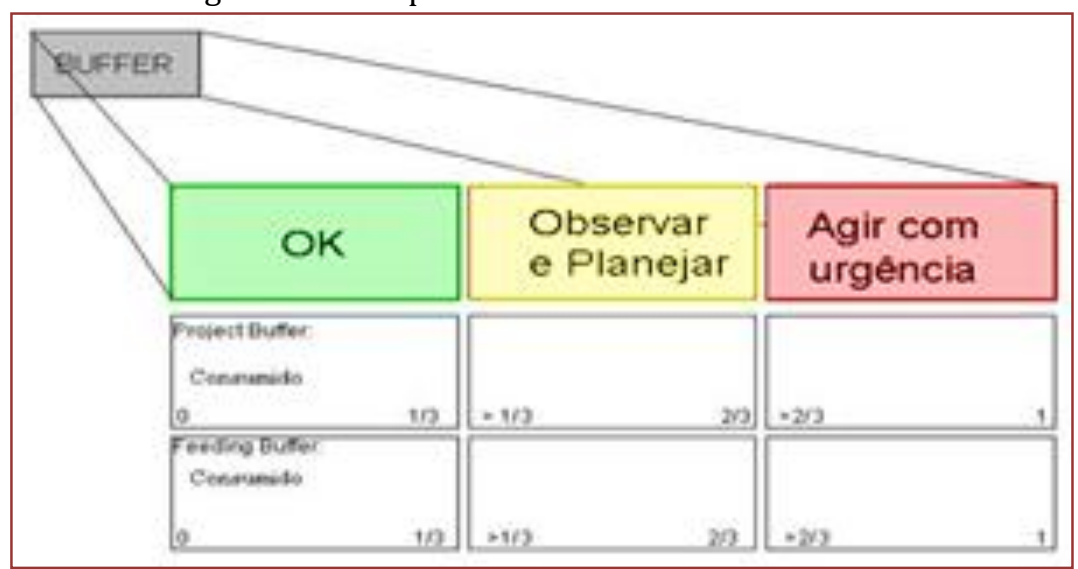

Fonte: Barcaui e Quelhas, (2004, p. 13). 
O tempo nos buffers será consumido e recuperado pelas atividades. Se uma atividade permanecer na parte verde, representa que está no prazo correto e nenhuma ação deve ser considerada pelo gerente de projetos. Se entrar na parte amarela é necessária atenção e um plano de recuperação deverá ser desenvolvido. Caso o buffer entre na parte vermelha o plano de recuperação desenvolvido anteriormente deve ser colocado em prática para que ele volte ao verde (Leach, 1999).

Este consumo de buffer é esperado que ocorra, uma vez que o desenvolvimento das atividades é orgânico, porém é importante que o gerenciamento do projeto seja direcionado para que o buffer se mantenha na parte verde.

\section{MÉTODO DE PESQUISA}

0 trabalho se caracteriza do ponto de vista de sua natureza, como uma pesquisa aplicada. Com relação à abordagem do problema, é utilizada a pesquisa qualitativa, onde o ambiente é a fonte direta da coleta de dados, tendo o pesquisador como instrumento chave e, pode apresentar dados, mas em geral não requer o uso de métodos e técnicas estatísticas, é descritiva e o processo e seu significado são os focos principais da abordagem (Silva e Menezes, 2005).

Do ponto de vista de objetivos, este trabalho caracteriza-se por uma pesquisa exploratória, uma vez que procura explicitar o problema relativo ao estudo de caso, envolvendo levantamento bibliográfico, análises e avaliações (GIL, 2008). Em termos de procedimentos técnicos, entre os apresentados por Gil (2008), e de acordo com a abordagem e os objetivos apresentados para a pesquisa, foi selecionado o Estudo de Caso. 0 que corrobora com Freitas e Jabbour (2011) e Marconi e Lakatos (2017), uma vez que procura explicitar o problema relativo ao estudo de caso, bem como analisar e avaliar uma abordagem de uso do método da Corrente Crítica no gerenciamento de tempo em projetos web.

Para a condução do trabalho foram estabelecidos determinados procedimentos, sendo eles: (1) levantamento e análise de referencial teórico e bibliográfico; (2) definição da abordagem de implementação da Corrente Crítica para o caso selecionado; (3) levantamento da situação atual do projeto selecionado para o estudo de caso; (4) aplicação do Método da Corrente Crítica no caso estudado; (5) conclusão e resultados.

Para o levantamento da situação atual do caso estudado foram utilizados dados de relatórios de horas utilizadas no projeto, obtidos por meio de software proprietário da empresa, compreendendo a data de inserção da atividade, a data de início da atividade pelo recurso, os intervalos e a data de entrega. Com base nesses dados foi traçada uma proposta de aplicação do Método da Corrente Crítica, iniciando-se pela divisão do job em atividades individuais, para que então fosse possível a criação da rede baseada em CCPM conforme apresentada anteriormente.

\section{ESTUDO DE CASO}

O estudo de caso ocorre em uma pequena empresa atuante na área de publicidade, localizada em São Paulo, capital. Neste trabalho a empresa é identificada pelo codinome PD. Entre os serviços prestados pela PD está o desenvolvimento de websites de pequeno a grande porte, com variados níveis de dificuldade, o que impacta diretamente no orçamento do projeto, bem como em sua duração e grau de incerteza.

Desde sua fundação até os dias de hoje a PD aumentou consideravelmente a quantidade de trabalho executado, o que levou a empresa em 2010 a criar um software proprietário para o gerenciamento do tempo das atividades desenvolvidas, chamado neste trabalho de SW, baseado em timesheet e kanban, onde cada usuário logado no sistema tem a possibilidade de visualizar suas tarefas do dia, sua descrição, data de entrega e demais especificidades do trabalho a ser realizado, bem como iniciar a contagem do tempo de uma atividade e finalizar a atividade iniciada, a fim de se obter o tempo total gasto com determinada atividade.

Neste contexto as atividades, chamadas internamente pela PD de job, são tratadas de forma isolada e não inseridas em um contexto de projeto, muitas vezes um job englobando um projeto como um todo. Há também a possibilidade de vários jobs serem inseridos com a mesma data de entrega, causando a multitarefa, bem como o sub-dimensionamento ou superdimensionamento do tempo para os jobs, causado por falha principalmente na coleta de requisitos e nas estimativas de tempo, riscos e incertezas do projeto. 
Para este estudo de caso foi selecionado o projeto de um website multi-idioma, que é dividido em dois websites distintos que compartilham algumas informações, o website do Brasil e o website dos Estados Unidos, solicitado por uma empresa multinacional do segmento de agronomia, onde o objetivo do projeto seria a mudança de plataforma dos websites. Para este projeto foi realizada uma reunião inicial para coleta de requisitos onde ficaram estabelecidos os ajustes a serem realizados, sendo posteriormente inseridos dois jobs no SW, um para o website do Brasil e outro para o website dos Estados Unidos. As datas previstas de entrega foram definidas durante a reunião, conforme o Quadro 3.

Quadro 3 - Datas de entrega das atividades.

\begin{tabular}{|c|l|c|}
\hline Atividade & \multicolumn{1}{|c|}{ Título } & Previsão de Entrega \\
\hline 1 & Site dos Estados Unidos & $05 / 04 / 2019$ \\
\hline 2 & Site do Brasil & $22 / 04 / 2019$ \\
\hline \multicolumn{2}{|c|}{ Fonte: Elaborado pelos autores (2019). }
\end{tabular}

Como é possível verificar, o projeto não foi divido em atividades, mas sim inseridos dois grandes jobs, um para cada website. As datas de entrega também não foram baseadas no restante do cronograma da produção, bem como não foram avaliadas suas dificuldades e incertezas, o que durante a execução do projeto mostrou-se seriamente prejudicial ao andamento do trabalho e ao relacionamento com o cliente, pois constantes atrasos e ajustes no prazo de entrega ocorreram, levando o projeto a atrasar em um mês, bem como prejudicando o andamento de outros projetos, pois à medida que o atraso aumentava era necessário que recursos que estavam alocados em outros projetos fossem inseridos neste para tentar recuperar o tempo, fazendo com que os projetos em que eles estavam fossem interrompidos. Outros pontos importantes a se destacar, e que contribuíram para que o projeto atrasasse, foram: (1) as pausas não programadas nas atividades para que os recursos executassem atividades paralelas e não relacionadas ao projeto, sendo que uma das pausas chegou ao montante de 6 dias; (2) o intervalo entre o final da atividade 1 e início da atividade 2, que teve a duração de 10 dias.

O Quadro 4a mostra o timesheet da atividade 1. 0 Quadro 4b mostra o timesheet da atividade 2, sendo a primeira linha de cada quadro o início da atividade e a última linha a entrega da atividade finalizada. Importante notar as linhas 2 e 3 do Quadro $2 b$ onde ocorre o maior intervalo entre as interações do recurso com a atividade, bem como notar que a atividade 2 foi iniciada na data em que foi prevista sua entrega.

Com base nas informações apresentadas, uma das possibilidades de melhoria no gerenciamento de projetos na PD é a adoção da Corrente Crítica para mitigar os problemas e facilitar o gerenciamento do tempo. "O fato de haver uma cultura de gerenciamento de projetos não garante a inexistência de deficiências" (Silva, Rodrigues e Lacerda, 2012, p. 12), porém algumas das deficiências relativas à gestão do tempo podem ser reduzidas caso o gerenciamento do tempo em projetos incorpore conceitos da Corrente Crítica.

(a)

\begin{tabular}{|c|c|}
\multicolumn{2}{|c|}{ Quadro 4 - Início, interaçõo } \\
\hline Interação & Data da Interação \\
\hline 1 & $01 / 04 / 2019$ \\
\hline 2 & $02 / 04 / 2019$ \\
\hline 3 & $03 / 04 / 2019$ \\
\hline 4 & $08 / 04 / 2019$ \\
\hline 5 & $09 / 04 / 2019$ \\
\hline 6 & $10 / 04 / 2019$ \\
\hline 7 & $11 / 04 / 2019$ \\
\hline 8 & $12 / 04 / 2019$ \\
\hline
\end{tabular}

Atividade 1 (a) e Atividade 2 (b).

(b)

\begin{tabular}{|c|c|}
\hline Internação & Data de Interação \\
\hline 1 & $22 / 04 / 2019$ \\
\hline 2 & $23 / 04 / 2019$ \\
\hline 3 & $24 / 04 / 2019$ \\
\hline 4 & $25 / 04 / 2019$ \\
\hline 5 & $26 / 04 / 2019$ \\
\hline 6 & $29 / 04 / 2019$ \\
\hline 7 & $30 / 04 / 2019$ \\
\hline 8 & $02 / 05 / 2019$ \\
\hline 9 & $03 / 05 / 2019$ \\
\hline 10 & $06 / 05 / 2019$ \\
\hline 11 & $07 / 05 / 2019$ \\
\hline 12 & $09 / 05 / 2019$ \\
\hline 13 & $13 / 05 / 2019$ \\
\hline 14 & $14 / 05 / 2019$ \\
\hline 15 & $20 / 05 / 2019$ \\
\hline 16 & $21 / 05 / 2019$ \\
\hline 17 & $22 / 05 / 2019$ \\
\hline
\end{tabular}

Fonte: Elaborado pelos autores (2019). 


\subsection{PROPOSTA DE IMPLEMENTAÇÃO DA CORRENTE CRÍTICA}

\subsubsection{CRIAR A REDE}

A proposta de implementação da Corrente Crítica no projeto website multi-idioma baseia-se na proposta de Barcaui e Quelhas (2004), Para a criação da rede foram utilizados os processos de Gerenciamento do Cronograma do Projeto constantes no Guia PMBOK, à exceção do controle do cronograma, o qual não foi utilizado nesta etapa. As atividades foram divididas em 7 fases: (1) Definição dos objetivos; (2) Escopo; (3) Mapa do site e wireframe; (4) Conteúdo e elementos visuais; (5) Desenvolvimento; (6) Testes e validação; (7) Lançamento (Adaptado de Meazey, 2017).

Os tempos de cada atividade foram definidos de acordo com a experiência dos recursos envolvidos no projeto e, para a criação do Gráfico de Gantt, 50\% do tempo de cada atividade foi removido e inserido o late start, conforme pode ser visualizado na Figura 2.

\subsubsection{IDENTIFICAR A CORRENTE CRÍTICA}

Após a criação da rede a contenção de recursos foi eliminada, removendo-se as concorrências entre as atividades que utilizam o mesmo recurso e evitando a multi-tarefa. Finalizado este processo a Corrente Crítica é identificada e pode ser verificada em destaque vermelho na Figura 3.

Figura 2 - Cronograma em Gráfico de Gantt.

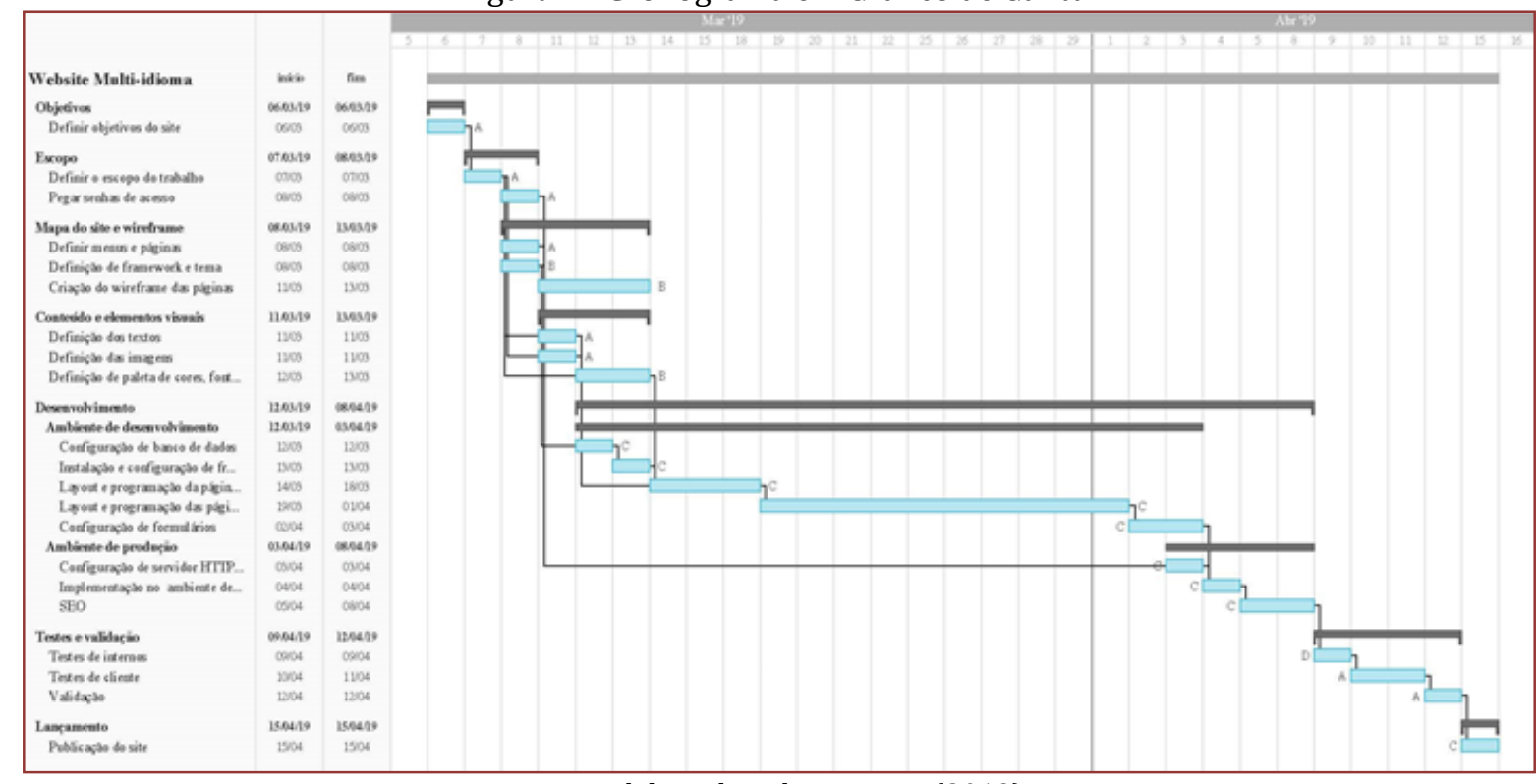

Fonte: Elaborado pelos autores (2019). 
Figura 3 - Eliminação de contenções e identificação da Corrente Crítica.

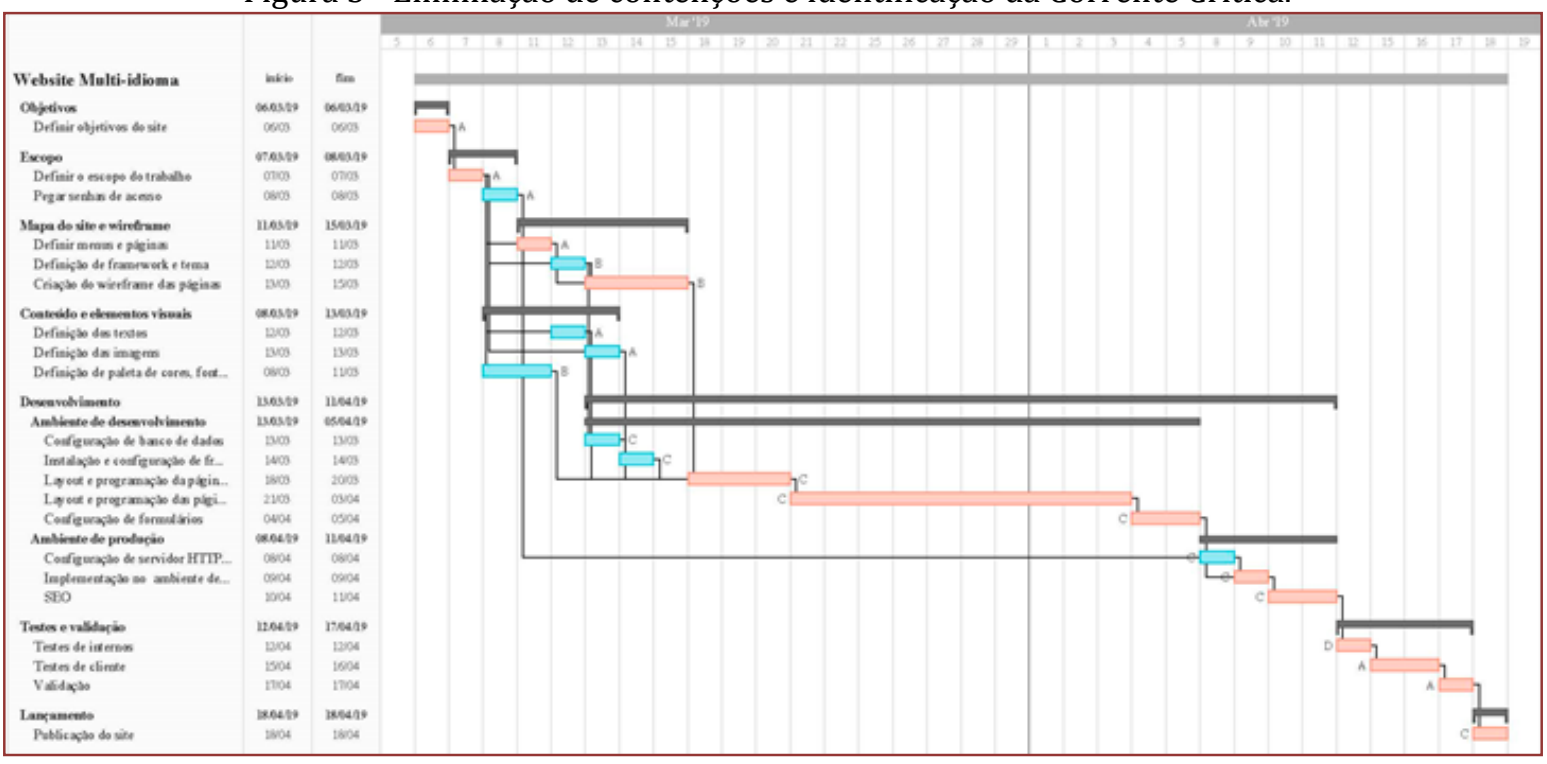

Fonte: Elaborado pelos autores (2019).

\subsubsection{PROTEGER A CORRENTE CRÍTICA}

A proteção da Corrente Crítica ocorre com a inserção do pulmão de projeto ao final da Corrente Crítica, calculado em $50 \%$ do tempo total retirado de cada tarefa, e dos pulmões de convergência em cada caminho convergente com a Corrente Crítica (Barcaui e Quelhas, 2004). 0 tempo total removido foi de 41 dias, sendo o pulmão de projeto inserido com o valor de 21 dias. Os devidos pulmões de convergência também foram inseridos, calculados também em 50\% do tempo retirado do caminho correspondente. A Figura 4 apresenta o diagrama de rede com a inserção dos pulmões, apresentados em destaque amarelo.

Figura 4 - Inserção dos pulmões de projeto e de convergência.

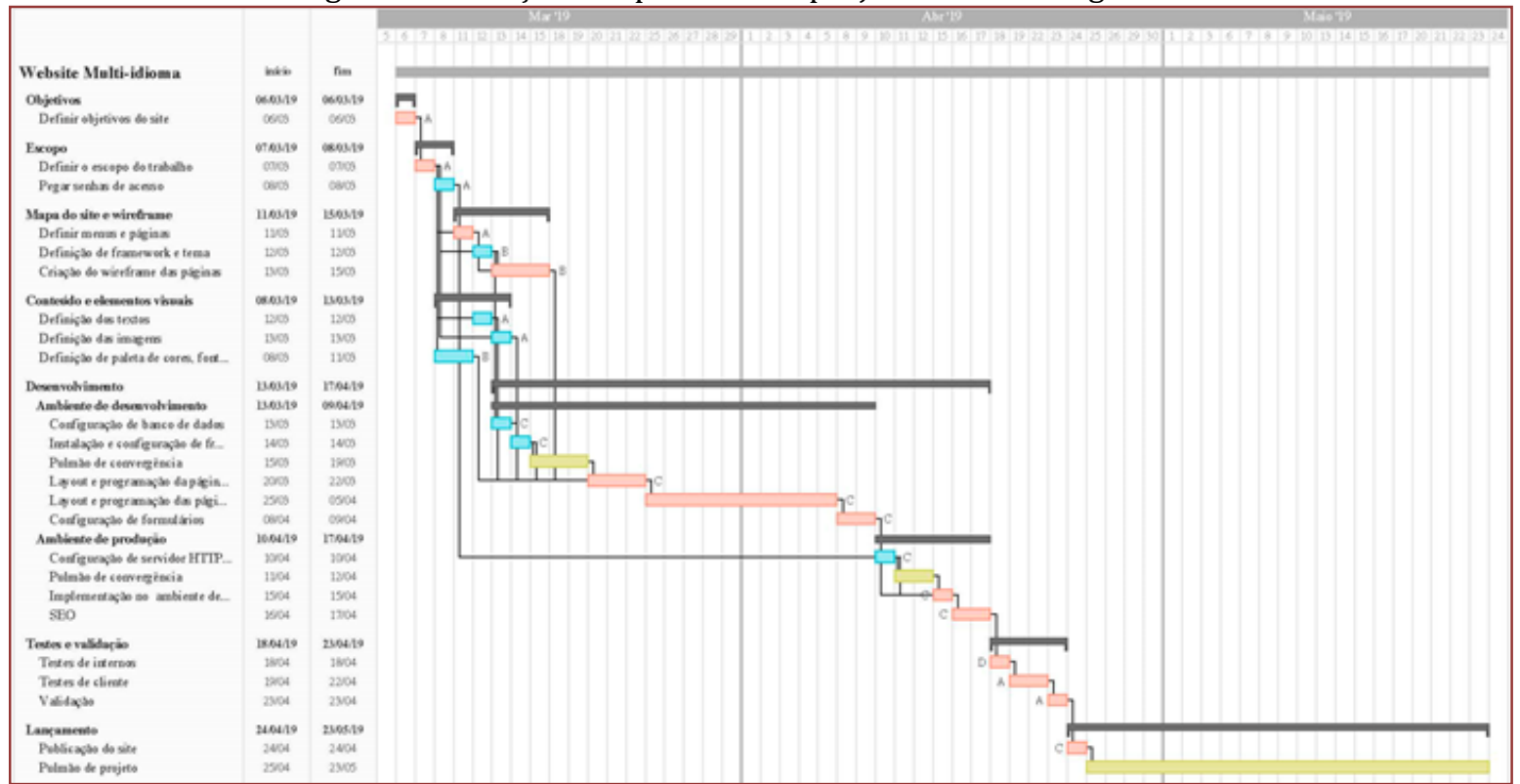

Fonte: Elaborado pelos autores (2019). 


\subsubsection{GERENCIAR OS BUFFERS}

Para o estudo de caso é proposto que o gerenciamento do projeto seja realizado através do gerenciamento dos pulmões para que a data de conclusão proposta para o projeto seja alcançada, mantendo-se sempre um nível adequado de segurança entre o final do caminho crítico e a data de finalização do projeto, bem como para que as medidas de recuperação de tempo possam ser desenvolvidas e aplicadas com antecedência.

\section{ANÁLISE E RESULTADOS}

Após a elaboração do diagrama de atividades, com seus respectivos tempos de duração, dependências e recursos, em cronograma no formato de gráfico de Gantt pode-se notar que os tempos de finalização do cenário atual e do cenário proposto são similares, sendo a data real de entrega do projeto em 22/05/2019 e a previsão proposta para entrega pelo estudo em 23/05/2019.

Apesar das datas praticamente coincidirem nota-se que três pontos divergem entre a abordagem utilizada pela empresa e a abordagem proposta, apresentados no Quadro 5.

Quadro 5 - Pontos divergentes entre as abordagens do projeto.

1. A formalização das atividades, utilizando-se o processo de Gerenciamento do Cronograma do Projeto, proposto pelo Guia PMBOK (PMI, 2019), e a divisão de atividades de web design proposta por Meazey (2017), formalizando o cenário em que o projeto será desenvolvido e tornando a visualização das atividades como um todo mais compreensível.

2. A duração do projeto atual contabilizou 38 dias e a proposta utilizando-se a Corrente Crítica para o projeto teria a duração de 31 dias, descontadas as seguranças providas pelos pulmões. Caso os pulmões fossem utilizados, o projeto no cenário proposto teria a duração de 57 dias, porém o projeto teria sido iniciado na data correta e os pulmões forneceriam um melhor gerenciamento do projeto para que os atrasos fossem mitigados.

3. Embora o cronograma desenvolvido utilizando-se a CCPM também apresente uma previsão de finalização do projeto superior à estabelecida com o cliente em reunião, é possível concluir que a data de entrega prometida não refletia a real situação do projeto, bem como foi estimada uma data sem a definição prévia da duração das atividades envolvidas.

$$
\text { Fonte: Elaborado pelos autores (2019). }
$$

De acordo com o exposto, é possível afirmar que no caso estudado a aplicação da CCPM impactaria de forma positiva na organização e gerenciamento do projeto, definindo as atividades e reduzindo seus tempos de duração e as probabilidades de atrasos pela incidência da Síndrome do Estudante e da Lei de Parkinson, bem como a eliminação da multi-tarefa, pelo correto gerenciamento dos recursos.

\section{CONCLUSÕES}

No trabalho foi analisado como a utilização da CCPM auxilia no gerenciamento do tempo em projetos de web, bem como a implantação do método proposto beneficia o gerenciamento do projeto objeto de estudo. Procurou-se demonstrar a aplicação a CCPM em um projeto de website multi-idioma da empresa PD e os benefícios advindos da correta utilização da teoria no gerenciamento do tempo do projeto, por meio do mapeamento das atividades e na elaboração do cronograma em Gráfico de Gantt, para que as atividades e suas durações pudessem ser melhor compreendidas.

A aplicação da CCPM mostrou-se eficaz quando aplicada ao caso estudado, uma vez que tornou possível a visualização das atividades do projeto, suas durações e recursos. Outro ponto positivo foi o desenvolvimento de um cronograma mais realista, uma vez que demonstrou que o projeto levaria mais tempo do que o previsto para ser realizado no cenário original. Por fim, recomenda-se a atualização do software utilizado pela PD no gerenciamento de tempo das atividades com a abordagem da CCPM. 


\section{REFERENNCIAS}

[1] Assunção, w. Proposta de método para determinação do pulmão de tempo em ambiente de múltiplos projetos com uso da corrente crítica. 2018. 257 f. Tese (doutorado em engenharia mecânica). Faculdade de engenharia mecânica. Universidade estadual de campinas, campinas - sp.

[2] Barcaui, a. B.; quelhas, o. A teoria das restrições aplicada à gerência de projetos: uma introdução a corrente crítica. Revista pesquisa e desenvolvimento engenharia de produção, itajubá, n. 2, p. 1-21, jul. 2004.

[3] Csillag, j. M.; corbett, t. Utilização da teoria das restrições no ambiente de manufatura em empresas no brasil. São paulo: núcleo de pesquisas e publicações - fgv, 1998. 93 p.

[4] Duarte, c. C. M.; biancolino, c. A.; storopoli, j. E.; riccio, e. L. Análise do conceito de sucesso aplicado ao gerenciamento de projetos de tecnologia da informação. Revista de administração da ufsm, santa maria, v. 5, n. 3, p. 459-478, 2012.

[5] Freitas, w. R. S.; jabbour, c. J. C. Utilizando estudo de caso(s) como estratégia de pesquisa qualitativa: boas práticas e sugestões. Estudo \& debate, lajeado, v. 18, n. 2, p. 07-22, 2011.

[6] Gil, a. C. Como elaborar projetos de pesquisa. 4 ed. São paulo: atlas, 2008.

[7] Goldratt, e. M. Corrente crítica. São paulo: nobel, 1998.

[8] Goldratt, e. M. Não é sorte: a aplicação dos processos de raciocínio da teoria das restrições. São paulo: nobel, 2004.

[9] Goldratt, e.m.; cox, j. A meta: um processo de melhoria contínua. 2. Ed. São paulo: nobel, 2002.

[10] Lacerda, d. P.; cassel, r. A.; rodrigues, l. H. Service process analysis using process engineering and the theory of constraints thinking process. Business process management journal, v. 16, n. 2, p. 264-281, 2010.

[11] Leach, l. P. Critical chain project management improves project performance. Project management journal, $\mathrm{v}$. 30, n. 2, p. 39-51, 1999.

[12] Lechler, t. G.; ronen, b.; stohr, e. A. Critical chain: a new project management paradigm or old wine in new bottles? Engineering management journal, v. 17, n. 4, p. 45-58, 2005.

[13] Luiz, o. R.; souza, f.; luiz, j. V. R.; jugend, d. Gestão de projetos por corrente crítica: uma análise bibliométrica. In: xxxv encontro nacional de engenharia de produção, 35, 2015, fortaleza. Anais... fortaleza: enegep, 2015. 15p.

[14] Marconi, m. A.; lakatos, e. M. Fundamentos de metodologia científica. 8.ed. São paulo: atlas, 2017.

[15] Maximiano, a. C. A. Administração de projetos: como transformar ideias em resultados. São paulo: atlas, 2014. 424 p.

[16] Meazey, m. The web design process in 7 simple steps. Webflow blog, delaware, mar. 2017. Design process. Disponível em: <https://webflow.com/blog/the-web-design-process-in-7-simple-steps>. Acesso em: 17 jun. 2019.

[17] Munns, a. K.; bjeirmi, b. F. The role of project management in achieving project success. International journal of project management, dundee, v. 14, n. 2, p. 81-87, 1996.

[18] Nazareth, m. M.; mello, l. C. B. B.; chakour, p. R. Estudo comparativo entre pert/cpm e corrente crítica. In: xxxv encontro nacional de engenharia de produção, 35., 2015, fortaleza. Anais... fortaleza: enegep, 2015. 17p.

[19] Project management institute (pmi). Guia pmbok®: um guia do conhecimento em gerenciamento de projetos. 6. Ed. Newton square: project management institute inc., 2019.

[20] Silva, e. M.; rodrigues, l. H.; lacerda, d. P. Aplicabilidade da corrente crítica da teoria das restrições no gerenciamento de projetos executivos de engenharia: um estudo de caso. Gestão e produção, são carlos, v. 19, n. 1, p. 1-16, 2012.

[21] Silva, e. L.; menezes, e. M. Metodologia da pesquisa e elaboração de dissertação. 4. Ed. Florianópolis: universidade federal de santa catarina, 2005.

[22] Smith, d. The effects of student syndrome, stress, and slack on information systems development projects. Issues in informing science and information technology, rondebosch, v. 7, p. 489-494, 2010. 


\section{Capítulo 6}

\section{Pesquisa operacional: Um estudo de caso para minimização de custos em uma barbearia}

\section{Devisson Mesquita dos Santos \\ Fernanda Leandra Leal Lopes \\ Pedro Matheus d'Oliveira \\ Syanne do Socorro Lobato Gonçalves \\ Yvelyne Bianca Iunes Santos}

Resumo: Este artigo teve como objetivo a utilização da Pesquisa Operacional para minimização de custos em uma barbearia localizada na cidade de Belém-Pa. Para isso, estabeleceu-se as variáveis, a função objetivo e as restrições em um modelo matemático solucionado por meio da ferramenta Solver do Software Microsoft Excel. A solução ótima aponta a redução de 2,92\% nos custos semanais, situação explicada pela experiência do gestor da empresa que opera perto da capacidade limite de produção dos recursos disponíveis. Desse modo, foram simulados cenários alternativos para o processo produtivo do empreendimento, a exemplo de aumento em $10 \%$ da demanda e contratação de um funcionário no período de maior fluxo de clientes. Verificou-se a necessidade de ampliar as horas produtivas disponíveis no intuito de atender o aumento da demanda e possuir folga de mão de obra para relocação por parte do gestor, com o objetivo de evitar gargalos em variações do fluxo de clientes durante a semana. Assim, recomenda-se investimentos em marketing, como promoções no intuito de apoiar a contratação de um funcionário.

Palavras-Chave: Minimização de custo; Tomada de decisão; Barbearia 


\section{INTRODUÇÃO}

Ainda que a crise econômica brasileira tenha afetado diversos segmentos nos últimos anos, um dos ramos que passou por processo de expansão foi o da barbearia, segundo dados da Euromonitor International, de 2014 até 2019 esse setor cresceu cerca de 7,1\%, no qual o lucro principal é proveniente do ramo da barba, cabelo e bigode. Atualmente, o setor emprega cerca cinco milhões de pessoas no país e possui alta demanda causada, principalmente, pelo consumo elevado de cosméticos pela população masculina, o que faz do Brasil o segundo maior mercado consumidor de produtos masculinos.

Entretanto, o setor que está em expansão apresenta alto nível de competividade, logo é essencial que os empreendimentos busquem diferenciais e estratégias que visem a diminuição de desperdícios, aumento da capacidade produtiva e redução de custos operacionais. Dessa forma, alguns problemas normalmente vivenciados por empresas podem ser evitados, como má administração do estoque, pelo excesso de materiais que são armazenados ou perda de validade; ausência de controle financeiro; e falta de inovação, pois com o aumento no número de empreendimentos, oferecer benefícios aos clientes é essencial para que esse tipo de ambiente se torne mais atrativo ao público.

Em vista disso, o estudo de caso foi realizado em uma barbearia situada em Belém-PA, que atua há três anos no mercado e conta com um total de nove funcionários. 0 objetivo geral do presente trabalho é reduzir os custos envolvendo, serviços, produtos e mão de obra por meio da utilização da Programação Linear (PL) como uma ferramenta de minimização de custos, a fim de auxiliar na tomada de decisão. 0 modelo matemático foi desenvolvido e solucionado na plataforma Microsoft Excel 2016, levando em consideração os dados da demanda do mês de abril de 2019 e da carga horária da mão de obra dos barbeiros.

O presente trabalho está subdividido em referencial teórico, metodologia, resultados e discussões e considerações finais. Os principais pontos abordados tiveram como base os dados fornecidos pela empresa em questão, a parte teórica e os cálculos baseados nas revisões feitas em livros e artigos relacionados à Pesquisa Operacional.

\section{REFERENCIAL TEÓRICO}

\subsection{PESQUISA OPERACIONAL}

De acordo com Arenales et al. (2015, p. 4), Pesquisa Operacional (PO) é definida como uma disciplina profissional que utiliza a aplicação da tecnologia da informação para a tomada de decisões apoiada em dados. Trata-se da construção de um modelo matemático que objetiva projetar, planejar e operar atividades produtivas que requerem alocações eficientes de recursos escassos.

Com o desenvolvimento da PO nas organizações, problemas relacionados à produção, como previsão de demandas e controle de estoques se tornaram importantes alvos de modelagem matemática. (MIGUEL et al., 2018). Assim, PO configura-se como uma importante ferramenta de eficiência e controle dos processos produtivos e, por conseguinte, de sobrevivência de empresas.

\subsection{PROGRAMAÇÃO LINEAR}

De acordo com Silva et al. (2017), a Programação Linear (PL) é um modelo utilizado para auxiliar em decisões estratégicas a fim de alcançar a maior eficiência dos recursos disponíveis dentro de um processo produtivo. Esse tipo de modelo consiste na construção de um modelo que sirva como instrumento de análise para o sistema real. Logo, os problemas envolvendo PL exibem equações que ajudam a descobrir um valor ótimo do objetivo em questão, por meio da melhor distribuição dos recursos envolvidos.

Determinado problema envolvendo PL apresenta uma parte que se quer maximizar ou minimizar, denominada de Função Objetivo, e onde estão as variáveis fundamentais; e outra parte, expressa na forma de equações matemáticas, denominada de restrições, formuladas a partir da configuração do problema.

\subsection{MODELAGEM E ESTRUTURA DE MODELOS MATEMÁTICOS}

Para Ragsdale (2010) modelo é um conjunto de relacionamentos matemáticos e suposições lógicas, implementado como representação de algum problema do mundo real. Portanto, sua resolução se dá a partir de alguns valores conhecidos ou previstos no modelo real (SODRÉ, 2007). 


\subsubsection{VARIÁVEIS DE DECISÃO}

Segundo Kogano et al (2011) variáveis de decisão são fatores envolvidos na função objetivo do problema que fornecem informações que servirão de base para a formulação do modelo. Essas informações são reproduzidas em forma de valores quantificáveis e são encontradas na resolução do modelo.

\subsubsection{FUNÇÃO OBJETIVO}

A função objetivo é a equação principal do modelo, que envolve todas as variáveis identificadas e representa a situação sob uma perspectiva geral (ANDRADE, 2014). Portanto, o objetivo em um problema de otimização é encontrar a solução ótima, maximizando ou minimizando uma função chamada de função objetivo (BARBOSA, 2016).

\subsubsection{RESTRIÇÕES}

De forma geral, as restrições são expressões ou equações que representam as limitações nos valores que podem ser atribuídos às variáveis de decisão (HILLIER e LIEBERMAN, 2013). Elas determinam o conjunto de soluções viáveis e devem ser apresentadas como uma relação linear de igualdade ou desigualdade utilizando-se as variáveis de decisão (JESUS, 2016).

\subsection{FERRAMENTA SOLVER}

0 uso de software para a resolução de problemas de programação linear é recorrente. O Solver é uma ferramenta que vem embutida no Microsoft Excel (software para criação e controle de planilhas). Tendo isso em vista, para a resolução do simplex foi utilizado esse software. O Solver permite fazer simulações em uma planilha e encontrar soluções para problemas mais complexos que necessitam de uma análise matemática de alto nível (MCFEDRIES, 2011).

\section{METODOLOGIA}

Para resolução do problema desenvolveu-se um modelo matemático linear através da metodologia abordada em Pesquisa Operacional e, por meio da ferramenta Solver do software Microsoft Excel, se encontrou a solução ótima.

\subsection{DADOS DA EMPRESA}

A empresa participante do estudo de caso integra o mercado há mais de três anos e encontra-se na cidade de Belém, no estado do Pará. Trata-se de uma microempresa do segmento de barbearia que oferece serviços de corte de cabelo, barba, barboterapia, sobrancelha, etc. 0 estabelecimento conta, atualmente, com nove colaboradores, dentre eles há quatro barbeiros, um funcionário responsável pelo marketing, dois atendentes e planejadores estratégicos e dois atendentes, sendo um deles um dos sócios da empresa. É importante se observar que os barbeiros não possuem salário fixo e recebem apenas comissões, cujo valor é incluído no preço do serviço. Seu horário de funcionamento é de segunda à sábado das 9:00 $\mathrm{h}$ às 21:00 h.

\subsubsection{DADOS DE CUSTOS}

Para realização do estudo, foram selecionados os serviços de corte de cabelo, barba, combo (cabelo e barba) barboterapia e sobrancelha. Os serviços de corte de cabelo e barba possuem quatro modalidades de preço, são elas: preço normal; preço com $20 \%$ de desconto para militares, aniversariantes, associados e parceiros; franquia (um serviço gratuito a cada sete cortes de cabelo e/ou barba para clientes com cartão fidelidade); pacote (dar direito a 4 ou 5 serviços por um preço menor). Coletou-se dados do custo médio dos serviços considerando os materiais utilizados na execução dos serviços. Também, optou-se por utilizar no modelo matemático dados das duas cervejas que possuem maior demanda na barbearia e o minoxdil, substância vendida para os clientes utilizarem em casa.

Abaixo apresenta-se as variáveis de custos da empresa com o intuito de minimiza-los. 
Tabela 1 - Custo por serviço e produto

\begin{tabular}{|c|c|c|c|c|c|}
\hline $\mathrm{Xi}$ & Serviço/Produto & $\begin{array}{c}\text { Preço } \\
\text { (R\$) }\end{array}$ & $\begin{array}{c}\text { Custo Comissão } \\
\text { (R\$) }\end{array}$ & $\begin{array}{l}\text { Custo Produto } \\
\text { (R\$) }\end{array}$ & $\begin{array}{c}\text { Custo Serviço } \\
\text { (R\$) }\end{array}$ \\
\hline $\mathrm{X} 1$ & Cabelo & 35,00 & 10,50 & 1,50 & 12,00 \\
\hline $\mathrm{X} 2$ & Cabelo com desconto & 28,00 & 10,50 & 1,50 & 12,00 \\
\hline X3 & Cabelo franquia & - & 10,50 & 1,50 & 12,00 \\
\hline $\mathrm{X} 4$ & Cabelo pacote & & 10,50 & 1,50 & 12,00 \\
\hline $\mathrm{X} 5$ & Barba & 35,00 & 10,50 & 1,50 & 12,00 \\
\hline $\mathrm{X} 6$ & Barba com desconto & 28,00 & 10,50 & 1,50 & 12,00 \\
\hline $\mathrm{X} 7$ & Barba franquia & - & 10,50 & 1,50 & 12,00 \\
\hline $\mathrm{X} 8$ & Barba pacote & - & 10,50 & 1,50 & 12,00 \\
\hline $\mathrm{X} 9$ & Combo & 60,00 & 18,00 & 1,50 & 19,50 \\
\hline $\mathrm{X} 10$ & Combo com desconto & 48,00 & 18,00 & 1,50 & 19,50 \\
\hline $\mathrm{X} 11$ & Combo franquia & - & 18,00 & 1,50 & 19,50 \\
\hline $\mathrm{X} 12$ & Combo pacote & - & 18,00 & 1,50 & 19,50 \\
\hline $\mathrm{X} 13$ & Cerveja 1 & 6,00 & - & 3,45 & - \\
\hline $\mathrm{X} 14$ & Sobrancelha & 10,00 & 5,00 & 1,30 & 6,30 \\
\hline $\mathrm{X} 15$ & Barboterapia & 20,00 & 6,00 & 1,30 & 7,30 \\
\hline $\mathrm{X} 16$ & Cerveja 2 & 7,00 & - & 3,55 & - \\
\hline $\mathrm{X} 17$ & Minoxidil 15\% & 170,00 & 34,00 & 85,00 & - \\
\hline
\end{tabular}

\subsubsection{DADOS DE DEMANDA}

Para construção do modelo também se coletou dados da demanda da barbearia dos serviços e produtos apresentados na tabela 1. Para determinação da demanda foi disponibilizada uma planilha eletrônica da empresa que possui detalhadamente a demanda real de todos os dias do mês de abril de 2019. Por conta da mudança no número de funcionários durante a semana, no estudo a semana foi dividida em dois períodos, sendo um de menor demanda (de segunda a quinta) e um de maior demanda (sexta a sábado). Para a determinação da demanda foram feitas médias para cada dia da semana, por exemplo, pegou-se todas as segundas do mês de abril e se tirou a média; o mesmo foi feito para os demais dias da semana. Após isso, somou-se a demanda média de segunda à quinta e de sexta à sábado. Os dados de demanda obtidos estão na tabela abaixo.

Tabela 2 - Demanda média do mês de abril

\begin{tabular}{|c|l|c|c|}
\hline \multicolumn{2}{|c|}{ Variáveis } & Demanda: Seg-Qui & Demanda: Sex-Sáb \\
\hline X1 & Cabelo & 50 & 39 \\
\hline X2 & Cabelo com desconto & 12 & 8 \\
\hline X3 & Cabelo franquia & 5 & 5 \\
\hline X4 & Cabelo pacote & 5 & 3 \\
\hline X5 & Barba & 9 & 8 \\
\hline X6 & Barba com desconto & 2 & 1 \\
\hline X7 & Barba franquia & 2 & 1 \\
\hline X8 & Barba pacote & 6 & 7 \\
\hline X9 & Combo & 14 & 9 \\
\hline X10 & Combo com desconto & 4 & 2 \\
\hline X11 & Combo franquia & 4 & 2 \\
\hline X12 & Combo pacote & 9 & 5 \\
\hline X13 & Cerveja 1 & 9 & 6 \\
\hline X14 & Sobrancelha & 7 & 4 \\
\hline X15 & Barboterapia & 1 & 2 \\
\hline X16 & Cerveja 2 & 1 & 5 \\
\hline X17 & Minoxidil 15\% & 1 & 0 \\
\hline
\end{tabular}

Fonte: Autores (2019) 


\subsection{FUNÇÃO OBJETIVO}

Devido a variação do número de funcionários e da demanda ao longo da semana, optou-se por trabalhar com dois modelos matemáticos. 0 primeiro modelo representa os dias de segunda à quinta $\mathrm{e}$, o segundo modelo representa os dias de sexta e sábado.

Para a formulação das funções objetivos foram utilizadas variáveis de decisão, que representam os custos médios de produtos e/ou serviços demandados durante os dias de segunda à quinta e de sexta e sábado ao longo do mês de abril.

$$
\operatorname{Min} \mathrm{Z}=\Sigma\left(\mathrm{Q}_{\mathrm{x}}{ }^{*} \mathrm{P}_{\mathrm{x}}\right)
$$

Onde Q representa a quantidade de produtos ou serviços e P o custo médio para um desses.

Tabela 3 - Preço médio dos serviços e produtos

\begin{tabular}{|c|l|c|}
\hline \multicolumn{2}{|c|}{ Variáveis } & Px (R \$) \\
\hline X1 & Cabelo & 12,00 \\
\hline X2 & Cabelo com desconto & 12,00 \\
\hline X3 & Cabelo franquia & 12,00 \\
\hline X4 & Cabelo pacote & 12,00 \\
\hline X5 & Barba & 12,00 \\
\hline X6 & Barba com desconto & 12,00 \\
\hline X7 & Barba franquia & 12,00 \\
\hline X8 & Barba pacote & 12,00 \\
\hline X9 & Combo & 19,50 \\
\hline X10 & Combo com desconto & 19,50 \\
\hline X11 & Combo franquia & 19,50 \\
\hline X12 & Combo pacote & 19,50 \\
\hline X13 & Cerveja 1 & 3,45 \\
\hline X14 & Sobrancelha & 6,30 \\
\hline X15 & Barboterapia & 7,30 \\
\hline X16 & Cerveja 2 & 3,55 \\
\hline X17 & Minoxidil 15\% & 85,00 \\
\hline & \multicolumn{2}{|c|}{ Fonte: Autores (2019) } \\
\hline
\end{tabular}

Como os custos são os mesmos para qualquer dia da semana, as funções objetivos são iguais para os dois modelos considerados. Portanto, para minimização de custos temos:

$$
\begin{aligned}
\text { Min } \mathrm{Z}_{1}=\operatorname{Min} \mathrm{Z}_{2}=12 \mathrm{X}_{1}+ & 12 \mathrm{X}_{2}+12 \mathrm{X}_{3}+12 \mathrm{X}_{4}+12 \mathrm{X}_{5}+12 \mathrm{X}_{6}+12 \mathrm{X}_{7}+12 \mathrm{X}_{8}+19,5 \mathrm{X}_{9}+19,5 \mathrm{X}_{10}+19,5 \mathrm{X}_{11} \\
& +19,5 \mathrm{X}_{12}+3,45 \mathrm{X}_{13}+6,3 \mathrm{X}_{14}+7,3 \mathrm{X}_{15}+3,55 \mathrm{X}_{16}+85 \mathrm{X}_{17}
\end{aligned}
$$

\subsection{RESTRIÇÕES}

Segundo as informaç̧ões recolhidas da barbearia, foram consideradas as seguintes restrições:

- Restrição em relação a oferta e demanda: equivalente para os dois modelos, a quantidade ofertada de produto ou serviço deve ser maior que a quantidade demandada, ou seja:

$$
O f_{x} \geq D_{x}
$$

- Restrição em relação as horas disponíveis: particular para cada modelo;

- Restrição de carga horária: particular para cada modelo;

- Restrição de não negatividade: equivalente para os dois modelos, como não é possível vender produtos ou serviços ofertados com valor negativo, então é necessário usar a restrição de não negatividade nos modelos: 


\subsubsection{RESTRIÇÕES DO MODELO 1}

Horas disponíveis: a barbearia tem disponível, nos dias de segunda a quinta, 3 barbeiros que totalizam uma carga horário de 122 horas de trabalho. Entretanto, os funcionários não exercem a função $100 \%$ do tempo disponível, visto que dependem de clientes e possuem intervalos, por isso foi considerado uma porcentagem de $70 \%$ da carga horário, portanto:

Chutiliz $=122 \times 0,7$

$\mathrm{Ch}_{\text {utiliz }} \leq 85,4$

- Carga horária: realizou-se uma média de quanto tempo se executa cada serviço. Dessa forma, temos que o cabelo ou a barba leva cerca de 30 minutos ( 0,5 hora), o combo (cabelo e barba) 60 minutos (1 hora), a sobrancelha 5 minutos $(0,083$ hora) e a barboterapia 12 minutos $(0,2$ hora). Portanto, temos que:

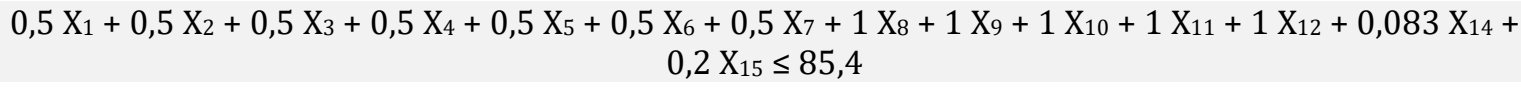

A quantidade de horas utilizadas de segunda à quinta-feira deve ser menor ou igual a quantidade de horas disponível dos três barbeiros que são 85,4 h.

\subsubsection{RESTRIÇÕES DO MODELO 2}

- Horas disponíveis: considerando o número de 4 barbeiros na sexta e sábado, um tempo disponível total de 80 horas para o trabalho e a porcentagem $70 \%$ da carga horária disponível, temos que:

$$
\begin{gathered}
\mathrm{Ch}_{\text {utiliz }}=80 \times 0,7 \\
\mathrm{Ch}_{\text {utiliz }} \leq 56
\end{gathered}
$$

- Carga horária:

$$
\begin{gathered}
0,5 X_{1}+0,5 X_{2}+0,5 X_{3}+0,5 X_{4}+0,5 X_{5}+0,5 X_{6}+0,5 X_{7}+1 X_{8}+1 X_{9}+1 X_{10}+1 X_{11}+1 X_{12}+0,083 X_{14}+0,2 \\
X_{15} \leq 56
\end{gathered}
$$

A quantidade de horas utilizadas de sexta e sábado deve ser menor ou igual a quantidade de horas disponível dos quatro barbeiros que são de 56 horas.

\section{RESULTADOS DA MODELAGEM E ANÁLISE DO PROBLEMA}

\subsection{SITUAÇÃO ATUAL DA EMPRESA}

Na tabela 4 está exposto o cenário atual da empresa, o qual é representado pelo cálculo de custos totais de

\begin{tabular}{|c|c|c|c|}
\hline Período & Seg-Qui & Sex-Sab & Total \\
\hline Número de Funcionários & 3 & 4 & \\
\hline Custos & $\mathrm{R} \$ 1.836,45$ & $\mathrm{R} \$ 1.343,55$ & $\mathrm{R} \$ 3.180,00$ \\
\hline Horas produtivas utilizadas & 85,4 & 56 & 141,4 \\
\hline
\end{tabular}
comissão de funcionários e utilização dos produtos nos períodos de segunda a quinta, assim como no período de final de semana (sexta e sábado).

Tabela 4 - Custos Reais Praticados pela Empresa

Fonte: Autores (2019)

De acordo com a tabela 4, pode-se afirmar que no cenário real, ou seja, atendendo toda a demanda média, a empresa utiliza um funcionário a mais nos finais de semana (sexta e sábado) no intuito de atender o volume maior de clientes, tendo nos demais dias da semana (segunda a quinta), um período de menor demanda. 


\subsection{SOLUÇÃO ÓTIMA}

Utilizando o Solver e o modelo exposto, foi encontrado o resultado ótimo de minimização de custos da empresa, conforme a tabela 5:

Tabela 5 - Solução Ótima

\begin{tabular}{|l|c|c|c|}
\multicolumn{1}{c}{ Período } & Seg-Qui & Sex-Sab & Total \\
\hline Número de Funcionários & 3 & 4 & \\
\hline Custos & $\mathrm{R} \$ 1.823,15$ & $\mathrm{R} \$ 1.263,85$ & $\mathrm{R} \$ 3.087,00$ \\
\hline Horas produtivas utilizadas & 77,3 & 54,7 & 132 \\
\hline \multicolumn{4}{r}{ Fonte: Autores (2019) }
\end{tabular}

Percebe-se que o resultado ótimo se aproxima muito do cenário atual vivenciado pela empresa, já que a utilização ótima de horas produtivas da mão de obra promovidas pelo modelo proposto se aproxima da quantidade utilizada atualmente pelo empreendimento. As folgas entre o cenário real e o resultado ótimo nos períodos de segunda a quinta e sexta e sábado foram, respectivamente de 8,1 horas e 1,3 horas.

Essa situação resulta na otimização de apenas R \$ 93,00 entre os custos simulados pelo Solver e os custos reais, ou seja, é obtida uma redução de $2,92 \%$. Importante ressaltar que esse quadro corrobora com a situação do processo produtivo da empresa, o qual encontra-se operando perto do limite de capacidade de produção dos funcionários.

Dessa forma, no intuito de fomentar a tomada de decisão pela empresa, foram simulados dois cenários de relevância para o processo produtivo da barbearia: aumento da demanda e contratação de um funcionário temporário.

\subsection{AUMENTO DA DEMANDA}

O presente cenário trata do aumento da demanda em $10 \%$ dos principais serviços. Foi simulado aumento da demanda nos serviços de $\mathrm{X}_{1}$ à $\mathrm{X}_{12}$.

A demanda de segunda à quinta é totalmente atendida, porém a folga de carga horária é pequena, sendo assim, se a demanda aumentar mais, não será possível atender todos os clientes.

O Solver não conseguiu encontrar uma solução para o aumento da demanda na sexta e no sábado, assim, não foi possível atender toda a demanda, pois não há carga horária suficiente para atender todos os clientes.

Sendo assim, verifica-se que a contratação de mais um barbeiro seria uma das possíveis soluções para este problema, já que não é permitida hora-extra. No entanto, deve-se levar em consideração que no local possuem quatro cadeiras para barbeiros, em vista disso a contratação de mais um barbeiro exigiria investimento para a alocação de mais um posto de trabalho para barbeiro na empresa. Então, a contratação é melhor justificada para aumento na demanda maior que $10 \%$.

\subsection{CONTRATAÇÃO DE UM FUNCIONÁRIO}

Com o objetivo de atender a demanda nos dias de alto volume de clientes, mais particularmente nos dias de sexta e sábado, cenário no qual a utilização de horas produtivas foi muito próxima do valor ótimo, foi simulado no Solver a contratação de um funcionário nesse período, com carga horária total de 20 horas semanais. Dentro desse cenário foi considerado, também, o aumento de $10 \%$ na demanda, uma vez que esse incremento no número de serviços/produtos não foi possível utilizando as horas produtivas disponíveis no cenário atual. Assim, foi criada a tabela 6 abaixo, a qual compara e expõe a diferença do lucro e da folga nas horas produtivas entre o cenário atual utilizando um funcionário extra, considerando um aumento de $10 \%$ da demanda. 
Tabela 6 - Diferença de lucro e Folga entre os cenários

\begin{tabular}{|c|c|}
\hline Diferença no Lucro & Folga Horas Produtivas \\
\hline $\mathrm{R} \$ 131,80$ & 15,87 \\
\hline \multicolumn{2}{|c|}{ Fonte: Autores (2019) }
\end{tabular}

Por meio da tabela 6, pode-se ressaltar que mesmo com a contratação de um funcionário, assim como todos os seus custos incluídos, ainda se verificou um quadro favorável, uma vez que o lucro aumentou em R\$ 131,80 comparado com o lucro no cenário atual. Além do mais, observa-se que o modelo simulado obteve 15,87 horas de folga, criando a possibilidade de o gestor gerenciar parte dessas horas disponíveis para o dia de semana, situação na qual possíveis gargalos em variações de demanda durante a semana seriam solucionados.

\section{CONSIDERAÇÕES FINAIS}

O objetivo do estudo foi minimizar os custos envolvendo, serviços, produtos e utilização de mão de obra por meio da utilização da Programação Linear e do Solver em uma barbearia na cidade de Belém-Pa. Com o uso de modelagem matemática e dividindo o modelo em períodos de menor demanda (segunda a quinta) e períodos de maior demanda (sexta e sábado), foi feita a minimização de custos semanais.

O cenário ótimo, em comparação com o cenário atual da empresa, teve como resultado uma redução de 2,92\% nos custos da empresa. Assim, percebe-se que a diminuição de custos ocorreu, porém a redução é pequena. Esse quadro é justificado pela experiência do gestor do estabelecimento que opera perto do limite da capacidade dos seus funcionários. Além disso, nota-se que as horas produtivas utilizadas no modelo ótimo apresentam pouca folga em relação do cenário atual, situação na qual torna-se relevante simular dois cenários alternativos para tomada de decisão na empresa: aumento de 10\% da demanda e contratação de um funcionário.

O cenário de aumento da demanda em mais de 10\% revela a utilização quase total das horas produtivas disponíveis, tendo no período de sexta e sábado a impossibilidade de atender os clientes. Já na situação alternativa de contratar um funcionário, considerando o contexto de aumento de $10 \%$ de demanda, revela-se um quadro de folga de mão de obra de quase 16 horas produtivas, tendo-se a possibilidade de relocar esse recurso para evitar gargalos com variações na demanda. No entanto, recomenda-se investimentos em marketing, a exemplo de promoções, para justificar a contratação de um funcionário em períodos de maior fluxos de clientes. Assim, percebe-se a importância de se apropriar de conhecimentos em PO para a tomada de decisão e contribuir para a melhor gestão do negócio.

\section{REFERÊNCIAS}

[1] Andrade, Eduardo Leopoldino de. Introdução à Pesquisa Operacional: Métodos e Modelos para a Análise de Decisão. 5 ed. Rio de Janeiro: LTC, 2014.

[2] Arenales, Marcos; Armentano, Vinícius; Morabito, Reinaldo; et al. Pesquisa Operacional para Cursos de Engenharia. 2. ed. São Paulo: Elsevier, 2015.

[3] Barbosa, Davi Prates Oliveira. Um modelo matemático de otimização da mistura de diferentes variedades de açúcar para atender ao padrão de qualidade de países importadores. 2016. 47 f. Tese - Curso de Modelagem Computacional, Instituto de Computação, Universidade Federal de Alagoas, Maceió, 2016.

[4] Cardoso, Andréa. Fundamentos da Pesquisa Operacional. 2011. Disponível em: <http://www.unifalmg.edu.br/matematica/files/file/po.pdf>. Acesso em: 12 maio, 2019.

[5] Ceciliano, Wellington Rodrigo Aparecido. Aplicação de um Método de Simulação-Otimização na Cadeia Produtiva de Minérios de Ferro. 228f. Dissertação (Mestrado em Engenharia de Sistemas Logísticos). Universidade de São Paulo, São Paulo, 2007.

[6] Euromonitor. Market research on consumer products, commercial industries, demographics trends and consumer lifestyles in Brazil. Includes comprehensive data and analysis, tables and charts, with five-year forecasts. 2019. Disponível em: <https://www.euromonitor.com/brazil>. Acesso em: 3 jun. 2019.

[7] Hillier, Frederick S.; Lieberman, Gerald J. Introdução À Pesquisa Operacional. 9. ed. São Paulo: Bookman, 2013. $1028 \mathrm{p}$. 
[8] Jesus, João B.; Favoni, Célio.; O Uso da Ferramenta Solver do Excel na Resolução de Problemas de Programação Linear. Jahu: FATEC, 2016. 5 p. Trabalho de Graduação.

[9] Kogano, K.S.H.; Lima, R.N.P.; Santos, Y.B.I; Moraes, M.S.O; Aplicação da Programação Linear para a Utilização Otimizada de Recursos Disponíveis em uma Empresa de Produção de Camarões. XXII Simpósio de Engenharia de Produção: Sustentabilidade na Cadeia de Suprimentos, São Paulo, 2011.

[10] Mcfedries, P. Fórmulas e funções com Microsoft Office Excel. Ed. Companion Website. 3ạ tiragem. 2011.

[11] Miguel, P. A. C. et al. Metodologia de pesquisa para engenharia de produção e gestão de operações. $3^{\mathfrak{a}}$ ed. Rio de Janeiro: Elsevier, 2018.

[12] Ragsdale, Cliff T.. Modelagem e Análise de Decisão. São Paulo: Cengage, 2010. 41 p.

[13] Silva, Ermes Medeiros da et al. Pesquisa Operacional: Programação Linear - Simulação. 5. ed. Rio de Janeiro: Atlas, 2017. 208 p.

[14] SODRÉ, Ulysses. Modelos Matemáticos. 2007. Disponível em:

<http://www.uel.br/projetos/matessencial/superior/pdfs/modelos.pdf>. Acesso em: 12 de Maio de 2019.> 


\section{Capítulo 7}

Aplicação do Software Arena para simulação $e$ modelagem de filas em um restaurante universitário

Vitor Abel Monteiro Alves

Leonardo Rosa Rohde

Ari Mateus Carvallio Neto

Renato Oliveira Serafim

Philip Soares do Amaral

Resumo: Este capítulo apresenta uma modelagem e simulação de filas de um restaurante universitário localizado no estado do Rio Grande do Sul. 0 estudo foi realizado a partir da aplicação do software Arena. Inicialmente foram coletados os dados, sendo estes, tempo entre chegadas e tempo de duração de cada atendimento. Posteriormente, os dados de entrada foram inseridos no programa Input Analyzer para mostrar as melhores distribuições probabilísticas de entrada. Ao ter-se concluído esta etapa foi realizada a modelagem computacional no software Arena, comparando a situação atual do sistema com cenários propostos pelos autores. Verificou-se que para atender melhor a demanda sem aumentar significativamente os custos, a melhor opção seria aumentar o número de buffets sem aumentar o número de caixas, já que estes não se caracterizaram como gargalos.

Palavras-chave: Arena; pesquisa operacional; teoria das filas; simulação; modelagem; gargalos; engenharia 


\section{INTRODUÇÃO}

Um dos principais problemas tratados em gerenciamento de negócios é a adequação do controle de filas a um atendimento eficiente da demanda com baixo custo. Para tentar solucionar este problema um dos pontos abordados em Pesquisa Operacional é o da Teoria das Filas (TF). Segundo Andrade (2015), a TF trata de problemas de congestionamento de sistemas, nos quais existem elementos que desejam ser atendidos em um posto de serviço e que devem aguardar pela disponibilidade do mesmo. A aplicação da TF pode auxiliar no estabelecimento de políticas de atendimento ao público, no cálculo de custos de uma operação, dimensionar equipes de manutenção, entre outras aplicações (ANDRADE, 2015).

Para melhor entender como é o funcionamento do processo ou operação que contém fila, as técnicas analíticas de TF evoluíram para modelos avançados de Simulação Computacional na segunda metade do século XX. Neste sentido, modelos de simulação computacional auxiliam na melhor compreensão dos impactos de decisões no desempenho e comportamento de um sistema estudado (CHWIF, 1999). Nesta linha de entendimento, Miyagi (2006) salienta que a Simulação Computacional pode ser uma ferramenta usada na fase de concepção de um sistema, antes que o projeto seja implementado.

A simulação pode ser dividida em duas categorias, as simulações contínuas ou de eventos discretos. Na contínua se considera o longo do tempo, em que ocorrem mudanças no estado do sistema, geralmente necessitando o uso de equações diferenciais para descrever a taxa de mudança das variáveis de estado, tornando-a relativamente complexa. Já a simulação por eventos discretos é usada quando há mudanças no estado dos sistemas em pontos aleatórios do tempo. A simulação de eventos discretos é usada com mais frequência para aplicações práticas (HILLIER; LIEBERMAN, 2013).

Segundo Lippel (2002) a realização de refeições fora de casa é uma tendência englobada dentro da terceirização dos serviços familiares. Estes serviços que anteriormente eram realizados por mulheres, que por sua vez, em função de seu novo posicionamento na sociedade contemporânea, buscam independência financeira e a realização profissional através do trabalho remunerado, assim como pela grande necessidade de respaldo financeiro familiar vivenciado nos dias atuais, deixando desta maneira de exercer estas atividades domésticas classificadas como não lucrativas.

O presente estudo tem como objetivo analisar o comportamento das filas presentes em um Restaurante Universitário localizado no estado do Rio Grande do Sul, bem como propor melhorias que otimizem o sistema, diminuindo o tempo de fila e melhorando a capacidade de atendimento. A realização do estudo se faz necessária devido ao alto número de estudantes que frequentam o restaurante e a incapacidade de o sistema comportar a demanda de maneira eficaz, principalmente em horários de pico.

\section{REFERENCIAL TEÓRICO}

\subsection{TEORIA DAS FILAS}

A Teoria das Filas é o estudo da espera usando o modelo de filas para representar diversos tipos de sistemas. Teoria das Filas é um tema estudado na área da Pesquisa Operacional que utiliza fundamentos básicos de processos estocásticos aliados à conceitos de matemática aplicada para analisar aspectos acerca da formação de filas e suas características. (BRUNS et al, 2001). Para Taha (2008) o estudo de filas trata da quantificação do fenômeno da espera em filas, utilizando medidas de desempenho como comprimento médio de uma fila, o tempo médio de espera em fila e a média de utilização da instalação, uma vez que os clientes ao chegarem em uma instalação de serviço podem iniciar o serviço imediatamente ou serão sujeitos a uma fila de espera. Chwif e Medina (2015) acrescentam que a Teoria das Filas não é um método de otimização, mas uma ferramenta de elaboração e de solução de modelos matemáticos que representam de maneira analítica o processo de formação de filas.

\subsection{SIMULAÇÕES COMPUTACIONAIS}

Na segunda metade do século XX, com o advento do aumento das capacidades de processamento dos computadores, surgiram os primeiros modelos computacionais para tratamento de filas. Tais modelos computacionais mostraram-se mais flexíveis que os modelos analíticos apresentados pela Teoria da Filas (PRAD0, 2014). Na década de 50 e 60 surgiram as primeiras linguagens computacionais para desenvolvimento de simuladores. Nas décadas de 70 e 80 popularizam-se os softwares visuais para construção de simuladores computacionais, muitos deles utilizando as linguagens e bibliotecas dinâmicas desenvolvidas nas décadas anteriores. Uma simulação computacional é a imitação de uma operação ou de 
um processo do mundo real. A construção de um modelo de simulação é baseada em um conjunto de considerações relacionadas ao sistema. Com o modelo construído, é possível investigar várias questões referentes ao processo real, bem como prever consequências de possíveis alterações e melhorias (BANKS et al, 2005).

Freitas Filho (2008) afirma que a simulação, principalmente a computacional, tem sido cada vez mais empregada como técnica que permite aos analistas verificarem ou encaminharem soluções, com a profundidade desejada, aos problemas com os quais lidam diariamente.

\subsection{SIMULAÇÃO DE EVENTOS DISCRETOS}

A simulação de eventos discretos consiste na modelagem de um sistema em que em pontos aleatórios de tempo ocorre uma mudança no estado do sistema (LAW E KELTON, 2000). Em um sistema de filas os eventos discretos são a chegada e saída de um cliente devido à finalização do serviço, já o estado do sistema seria o número de clientes existentes em sua totalidade (HILLIER; LIEBERMAN, 2013).

De acordo com Brailsford e Hilton (2000) as simulações de eventos discretos permitem ser analisadas como uma rede de fila ou atividade, na qual os objetos do sistema são distintos individualmente e a duração das atividades é apresentada por meio de distribuições de probabilidades por cada indivíduo, sendo os modelos simulados em espaços de tempos desiguais, quando há um acontecimento no sistema.

Como a passagem do tempo possuí um papel fundamental sobre a simulação de eventos discretos, são utilizados modelos dinâmicos (BANKS, 1998). Outro ponto sobre este tipo de simulação é que ela possui uma relação de dependência com uma base de dados abrangente e detalhada, para que o processo de simulação ocorra (MAYO, 2003).

\subsection{SOFTWARE ARENA}

Um dos softwares mais utilizados no desenvolvimento de simuladores computacionais é o Arena. Com um ambiente gráfico integrado, o software possui recursos para a análise estatística, modelagem de processos, animação e análise de resultados (PARAGON, 2019). De acordo com Silva (2007), o Arena é um programa utilizado para modelar os mais variados ambientes, simulando um conjunto de processos utilizados na manufatura, serviços, entre outros. Assim como os demais softwares de simulação computacional, o Arena é utilizado para visualização do sistema a ser modelado como constituído de um conjunto de estações de trabalho que prestam serviços aos clientes, sendo utilizado para simular os mais diversos ambientes, desde linhas de produção até o fluxo de clientes em filas de lojas ou bancos.

\section{METODOLOGIA}

Foi realizado um levantamento bibliográfico sobre as metodologias disponíveis na área de simulações computacionais, com o intuito de otimizar o desenvolvimento deste estudo e sua compreensão. Desta forma, o presente estudo foi desenvolvido de acordo com as etapas propostas por Chwif e Medina (2015) para desenvolvimento de um modelo de simulação computacional, sendo elas apresentadas graficamente na imagem a seguir (Figura 1). 
Figura 1 - Etapas de simulação de eventos discretos

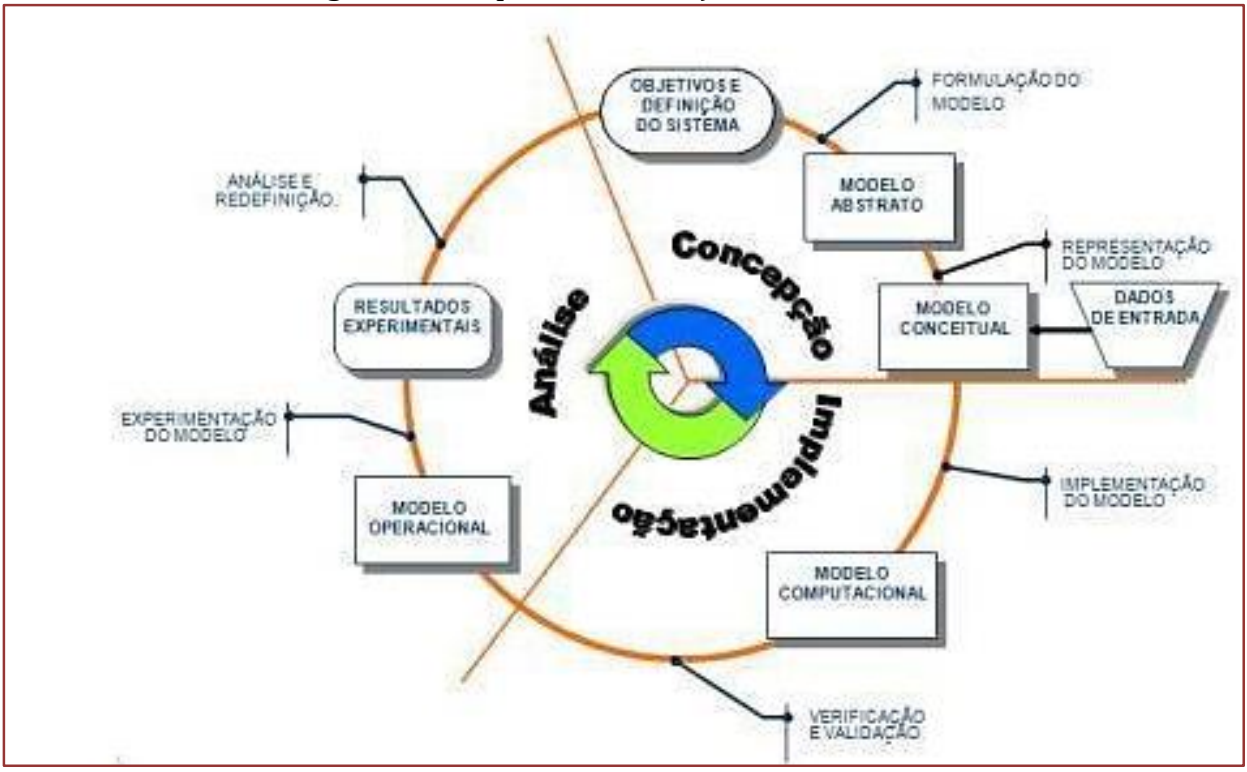

Fonte: (CHWIF, 1999)

\subsection{CONCEPÇÃO OU FORMULAÇÃO DO MODELO}

Nesta primeira etapa deve-se entender com clareza o sistema a ser simulado, bem como seus objetivos. Define-se o escopo do modelo, as hipóteses e o nível de detalhamento. São coletados os dados de entrada e se deve tornar o modelo conceitual. Uma das etapas mais importantes na estruturação de um estudo de simulação é a etapa de modelagem de dados de entrada.

Os modelos de entrada são os modelos probabilísticos que representarão a natureza aleatória de um dado fenômeno, já a modelagem de dados é o processo em que será escolhida a melhor representação deste fenômeno que está sendo analisado. Segundo Yamnitsky (1997) existem certas condições que quando respeitadas facilitam a modelagem de dados, sendo elas:

a) $\quad 0$ desenvolvimento da entrada de dados pode ser constituído por uma série de variáveis aleatórias independente e identicamente distribuída;

b) A distribuição das variáveis aleatórias pode ser aproximada por algum modelo probabilístico conhecido como: Normal, Beta, Erlang, Exponencial, Gama, Lognormal, Poisson, Triangular, Uniforme e Weibull, por intermédio de seus testes de aderência;

c) Os dados estão acessíveis de forma que se consiga estimar seus parâmetros.

0 estudo de modelagem pode ainda ser resumido em três partes, sendo elas: coleta de dados (também encontrada na literatura como amostragem), tratamento de dados, fase em que são extraídas medidas de posição e de dispersão da variável aleatória que está sendo estudada e inferência. Realizadas estas etapas é necessário lembrar que o modelo conceitual gerado tem como objetivo a facilitação e o entendimento de todos os integrantes do projeto.

\subsection{IMPLEMENTAÇÃO DO MODELO}

Nesta fase o modelo conceitual, que anteriormente foi realizado, é agora transformado em um modelo computadorizado, por meio de alguma linguagem de simulação ou um software de simulação. Devido aos avanços tecnológicos dos simuladores computacionais atuais alguns autores já sugerem/estimam que o tempo que a atividade de implementação deve consumir de todo o processo da metodologia da simulação deve estar na casa de $20 \%$ a $30 \%$.

Deve-se comparar o modelo computacional que foi implementado com o modelo conceitual. 0 objetivo desta comparação é avaliar se o seu desempenho atende aos requisitos estabelecidos na fase de 
concepção. Para que ocorra a validação da simulação computadorizada, alguns resultados devem ser obtidos e verificados se os mesmos apresentam uma representação precisa do modelo real.

Loureiro (2009) afirma que a eficiência do modelo está conectada com o processo de escolha de quais partes do sistema estudado de ser levadas em consideração, visto que o intuito da simulação é prover uma solução ao problema estudado. Considerar detalhes irrelevantes ao modelo acarretará em níveis altos de custos de modelagem e tempos de resposta mais longos sem que, se possua um ganho real da precisão do modelo.

\subsection{ANÁLISE DOS RESULTADOS DO MODELO}

De acordo com Oliveira (2010) nesta última etapa de um processo de simulação, na fase de análise, o modelo computacional que agora está validado, chamado agora de modelo operacional, está apto para receber diversos experimentos. Nesta fase o modelo é testado diversas vezes com o intuito de analisar e documentar seus resultados. Com esses resultados, é possível concluir e recomendar possíveis melhoras no sistema.

É importante salientar que, não se deve interpretar os processos de concepção, implementação e análise como processos lineares, uma vez que várias interações entre as etapas e realimentações do processo podem ocorrer.

Kleijnen et al. (2005) relatam que diversos estudos de simulação podem alcançar mais de suas análises por utilizar a teoria estatística de planejamento de experimentos construída com o intuito específico de explorar modelos computacionais

Neste sentido, para concepção do sistema, os autores do presente trabalho analisaram o período do almoço de um restaurante universitário. Após mapeamento dos processos e compreensão do sistema iniciou- se a fase de coleta de dados, especificamente os tempos de chegadas e de atendimentos. Os pesquisadores coletaram os tempos de chegada e atendimentos no horário almoço, onde a geração de fila atinge seu ápice. Foram coletados os dados de entrada no sistema (tempo entre chegadas - TEC), tempo de serviço de buffet e tempo de atendimento do caixa. Após a coleta, cada grupo de dados (chegada e atendimentos) recebeu o tratamento estatístico também recomendado por Chwif e Medina (2015). Para uma melhor compreensão das atividades executadas pelos autores é apresentada a imagem abaixo (Figura 2).

Figura 2 - Etapas realizadas para o estudo

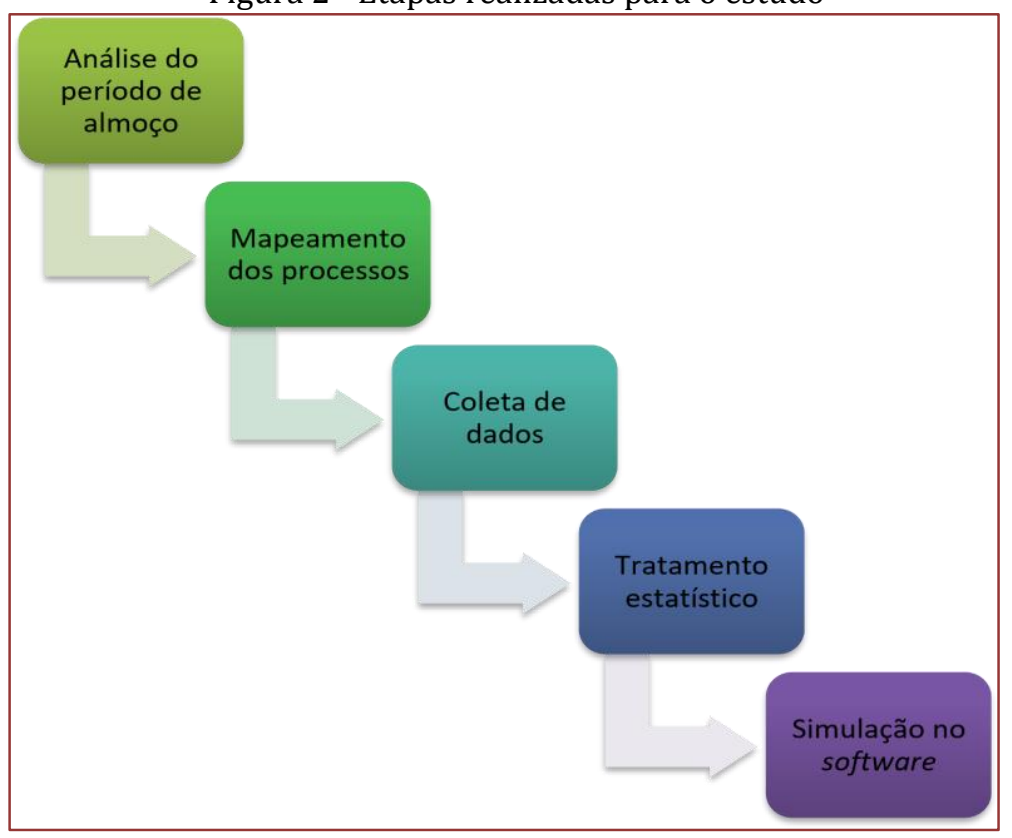

Fonte: Autores (2019) 
Inicialmente foram retirados da amostra os outliers superiores e inferiores pelo critério da amplitude interquartílica (IQR - Interquartile Range).

$$
\begin{aligned}
& \text { Limite Inferior }=\mu-(1,5) * I Q R \\
& \text { Limite Supeior }=\mu+(1,5) * I Q R
\end{aligned}
$$

Uma vez subtraídos os outliers das amostras, procedeu-se com a construção dos histogramas e teste de hipótese Chi-quadrado para verificação de aderência às distribuições. A quantidade e tamanho das classes nos histogramas foram definidas pelo critério de $\operatorname{Struges}\left(k=1+3,3 \log _{10} N\right)$. Com o objetivo de reduzir o erro quadrado foram verificados histogramas com mais/menos uma e duas classes além do valor recomendado pelo critério de Struges, de modo a melhorar aderência dos dados coletados à distribuição teórica. Após, testou-se a hipótese chi-quadrado para verificar a aderência dos dados coletados à distribuição teórica. Todos os dados coletados foram tratados e analisados com auxílio do software Input Analyzer. Finda a etapa inicial de concepção do sistema e análise dos dados, procedeu-se com a construção do simulador computacional. Os autores optaram pelo uso do software Arena considerando as vantagens e atributos já mencionados no referencial teórico deste documento.

\section{CONCEPÇÃO OU FORMULAÇÃO DO MODELO}

O Restaurante Universitário (RU) estudado é caracterizado por uma entrada de fila única com disciplina fifo. Nesta fila principal de entrada é feita a conferência e identificação dos estudantes onde são exigidos documento com foto e número de matrícula. Após ingressar no estabelecimento os estudantes enfrentam uma nova fila de caixa, onde devem apresentar o ticket refeição ou comprovante de isenção de pagamento. Por fim, os estudantes ingressam no serviço de buffet. No estabelecimento há dois serviços de buffet com pratos distribuídos linearmente. A figura 3, ilustra o fluxograma do RU.

Figura 3 - Fluxograma do Restaurante Universitário

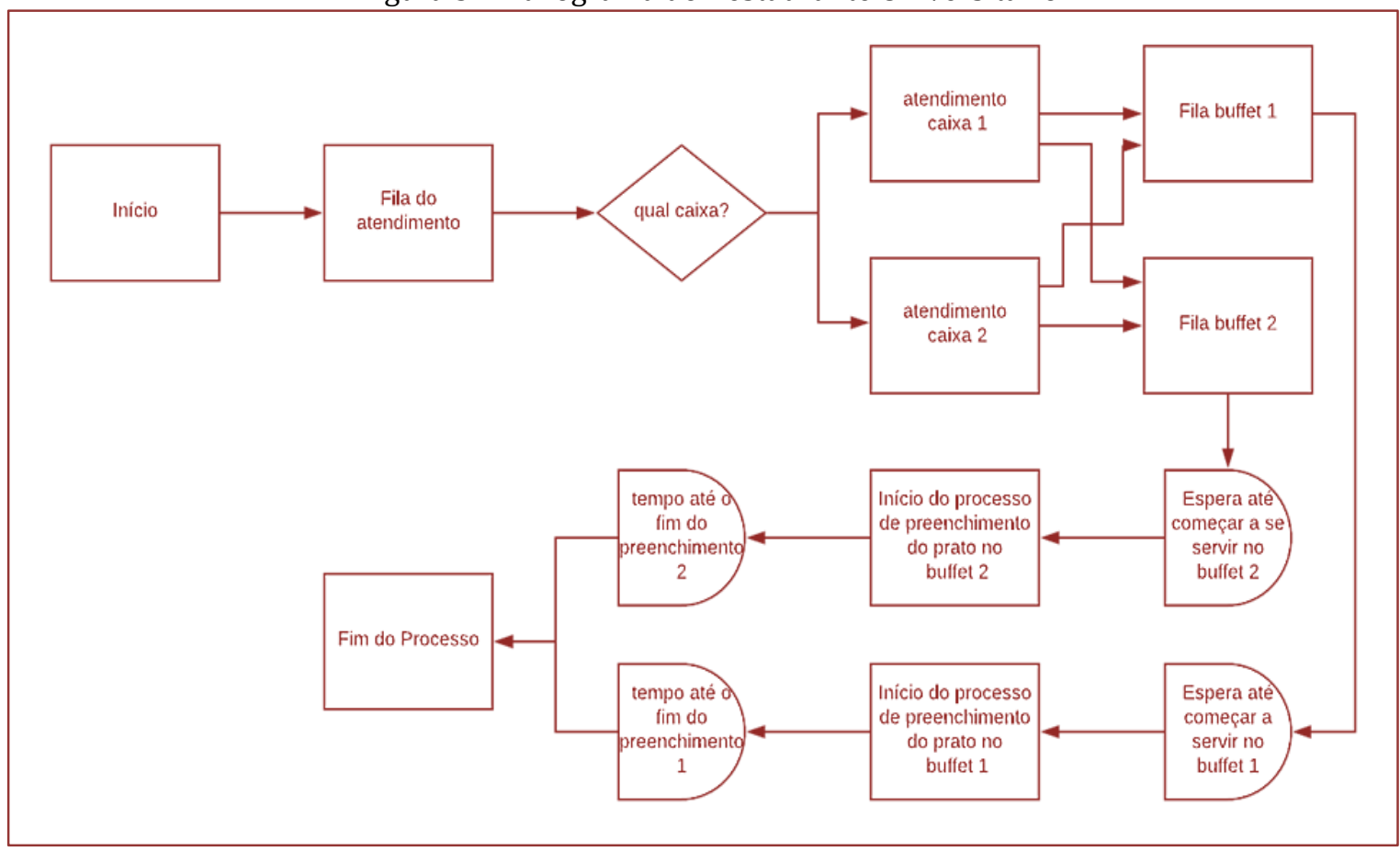

Fonte: Autores (2019)

\section{ANÁLISE DOS DADOS COLETADOS}

De acordo com o modelo, quatro processos necessitaram de coleta de dados: tempo de chegadas no RU, atendimento no caixa e dois serviços de buffet. A imagem abaixo (Figura 4) resume as análises realizadas conforme descrito na seção de metodologia. 
Figura 4 - Dados Coletados

\begin{tabular}{|c|c|c|c|c|}
\hline Processo & Chegada RU & Atendimento caixa & Buffet 1 & Buffet 2 \\
\hline Amostra inicial & 100 & 51 & 31 & 31 \\
\hline Outliers & 5 & 6 & 2 & 2 \\
\hline Amostra final & 95 & 45 & 29 & 29 \\
\hline Distribuição & $\begin{array}{l}\text { Exponencial com módia } \\
4,42\end{array}$ & $\begin{array}{l}\text { Normal com média } 11 \\
\text { e desvio padrão } 3,6\end{array}$ & $\begin{array}{l}\text { Normal com média } 168 \\
\text { e desvio padrão } 17,8\end{array}$ & $\begin{array}{l}\text { Normal com média } 184 \\
\text { e desvio padrão } 5,85\end{array}$ \\
\hline Erro quadrado & 0,0011 & 0,0052 & 0,017 & 0,039 \\
\hline Classes & 9 & 6 & 5 & 0,005 \\
\hline Histograma & & & & \\
\hline
\end{tabular}

Fonte: Autores (2019)

\section{RESULTADOS DAS SIMULAÇÕES COMPUTACIONAIS}

Após construção do modelo computacional no software Arena simulou-se um período de uma hora que corresponde ao período de pico de funcionamento do estabelecimento. Neste período observou-se um acréscimo constante nas filas do caixa e buffet correspondente a realidade do RU estudado. Os dois caixas e serviços de buffet não são suficientes para redução ou absorção das filas de modo que todos os recursos apresentam taxa de ocupação total. As filas só se reduzem com a queda da taxa de chegada de estudantes ao local. Em apenas 10 minutos de funcionamento as filas para o buffet atingiram o comprimento de 31 entidades enquanto no caixa o valor era de 10 entidades. Em média os estudantes precisam aguardar 6,1 minutos na fila do buffet antes de começarem a se servir. Tais resultados apontam a incapacidade do RU de atender a demanda universitária, razão pela qual muitos estudantes evitam o RU em horários de pico. Se todos os estudantes procurassem o RU no horário habitual de almoço a situação seria ainda mais adversa, mas tal cenário não fez parte do escopo deste estudo. A imagem a seguir (Figura 5) apresenta a situação atual dos processos do RU.

Figura 5 - Processos do cenário encontrado

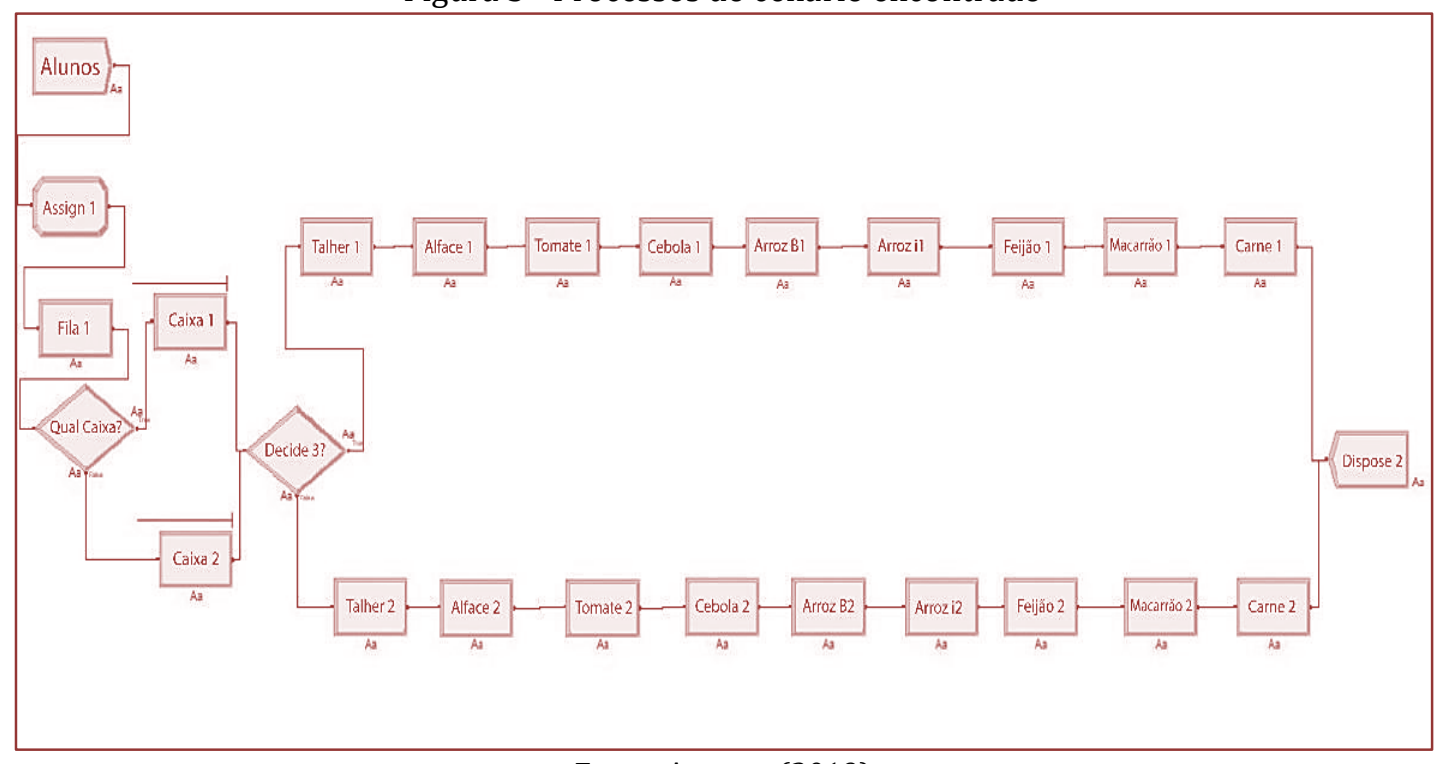


Com a intenção de melhorar os serviços prestados foram sugeridos cenários alternativos com uso de mais caixas e buffets de modo a reduzir as filas atuais. Observa-se que o aumento no número de buffets para seis serviços simultâneos seria suficiente para atender a demanda dos estudantes no horário de pico. Com seis serviços de buffet os estudantes aguardariam entre 2.6 e 3.1 minutos nesta etapa com filas médias de 5.1 entidades por serviço. Verificou-se também que não há necessidade de aumentar o número de caixas, pois o gargalo do sistema ocorre de fato nos serviços de buffet. As constantes filas no sistema tornam os recursos totalmente ocupados mesmo neste novo cenário com seis serviços de buffet. A visualização do cenário proposto é apresentada pela Figura 6.

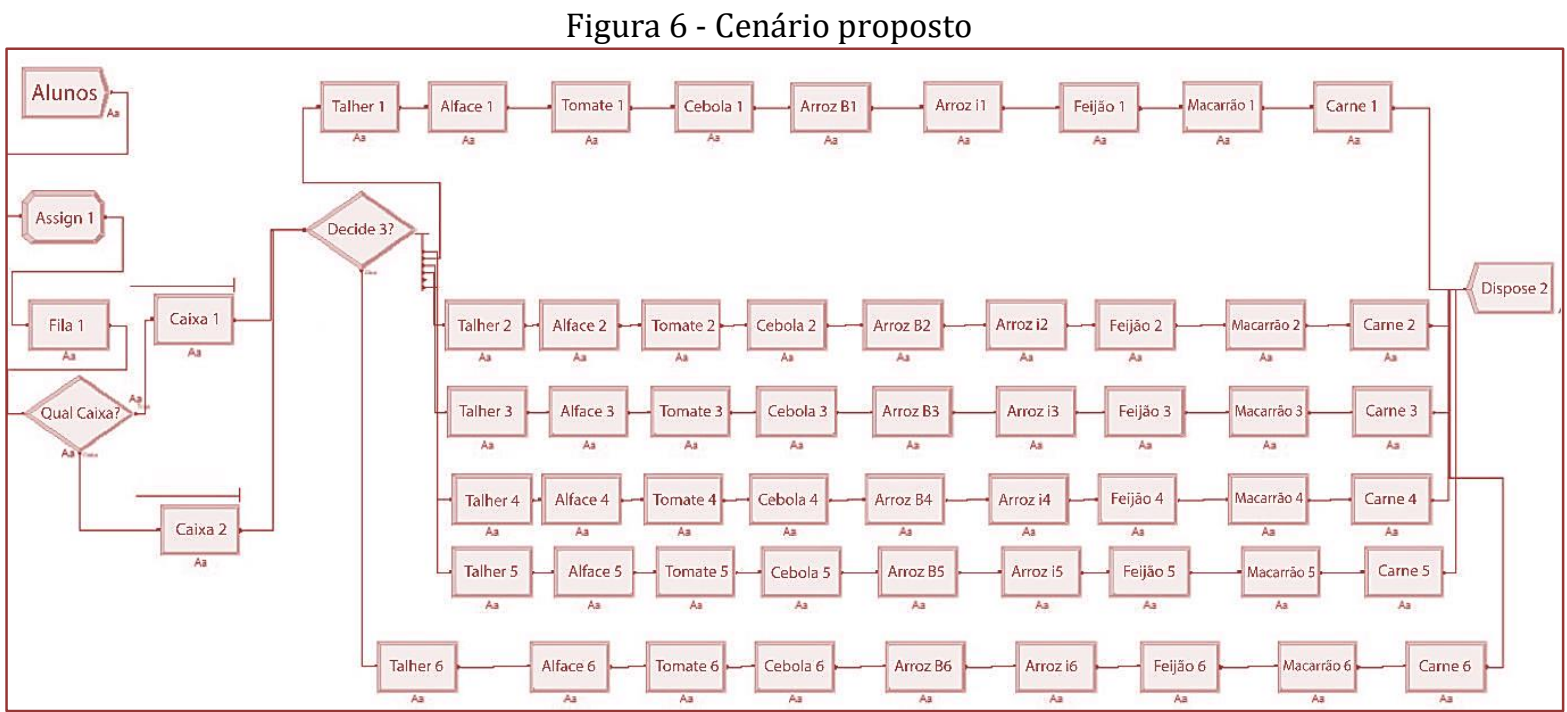

Fonte: Autores (2019)

Contudo, verificou que a taxa de ocupação total ocorre apenas no serviço do primeiro prato do buffet, apresentado os pratos subsequentes ociosidade. Isso ocorre pela distribuição linear dos pratos, layout mais utilizados nestes serviços. Contudo esse tipo de disposição gera ociosidade nos pratos seguintes caso o atendimento se prolongue no prato inicial. Observou-se nos resultados uma taxa média de $40 \%$ de ocupação nos pratos subsequentes ao primeiro, delatando a alta ociosidade deste modelo. Sugere-se a alternativa adotada por alguns buffets de distribuir os pratos de modo circular de forma que as entidades possam iniciar o serviço de buffet por qualquer prato reduzindo a ociosidade do sistema. Inevitavelmente o aumento no número de buffet e a alteração para uma distribuição circular dos pratos exigiria modificações no layout do RU que poderiam alterar os tempos de serviços demandando nova pesquisa e coleta de dados. Neste sentido entendem-se que a solução mais rápida e eficaz para o sistema contempla o aumento no número de buffet ainda que sejam necessários investimentos adicionais para aquisição de mesas térmicas. A adição de funcionários no caixa traria custos mensais desnecessários agravando o gargalo que se encontra no serviço de autoatendimento de buffet.

\section{CONCLUSÃO}

Ao se avaliar os dados gerados no presente estudo, foi possível compreender o comportamento das filas e atendimento no Restaurante Universitário no período do almoço de um sábado em horário de maior demanda. Como é a única unidade aberta para atender a demanda de toda a comunidade universitária, adequada a sua escolha para a análise.

O uso do software Arena auxiliou nas simulações do modelo atual e em possíveis alterações no sistema que resultam em diminuição do tempo de fila e melhoria do atendimento dos caixas, tendo assim um ambiente mais agradável tanto para estudantes como para os funcionários do restaurante.

Analisando os dados coletados e os relatórios gerados pelo Arena concluímos que o atual sistema não é capaz de atender a demanda de maneira eficiente, dependendo da variação da chegada de elementos na fila, já que a média do tempo de atendimento dos caixas é maior. A teoria das filas aliada a simulação computacional auxiliou na compreensão dos processos ali presentes e realizar projeções de melhoria, sem necessitar implementá-las, o que é justamente o viés e o propósito das simulações: realizar experimentos 
no cenário fictício para que se possua ganhos no cenário real, sem correr os riscos de inerentes ao cenário real.

\section{REFERÊNCIAS}

[1] Andrade, Eduardo Leopoldino. Introdução à pesquisa operacional: Métodos e modelos para análise de decisões. 5. ed. Rio de Janeiro: LTC, 2015.

[2] Banks, Jerry. (1998). Principles of simulation. In: BANKS, J. (Ed.) (1998). Handbook of Simulation. New York: John Wiley \& Sons, 1998.

[3] Banks, Jerry. et al. Discrete event system simulation. 4. ed. New Jersey: Pearson Prentice Hall, 2005.

[4] Brailsford, Sally. Hilton, Nicola. A Comparison of Discrete Event Simulation and System Dynamics for Modelling Healthcare Systems, Proceedings of ORAHS (Riley, J. ed.). Glasgow Caledonian University, 2000.

[5] Bruns, Rafael de. et al. Pesquisa Operacional: Uma aplicação da teoria de filas a Um sistema de atendimento. XXI Encontro Nacional de Engenharia de Produção (Enegep), 2001, Salvador.

[6] Chwif, Leonardo; Medina, Afonso Celso. Modelagem e Simulação de Eventos Discretos: Teoria e Aplicações. 4. ed. São Paulo: Campus-Elsevier, 2015.

[7] Freitas Filho, Paulo José de. Introdução à Modelagem e Simulação de Sistemas com Aplicações em Arena. 2a Edição. Visual Books. Florianópolis, 2008.

[8] Hillier, Frederick. Lieberman, Gerald. Introdução à Pesquisa Operacional, 9. ed. Porto Alegre: Amgh Editora Ltda, 2013.

[9] Law, Averill; Kelton, David. Simulation modeling and analysis. 3rd ed. New York: McGraw-Hill, 2000.

[10] Lippel, Isabela Laginski. Gestão de Custos em Restaurantes Utilização do Método ABC. 2002.185 f. Dissertação (Mestrado) - Curso de Engenharia de Produção, Centro Tecnológico, Universidade Federal de Santa Catarina, $\quad$ Florianópolis, $2002 . \quad$ Disponível em: https://repositorio.ufsc.br/xmlui/bitstream/handle/123456789/83249/192881.pdf?sequence=1\&isAllowed=y. Acesso em: 27 abr. 2019.

[11] Loureiro, Sérgio Adriano. Uso integrado de métodos de simulação de eventos discretos e contínuos na resolução de problemas logísticos em parques de diversão. 2009. 115 p. Dissertação (mestrado) - Universidade Estadual de Campinas, Faculdade de Engenharia Civil, Arquitetura e Urbanismo, Campinas, SP. Disponível em: <http://www.repositorio.unicamp.br/handle/Reposip/257670>. Acesso em: 13 ago. 2018.

[12] Mayo, Donna;Wichmann, Kanud Erik. Tutorial on Business and Market Modeling to Aid Strategic Decision Making: System Dynamics in Perpective and Selecting Appropriate Analysis Approchaes. Proceedings of the 2003 Winter Simulation Conference, 2003.

[13] Miyagi, Paulo Eigi. Introdução à simulação discreta. USP, São Paulo, 2006.

[14] Montgomery, Douglas C. Estatística aplicada e probabilidade para engenheiros. 6. ed. Rio de Janeiro LTC 2016.

[15] Oliveira, Mona Liza Moura. Analise da aplicabilidade da técnica de Modelagem Idef-Sim nas etapas de um projeto de simulação de eventos discretos. 2010. 168 f. Dissertação (Mestrado em Engenharia de Produção) Universidade Federal de Itajubá, Itajubá, 2010.

[16] Paragon Decision science. Arena - Paragon, 2018. Página inicial. Disponível em: <http://www.paragon.com.br/softwares/arena/>. Acesso em: 28 de abr. de 2019.

[17] Prado, Darci. Teoria das filas e da simulação. 5. ed. São Paulo: Falconi, 2014.

[18] Silva, Liane Márcia Freitas; Pinto, Marcel de Gois; Subramanian, Anand. Utilizando o software Arena como Ferramenta de Apoio ao Ensino em Engenharia de Produção. XXVIII Encontro Nacional de Engenharia de Produção: 09 a 11 out. 2007.

[19] Taha, Hamdy. Pesquisa operacional. 8. ed. São Paulo: Person Prentice Hall, 2008. 


\section{Capítulo 8}

Utilização do Recurso de Callback para a eliminação de subrotas em um problema de roteamento de veículos com entrega e coleta simultaneas de múltiplos produtos

Roza Maria Zoellner Lopes

Ruany Batista Leite Doehnert

Gustavo Valentim Loch

José Eduardo Pécora Junior

Cassius Tadeu Scarpin

Resumo: 0 problema de roteamento de veículos com entrega e coleta de múltiplos produtos (VRPSPD) é muito utilizado na prática em cenários onde somente coletar o produto não é suficiente para atender os requisitos do sistema. 0 presente artigo visa a aplicação do recurso de Callback para a eliminação de subrotas em um VRPSPD, para testar a eficiencia do método, primeiramente o problema de programação inteira misto com a inclusão de restrições de relaxamento será resolvido, após, o mesmo problema será solucionado utilizando o recurso Callback para eliminar as subrotas. Com os testes realizados, pode-se observar que o recurso Callback é um método tão eficiente quanto a utilização de uma restrição para evitar subrotas, sendo que na maioria dos casos, geralmente os mais complexos, obtem o resultado em um tempo menor.

Palavras-chave: Problema de roteamento de veículos; Recebimento e coleta simultâneos; Múltiplos produtos; Callback. 


\section{INTRODUÇÃO}

A realização do transporte de mercadorias é um processo muito relevante para a logística da cadeia de suprimentos, por isso, as empresas estão cada vez mais focando nele para a obtenção de redução de custos em seu sistema (Yousefikhoshbakht, Didehvar, and Rahmati 2015).

0 roteamento de veículos com entregas e coletas simultâneas é muito importante, pois aborda muitos modelos de negócios onde somente a entrega do produto não satisfaz suas necessidades, como em serviços de entregas em paletes, onde é necessária a captação do mesmo posteriormente, garrafas retornáveis, indústria do varejo, na qual produtos que apresentam defeitos podem ser recolhidos, entre outros (Alshamrani, Mathur, and Ballou 2007).

No presente artigo, o problema abordado é retirado de (Zhang et al. 2019), o qual apresenta o roteamento de veículos com coleta e entrega simultânea de produtos diversificados de uma empresa de fast fashion. Veículos com carga homogênea saem do depósito (armazém) percorrendo todos os pontos de venda apenas uma vez por rota, e voltando ao depósito ao fim do roteiro. 0 problema possui o diferencial de que os produtos retirados de um ponto de venda podem ser redistribuídos para atender a demanda dos outros clientes, tornando-o mais complexo de ser resolvido.

(Wang 2018), resolveu o problema para realizar entrega de refeições para diversos fornecedores, onde, o serviço de logística coleta os produtos nos fornecedores e entrega para os clientes, sendo definido um tempo máximo para a entrega. Os veículos saem de muitos pontos de depósito. A metodologia utilizada foi comparar a implementação de três serviços logísticos: Exclusivo, cada veículo atende apenas um fornecedor; compartilhado: um veículo pode atender mais de um fornecedor após terminar a entrega do anterior; compartilhado + serviços logísticos, cada veículo pode servir mais de um fornecedor enquanto ainda está na rota do anterior. Sendo resolvido através de duas heurísticas, a iterated local search e a adaptive large neighborhood search que têm como solução inicial o resultado obtido através de uma heurística construtiva.

(Bouanane, Benadada, and Bencheikh 2018) modelaram e resolveram o problema para realizar a entrega e coleta de produtos para diversos clientes com múltiplos depósitos, considerando o nível de estoque, visando minimizar o custo de viagem e de utilização de veículos, o problema foi resolvido através do desenvolvimento de um algoritmo genético (GA) híbrido.

(Alshamrani, Mathur, and Ballou 2007), abordaram o problema de distribuição de sangue em hospitais. 0 sangue é entregue em caixas térmicas próprias para ser conservado, sendo essas caixas reaproveitadas. Por isso, o problema consiste em realizar a logística de entrega e coleta simultâneas das caixas com um veículo único que possui capacidade limitada; se ao realizar a entrega das caixas o veículo não possuir capacidade suficiente para coletar caixas vazias, a coleta pode ser adiada, mas uma penalidade será adicionada ao sistema. 0 problema tem o objetivo de minimizar a rota e a penalidade por não conseguir retirar os compartimentos vazios na mesma viagem de entrega. É realizada uma solução composta por duas partes: primeiro é encontrada a solução para a rota através do procedimento de inserção arbitrária, após, é utilizada a heurística de nivelamento ponderado para considerar os custos de penalidades envolvidos.

Todos os problemas citados acima utilizaram uma restrição para evitar a formação de subrotas.

A função Callback possibilita realizar um retorno quando determinado evento acontece, sendo muito conhecida na programação (Wang et al. 2018).

Pode-se chamar a função Callback presente em alguns solucionadores MIP e adicionar lazy contraints, restrições que não fazem parte do escopo inicial do problema ao ser resolvido pelo solucionador, mas que são necessárias para a resolução do problema e adicionadas após determinada condição ocorrer (Lundel, Andreas, and Kroqvist, Jan. 2019).

Um problema que aborda o VRP com a utilização do recurso Callback é o resolvido por (Li et al. 2018), que consiste em determinar a rota de tratores que carregam contêineres cheios até os clientes e retornam com vazios, considerando as janelas de tempo, e visa minimizar o custo total de funcionamento dos tratores. 0 problema inteiro misto é formulado e resolvido pelo algoritmo de decomposição de Benders envolvendo cortes e utilizando o CPLEX para pequenas instâncias, e a heurística de economia e de busca local para problemas maiores. Sendo a utilização do recurso de Callback para a definição dos cortes que devem ser realizados. 
Portanto, como o recurso de Callback para eliminação de subrotas não foi abordado para problemas de VRPSPD, esse estudo realizou a comparação entre a utilização de uma restrição para evitar subrotas para o problema relaxado retirado de (Zhang et al. 2019), com a utilização do recurso de Callback com a mesma finalidade, para avaliar a eficiência do mesmo. Observou-se que o Callback apresentou melhores resultados em comparação ao modelo relaxado.

0 restante do trabalho está estruturado da seguinte maneira: na Seção 2 é realizada a descrição mais detalhada do problema abordado, a modelagem matemática exata, a modelagem do modelo relaxado e as alterações necessárias para a implementação do recurso de Callback, na seção seguinte, os resultados computacionais, e por fim, a conclusão do estudo.

\section{DESCRIÇÃO DO PROBLEMA}

O presente artigo utilizou o problema resolvido por (Zhang et al. 2019) para uma indústria de fast fashion, onde uma frota ilimitada e homogênea realiza a entrega de produtos em lojas e a coleta dos itens que não estão obtendo vendas simultaneamente, sendo que os itens retirados de uma loja podem ser redistribuídos para as demais, aumentando a complexidade do problema, pois os itens de reabastecimento não precisam sair necessariamente do armazém. Os veículos devem sair e voltar para o armazém, sendo que cada cliente pode ser visitado apenas uma vez. São considerados os custos de transportar os produtos de um ponto ao outro e os custos de retirada e devolução dos produtos do armazém, pois a frota utilizada é terceirizada. Foi realizada uma adaptação ao modelo formulado por (Zhang et al. 2019), onde as distâncias de um ponto de venda para outro são assimétricas, no presente artigo, são consideradas distâncias euclidianas de pontos aleatórios, pois não foi possível obter as distâncias reais utilizadas.

\section{MODELO MATEMÁTICO}

Serão apresentados os índices, parâmetros, variáveis e restrições retirados de (Zhang et al. 2019), tanto do modelo exato, quanto do modelo relaxado utilizado para realizar os testes.

\subsection{MODELO MATEMÁTICO}

Índices

i - nó de partida

j - nó de chegada

h - tipo de produto

Parâmetros

n: número de pontos de venda.

m: número de tipos de produtos.

$V$ : conjunto de pontos de venda mais o armazém; $V=\{0,1, \ldots, n\}$.

$S$ : conjunto de pontos de pontos de venda; $S=\{1,2, \ldots, n\}$.

$\mathrm{H}$ : conjunto de produtos; $\mathrm{H}=\{1,2, \ldots, \mathrm{m}\}$.

$\mathrm{C}_{\mathrm{i}, \mathrm{j}}$ : custo de viagem de i para $\mathrm{j}$.

w: custo de retirar/colocar produtos no armazém.

$d_{i, h}$ : se di,h $<<$ é a quantidade do produto $h$ entregue no ponto $i$, se $d_{i, h}>0$ é a quantidade de produto $h$ retirado do ponto i;

Cap: capacidade dos veículos; 


\section{Variáveis de decisão:}

$\mathrm{X}_{\mathrm{i}, \mathrm{j}}$ : variável binária, 1 se o veículo atravessa o arco (i,j); 0 caso contrário;

$\mathrm{Q}_{\mathrm{i}, \mathrm{j}, \mathrm{h}}$ : quantidade do produto $\mathrm{h}$ entregue no $\operatorname{arco}(\mathrm{i}, \mathrm{j})$;

$\mathrm{B}_{\mathrm{i}}$ : variável auxiliar para eliminar subrotas;

Função objetivo

$$
\operatorname{Min} \sum_{i \in V} \sum_{j \in V} C_{i, j} x_{i, j}+\sum_{i \in S} \sum_{h \in H} W\left(Q_{0, i, h}+Q_{i, 0, h}\right)
$$

s.a.:

$$
\begin{aligned}
& \sum_{\mathrm{j} \in \mathrm{V} \backslash\{i\}} \mathrm{x}_{\mathrm{i}, \mathrm{j}}=1, \quad \forall \mathrm{i} \in \mathrm{S} \\
& \sum_{\mathrm{j} \in \mathrm{V} \backslash\{\mathrm{i}\}} \mathrm{x}_{\mathrm{j}, \mathrm{i}}=1, \quad \forall \mathrm{i} \in \mathrm{S} \\
& \sum_{\mathrm{j} \in \mathrm{V} \backslash\{\mathrm{i}\}} \mathrm{Q}_{\mathrm{j}, \mathrm{i}, \mathrm{h}}+\mathrm{d}_{\mathrm{i}, \mathrm{h}}=\sum_{\mathrm{j} \in \mathrm{V} \backslash\{\mathrm{i}\}} \mathrm{Q}_{\mathrm{i}, \mathrm{j}, \mathrm{h}}, \quad \forall \mathrm{i} \in \mathrm{S}, \mathrm{h} \in \mathrm{H} \neq \mathrm{i} \\
& 0 \leq \sum_{\mathrm{h} \in \mathrm{H}} \mathrm{Q}_{\mathrm{i}, \mathrm{j}, \mathrm{h}} \leq \mathrm{CapX} \mathrm{X}_{\mathrm{i}, \mathrm{j}}, \quad \forall \mathrm{i}, \mathrm{j} \in \mathrm{V}, \mathrm{j} \neq \mathrm{i} \\
& \mathrm{B}_{\mathrm{j}} \geq \mathrm{B}_{\mathrm{i}}+1-\left(1-\mathrm{X}_{\mathrm{i}, \mathrm{j}}\right) \mathrm{M}, \quad \forall \mathrm{i}, \mathrm{j} \in \mathrm{S}, \mathrm{j} \neq \mathrm{i} \\
& \mathrm{X}_{\mathrm{i}, \mathrm{j}} \in\{0,1\}, \quad \forall \mathrm{i}, \mathrm{j} \in \mathrm{V} \\
& \mathrm{Q}_{\mathrm{i}, \mathrm{j}, \mathrm{h}} \in \mathrm{Z}^{+}, \quad \forall \mathrm{i}, \mathrm{j} \in \mathrm{V}, \mathrm{j} \neq \mathrm{i}, \mathrm{h} \in \mathrm{H} \\
& B_{i} \geq 0, \quad \forall i \in S
\end{aligned}
$$

A função objetivo (1) minimiza o custo das operações de entrega. As restrições (2) e (3) garantem que cada nó seja visitado apenas uma vez. A restrição (4) assegura que tudo que precisa ser retirado e entregue de produto em cada nó seja satisfeito. A restrição (5) garante que a capacidade do veículo não seja excedida, sendo que nesse modelo todos os veículos possuem a mesma capacidade. A restrição (6) elimina as subrotas, onde o valor de M é igual a n. As restrições (7) a (9) delimitam os valores que as variáveis de decisão podem tomar.

\subsection{MODELO MATEMÁTICO RELAXADO}

(Zhang et al. 2019) adicionaram algumas restrições redundantes ao problema para obter uma formulação do modelo relaxado que permite acelerar o processo de solução. Com as restrições abaixo a variável $Q$ pode deixar de ser inteira.

$$
\begin{aligned}
& d_{i, h} \leq \sum_{j \in V \backslash\{i\}} Q_{i, j, h} \leq \operatorname{Cap}+d_{i, h}, \quad \forall i \in S, h \in H \\
& -d_{j, h} X_{i, j} \leq Q_{i, j, h} \leq \text { Cap }-d_{j, h} X_{i, j}, \quad \forall i, j \in S, j \neq i, h \in H
\end{aligned}
$$




$$
\begin{gathered}
\sum_{\mathrm{j} \in \mathrm{V} \backslash\{i\}} \sum_{h \in H} \mathrm{Q}_{\mathrm{i}, \mathrm{j}, \mathrm{h}} \leq \mathrm{Cap}+\sum_{\mathrm{h} \in \mathrm{H}} \mathrm{d}_{\mathrm{i}, \mathrm{h}}, \quad \forall \mathrm{i} \in \mathrm{S} \\
\sum_{\mathrm{h} \in \mathrm{H}} \mathrm{Q}_{\mathrm{i}, \mathrm{j}, \mathrm{h}} \leq \mathrm{Cap}-\mathrm{X}_{\mathrm{i}, \mathrm{j}} \sum_{\mathrm{h} \in \mathrm{H}} \mathrm{d}_{\mathrm{j}, \mathrm{h}}, \quad \forall \mathrm{i}, \mathrm{j} \in \mathrm{S}, \mathrm{j} \neq \mathrm{i}
\end{gathered}
$$

\subsection{RECURSO DE CALLBACK}

0 recurso de Callback foi utilizado para evitar a formação de subrotas no problema, inicialmente o modelo é resolvido sem uma restrição que evita a formação de subrotas, porém, toda vez que uma subrota é encontrada, uma lazy constraint é adicionada ao modelo, fazendo com que aquela subrota seja eliminada.

Portanto, foram necessárias algumas alterações no modelo: a restrição (6) é retirada, na definição da viarável Xi,j foram criadas as variáves em que i = j, por isso, para evitar que um nó seja designado para ele mesmo, uma restrição é adicionada. A fim de guardar as subrotas cria-se um vetor com o nome de Tour.

Se o número de rotas encontradas for menor que n significa que houve a formação de uma subrota e a lazy constraint é adicionada ao problema. Considere nt o tamanho do vetor Tour.

$$
\sum_{i=0}^{\text {nt }} \sum_{j=0}^{\text {nt }} X_{i, j} \leq \text { Tour }-1 \quad \forall X_{i, j} \in \text { Tour }
$$

Restrição para que um nó não seja designado para ele mesmo:

$$
\mathrm{X}_{\mathrm{i}, \mathrm{j}}=0 \quad \forall \mathrm{i}=\mathrm{j}
$$

\section{RESULTADOS COMPUTACIONAIS}

Os testes de comparação entre as duas metodologias foram realizados em um computador Intel core i58250U, com 8Gb de memória ram, utilizando o solver Gurobi 8.1.1 em suas configurações padrões. Foi estipulado um tempo máximo de duas horas para a obtenção da solução.

Para validar o modelo, foi realizado um teste em duas pequenas instâncias, tanto para o modelo exato relaxado proposto no artigo de (Zhang et al. 2019), quanto para o recurso de Callback implementando. Foram mantidos fixos a quantidade de mercadoria requerida/retirada dos pontos, o custo de ir de um ponto ao outro, custo de retirada da mercadoria do armazém e as coordenadas dos pontos. Os resultados dos testes estão na tabela abaixo:

Tabela 9- Validação do Modelo

\begin{tabular}{|c|c|c|c|c|c|c|c|c|c|}
\multicolumn{1}{c|}{ CallBack no Modelo Relaxado } \\
\hline instância & $\mathrm{n}$ & $\mathrm{m}$ & cap & FO & GAP & Tempo(s) & FO & GAP & Tempo(s) \\
\hline 1 & 2 & 2 & 15 & 698,6 & $0,00 \%$ & 0,01 & 698,6 & $0,00 \%$ & 0,01 \\
\hline 2 & 3 & 2 & 15 & 1210 & $0,00 \%$ & 0,14 & 1210 & $0,00 \%$ & 0,04 \\
\hline
\end{tabular}

A seguir, seguem os desenhos das rotas para as duas instâncias: 
Figura 1- Rota intância 1

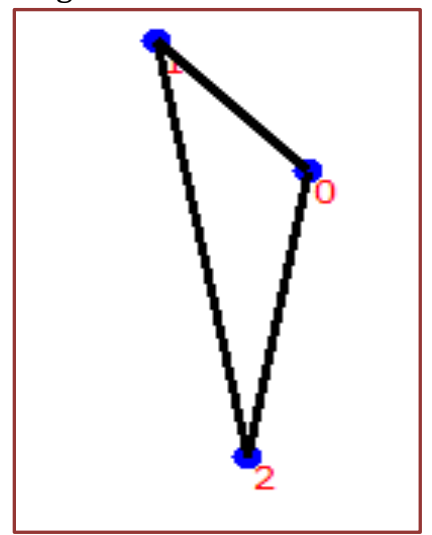

A rota ótima encontrada no teste foi: 0-2-1-0.

Figura 2 - Rota instância 2

A rota ótima obtida foi de 0-3-1-2-0.

Após, foram realizados testes com algumas instâncias para determinar se com a utilização do recurso de Callback para a eliminação de subrotas é possível obter a solução sem perda de tempo no processo. Para tanto, os parâmetros de pontos de venda, tipos de mercadoria e capacidade foram alterados em cada instância, mantendo dois fixos enquanto outro varia, e replicados para 2 sementes distintas que determinam o sorteio dos parâmetros $d_{\text {in }}$ (quantidade de mercadoria que cada ponto de venda está necessitando e que precisa ser retirado) que varia de -5 até 10 e das coordenadas x e y dos pontos de venda que variam de 2 até 300 .

Os resultados dos testes são apresentados na Tabela 2. As instâncias que não obtiveram resultado no tempo determinado apresentam um traço em suas linhas e o tempo computacional em destaque representa as instâncias em que a implementação do recurso Callback obteve melhor resultado. 
Tabela 10- Resultados computacionais

\begin{tabular}{|c|c|c|c|c|c|c|c|c|c|}
\hline \multirow[b]{2}{*}{ Instancia } & \multirow[b]{2}{*}{$\mathrm{n}$} & \multirow[b]{2}{*}{$\mathrm{m}$} & \multirow[b]{2}{*}{ cap } & \multicolumn{3}{|c|}{ Modelo Relaxado } & \multicolumn{3}{|c|}{ CallBack no Modelo Relaxado } \\
\hline & & & & $\begin{array}{c}\text { Função } \\
\text { Objetivo }\end{array}$ & GAP & Tempo(s) & $\begin{array}{c}\text { Função } \\
\text { Objetivo }\end{array}$ & GAP & Tempo(s) \\
\hline 1 & 10 & 4 & 100 & 2950 & $0,00 \%$ & 0,31 & 2950 & $0,00 \%$ & 0,45 \\
\hline 2 & 10 & 4 & 100 & 3006 & $0.00 \%$ & 25,78 & 3006 & $0.00 \%$ & 33,09 \\
\hline 3 & 20 & 4 & 100 & 4610 & $0,03 \%$ & 5808,99 & 4610 & $0,00 \%$ & 130,75 \\
\hline 4 & 20 & 4 & 100 & 4160 & $7,00 \%$ & 3965.97 & - & - & - \\
\hline 5 & 30 & 4 & 100 & 4700 & $0,00 \%$ & 1692,99 & 4700 & $0,00 \%$ & 2535,92 \\
\hline 6 & 30 & 4 & 100 & 8920 & $0.00 \%$ & 43,99 & 8920 & $0.00 \%$ & 27,01 \\
\hline 7 & 10 & 2 & 200 & 1670 & $0,00 \%$ & 0,18 & 1670 & $0,00 \%$ & 0,12 \\
\hline 8 & 10 & 2 & 200 & 1600 & $0,00 \%$ & 0,53 & 1600 & $0,00 \%$ & 0,66 \\
\hline 9 & 20 & 2 & 200 & 2110 & $0,00 \%$ & 0,95 & 2110 & $0,00 \%$ & 0,69 \\
\hline 10 & 20 & 2 & 200 & 2700 & $0,00 \%$ & 5,91 & 2700 & $0,00 \%$ & 7,53 \\
\hline 11 & 30 & 2 & 200 & 2730 & $0,00 \%$ & 10,56 & 2730 & $0,00 \%$ & 5,99 \\
\hline 12 & 30 & 2 & 200 & 5080 & $0,00 \%$ & 17,79 & 5080 & $0,00 \%$ & 7,88 \\
\hline 13 & 40 & 2 & 200 & 3310 & $0,00 \%$ & 46,4 & 3310 & $0,00 \%$ & 15,03 \\
\hline 14 & 50 & 2 & 200 & 6830 & $0,0068 \%$ & 245,68 & 6830 & $0,00 \%$ & 98,44 \\
\hline 15 & 60 & 2 & 200 & - & - & - & 5120 & $0,01 \%$ & 1331,89 \\
\hline 16 & 70 & 2 & 200 & - & - & - & - & - & - \\
\hline 17 & 10 & 4 & 200 & 2860 & $0,00 \%$ & 0,39 & 2860 & $0,00 \%$ & 0,14 \\
\hline 18 & 10 & 4 & 200 & 2750 & $0,00 \%$ & 0,43 & 2750 & $0,00 \%$ & 0,21 \\
\hline 19 & 20 & 4 & 200 & 4340 & $0,00 \%$ & 4 & 4340 & $0,00 \%$ & 3 \\
\hline 20 & 20 & 4 & 200 & 3890 & $0,00 \%$ & 17,74 & 3890 & $0,00 \%$ & 5,78 \\
\hline 21 & 30 & 4 & 200 & 4400 & $0,00 \%$ & 44,81 & 4400 & $0,00 \%$ & 25,6 \\
\hline 22 & 30 & 4 & 200 & - & - & - & 8570 & $0,00 \%$ & 599,6 \\
\hline 23 & 40 & 4 & 200 & - & - & - & 5390 & $0,00 \%$ & 866,51 \\
\hline 24 & 40 & 4 & 200 & - & - & - & 1150 & $0,01 \%$ & 1389,27 \\
\hline 25 & 40 & 4 & 200 & - & - & - & - & - & - \\
\hline
\end{tabular}

É possível observar que a utilização do recurso de Callback para a eliminação de subrotas obteve a solução em menor tempo computacional em 17 das 23 instâncias que obtiveram resultado no tempo estipulado, sendo que no outro método o tempo computacional é menor em geral para instâncias menores.

Destaca-se também que na instância 4 a melhoria obtida no tempo computacional foi de 5678,24 segundos e que nos testes 15, 22, 23 e 24, a utilização do recurso de Callback obteve a solução dentro do tempo estipulado enquanto a outra metodologia não.

\section{CONCLUSÃO}

Neste trabalho, foi proposta a implementação do recurso de CallBack para a eliminação de subrotas no problema de roteamento de veículos com coleta e entrega simultânea de produtos variados e realizadas comparações em termos de tempo computacional com o modelo exato relaxado. 
Com os resultados obtidos, é possível constatar que a utilização do recurso de Callback para a exclusão de subrotas obtém a solução em menor tempo que o modelo exato relaxado em $74 \%$ das instâncias.

A aplicação do recurso de CallBack proposto para esse problema, se mostrou satisfatória para eliminação de subrotas. No entanto, para instâncias maiores, por ser um problema de alta complexidade, somente a relaxação do modelo exato não obtem resultados em tempo viável. Dessa forma, uma sugestão para trabalhos futuros é a utilização de heurísticas que proporcionem uma solução em melhores tempos computacionais para a obtenção da solução inicial, e após, resolver com o modelo exato utilizando o Callback para a eliminação das subrotas.

\section{REFERÊNCIAS}

[1] Alshamrani, Ahmad, Kamlesh Mathur, and Ronald H. Ballou. 2007. "Reverse Logistics: Simultaneous Design of Delivery Routes and Returns Strategies." Computers and Operations Research 34(2): 595-619.

[2] Bouanane, Khaoula, Youssef Benadada, and Ghizlane Bencheikh. 2018. "Application of a Hybrid Genetic Algorithm to Solve the Multi-Depots Vehicle Routing Problem with Simultaneous Delivery and Pickup and Inventory Restrictions." Proceedings - GOL 2018: 4th IEEE International Conference on Logistics Operations Management: 1-9.

[3] Li, Hongqi, Xiaorong Jian, Xinyu Chang, and Yingrong Lu. 2018. "The Generalized Rollon-Rolloff Vehicle Routing Problem and Savings-Based Algorithm." Transportation Research Part B: Methodological 113: 1-23. https://doi.org/10.1016/j.trb.2018.05.005.

[4] Lundel, Andreas, and Kroqvist, Jan. 2019. "Integration of Polyhedral Outer Approximation Algorithms with MIP Solvers Through Callbacks And Lazy Constraints". AIP Conference Proceedings. Vol. 2070. No. 1. AIP Publishing.

[5] Wang, Fei, Decker,James, Wu,Xilun, Essertel,Gregory, and Rompf, Tiark. 2018. "Backpropagation with Continuation Callbacks: Foundations for Efficient and Expressive Differentiable Programming". Proceedings of the 32nd International Conference on Neural Information Processing Systems (pp. 10201-10212). Curran Associates Inc.

[6] Wang, Zheng. 2018. "Delivering Meals for Multiple Suppliers: Exclusive or Sharing Logistics Service." Transportation Research Part E: Logistics and Transportation Review 118(November 2017): 496-512. https://doi.org/10.1016/j.tre.2018.09.001.

[7] Yousefikhoshbakht, Majid, Frazad Didehvar, and Farhad Rahmati. 2015. "A Mixed Integer Programming Formulation for the Heterogeneous Fixed Fleet Open Vehicle Routing Problem." Journal of Optimization in Industrial Engineering 18: 37-46.

[8] Zhang, Zhenzhen, Brenda Cheang, Chongshou Li, and Andrew Lim. 2019. "Computers and Operations Research Multi-Commodity Demand Fulfillment via Simultaneous Pickup and Delivery for a Fast Fashion Retailer." Computers and Operations Research 103: 81-96. https://doi.org/10.1016/j.cor.2018.10.020. 


\section{Capítulo 9}

\section{Mobilidade universitária: Um estudo de caso da Universidade Federal do Amazonas}

\section{Fernando Henrique da Paixão Duarte}

Ariane Pereira Gatti

\section{Willians Antônio Malveira da Silva}

Resumo: Juntamente com os desafios do processo de urbanização, pode ser observado que as universidades no mundo passaram por reavaliação da dinâmica de mobilidade. E neste contexto é que se desenvolve este estudo, para avaliar os impactos ambientais e nível de serviços de mobilidade no campus da Universidade Federal do Amazonas (UFAM), campus-Manaus. 0 Plano de Mobilidade Universitária (PMU) é um projeto de extensão que desenvolveu a pesquisa visando analisar o nível de serviço e propor melhoras adequadas ao perfil da comunidade universitária. Foi observado que o Campus da UFAM Manaus, adota um formato de mobilidade definido como micro urbana, por adotar um sistema de transporte abastecido por coletivos. Esse sistema é necessário devido às grandes dimensões desses locais, viabilizando o acesso e o deslocamento interno, os resultados da primeira fase da pesquisa mostrou que mais de $50 \%$ dos que responderam os questionários utilizam coletivos e que este modelo gera uma emissão de 1058302 de $\mathrm{CO}_{2} \mathrm{Kg} /$ Ano.

Palavras-chave: Mobilidade Universitária, Mobilidade sustentável, Engenharia da sustentabilidade, Economia circular . 


\section{INTRODUÇÃO}

As cidades geram diversos problemas e desenvolvem mecanismos para resolve-los em si mesmas. Contudo, um dos mais significativos problemas gerados nos ambientes urbanos é relacionado ao nível de emissão de gases do efeito estufa. Para alguns estudiosos do tema, as cidades geram algo entorno de $80 \%$ das emissões, assim também entende Yigiticanlar et.al (2018). Neste ponto, são desenvolvidas novas tecnologias que garantem que os processos e as atividades urbanas sejam ecoeficientes.

Na visão de H. Kumar, et.al (2018), a transformação da cidade em uma smart-city depende de uma integração tecnológica coletiva e de componentes transicionais. Como pode ser observado, ao ser desenvolvido um projeto voltado para a sustentabilidade urbana, se desenvolve um projeto multidisciplinar, portanto deve ser desenhado linhas de ação e prioridades.

A cidade de Manaus teve um relevante crescimento, o que demandou investimentos em Infraestrutura. Neste contexto, há reflexos no ambiente universitário uma vez que proporcionalmente ao crescimento da cidade há aumento na demanda de viagens tanto no ambiente interno como no ambiente externo do campus ,no sentido de interconexão e entradas e saídas. Foi observado que a sustentabilidade dos sistemas de transportes aumenta à medida que aumentamos a flexibilidade do sistema. Isto implica em melhoria da qualidade de serviço do modelo e descarbonização do sistema. Além destes fatores é necessário ser trabalhado a infraestrutura para que permita acessibilidade a pessoas com deficiência.

Assim, uma relevância é a minimização dos impactos no ambiente, isto é importante uma vez que as cidades geram impactos local e global. A nível local, temos a devastação de florestas, contaminação de água e solos, por outro lado as emissões de gases de efeito estufa, que geram impactos a nível global. Neste ponto, é que há uma relevante contribuição do campus universitário da Universidade Federal do Amazonas, a extensão territorial do campus tem uma cobertura florestal,considerada comoo terceiro maior fragmento florestal do mundo com algo em torno de 700 hectares. A Universidade Federal do Amazonas(UFAM) apresenta em seu espaço físico uma área de aproximadamente 6 milhões de metros quadrados, que se divide entre o campus da capital e sedes do interior, em área construída os valores se aproximam de $260 \mathrm{mil} \mathrm{m}^{2}$, com cerca de $40 \mathrm{mil}$ alunos matricula do sem cursos de graduação e pósgraduação, gerando então a necessidade de um sistema de mobilidade que atenda toda a comunidade acadêmica.

Para atender toda a comunidade acadêmica, a universidade disponibiliza ônibus que fazem a integração dos alunos pelos setores do campus até a avenida principal mais próxima, além de uma ampla área de estacionamento ao redor da sunidades acadêmicas. A prefeitura da cidade de Manaus está presente oferecendo linhas de ônibus que partem da universidade e outras que passam por dentro do campus, o que facilita no deslocamento dos usuários.

Esse sistema de integração, onde há uma linha de ônibus ou veículo disponível no local não é exclusividade, o mesmo pode ser encontrado na indústria, em portos, aeroportos ou qualquer local onde há uma grande concentração de atividade humana.

A limitação dos acadêmicos a esses tipos de transportes gera impactos tanto ambientais quanto sociais. Esse artigo estuda o atual meio de deslocamento utilizado pela comunidade e compara com outros sistemas que já estão aplicados em outras universidades, visando melhorar a mobilidade e diminuir danos ambientais.

\section{MOBILIDADE UNIVERSITÁRIA}

Em virtude das dimensões do campus Universitário, estes espaços demandam uma gestão de mobilidade, o que tem sido um desafio semelhante ao espaço das cidades. Recentemente se tem estudado nos ambientes universitários como implementar modelos mais sustentáveis, este é o caso do estudo de David Kaplan (2015) que estudou o nível de sustentabilidade da mobilidade de Kent State University.

A partir da elaboração do questionário, obteve-se respostas acerca de quais são proporções dos veículos utilizados para que a comunidade possa se deslocar para o campus. Os dados obtidos podem ser observados no gráfico 1. 


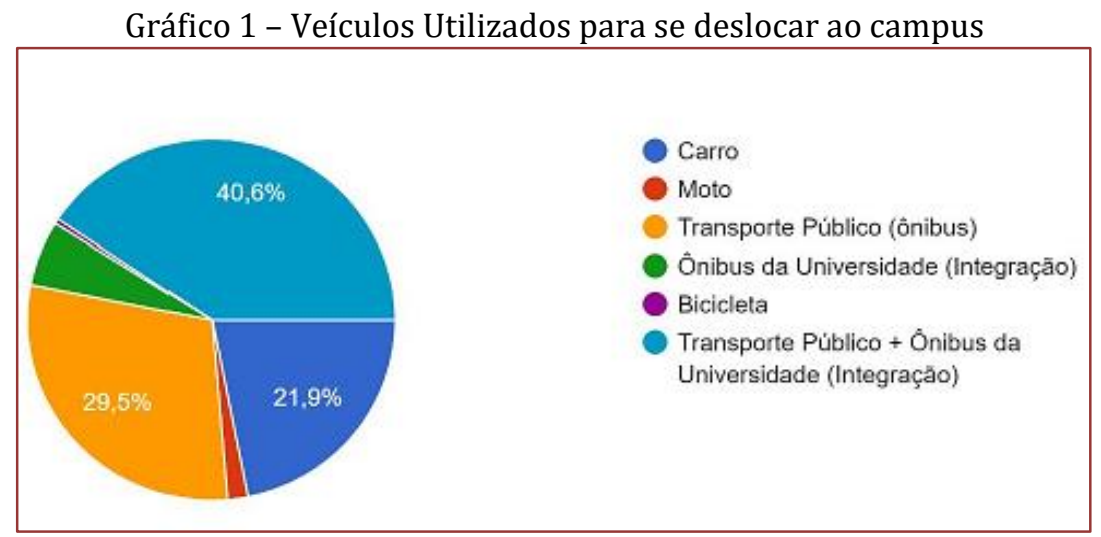

Fonte: Autores(2019)

Apesar da disposição do serviço público de ônibus oferecido pela prefeitura de Manaus, observou-se uma quantidade significativa de carros que circulam pelo campus, aumentando os danos ambientais e sociais causados pelo uso de veículos individuais.

Segundo Vídeo institucional divulgado pela TV UFAM (canal de Televisão da Universidade Federal do Amazonas) em sua conta na plataforma de vídeo YouTube, a universidade conta com um total de 1.700 docentes e 40 mil discentes, além de 1600 técnicos, o que fomenta a necessidade de um sistema de mobilidade adequado, dada a extensão do campus, como pode ser visto na figura 1, levando em conta a frequência da comunidade, mostrado no gráfico 2 .

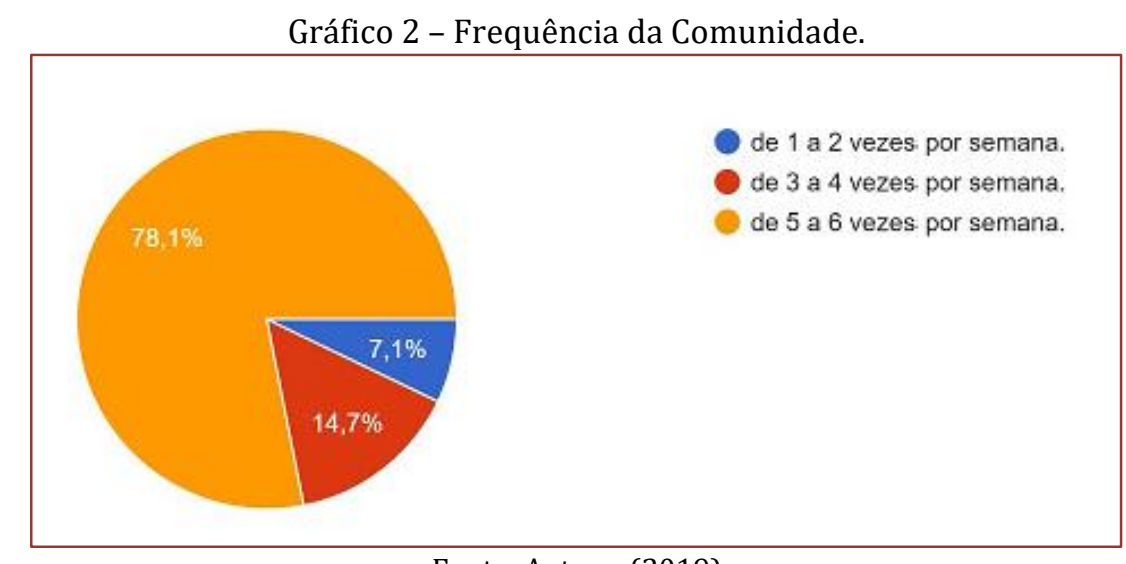

Fonte: Autores(2019)

A UFAM atende à alunos de todas as zonas da cidade de Manaus e de municípios do interior, o que gera diferentes tipos de trajetos tendo a necessidade de uma ampla oferta de ônibus para todos. A cidade de Manaus dispõe de cinco terminais de ônibus onde pode ser feito a conexão entre os usuários em diferentes ônibus, o que diminui a necessidade de diferentes linhas de ônibus dentro do campus. Por outro lado ,essa confiança em conexões nos terminais de ônibus acaba por deixar as viagens mais longas e exaustivas.

Em consulta à comunidade sobre o tempo em que os mesmos levam para se deslocar para a universidade, gráfico 3 , e da universidade, gráfico 4 , obteve-se os seguintes resultados: 


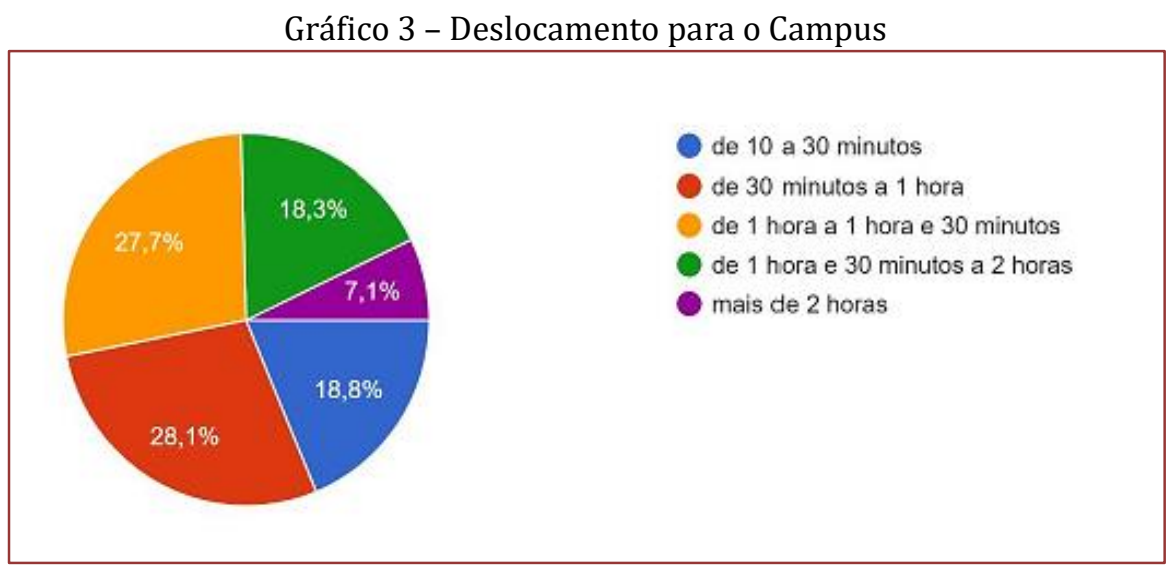

Fonte: Autores(2019)

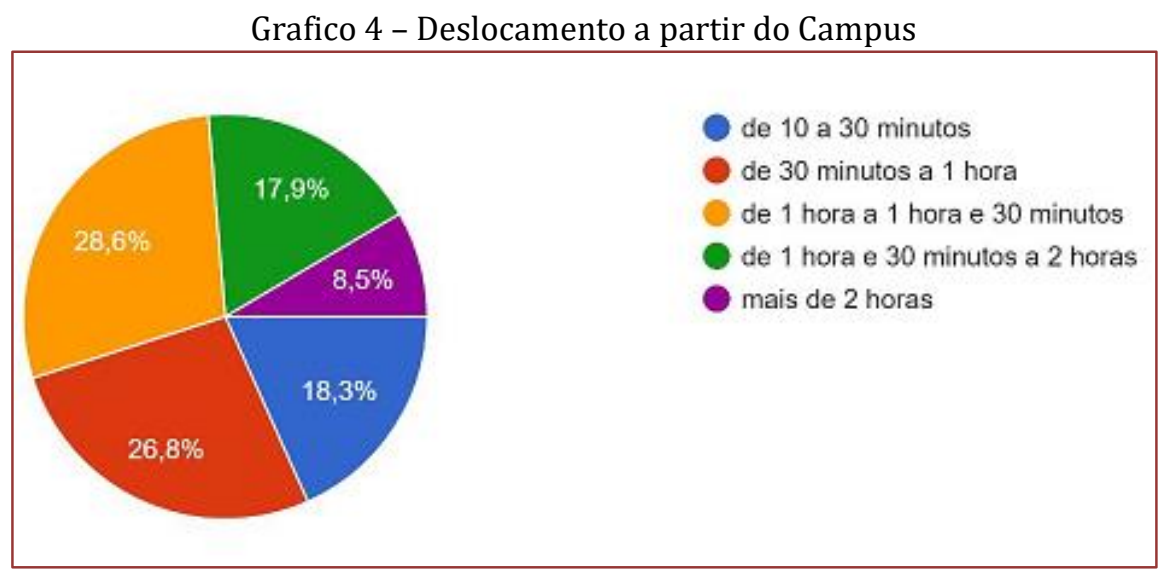

Fonte: Autores(2019)

A universidade dispõe para o deslocamento da comunidade alguns ônibus exclusivos, os mesmos têm como destino a avenida mais próxima, além de locais específicos dentro da universidade. Esse deslocamento é de forma contínua desde a abertura da universidade até o término das atividades. Por consequência disso o consumo de combustível desses veículos, juntamente com os veículos disponibilizados pela prefeitura de Manaus, vem afetando o meio ambiente e a qualidade de vida dos que frequentam a universidade e da comunidade ao redor.

Em consulta às empresas responsáveis pela frota de ônibus que executa essas viagens no campus, foram obtidos os dados dispostos na tabela 1, levando em conta os dias que os mesmos circulam no campus e a quantidade de viagens que fazem.

Tabela 1- Emissão de $\mathrm{CO}_{2}$ na universidade pelos ônibus circulantes

\begin{tabular}{|c|c|c|c|c|c|c|}
\hline \multirow[b]{2}{*}{ Linhas } & \multicolumn{2}{|c|}{ Extensão total/viagem } & \multicolumn{2}{|c|}{ Viagens diárias } & \multirow[b]{2}{*}{$\begin{array}{c}\text { Extensão } \\
\text { percorrida } \\
\text { por ano }\end{array}$} & \multirow[b]{2}{*}{$\mathrm{CO}_{2} \mathrm{~kg} / \mathrm{ano}$} \\
\hline & $\begin{array}{l}\text { Campus - } \\
\text { Campus }\end{array}$ & $\begin{array}{c}\text { Campus - Av. } \\
\text { General } \\
\text { Rodrigo Otávio }\end{array}$ & Dias úteis & Sábados & & \\
\hline Integração & 12,2 & - & 62 & 56 & 334558 & 360858,4 \\
\hline Linha 1 & 29 & 24,5 & 43 & 17 & 424116 & 457410,9 \\
\hline \multirow[t]{2}{*}{ Linha 2} & 31,5 & 27 & 50 & 21 & 224089,6 & 240032,8 \\
\hline & & & & & Total & 1058302,2 \\
\hline
\end{tabular}

Fonte: Autores(2019) 


\section{METODOLOGIA}

Inicialmente, foi elaborado um cronograma de execução das tarefas para o estudo de mobilidade, fazendo a revisão bibliográfica e definindo as estratégias para fazer o levantamento de dados e resultados. Definiuse que era necessário a elaboração de uma pesquisa entrevistando a comunidade acadêmica.

Para elaborar o questionário foi levado em conta as preferências da comunidade, tais como os meios mais usados para se deslocar e períodos de utilização dos mesmos. 0 método utilizado para a elaboração e coleta de dados do mesmo foi o Google Forms, uma plataforma que disponibiliza alguns métodos para a criação de formulários. Dentre as questões abordadas estão:

- $\quad 0$ meio de transporte utilizado pela comunidade;

- $\quad$ A frequência dos que vão ao campus;

- $\quad$ O turno em que vão ao campus;

- $\quad 0$ tempo de deslocamento para o campus;

- $\quad 0$ tempo de deslocamento do campus para casa ou trabalho.

- A utilização dos veículos disponibilizados pela universidade.

Por meio de consulta a comunidade acadêmica, em especial aos discentes (maior parte do campus) verificou-se as questões acima e obteve-se um total de 224 respostas.

Ao considerar que a mobilidade da UFAM tem sido atendida em um formato convencional de transportes, sendo na maioria dos casos dos grupos de estudantes que utilizam os coletivos e em partes veículos próprios ou de aplicativos. No caso em estudo, avaliamos o nível de emissões de $\mathrm{CO}_{2}$ no sistema de mobilidade dos discentes que usam o transporte coletivo.

\subsection{MÉTODO TOP-DOWN DE CÁLCULO DA EMISSÃO DE $\mathrm{CO}_{2}$}

O método top-down, apresentado por Álvares \& Link ( 2001)é uma forma de estimar a quantidade de emissões de Gases de Efeito Estufa através de três passos, tendo como para cálculo os dados de produção e consumo de energia.

O primeiro passo é utilizado para efetuar o Cálculo do Consumo de Energia (CC):

$$
C C=C A \cdot F_{\text {conv }} \cdot 45,2 \cdot 10^{-3} \cdot F_{\text {conv }}
$$

Onde:

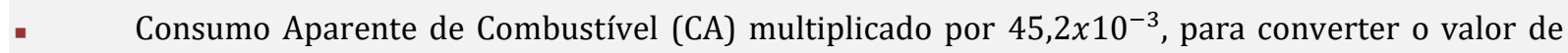
energia de $1 \mathrm{t} E P$ brasileiro para terajoule (TJ).

- $\quad$ Fator de Conversão $F_{(\text {conv })}$, varia de acordo com o combustível utilizado.

- Fator de Correção $F_{(c o n v)}$, muda de acordo com a fase química que se encontra o combustível. 0 Fator de correção estabelecido para combustíveis sólidos e líquidos o Fcorr = 0,95.

O segundo passo é o cálculo da Quantidade de Carbono (QC): 


$$
Q C=C C \cdot F_{\text {emiss }} \cdot 10^{-3}
$$

Onde:

- $\quad$ CC é o consumo de energia, resultado da equação anterior;

- $\quad F_{\text {emiss }}$ é fator de emissão de carbono (tC/TJ), para o diesel o valor do IPCC, 1996 e MCT, 1999 do Femiss é de 20,2 tC/TJ;

- $10^{-3}$ é o fator de conversão para gigagramas de carbono (GgC).

Por fim, o terceiro passo é o cálculo das Emissões de $\mathrm{CO}_{2}$ (ECO2). Baseado na quantidade de carbono existente em uma molécula de $\mathrm{CO}_{2}$, desta forma, é multiplicada a quantidade de carbono (QC) pela razão do peso molecular do dióxido de carbono e do carbono.

$$
E C O_{2}=Q C \frac{44}{12}
$$

\section{CONCLUSÃO}

0 atual sistema de mobilidade aplicado na universidade vem se mostrando ineficiente como mostrado no gráfico 1 , cerca de $22 \%$ da comunidade acadêmica tem optado pelo uso de veículo individual, o que contribui para o aumento de emissão de gases poluentes. Além do atual sistema existente, a universidade não possui nenhum outro meio de compartilhamento de veículos para seus discentes e docentes, o que dificulta no deslocamento pelo campus, devido as suas dimensões.

Cerca de $75 \%$ da população do campus utiliza o transporte público para se deslocar para o campus e do campus, tendo em vista a existência de sistema de transporte público disponível para todos. 0 que leva-se a crer que o serviço que está sendo prestado não está satisfazendo a comunidade e deve ser investigado medidas de melhoria.

Quando questionados sobre o tempo em que levam para se deslocar do campus e para o campus, obtevese em sua maioria tempos bastante elevados e pode ser observado as condições dos veículos e de vias, o que implica em uma certa perda no nível de serviço, o que gera desconforto ao usuário, pois o mesmo pretende fazer sua viagem de forma segura e rápida. Quanto aos energéticos e dos níveis de emissões do sistema. Pode ser observado, que o sistema pode ser mais eficiente, e gerar menos externalidades negativas, no que se referea emissão de material particulado e $\mathrm{CO}_{2}$. Se considerado a pegada ecológica para este serviço no campus, a Universidade Federal tem uma área arborizada de 700 hectares que por ser uma área de mata já desenvolvida, não é expressiva no resgate de carbono. Mas, é um fator positivo.

\section{REFERÊNCIAS}

[1] Acessoria de Comunicação - Ufam. Vídeo Institucional Ufam. 2017(1m24s). Disponível em :< https://www.youtube.com/watch?v=olhfwZ14Ciw>. Acesso em: 14 de out. 2019.

[2] Acessoria de Comunicação - Ufam. Ufam, 110 anos Construindo o Futuro na Amazônia. (2m10s). Disponível em :<https://www.youtube.com/watch?v=AR8Z-S4HMro >. Acesso em: 14 de out. 2019.

[3] Álvares JR, O. de M.; Linke, Renato Ricardo Antônio. Metodologia simplificada de cálculo das emissões de gases do efeito estufa de frotas de veículos no Brasil. São Paulo: Cetesb, v. 182, 2001.

[4] Caragliu, Andrea; Del Bo, Chiara F. Smart innovative Cities: The impactofSmartCity policies on urban innovation. Technological Forecasting and Social Change, v. 142, p. 373-383, 2019.

[5] Dell'olio, Luigi et al. A methodology to promote sustainable mobility in college campuses. Transportation Research Procedia, v. 3, p. 838-847, 2014.

[6] Kaplan, David H. Transportation sustainability on a university campus. International Journal of Sustainability in Higher Education, v. 16, n. 2, p. 173-186, 2015.

[7] Kumar, Harish et al. Moving towards smart cities: solutions that lead to the smart city transformation framework. Technological forecasting and social change, 2018.

[8] Yigitcanlar, Tan et al. Understanding 'smart cities': Intertwining development drivers with desired outcomes in a multidimensional framework. Cities, v. 81, p. 145-160, 2018. 


\section{Capítulo 10}

Aplicação do Método THOR ao problema de seleção de um Enterprise Resource Planning (ERP) para uma fábrica de tortas

\section{Rachel Medina Trindade}

Thays Marques Rodrigues

Marcos dos Santos

Fabricio Maione Tenório

Angélica Rodrigues de Lima

Carlos Francisco Simões Gomes

Resumo: 0 presente estudo tem como objetivo selecionar um ERP a partir da aplicação do método de apoio a decisão multicritério THOR para uma fábrica produtora de tortas localizada na cidade do Rio de Janeiro. A seleção do sistema ERP contribuirá para que a empresa consiga unificar os dados dos processos e proporcionar uma significativa melhora na gestão dos negócios. Um sistema Enterprise Resource Planning (ERP) tem o objetivo de amparar e unir informações de toda a empresa. 0 compartilhamento de informações entre o chão de fábrica e os sistemas de gestão pode permitir que os fabricantes alcancem novos níveis de eficiência. O ERP contribui para definir padrões que serão aplicados. Ajuda, de modo especial, na centralização das informações da fábrica em apenas uma fonte de dados, a partir da qual são geradas informações para diferentes setores; essa estratégia reduz a margem de erros, pois todas as informações estarão integradas entre si, o que facilita a análise e a tomada de decisões. Uma das mais importantes vantagens do ERP é que permite a integração entre todos os setores, tornando mais fácil a gestão de produção, integrando máquinas, identificando e tratando os pontos mais graves, ajudando a reduzir custos e estoques, monitorar refugos e aprimorar os prazos de entrega.

Palavras-chave: Método de Apoio a Decisão; Método THOR; Enterprise Resource Planning (ERP). 


\section{INTRODUÇÃO}

O cenário de globalização e o avanço da tecnologia tornaram o mercado ainda mais competitivo, despertando a atenção das micro e pequenas empresas para o investimento em recursos que possibilitam o crescimento e aumento da competitividade. Sendo assim, investir em um sistema de gestão, como os softwares, é bastante relevante para os empresários, pois proporciona o controle eficiente das tarefas financeiras, fluxos de trabalho, gestão de entrega, gestão de estoque e outros elementos que estão presentes nas atividades da empresa.

Mendes (2007) define um ERP (Enterprise Resource Planning) como a combinação das práticas, procedimentos e processos utilizados em uma empresa ou organização para implantar suas políticas de gestão, de modo a ser mais eficiente na obtenção e alcance dos objetivos proveniente delas do que quando há diversos sistemas individuais atuando ao mesmo tempo. Na visão de Moraes et al, (2004), o ERP é uma ferramenta de suporte à gestão da informação na pequena empresa, pois ele possibilita a automatização de tarefas, auxiliando o controle das operações, coletando e fornecendo dados e informações em tempo real e, desse modo, auxiliando a tomada de decisão e gerenciamento estratégico do negócio, aumentando a capacidade dos gerentes e administradores da empresa de encontrar e resolver antecipadamente os problemas referentes a processos, operações e planejamento da empresa.

O ERP auxilia a empresa na redução de custos e obtenção de lucro, gerando um ganho de produtividade, visibilidade da empresa pelo mercado, uma forma mais eficaz de relacionamento com clientes e fornecedores, e mais uma série de fatores que, conjuntamente, geram o crescimento da empresa e consolidam sua marca no mercado.

Dentro desse contexto, o presente estudo irá selecionar, por meio da aplicação do método de apoio a decisão multicritério THOR, um sistema ERP (Enterprise Resource Planning) que atenda e seja adequado às necessidades operacionais de uma pequena fábrica de tortas localizada na cidade do Rio de Janeiro.

\section{DESCRIÇÃO DO PROBLEMA}

O presente trabalho estuda sobre o problema da empresa de pequeno porte chamada Fábrica de Tortas Nene, localizada em Mesquita, na baixada do Rio de Janeiro. A fábrica produz tortas e bolos, e contém uma cartela de clientes e revendedores obtendo produção sobre pedido realizado, a mesma contém uma deficiência na gestão de estoque que prejudica na produção e no controle dos materiais em estoque.

Em pequenas empresas, ainda é comum à utilização de planilhas para o controle de finanças e estoques. Tal método funciona enquanto a empresa dá seus primeiros passos, mas se mostra deficitário conforme a evolução do negócio, contando que as contratações e o volume de operações aumentam e então começa a ocorrer divergências entre números financeiros, produção, estoque e gestão. Os riscos e impactos com esse método de controle podem ser agudos e críticos, trazendo problemas como: perda de documentos e informações importantes, multas por falta de organização, falta de uma visão consolidada dos processos da empresa (o que limita o crescimento), perda de insumos por deficiências no controle do estoque, perda de tempo para tentar localizar onde estão as falhas que levaram a esses problemas e, sobretudo, problemas na tomada de decisão.

Seguindo essa forma de controle, o gestor apenas terá informações competitivas e importantes se os dados se mantiverem organizados e interligados entre si. A integração facilita o acesso aos dados de diferentes áreas e oferece maior transparência no diagnóstico e tomada de decisão. Baseado nisso, um sistema integrado traria maiores benefícios para a empresa e também ajudaria o gestor a manter a ordem e o controle.

Em um negócio, a falta de controle pode ser o causador de muitos problemas que afetam o crescimento e faturamento da empresa. Quando não há controle dos materiais, se torna mais difícil planejar a aquisição dos mesmos, o que torna vulnerável à compra dos insumos no varejo afetando diretamente a margem de lucro dos produtos finais. Além de ocasionar a falta de certos materiais, expondo a fábrica a pedidos que não poderão ser atendidos. Desta forma, o cliente insatisfeito irá preferir comprar em concorrentes. Podemos citar também, os produtos obsoletos que por estar a muito tempo em estoque, podem estar com prazos de validade vencidos, e a utilização destes produtos submete a organização a ações judiciais. A Nene Tortas, por ser uma fábrica de pequeno porte onde não se encontra uma gestão capaz controlar com eficiência o estoque de insumos, está vulnerável a tais problemas. A Figura 1 abaixo expõe de maneira mais clara todos os problemas que a empresa esta enfrentando: 
Figura 3: Mapa mental dos problemas da fábrica.

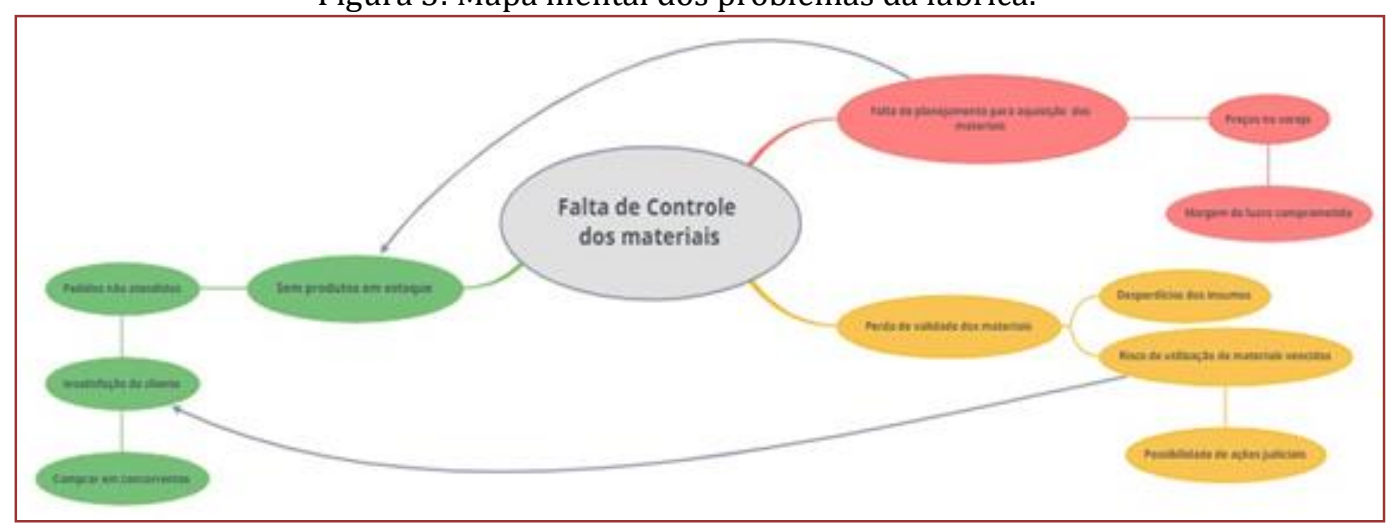

Fonte: Autores (2019).

Santos et al. (2013) afirmam que a Pesquisa Operacional (PO) lança mão de modelos matemáticos e/ou lógicos, com o objetivo de resolver problemas de dentro das organizações, apresentando um caráter eminentemente multidisciplinar. A escolha de um software corporativo pode tornar-se uma tarefa árdua para o gestor de uma pequena fábrica que ainda não compreende quais as funcionalidades o ERP deve obter para o sucesso do negócio. Afinal, o sistema ERP deve estar alinhado aos objetivos e ao perfil do empreendimento, permitindo que suas funções se integrem cada vez mais à cadeia operacional e, com isso, facilitando a criação de fluxos de trabalho mais ágeis e com menos erros.

Na Figura 2, é apresentado um mapa mental elaborado para facilitar a visualização das condições de contorno do problema proposto.

Figura 4: Mapa mental com as condições de contorno do problema

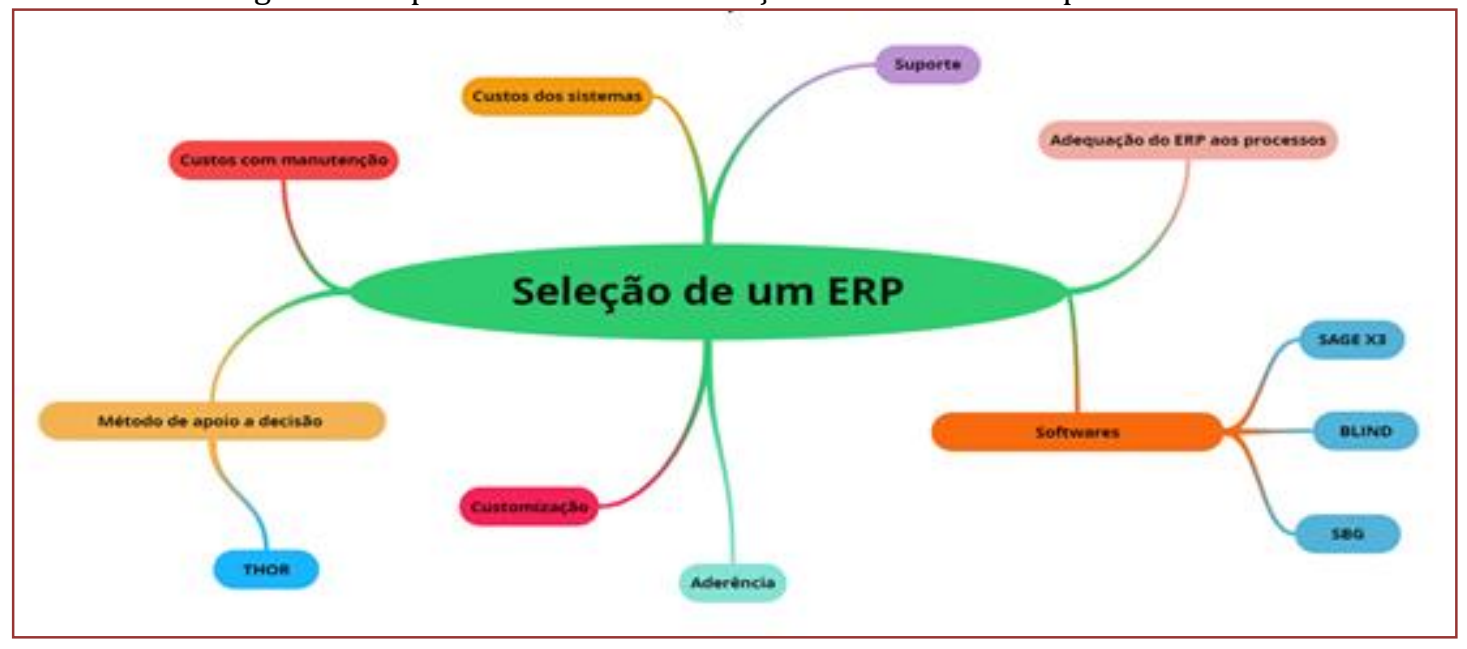

Fonte: Autores (2019).

Aplicar o método de apoio a decisão multicritério THOR que irá organizar e situar os principais critérios e as alternativas disponíveis no mercado, auxilia significantemente o processo decisório, dispondo as informações de forma clara e concreta para que o gestor tome decisões de forma assertiva e aderente ao cenário da empresa.

\section{FUNDAMENTAÇÃO TEÓRICA}

\subsection{GESTÃO DE ESTOQUE}

\subsection{ENTERPRISE RESOURCE PLANNING (ERP)}

De acordo com Souza (2000), Enterprise Resource Planning (ERP) são sistemas de informação integrados que tem o objetivo de dar suporte a maioria das operações de uma empresa e são geralmente divididos em módulos que se comunicam e atualizam uma base de dados central, que envolve diversos setores, de modo que a informação que foi alimentada em um módulo é disponibilizada para os módulos que dela depende, 
instantaneamente. Os sistemas ERP permitem ainda a utilização de ferramentas de planejamento que podem analisar o impacto de decisões de produção, matéria prima, finanças ou recursos humanos em toda empresa.

O ERP é um software que permite a integração das informações que surgem pela empresa, esse sistema determina sua própria lógica à estratégia, à cultura e a à organização da instituição. É uma sistemática que procura atender a todo tipo de companhia e seu projeto reflete uma série de possibilidades sobre como operam as organizações e é preparado para desenvolver as melhores práticas de negócio, porém fica a critério do cliente para definir a melhor prática e atender às suas necessidades (DAVENPORT, 1998). Existem áreas específicas que o sistema ERP interliga, segue a Figura 3 abaixo que está representando as áreas de integração do sistema.

Figura 5: Integração entre as principais áreas de uma empresa.

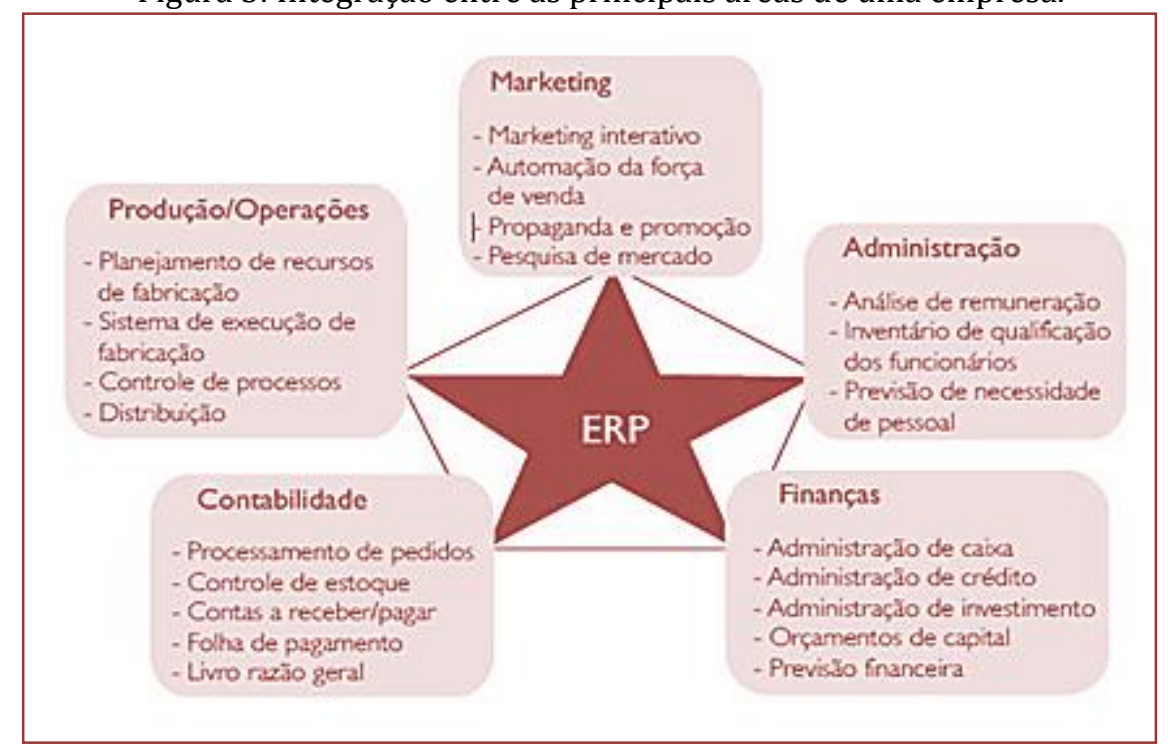

Fonte: O’Brien (2007).

Colangelo Filho (2001) também define as principais áreas de aplicação dos sistemas ERP, que são: Finanças e Controles (Contabilidade financeira, contas a pagar, contas a receber, ativo imobilizado, orçamentos, contabilidade gerencial, custos e análise de rentabilidade), Operações e Logísticas (Suprimentos, administração de materiais, gestão da qualidade, planejamento e controle de produção, Custos de produção, previsão de vendas, entrada de pedidos, faturamento, gestão de projetos) e Recursos Humanos (Recrutamento e seleção de pessoal, treinamentos, benefícios, desenvolvimento pessoal, medicina e segurança do trabalho, remuneração e folha de pagamento.

\subsection{PESQUISA OPERACIONAL E O APOIO À DECISÃO}

A Pesquisa Operacional é uma ferramenta matemática que auxilia no processo de tomadas de decisão em situações reais, é bastante empregada como ferramenta no apoio a decisão quando há enfrentamento dos problemas no ambiente de negócios (Barbosa e Zanardini, 2015).

Santos et al, (2016) afirmam que a Pesquisa Operacional atua em cinco grandes áreas que se interrelacionam, conforme apresentado na Figura 4. 
Figura 6: Áreas da Pesquisa Operacional.

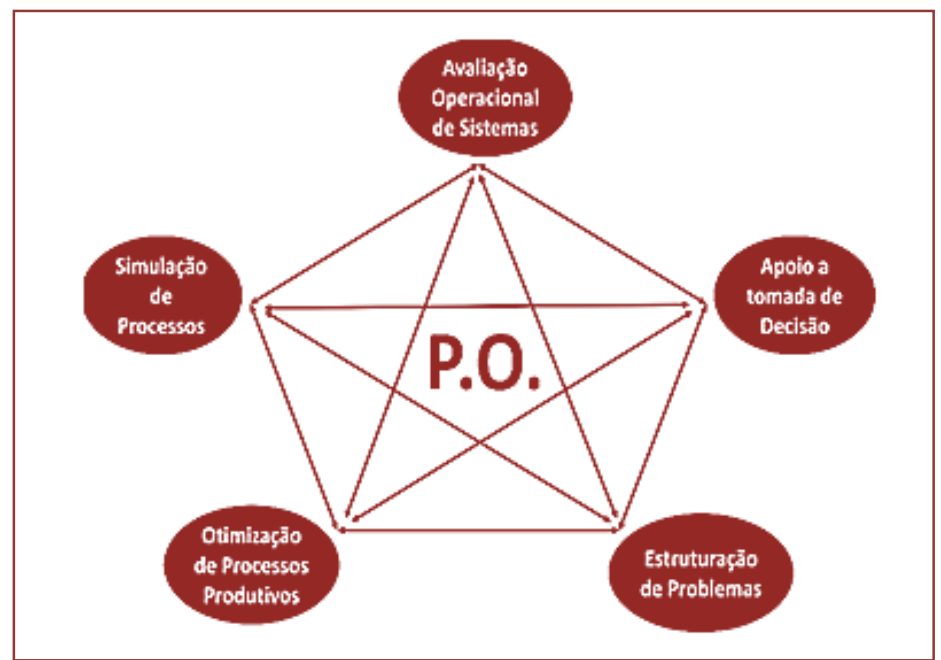

Fonte: Santos et al. (2016)

Importante abordar que, apesar de obter diversas áreas de PO, somente uma dessas foi abordada no presente estudo: Apoio à tomada de decisão.

\subsection{O MÉTODO THOR}

O THOR é um método de apoio multicritério à decisão que tem o objetivo de ordenar as alternativas, por meio de um processo de decisão, eliminando os critérios redundantes com a utilização da TCA (Teoria dos Conjuntos Aproximativos), e verifica se existem informaç̧ões duplas, imprecisão dos processos de decisão e sua quantidade (Gomes, 1999).

Para Gomes e Costa (2011), o sistema é baseado em três algoritmos: Modelagem de Preferência; Teoria da Utilidade e; Teoria de Multiatributo. Através da utilização destas teorias, é permitido quantificar a atratividade de uma alternativa por meio da criação de uma função agregação não-transitiva. 0 THOR ainda permite analisar de forma rápida e eficiente as alternativas, considerando na análise o nãodeterminismo do processo de atribuição de pesos, quantificando o não-determinismo e o reaplicando no processo de ordenação das alternativas.

Segundo Gomes (1999), O THOR exerce as seguintes contribuições:

- Apresenta um algoritmo híbrido que integra simultaneamente os conceitos do TCA, teoria dos Conjuntos Nebulosos (TCN) e Teoria da Utilidade e modelagem de Preferências;

- $\quad$ Ordena alternativas discretas em processos decisórios transitivos ou não;

- Elimina os critérios que são redundantes considerando que se existe dualidade na informação através do TCA e se ocorre imprecisão no processo decisório por meio da Teoria dos Conjuntos Nebulosos;

- Quantifica a imprecisão utilizando o AMD;

- Permite juntamente a entrada de dados de diferentes decisores, possibilitando que expressem seu(s) juízo(s) valor em escala de razões, intervalo ou ordinal. 0 decisor pode executar o método sem atribuir pesos aos critérios; elimina a necessidade de determinar um valor, de alguns algoritmos que se baseiam na Modelagem de Preferência.

Inicialmente é necessário que se estabeleça as alternativas para a decisão e os critérios necessários para medir cada alternativa, a partir disso segue os parâmetros de determinação para a utilização do método.

Para que seja aplicado, há a necessidade do decisor estabelecer a relevância (em peso), uma preferência (p) e uma indiferença (q) de cada critério, concluindo com a definição da discordância. Vieira et al (2006, apud Tenório, Dos Santos e Gomes, 2019) explica que determinar uma discordância para os critérios se compara a não existência de parâmetros em que a intensidade de favoritismo entre uma e outra não exceda um limite considerável.

Tenório, Dos Santos e Gomes (2019) afirmam que se faz necessário medir o nível de certeza dos decisores, 
sendo ele relacionado de 0 a 1 . Essa definição ajuda a medir a certeza do peso de cada critério, estabelecendo um índice de certeza igual a 1, significa que o decisores estão seguros sobre o peso dado ao critério e um índice de certeza igual a 0 , significa a total falta de certeza do decisores sobre o peso estabelecido.

Segundo Gomes (1999) existem três definições que determina uma alternativa melhor que a outra, representadas pelas equações a seguir:

$\mathrm{S} 1: \sum_{j=1}^{n}\left(w_{j} \mid a P_{j} b\right)>\sum_{j=1}^{n}\left(w_{j} \mid a Q_{j} b+a I_{j} b+a R_{j} b+b Q_{j} a+b P_{j} a\right)$
$\mathrm{S} 2: \sum_{j=1}^{n}\left(w_{j} \mid a P_{j} b+a Q_{j} b\right)>\sum_{j=1}^{n}\left(w_{j} \mid a I_{j} b+a R_{j} b+b Q_{j} a+b P_{j} a\right)$
$\mathrm{S} 3: \sum_{j=1}^{n}\left(w_{j} \mid a P_{j} b+a Q_{j} b+a I_{j} b\right)>\sum_{j=1}^{n}\left(w_{j} \mid a R_{j} b+b Q_{j} a+b P_{j} a\right)$

Segundo Tenório, Gomes e Santos (2019), entende-se que para uma alternativa ser melhor, fazem-se necessárias três situações: S1, S2 e S3. Sendo a primeira situação (S1), a atratividade ocorre em situações onde aPjb, comparando a alternativa 1 com outras alternativas, a 1 será comparada levando em consideração os limites de preferência, indiferença e discordância, e assim identificando se a condição é satisfatória. Nos casos de satisfatória, descobre-se que a alternativa 1 é melhor que a 2. Na segunda situação (S2), sua atratividade ocorre em situações onde aPjb e aQjb e na situação terceira (S3), a atratividade ocorre aPjb, aQjb e aljb.

De acordo com Rangel e Gomes (2010), as duas últimas situações comparam diferenças mínimas onde é possível uma ser melhor que a outra.

Existe uma relação entre p, q e discordância que está expressa abaixo:

$$
\begin{aligned}
\mathrm{aPb} & \leftrightarrow \mathrm{g}(\mathrm{a})-\mathrm{g}(\mathrm{b})>\mathrm{p} \\
\mathrm{aIb} & \leftrightarrow-\mathrm{q} \leq \operatorname{gg}(\mathrm{a})-\mathrm{g}(\mathrm{b}) \mid \mathrm{q} \\
\mathrm{aQb} & \leftrightarrow \mathrm{q}<|\mathrm{g}(\mathrm{a})-\mathrm{g}(\mathrm{b})| \leq \mathrm{p}
\end{aligned}
$$

\section{ESTUDO DE CASO}

\subsection{LEVANTAMENTO DE DADOS}

Na função de ajudar no processo decisório da aquisição de um sistema integrado, utilizou-se o Método THOR embasado em cinco critérios levantados em conjunto com os proprietários:

- Manutenção: Trabalho realizado pela fornecedora do sistema escolhido que garante o funcionamento adequado dele. Essa manutenção pode acarretar novos custos à empresa; (Até R\$ 270,00)

- Custo do Sistema: É o investimento que a empresa terá para implantar o sistema escolhido. Este custo envolve todas as despesas de pré-implantação; (Até $\mathrm{R} \$ 1.000,00$ )

- Suporte: Este critério visa quantificar a qualidade do suporte oferecido, ou seja, tempo para solucionar uma dúvida, nível de resolução de problemas, entre outros; (Min de 24h de atendimento)

- Aderência: Neste critério se identifica o quão aderente o software será para que se obtenha a satisfação na implementação, isto é, para que se exija menos horas de consultoria especializada; (Implementado completamente em até 2 meses)

- Customização: Se relaciona as atividades realizadas no sistema, antes de sua implementação, com intuito de adequar procedimentos da empresa no mesmo. Através disso, este critério visa quando será necessário mudar cada alternativa. (Minimo 4 módulos)

Com base no levantamento dos critérios, foi repassado a realidade da empresa para um especialista em sistema integrado e através disso foram definidos os ERP no Quadro 1 abaixo 
Quadro 1: Descrição dos sistemas integrados escolhidos.

\begin{tabular}{|c|l|}
\hline Sistema & $\begin{array}{l}\text { Descrição } \\
\text { BLING }\end{array}$ \\
\hline SAGE X3 & $\begin{array}{l}\text { Software direcionado a micro e pequenas empresas que apresentam lojas virtuais, de preço } \\
\text { econômicos. }\end{array}$ \\
\hline SBG & $\begin{array}{l}\text { Software destinado a empresto mercado, bem comum e direcionado para vários segmentos } \\
\text { tendo clientes em vários locais no mundo. }\end{array}$ \\
\hline
\end{tabular}

Fonte: Autores (2019).

\subsection{MODELAGEM MATEMÁTICA: O MÉTODO THOR}

Para a implementação do método pode se fazer necessário mais de um decisor para apresentarem seus valores em escala de razões. Para sua aplicabilidade é preciso determinar pesos a cada critério. Após, devem-se estabelecer os limites de preferência $(p)$ e indiferença $(q)$ para cada critério e a discordância.

Para a implementação do método pode se fazer necessário mais de um decisor para apresentarem seus valores em escala de razoes. Para sua aplicabilidade é preciso determinar pesos a cada critério. Sabendo que o Decisor 1 e 2 são os proprietários da Fábrica de Tortas e são conhecedores de todos as necessidades e custos da empresa, o Decisor 3 é o funcionário que ajuda na gestão da loja.

Após realizou-se uma média aritmética dos pesos dados por cada decisor para se obter o peso médio de cada critério, de acordo com a Tabela 1.

Tabela 11: Definição dos pesos.

\begin{tabular}{|c|c|c|c|c|c|}
\hline \multirow{2}{*}{ Critérios } & Custo & $\begin{array}{c}\text { Manutenç } \\
\text { ão }\end{array}$ & Suporte & Customizaç ão & Aderência \\
\hline Decisor 1 & 5 & 4 & 3 & 1 & 0 \\
\hline Decisor 2 & 5 & 3 & 3 & 1 & 1 \\
\hline Decisor 3 & 5 & 5 & 4 & 1 & 0.5 \\
\hline Peso & 5 & 4 & 3.33 & 1 & 0.5 \\
\hline
\end{tabular}

Após a definição do peso com os decisores, pode-se relacionar os valores de cada critério referente à cada alternativa, de acordo com a Tabela 2 a seguir.

Tabela 12: Matriz de Decisão com critérios, alternativas e pesos.

\begin{tabular}{|c|c|c|c|c|c|}
\hline Pesos & 5 & 4 & 3.33 & 1 & 0.5 \\
\hline Critérios & $\begin{array}{c}\text { Custo } \\
(\leq \mathrm{r} \$ 1.000,00)\end{array}$ & $\begin{array}{l}\text { Manutenção } \\
(\leq r \$ 270,00)\end{array}$ & $\begin{array}{c}\text { Suporte } \\
(\geq 24 \text { horas })\end{array}$ & $\begin{array}{l}\text { Customização } \\
\text { ( } \geq 4 \text { módulos) }\end{array}$ & $\begin{array}{c}\text { Aderência } \\
(\leq 2 \text { meses })\end{array}$ \\
\hline Bling & $\mathrm{R} \$ 300,00$ & $\mathrm{R} \$ 45,00$ & 8 & 6 & 0,25 \\
\hline Sage x3 & $\mathrm{R} \$ 850,00$ & $\mathrm{R} \$ 250,00$ & 24 & 20 & 1,5 \\
\hline Sbg & $\mathrm{R} \$ 720,00$ & $\mathrm{R} \$ 150,00$ & 12 & 15 & 0,75 \\
\hline
\end{tabular}

Fonte: Autores. (2019)

Após, devem-se estabelecer os limites de preferência $(p)$ e indiferença $(q)$ para cada critério e a discordância, de acordo com a Tabela 3 abaixo:

Tabela 13: Definição de $P, Q$ e Discordância para cada critério.

\begin{tabular}{|c|c|c|c|c|c|}
\hline Critérios & \multicolumn{2}{c}{$\begin{array}{c}\text { Custo (r\$) } \\
\text { Manutenção } \\
(\mathrm{r} \$)\end{array}$} & $\begin{array}{c}\text { Suporte } \\
\text { (horas) }\end{array}$ & $\begin{array}{c}\text { Customizaçã } \\
\text { o(modulos) }\end{array}$ & $\begin{array}{c}\text { Aderênci } \\
\text { a (meses) }\end{array}$ \\
\hline$P$ & 400 & 100 & 4 & 10 & 1,5 \\
\hline$Q$ & 150 & 50 & 1 & 5 & 0,75 \\
\hline Discor. & 600 & 225 & 25 & 45 & 4 \\
\hline
\end{tabular}

Fonte: Autores. (2019) 
Com a utilização de um software desenvolvido em Python no Instituto Militar de Engenharia (IME), chamado THOR 1, que é capaz de calcular exatamente os dados colocados, aplicando o método usado no presente estudo, foram imputados os dados registrados na Tabela 1,2 e 3.

Incluiu-se a quantidade de alternativas e critérios dentro do fator de decisão: BLING, SAGE X3 e SBG. E cinco critérios: Custo, Manutenção, Suporte, Customização e Aderência. Após, incluiu-se o valor de peso, $P$, $Q$ e a discordância de cada critério, conforme Figura 5 a seguir.

Figura 7: Alternativas e critérios inseridos no software desenvolvido no IME.

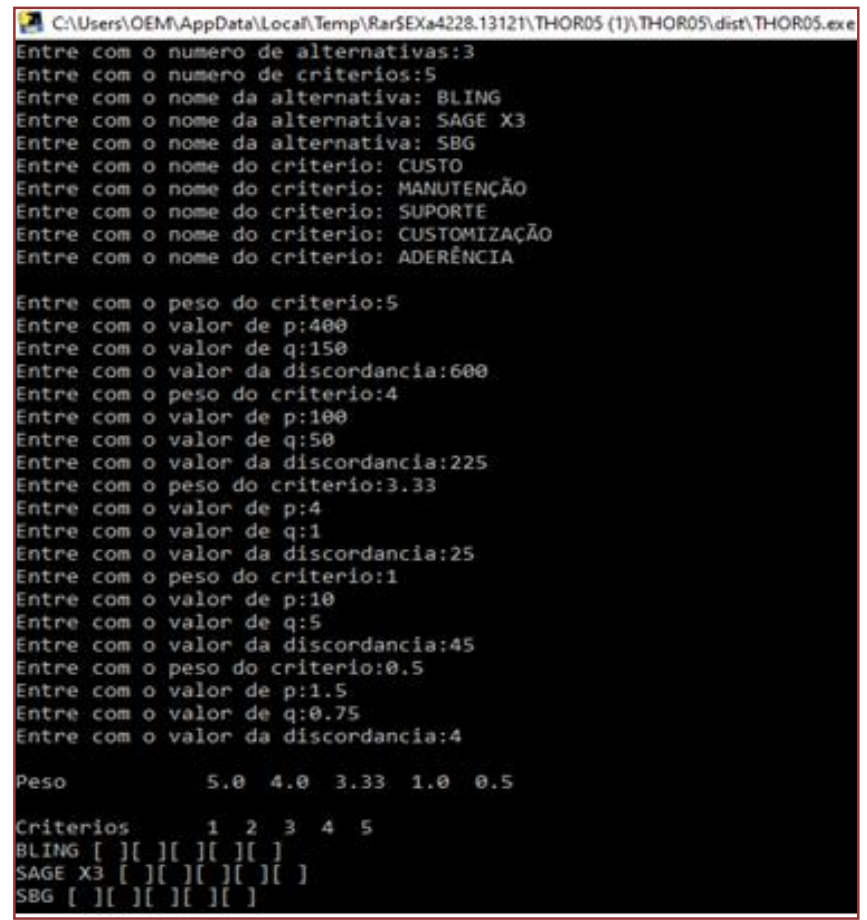

Fonte: Autores (2019).

Incluiu-se no sistema, Figura 6, os valores referentes a cada critério registrados anteriormente na Tabela 3.

Figura 8: Preenchimento da Matriz de Decisão.

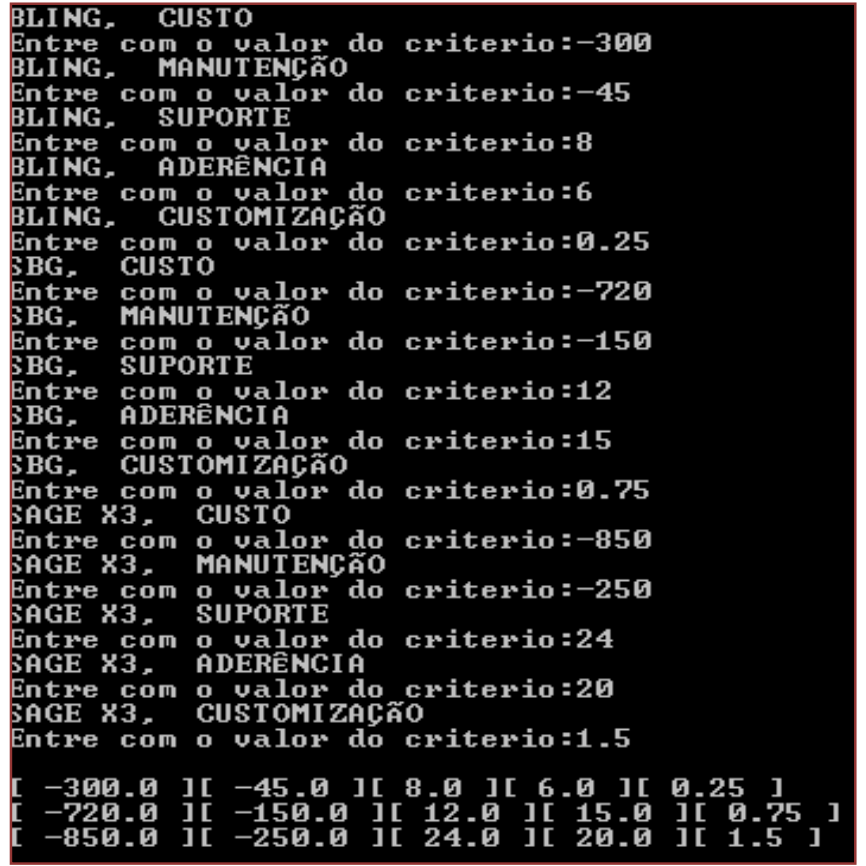

Fonte: Autores (2019). 
Na Figura 7, são apresentados os resultados apresentados pelo sistema:

Figura 9: Resultados do método THOR apresentados pelo sistema

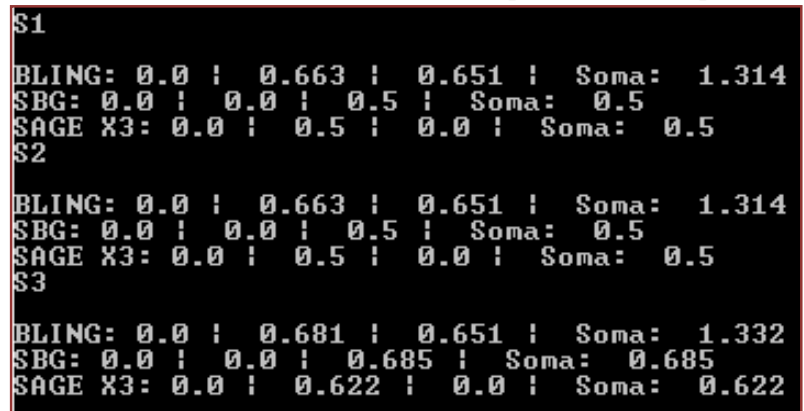

Fonte: Autores (2019)

\section{RESULTADOS E DISCUSSÕES}

Os resultados encontrados através do sistema foram: BLING como o que melhor atendeu ao processo decisório, após o SBG e SAGE X3.]

Conforme os resultados, SAGE X3 apresentou pouca significância para o negócio estudado, mesmo sendo ele totalmente direcionado para diversos segmentos e tendo uma relevância significativa para setores comercias, facilitando formas de vendas e pagamentos. Porém foram atribuídos pesos maiores para os critérios de custo de aquisição e manutenção, por isso a perda do SAGE X3 foi notória desde o início por apresentar o maior custo dentre os dois critérios.

Baseado ainda nos resultados, o SBG obteve um resultado intermediário, apesar de ser utilizado em microempresas e até em multinacionais, porém ainda assim esse sistema obtém um alto custo de aquisição para a empresa e apesar de ter um custo menor de manutenção que o SAGE X3, ainda assim, com os maiores pesos sendo em manutenção e custo de aquisição, ele não teve um resultado esperado, porém seria uma $2^{\circ}$ opção para a empresa.

BLING foi o sistema que melhor se adequou aos critérios pontuados pelos decisores. Por ser uma empresa de pequeno porte e em crescimento, esse software atende bem as necessidades da empresa com relação aos controles importantes para que a mesma consiga se desenvolver e crescer ainda mais.

\section{CONCLUSÃO}

Com base nos fatos expostos, pode-se concluir o quão importante é um método de apoio à decisão para cooperar com a escolha de uma determinada necessidade em uma empresa, sendo este micro, pequeno, médio ou grande porte.

0 método de apoio à decisão multicritério THOR foi aplicado de modo satisfatório e apoiou totalmente os gestores na tomada de decisão do sistema. O software ERP BLING mostrou-se mais adequado às necessidades da empresa estudada no atual momento da empresa, e como foi abordado no desenvolvimento do estudo, BLING é um ERP voltado à micro e pequenas empresas e possui um baixo custo de aquisição e manutenção, tais critérios foram fortes atrativos para os decisores.

Com a aplicação do método e a utilização da ferramenta THOR 1, o processo decisório apresentou informações claras facilitando e norteando a tomada de decisão dos gestores.

Como trabalho futuro, seria de suma importância acompanhar o crescimento da empresa, porque no atual momento, o software escolhido atende perfeitamente, porém através do crescimento da mesma existe a possibilidade de surgir novas demandas, por isso, será necessário um novo estudo para um momento futuro da empresa. 


\section{REFERENNCIAS}

[1] Barbosa, M.A. \& Zanardini, R.A.D. Iniciação à pesquisa operacional no ambiente de gestão. 2. ed. Curitiba, PR: Intersaberes, 2015.

[2] Colangelo Filho, Lucio. Implantação de Sistemas ERP (Enterprise Resources Plan- ning): um enfoque de longo prazo. São Paulo: Atlas, 2001.

[3] Davenport, T. H. Putting the enterprise into the enterprise system. Harvard Business Review, p.121-131, jul./aug.1998.

[4] Gomes, C. F. S. Thor - um algoritmo híbrido de apoio multicritério à decisão para processos decisórios com alternativas discretas. 1999. Tese (Doutorado em Engenharia de Produção) - Universidade Federal do Rio de Janeiro, Rio de Janeiro, 1999.

[5] Gomes, C. F. S.; Costa, H. G. Aplicação de Métodos Multicritério ao Problema de Escolha de Modelos de Pagamentos Eletrônicos por Cartão de Crédito. In: Simpósio Brasileiro de Pesquisa Operacional (SBPO), 43., 2011, Ubatuba. Anais. Ubatuba: Sociedade Brasileira de Pesquisa Operacional, 2011.

[6] Mendes, J. V.; Escrivão Filho, E. Atualização tecnológica em pequenas e médias empresas: proposta de roteiro para aquisição de sistemas integrados de gestão (ERP). Gestão e Produção, v.14, n.2, p.281-293, mai-ago.2007.

[7] Moraes, G. D. A.; Terrence, A. C. F.; Escrivão Filho, E. A Tecnologia da Informação como suporte à gestão estratégica da informação na pequena empresa. Revista de Gestão da Tecnologia e Sistemas de Informação, Vol. 1, No. 1, p 28-44, 2004.

[8] Rangel, L. A. D.; Gomes, L. F. A. M. O Apoio Multicritério de Decisão na avaliação de candidatos. Production. Associação Brasileira de Engenharia de Produção. v. 20, n. 1, p. 92-101, 2010.

[9] Santos, Marcos dos; Martha, Leonardo da Costa; Quintal, Renato Santiago; Martins, Ernesto Rademaker. Redimensionamento da Linha de Produção de uma Fábrica de Sacos de Lixo Empregando Simulação de Eventos Discretos. Caderno de Cultura e Ciência, Ano XI, v.15, n.1, 2016.

[10] Santos, Marcos. Simulação da Operação de um Sistema Integrado de Informações para o atendimento préhospitalar de emergência no município do Rio de Janeiro. Dissertação de M.Sc., COPPE/UFRJ, Rio de Janeiro, Brasil, 2013.

[11] Souza, Cezar Alexandre de. Sistemas integrados de gestão empresarial: estudos de caso de implementação de sistemas ERP. Dissertação (Mestrado) - Faculdade de Economia e Administração, Universidade de São Paulo, São Paulo: FEA / USP, 253 p. (2000)

[12] Tenorio, F. M., Araujo, J. C., Santos, M., C.F.S. (2019). Thor 1 [Computer Software]. Rio de Janeiro.

[13] Tenorio, Fabricio Maione; Santos, Marcos dos; Gomes, Carlos Francisco Simões. Revisitando o método Thor: uma pesquisa bibliométrica. In: Simpósio de Pesquisa Operacional e Ogística da Marinha, 19., 2019, Rio de Janeiro, RJ. Anais [...]. Rio de Janeiro: Centro de Análises de Sistemas Navais, 2019.

[14] Vieira, G. B. B. et al. Identificação de hub ports na costa brasileira - uma comparação entre a análise conjunta e o sad-thor. In: XXXVIII Simpósio Brasileiro de Pesquisa Operacional. Goiânia, GO: Sociedade Brasileira de Pesquisa Operacional, 2006. p. 984-995. 


\section{Capítulo 11}

Aplicação do Método SAPEVO-M para seleção de uma transpaleteira em uma Empresa do Setor Moveleiro RJ

\section{Cristiano da Silva Severino}

Lucas Santiago de Sousa

Marcos dos Santos

Rubens Aguiar Walker

Resumo: Nos dias atuais, com o desenvolvimento da tecnologia e um cenário econômico cada vez mais acirrado, as empresas têm buscado por eficiência e agilidade na execução dos serviços e na fabricação dos seus produtos. Diante deste cenário, o presente trabalho busca eleger um modelo de transpaleteira que esteja de acordo com as necessidades da empresa Noah Varejo S.A, a qual se encontra com dificuldades no transporte e armazenamento dos produtos, com a ergonomia dos operadores e com as transpaleteiras que transportam as cargas de forma inadequada. Para obter o resultado proposto neste trabalho será apresentado e utilizado o método SAPEVO-M, que irá verificar e demonstrar qual a melhor transpaleteira entre três modelos, que possuem múltiplos critérios e decisores diferentes. A seleção da transpaleteira será de crucial importância, uma vez que possui influência direta nas necessidades da empresa.

Palavras-Chave: Transpaleteira, Transporte de Produtos, Método SAPEVO-M. 


\section{INTRODUÇÃO}

Nos dias atuais, com o avanço da tecnologia e um cenário econômico mais competitivo, as empresas têm direcionado as estratégias e planejamentos para que possam reduzir gastos desnecessários, aumento de lucratividade e a produção e prestação de serviços em escalas maiores.Com esse contexto, os avanços tecnológicos nas indústrias possibilitaram a padronização dos produtos e gradualmente a produção deixou de ser feita de forma artesanal e passou a ser feita de forma industrializada (MELLO et al., 2009).

o comércio e produção internacional moveleira varejista apresenta uma disposição extremamente concentrada basicamente em 10 países, sendo estes 10 países representando $77 \%$ da produção mundial de móveis totais. Em primeiro lugar, destaca-se a China com 44,1\%, seguida dos EUA com 9,8\%, Alemanha com $4,6 \%$, Itália com $4,1 \%$ e o Brasil com $3,2 \%$. Neste cenário, o Brasil ocupa o quinto lugar dos principais produtores dos móveis.

De acordo com FIEP (2017), o segmento moveleiro brasileiro é constituído por 22.482 empresas, sendo que, a aglomeração principal do setor moveleiro varejista está localizada nas regiões Sul e Sudeste do País, reunindo aproximadamente 16.170 empresas (cerca de 77,1\%).

Conforme dados do IBGE 2015, o setor mobiliário brasileiro cresceu 21\% entre os anos de 2002 e 2015, e conforme dados do Ministério do Trabalho e Emprego 2011, o setor foi responsável por cerca de 269.000 empregos diretos, este valor representa 3,5\% do emprego formal da indústria de transformação brasileira.

0 valor bruto da produção mobiliária do Brasil chegou a 22,98 bilhões em 2010, conforme a Pesquisa Industrial Anual do IBGE, sendo que este valor representa 1,3\% do valor produzido pela indústria de transformação brasileira.

\section{DESCRIÇÃO DO PROBLEMA}

\subsection{AUMENTO DA PRODUTIVIDADE}

A Noah Varejo S.A é a empresa que opera marcas ícones do ramo moveleiro e que há décadas está presente no mercado varejista brasileiro.Segundo Gapski (2003), as organizações buscam aperfeiçoar seus processos relacionados à logística, sendo o armazenamento e transporte como fatores de total importância para a logística total. 0 aprimoramento tecnológico concedeu o desenvolvimento dos processos logísticos através de inúmeros métodos distintos, incluindo valores de qualidade, tempo, custos e do fluxo de informações nos processos.

Além desses problemas, o setor moveleiro é marcado pela desorganização funcional e gerencial do setor produtivo, e as principais perdas nestas atividades se relacionam ao desperdícios de recursos e de trabalho humano, o que acarreta uma baixa produtividade para o setor (Cenachi; Romeiro, 2004).

Segundo Kato (2003) o sucesso confirmado de uma organização empresarial ocorre quando o serviço ou produto é entregue ao devido cliente no momento e tempo ideal, de modo que tenha impactos visíveis e agregue valor. Desta forma, para as empresas alcançarem o devido sucesso as pesquisas efetuadas nos processos logísticos, a estratégia alcançou patamares relevantes, onde trouxeram novos horizontes para a visão holística de desempenho com foco em âmbito mundial.

Durante as rotinas operacionais da Noah Varejo S.A, foram constatados que o Centro de Distribuição 1401 apresenta dificuldades no processo de transporte e armazenamento dos produtos, problemas com a ergonomia dos operários da equipe interna do Centro de Distribuição que realizam as movimentações dos produtos e com as transpaleteiras que se encontram inadequadas para o suporte da cargas dos produtos envolvidos nestes processos. Tais fatos traziam um impacto negativo, onde afetavam diretamente no resultado de eficiência e eficácia da organização. 0 transporte e armazenamento inadequado pode ocasionar percas parciais e até totais nos produtos, gerando custos elevados, baixa produtividade, insatisfação dos clientes e gerando sobrecargas operacionais na área da logística reversa da empresa.

Desta forma, pode-se constatar que as transpaleteiras fazem parte de um processo crucial para a empresa visto que, podem contribui para o bom funcionamento dos principais processos do centro de distribuição e dos respectivos interesses da empresa, e por este motivo devem sempre estar em perfeitas condições de funcionamento e conservação. 
Verificou-se que os principais desperdícios eram oriundos do mau acondicionamento dos produtos nas transpaleteiras, e pelas características e dimensões das máquinas que não se adequam mais aos produtos que são entregues resultam em perda parcial ou total dos produtos que são entregues e que retornam para o Centro de Distribuição, sendo direcionados para o setor de logística reversa.

Com essas informações, estruturou-se os gráficos 1 e 2 dos desperdícios em valores (R\$) e em quantidades (unidades) nos meses de Agosto à Dezembro de 2018, para melhor entendimento e relevância para o processo, conforme figura abaixo:

\section{Gráfico 1: Valores de desperdícios de produtos (R\$)}

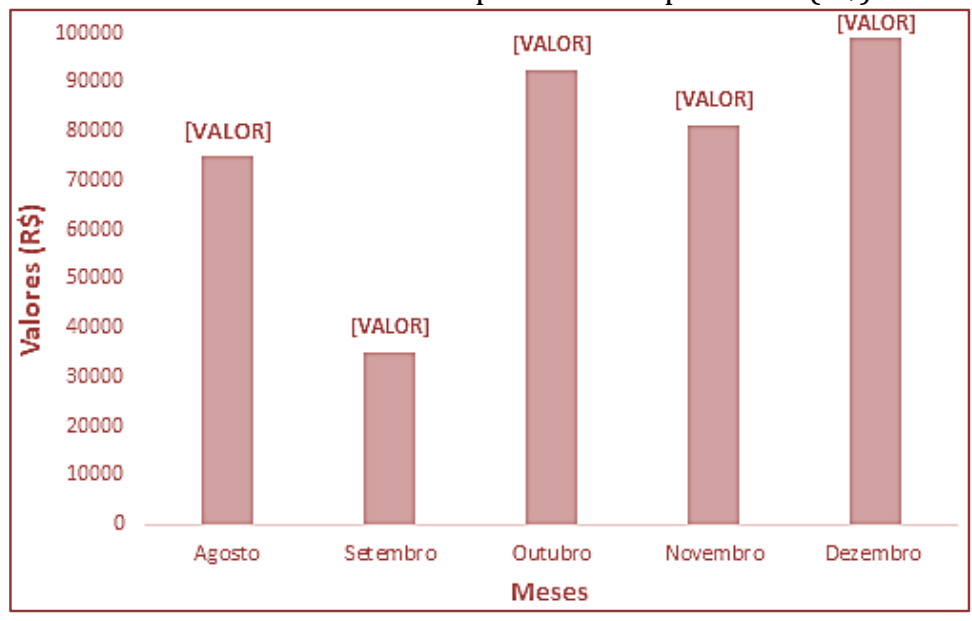

Fonte: Autores (2019)

Gráfico 2: Quantidade de desperdícios (Unidades)

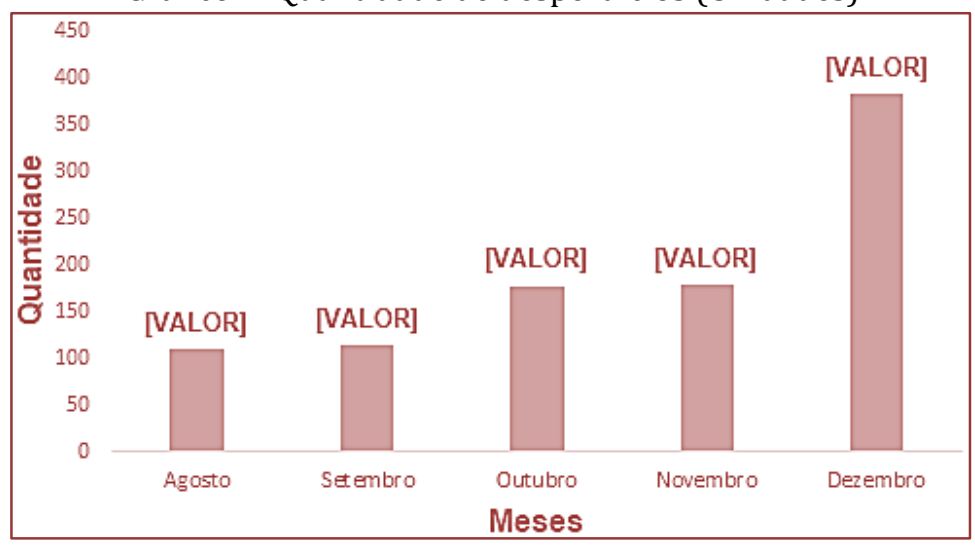

Fonte: Autores (2019)

\section{FUNDAMENTAÇÃO TEÓRICA}

\subsection{PESQUISA OPERACIONAL}

Segundo Hillier \& Lieberman (2006), a Pesquisa Operacional (PO), teve seu surgimento há muitas décadas atrás, quando a abordagem científica começou a ser utilizada como método de solução para os grandes problemas das organizações que surgiam naquela época. Porém, a nomenclatura Pesquisa Operacional passou a ser atribuído neste ambiente a partir da Segunda Guerra Mundial.

Com todo o ambiente caótico da guerra, constatou-se uma necessidade muito grande da alocação e distribuição, de forma eficaz, os recursos que se tornavam cada vez mais escassos nas inúmeras operações militares que aconteciam diariamente (Taha, 2008). Diante deste cenário, os altos comandos militares efetuaram a reunião de um número expressivo de cientistas para que pudessem implementar uma abordagem científica sobre os problemas táticos e gerencias que ocasionavam um número alto de desperdícios em um cenário de recursos escassos e onde se buscavam alta eficiência. Os mesmos cientistas foram os precursores nesta base de estudo que hoje é conhecida como Pesquisa Operacional. 
Para Arenales (2015) a Pesquisa Operacional é entendida como a aplicação de métodos científicos para a solução de problemas de alta complexidade, afim de auxiliar o processo de tomada de decisões, entre as quais podemos destacar: a projeção, o planejamento e a operação de sistemas em ocasiões que necessitem de alocações de forma eficaz com recursos escassos.

O progresso da Pesquisa Operacional teve dois fatores importantes, o primeiro foi o aprimoramento das técnicas e métodos para a formulação de problemas que ocorriam, e o segundo foi a disseminação e popularização dos computadores (Moreira, 2007).

A Pesquisa Operacional pode ser aplicada em diversos setores como de transportes, serviços públicos, financeiros dentre muitos outros, sempre na busca de demonstrar a melhor solução para toda a organização (Bilinski et al., 2016). Essa base de aplicabilidade é possível pois a Pesquisa Operacional visa o bom gerenciamento e a gestão de certas operações (Moreira, 2007).

Para Arenales (2007) são necessários três pilares fundamentais para a aplicação da Pesquisa Operacional. 0 primeiro pilar consiste em compreender um sistema complexo específico, identificar e realizar a separação dos pontos mais importantes em um modelo matemático. 0 segundo pilar compreende a prática de desenvolvimento de métodos para os exemplos e a aplicação de pacotes comerciais para conhecimento das técnicas utilizadas. O terceiro pilar abrange a comunicação com os clientes para compreender o problema e desta forma esclarecer os resultados que não foram intuitivos. Conforme Arenales et al. (2015, p.1), as constantes e progressivas inseguranças e dificuldades presentes no século XXI, tornaram a Pesquisa Operacional cada vez mais relevante.

A utilização de recursos sempre foi o objetivo principal da constante preocupação da humanidade, principalmente levando em consideração os recursos críticos e as possíveis consequências das decisões de alocações deste podem acarretar, seja positiva ou negativa, assim a Pesquisa Operacional pode encontrar a melhor distribuição possível dos recursos, atingindo um valor ideal do objetivo estabelecido (ANDRADE, 1989).

\subsection{MÉTODOS MULTICRITÉRIOS PARA SUSTENTAR UMA DECISÃO}

Os primeiros métodos de apoio ou de análise multicritério à decisão começaram a surgir na década de 1970, com o objetivo principal de encarar algumas situações específicas, em que o decisor muitas vezes, precisaria solucionar um problema no qual existissem diversos objetivos a serem conquistados de forma conjunta (Gomes; Araya; Carignano, 2011).

Segundo Gomes e Gomes (2019), os métodos de apoio multicritério para decisão (AMD) são definidos como técnicas de assessoria para aqueles que participarão do processo decisório (seja um grupo ou apenas um indivíduo) na qual precisam tomar decisões sobre questões complexas com diferentes pontos de vista e com critérios bem distintos.

Um dos ramos da pesquisa operacional é a tomada de decisão que busca alcançar os resultados que mais se adequam aos diversos cenários complexos e estruturados, com diversos indicadores, critérios ou objetivos divergentes (Kumar et al., 2017). O objetivo é justamente servir de auxílio quando todas as alternativas e critérios múltiplos são divergentes. (Gonçalves; Machado, 2015).

Os critérios precisam ser bem definidos, uma vez que aquele que tomará a decisão (Decision Maker) saiba a real necessidade. Além disso, os critérios podem ter importâncias distintas entre si, e isto torna necessário atribuir pesos a estes critérios para definir sua importância (Hora, Costa, 2015).

Conforme Almeida (2011), o método de decisão é conduzido almejando examinar propósitos múltiplos, que estão fortemente relacionados as possíveis consequências da seleção das possíveis alternativas a serem verificadas.

Para Gomes et al. (2009), os processos teóricos de decisões consideram os indivíduos racionais nos casos em que os problemas são menos complexos e suas decisões são mais simplificadas. Contudo, nos casos que possuem uma ambientação e problemática mais estruturada, torna-se necessário algum tipo de metodologia teórica ou processo que transponha a limitação humana, e nos casos que há critérios de decisão distintos, os indivíduos costumam apresentar também opiniões divergentes. 


\subsubsection{ANALYTIC HIERARCHY PROCESS (AHP)}

Este método consiste em considerar diversos critérios pela divisão da hierarquia do problema (Saaty, 2013). As principais bases deste método são: as comparações paritárias, escala de hierarquia e fundamental. Desta forma deve-se estruturar o problema hierarquicamente, comparando seus critérios de forma paritária e obter os valores de prioridades, a consistência dos resultados e selecionar por último a melhor alternativa global.

Para Gomes (2009), o AHP é um método que busca identificar os critérios de maior importância e quais são as proporções destas importância, através de uma comparação paritária dos critérios.

\subsubsection{ELIMINATION ET CHOIX TRADUISANT LA REALITÉ (ELECTRE)}

Este método significa Eliminação e Escolha como forma de Expressão da Realidade, no qual foi desenvolvido e aplicado pela primeira vez por Bernard Roy no término da década de 1960 para justamente resolver um problema no qual necessitaria escolher uma solução entre diversos critérios e alternativas (Mendoca, 2011).

A base principal deste métodos é a não capacidade de comparação (incomparabilidade), ou seja, quando não possui ênfase, e também na questão que o resultado pode não ser compensado, ou seja, não haver equilíbrio entre os critérios (Acolet, 2008 apud Gomes, 2007). Este método possui algumas versões, mas que partem do mesmo fundamento, apenas tendo diferenciação nas operações matemáticas finais, obtendo assim um resultado específico para cada versão.

As versões destes método possuem a mesma exploração das correlações de superação entre as alternativas, visando obter como resultado a classificação entre as mesmas. Sendo que, de uma versão para outra pode haver divergências de aplicação e definição nestas relações para o resultado final das alternativas (Wang; Triantaphyllou, 2008).

\subsubsection{PREFERENCE RANKING ORGANIZATION METHOD FOR ENRICHMENT EVALUATIONS (PROMETHEE)}

Segundo Brans e Mareschal (2005), o Promethee foi apresentado pela primeira vez por Jean-Pierre Brans em 1982, e foi estruturado a partir do método Electre, visando ter um método mais simplificado já que o ELECTRE necessita de muitos parâmetros que podem não apresentar significado para o decisor.

Campos (2011) destaca que a relação entre os métodos Promethee e Electre é tão expressiva que na metodologia mais antiga, é necessário atribuir parâmetros que podem ser de difícil mensuração para o decisor, tornando mais subjetivo. Já o método Promethee é mais robusto à oscilação nos parâmetros, sendo indicada para sistemas com preferências complexas.

O método Promethee também possuem suas diferentes versões igual ao Electre, porém se assemelha com o AHP na comparação paritária resultando no desempenho de cada alternativa com determinado critério (Brans e Mareschal, 2005).

\subsubsection{MÉTODO SAPEVO-M}

O método Simple Aggregation of Preferences Expressed by Ordinal Vectors (SAPEVO) foi criado por Gomes, Mury e Gomes (1997), e consiste, simplesmente em dois processos:

- As preferências entre critérios são transformadas ordinalmente, expressados através de um vetor que representa os pesos destes critérios.

- As preferências entre as alternativas que constam em uma gama de critérios são transformadas ordinalmente. À medida que são agregadas as preferências em relação aos critérios, em segunda instância, é construída uma matriz de avaliação.

A metodologia SAPEVO-M (Simple Aggregation of Preferences Expressed by Ordinal Vectors - Multi Decision Makers) representa uma reformulação da versão original do método que somente tornava possível a avaliação exclusiva de um decisor anteriormente. Este novo método contempla diversos decisores, além de aplicar um método de normalização das matrizes de avaliação, enriquecendo e aumentando a consistência do modelo (Teixeira et al., 2019). 
O Método SAPEVO-M consiste preliminarmente na transformação da preferência de forma ordinal entre os critérios, expressada por um vetor que é equivalente aos pesos dos critérios. Logo após, é realizada também a transformação da preferência entre as alternativas de forma ordinal dentro de um conjunto de critérios estabelecidos, que são expressas por uma matriz. Uma sequência de comparações em forma de pares entre as seleções sejam os critérios ou as alternativas que constam em um critério, expressam as informações específicas de cada decisor.

\subsubsection{FERRAMENTA SAPEVO WEB}

O método SAPEVO-M também está disponível em uma plataforma computacional chamada SapevoWeb que pode ser facilmente acessada pelo seguinte endereço: www.sapevoweb.com. A plataforma apresenta uma interface muito dinâmica e de fácil manuseio, apresentando os resultados finais em um espaço de tempo reduzido (Teixeira et al., 2018). A plataforma SapevoWeb destaca a expressão de valores numéricos associados ao ranking da apresentação do resultado desejado. Desta forma, o SAPEVO-M não se limita somente à disposição das alternativas em uma ordenação, com a criação do SapevoWeb, é possível distinguir como uma alternativa ficou melhor ordenada comparada à outra (Teixeira et al.,2019).

Com todo o embasamento teórico descrito sobre os métodos multicritérios e os modelos mais consagrados ao longo dos anos e sobre as respectivas importâncias neste assunto, fora constatado que o método SAPEVO-M permanece sendo o mais relevante em sua modalidade, tornando-o um próprio estado da arte moderno no que se refere aos métodos de multicritério.

O método SAPEVO-M foi escolhido pela situação da empresa ser da problemática do tipo P.y, que tem como objetivo elucidar a decisão através de um reagrupamento parcial ou total de todas as divisões de equivalência. Tais divisões são ordenadas parcial ou completamente, dependendo das preferências dos decisores, tornando o resultado um processo de ordenação das alternativas.

\section{MODELAGEM MATEMÁTICA}

\subsection{ALTERNATIVAS DE TRANSPALETEIRAS}

Com todo o desenvolvimento do maquinário industrial, é de extrema importância estar sempre relacionando o que o mercado tecnológico tem a oferecer com as reais necessidades das organizações. Sabendo que as transpaleteiras são essenciais no processo logístico interno da empresa, foi de grande importância avaliar os modelos que mais se destacam no mercado atual. Com isso, foram verificados os três modelos de transpaleteiras que tiveram maior número de vendas nos últimos dois anos. Estes modelos são usados por grandes centros logísticos e que possuem ótima avaliação por especialistas. Os três modelos estão apresentados a seguir:

A série MP são transpaleteiras que apresentam ótima dirigibilidade e que foram desenvolvidas para proporcionar melhor ergonomia e facilidade de movimentação com a maior eficiência possível. Esses modelos foram projetados para operação em carregamento e descarregamento em diversas distâncias.

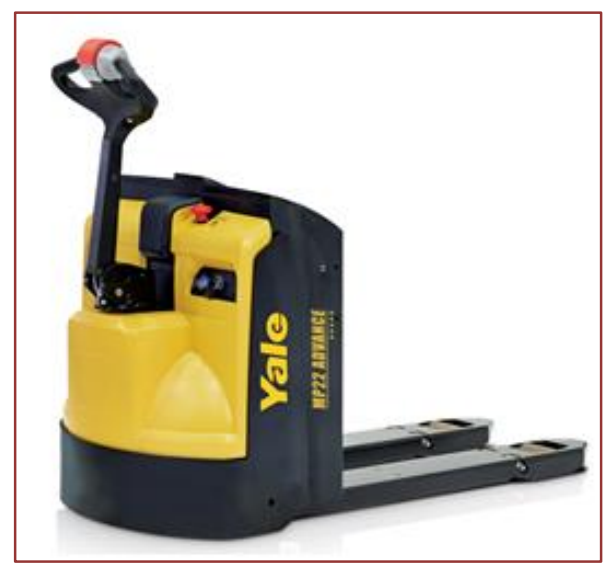

Fonte: yale.com 


\section{Características gerais:}

- $\quad$ Capacidade no transporte da carga (kg): 2000

- $\quad$ Carga sobre eixos de tração, valor com carga (Kg): 948 / 1595

- $\quad$ Carga sobre eixos de, sem carga (Kg): 420 / 123

- Proporções do Garfo (l x c x e) (mm): 64 / 1156 / 172

- $\quad$ Elevação mínima dos garfos (mm): 85

- $\quad$ Elevação limite dos garfos (mm): 130

- Rodas: poliuretano

- Suprimento: energia elétrica

- $\quad$ Modelo de Freio: eletromagnético

A Paletrans está ampliando sua carteirade produtos com o lançamento da máquina de pedidos horizontal SP25H. A máquina com o operador embarcado pode atender operações em armazéns, centros logísticos e de distribuição com eficiência e ganho de tempo em operações de seleção de pedidos sobre paletes, oferecendo tecnologia similar existente nas modernas empilhadeiras retráteis PR20i, como painel que mostra a posição da roda tracionária, conta com velocímetro digital inlcuso, a porcentagem da bateria restante, remoção lateral da bateria e direção elétrica.

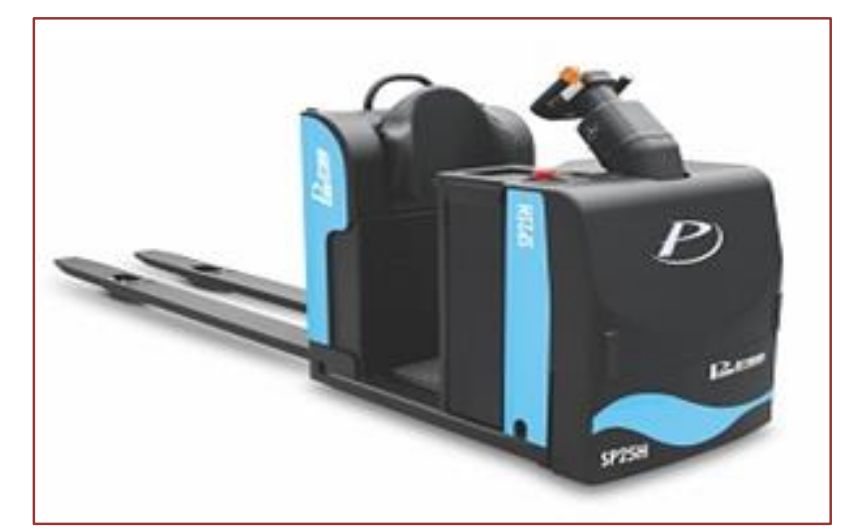

Fonte: paletrans.com.b

\section{Características gerais:}

- $\quad$ Capacidade no transporte da carga (Kg): 2800

- $\quad$ Carga sobre eixos de tração, valor com carga (Kg): 1498 / 2272

- Carga sobre eixos de tração, sem carga (Kg): 976 / 294

- Proporções do Garfo (c x l x e.) (mm): 2400 / 170 / 75

- $\quad$ Elevação mínima dos garfos (mm): 85

- $\quad$ Elevação limite dos garfos (mm): 210

- Rodas: poliuretano

- Suprimento: energia elétrica

- Modelo de Freio: eletromagnético 
ERX é um tipo de paleteira elétrica que apresenta velocidade, dinamismo e conforto. É o tipo de máquina perfeito para o deslocamento de forma horizontal de materiais ou mercadorias, além do carregamento ou descarregamento de contêiners e veículos, até mesmo em lugares que possuem docas niveladoras. 0 modelo ERX possui também o sistema optativo na direção elétrica, aumento signifcativamente a questão ergonômica, sendo ideal para utilização em atividades que possuem limitação física.

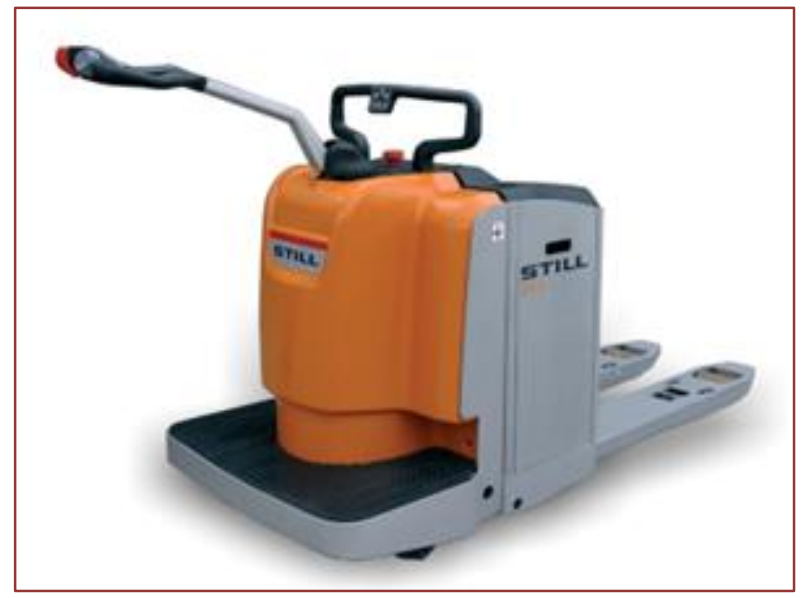

Fonte: still.com

Características gerais:

- Capacidade no transporte da carga (Kg): 2750

- $\quad$ Carga sobre eixos de tração, com carga (Kg): 1300 / 2329

- Carga sobre eixos de tração, sem carga (Kg): 670 / 208

- Proporções do Garfo (c x l x e) (mm): 1150 / 230 / 57

- $\quad$ Elevação mínima dos garfos (mm) 85

- $\quad$ Elevação limite dos garfos(mm) 152

- Rodas: poliuretano

- Suprimento: energia elétrica

- Modelo de Freio: eletromagnético

\subsection{DESENVOLVIMENTO DO MODELO MATEMÁTICO}

\subsection{1 - CRITÉRIOS UTILIZADOS}

Com os modelos das transpaleteiras e os decisores já definidos, os critérios que serão examinados nos modelos e que darão prosseguimento no trabalho foram avaliados através de uma reunião pelos respectivos gerentes em conjunto com os operadores. Nesta reunião foram expostos os principais critérios necessários para as operações diárias:

- Carga de transporte: Avaliação da capacidade de carga da transpaleteira, considerando relevante as necessidades do transporte. É importante que a transpaleteira consiga carregar os produtos de forma eficiente, sem ocasionar paradas devido ao excedente de cargas.

- Força de carga: Avaliação da força que a transpaleteira apresenta no momento que está realizando o transporte das cargas e produtos. É importante a máquina apresentar uma força de carga suficiente para não impactar na velocidade de deslocamento. 
- Ergonomia: Avaliação dos aspectos ergonômicos da transpaleteira, dentre eles, os tipos de assoalho, modelo de empunhadura do timão, e principalmente os apoios lombares. É importante para não tornar o processo de operação da transpaleteira estressante e cíclico, influenciando diretamente no bom estado físico e mental do operador.

\subsubsection{DEFINIÇÃO DOS DECISORES}

Após a apresentação e descrição dos modelos de transpaleteiras, foram selecionados os atores que estariam relacionados ao processo decisório. Estes atores são de total importância nos processos pois administram as operações internas e de todo o maquinário presente no Centro de Distribuição:

- Gerente de Operações do Centro de Distribuição

- Gerente de Manutenção do Centro de Distribuição

\subsection{UTILIZAÇÃO DA PLATAFORMA SAPEVOWEB}

Esta plataforma computacional para utilização do método multicritério SAPEVO-M encontra-se disponível no endereço da web: www.sapevoweb.com. Segundo Teixeira et al. (2018), esta plataforma é um tipo de programa que conta uma agradável e dinâmica interface gráfica, apresentando os resultados desejados com processamento computacional reduzido. A plataforma foi criada com o propósito de reunir as respectivas opiniões que foram expressas pelos decisores, realizando todo o procedimento matemático necessário dentro da metodologia SAPEVO-M, e obtendo como resultado a ordenação decrescente das alternativas apresentadas.

Após o acesso da plataforma SAPEVOWEB, e preenchimento das informações do projeto, os decisores, as alternativas e os critérios, foi necessário realizar a comparação paritária dos critérios, expressas pelo Gerente de Operações, conforme figura:

\subsubsection{AVALIAÇÃO DOS CRITÉRIOS PARA O DECISOR 1 (GERENTE DE OPERAÇõES)}

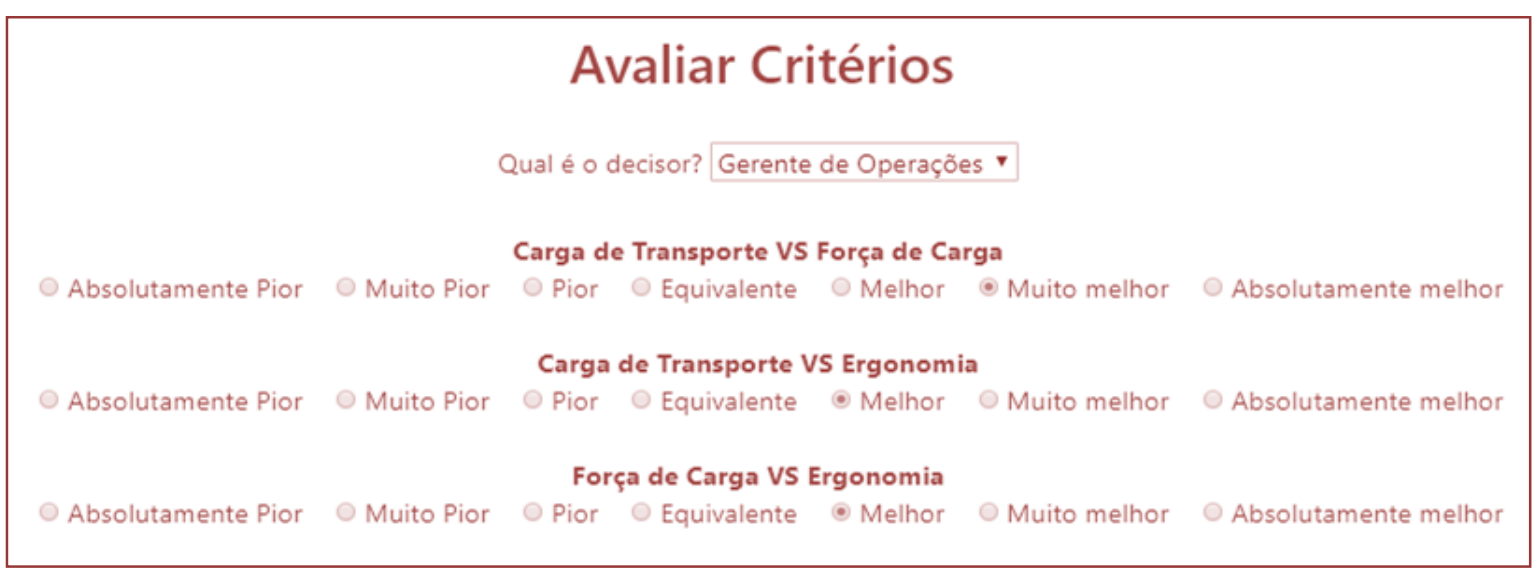

Fonte: sapevoweb.com 


\subsubsection{AVALIAÇÃO DOS CRITÉRIOS PARA O DECISOR 2 (GERENTE MANUTENÇÃO)}

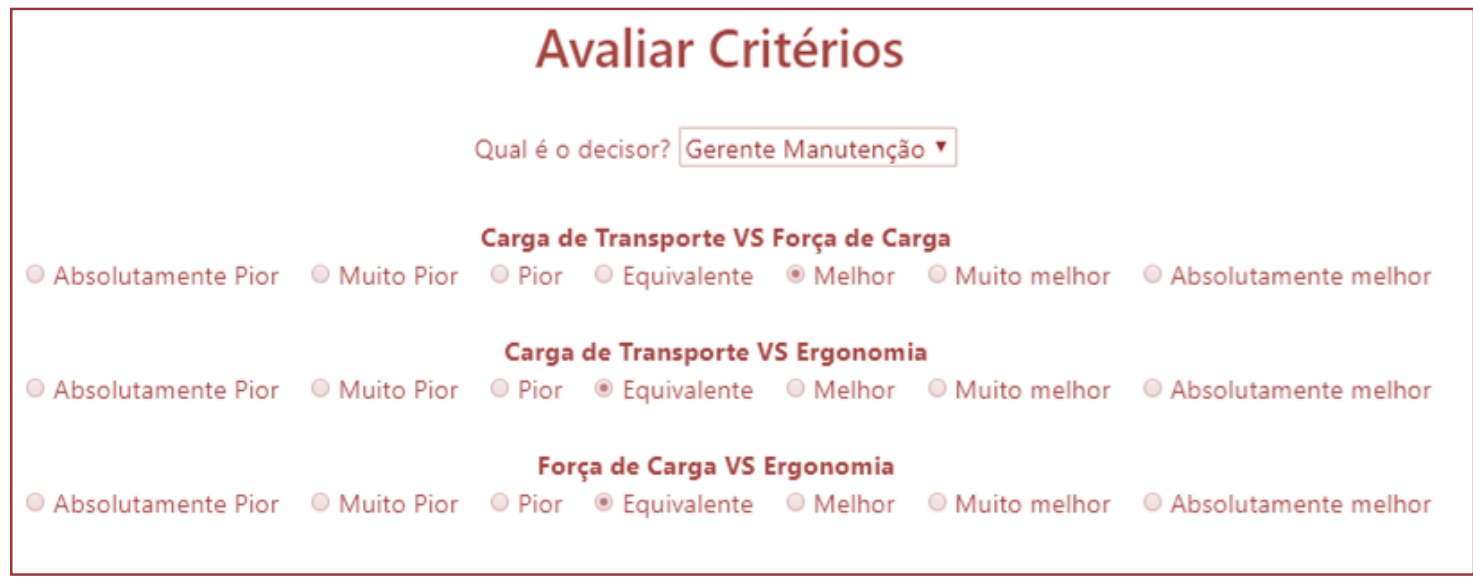

Fonte: sapevoweb.com

\subsubsection{AVALIAÇÃO DAS ALTERNATIVAS PARA DECISOR 1 (GERENTE DE OPERAÇÕES)}

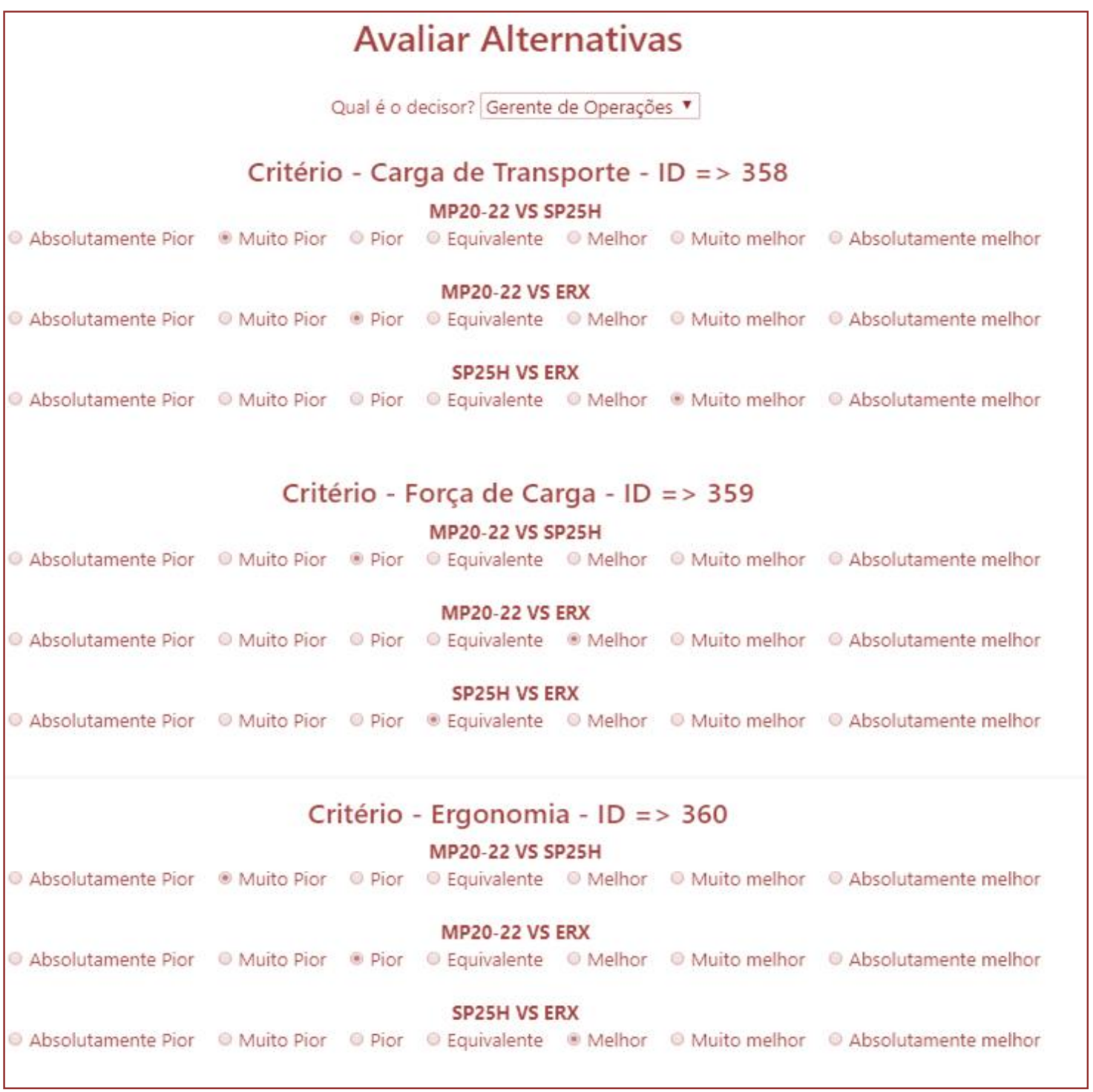

Fonte: sapevoweb.com 


\subsubsection{AVALIAÇÃO DAS ALTERNATIVAS PARA O DECISOR 2 (GERENTE MANUTENÇÃO)}

\begin{tabular}{|c|c|c|c|c|c|c|}
\hline \multicolumn{7}{|c|}{ Avaliar Alternativas } \\
\hline \multicolumn{7}{|c|}{ Qual é o decisor? Gerente Manutenção $\mathbf{~}$} \\
\hline \multicolumn{7}{|c|}{ Critério - Carga de Transporte - ID => 358} \\
\hline \multicolumn{7}{|c|}{ MP20-22 VS SP25H } \\
\hline Absolutamente Pior & Muito Pior & - pior & Equivalente & Melhor & Muito melhor & Absolutamente melhor \\
\hline \multicolumn{7}{|c|}{ MP20-22 VS ERX } \\
\hline Absolutamente Pior & Muito Pior & Pior & - Equivalente & Melhor & Muito melhor & - Absolutamente melhor \\
\hline \multicolumn{7}{|c|}{ SP25H VS ERX } \\
\hline Absolutamente Pior & Muito Pior & O Pior & Equivalente & - Melhor & Muito melhor & - Absolutamente melhor \\
\hline \multicolumn{7}{|c|}{ Critério - Força de Carga - ID => 359} \\
\hline \multicolumn{7}{|c|}{ MP20-22 VS SP25H } \\
\hline Absolutamente Pior & - Muito Pior & Pior & Equivalente & Melhor & Muito melhor & Absolutamente melhor \\
\hline \multicolumn{7}{|c|}{ MP20-22 VS ERX } \\
\hline Absolutamente Pior & Muito Pior & Pior & - Equivalente & Melhor & Muito melhor & - Absolutamente melhor \\
\hline \multicolumn{7}{|c|}{ SP25H VS ERX } \\
\hline Absolutamente Pior & Muito Pior & Pior & Equivalente & - Melhor & Muito melhor & - Absolutamente melhor \\
\hline \multicolumn{7}{|c|}{ Critério - Ergonomia - ID => 360} \\
\hline \multicolumn{7}{|c|}{ MP20-22 VS SP25H } \\
\hline Absolutamente Pior & Muito Pior & - Pior & Equivalente & Melhor & Muito melhor & Absolutamente melhor \\
\hline \multicolumn{7}{|c|}{ MP20-22 VS ERX } \\
\hline Absolutamente Pior & Muito Pior & O Pior & - Equivalente & Melhor & Muito melhor & - Absolutamente melhor \\
\hline \multicolumn{7}{|c|}{ SP25H VS ERX } \\
\hline Absolutamente Pior & Muito Pior & Pior & Equivalente & Melhor & - Muito melhor & Absolutamente melhor \\
\hline
\end{tabular}

sapevoweb.com

\subsubsection{OBTENÇÃO DOS PESOS RELATIVOS DOS CRITÉRIOS E AS RESPECTIVAS ORDENAÇÕES}

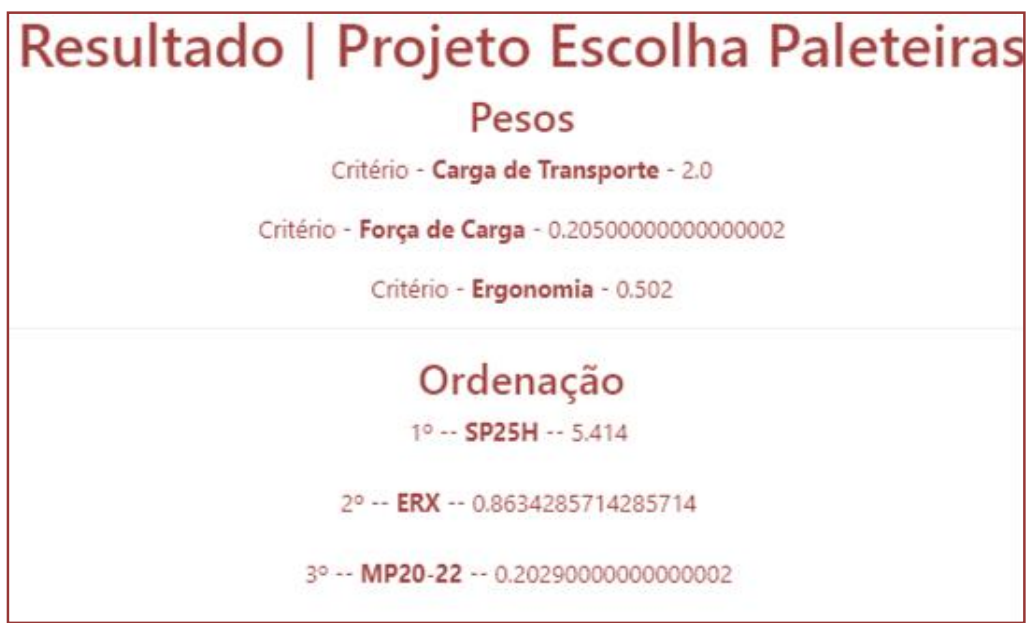

Fonte: sapevoweb.com 


\section{RESULTADOS ALCANÇADOS}

Conforme o modelo desenvolvido pela ferramenta SAPEVO Web, a opção que satisfaz os critérios para aquisição será a paleteira $\mathrm{SP} 25 \mathrm{H}$, pois a mesma apresenta vantagens quando analisados aos valores de critérios, porém o resultado obtido não se torna necessariamente a solução ótima, foi apenas um embasamento para a escolha da decisão oriundo de uma metodologia matemática. 0 resultado desta solução reúne diversos critérios importantes para a empresa e seus processos como um todo, já que se aproxima das necessidades reais da operação como um todo.

\section{CONSIDERAÇÕES FINAIS}

Tomando como base as operações de movimentação dos materiais e produtos das empresas e todo processo logístico envolvido, a boa escolha de uma máquina e que paralelamente contribua para a conservação ergonômica do usuário contribui de maneira a reduzir os riscos de avarias e os números excessivos de acidentes de trabalho. Todas as características apresentadas das transpaleteiras permitirão maior eficiência no transporte, uma vez que as máquinas contam com alta tecnologia desde a fabricação dos materiais até as montagens das mesmas, além de conseguir transportar um maior volume de carga de uma forma mais segura e eficaz, pois o garfo seria de dimensões maiores e aumentaria a sustentabilidade dos materiais. Por se tratar de uma máquina, o custo de manutenção se torna menor, pela existência de assistências técnicas especializadas. Portanto, nota-se que existe diversas variáveis que influenciam no momento da decisão, mas uma coisa é certa, há necessidade de uma máquina que realize essas operações de uma maneira prevalecente.

\section{REFERENCIAL}

[1] Andrade, E.L. Introdução à Pesquisa Operacional. Rio de Janeiro: Livros Técnicos e Científicos, p.156- 171, 1989.

[2] Andrade, E. L. Problemas de Congestionamento das Filas. In: Andrade, E. L. Introdução à Pesquisa Operacional: Métodos e modelos para análise de decisões. Ed. 4. Rio de Janeiro: LTC, 2009. Cap. 6, p. 104-120.

[3] Arenales, Marcos et al. Pesquisa operacional. Rio de Janeiro: Elsevier, 2007.523 p.

[4] Arenales, M.; Armentano, V.; Morabito, R.; Yanasse, H. Pesquisa Operacional para Cursos de Engenharia. São Paulo: Editora Campus, 2007.

[5] Arenales, M. et al. Pesquisa Operacional: Para cursos de engenharia. 2ª ed. Rio de Janeiro: Elsevier, 2015.

[6] Bastos, L. N. V.; Almeida, A. T. DE. Utilização do método Promethee II na análise das propostas de preços em um processo de licitação. XXII Encontro Nacional de Engenharia De Produção. Curitiba, PR, Brasil, 23 a 25 de outubro de 2002.DIAS, Marco Aurélio P. Administração de materiais: uma abordagem logística. 6ạ ed., São Paulo: Atlas, 2012.

[7] Bilinski, P. A. et al. Aplicação da Pesquisa Operacional na Otimização da Lucratividade de uma Empresa do Segmento de Marcenaria. In: Encontro Nacional de Engenharia de Produção (ENEGEP), 36. 2016. João Pessoa, PB. Anais... João Pessoa: Abepro, out. 2016.

[8] Brans, Jean-Pierre; Mareschal, Bertrand. Promethee methods. In: Figueira, José; Greco, Salvatore; Ehrgott, Matthias. (Org.) Multiple criteria decision analysis: state of the art surveys. New York: Springer, 2005, p.163-195.

[9] FIEP. Federação de Indústrias do Estado do Paraná, 2017. Disponível em < http://www.sistemafiep.org.br/uploadAddress/Panorama_Moveis_final_v2017[84568].pdf>, Acesso em: 25 Out. 2019.

[10] Gapski, O. L. Controle de nível de estoque no setor varejista com base no gerenciamento do inventário pelo fornecedor: aplicação do modelo no A. Angeloni Cia Ltda e Procter \& Ghamble S.A. 2003. Dissertação (Mestrado em Engenharia de Produção) - Universidade Federal de Santa Catarina, Florianópolis, 2003.

[11] GoMES, L. F. A. M.; Araya, M. C. G.; Carignano, C. Tomada de Decisões em Cenários Complexos. São Paulo: Cengage Learning, 2011.

[12] Gomes, L. F. A. M., e Gomes, C. F. S. Princípios e métodos para a tomada de decisão: Enfoque multicritério (6a ed.). São Paulo: Atlas. (2019).

[13] Gonçalves, C. D. F.; Dias, J. A. M.; Machado, V. A. C. Multi-criteria decision methodology for selecting maintenance key performance indicators. International Journal of Management Science and Engineering Management, v. 10, n. 3, p. 215-223, 2015.

[14] Gomes, E.G.; Soares de Mello, J.C.C.B.; Souza, G.S.; Angulo Meza, L.; Mangabeira, J.A.C. Efficiency and 
sustainability assessment for a group of farmers in the Brazilian Amazon. Annals of Operations Research, v. 169 (1), p 167-181, 2009.

[15] Gomes, L. F. A. M. Teoria da decisão. (Coleção debates em Administração). São Paulo: Thomson Learning, 2007.

[16] Gomes, L. F. A. M.; Mury, Antonio R.; Gomes, Carlos FS. Multicriteria ranking with ordinal data. Systems Analysis Modelling Simulation, v. 27, p. 139-146, 1997.

[17] Gomes, L. F. A. M.; Araya, M. C. G.; Carignano, C. Tomada de decisão em cenários complexos. São Paulo: Pioneira Thomson Learning, 2009.

[18] Hillier, F. S., Lieberman, G. J. Introdução a Pesquisa Operacional. São Paulo: McGraw-Hill, 2006.

[19] Kato, J. M., 2003, Avaliação de desempenho de sistemas logísticos através do Seis Sigma e Balanced Scorecard, Rev. Business FAE, Curitiba, v.6, n.2, pp.113-124.

[20] KUMAR, A. et al. A review of multi criteria decision making (MCDM) towards sustainable renewable energy development. Renewable and Sustainable Energy Reviews, v. 69, p. 596-609, 2017.

[21] Mendoca, Fabricio Molica de; ET AL. Avaliação de desempenho de redes de empresas produtoras de artesanato: o caso da região de campo das vertentes em minas gerais por meio da aplicação do método Electre III. XXXI Encontro Nacional de Engenharia De Produção. Belo Horizonte, MG, Brasil, 04 a 07 de outubro de 2011.

[22] Paletrans. Linha SP25H - Todos os números de série, 2016. Disponível em: < http://www.paletrans.com.br/pt-br/produtos/manuais>. Acesso em 01 junho 2019.

[23] Still. Transpaleteira Elétrica ERX, 2019. Disponível em: < https://www.still.com.br/lamina-tecnicaerx.0.0.html>. Acesso em 11 junho 2019.

[24] Saaty, Thomas L. Multicriteria Decision Making: The Analytic Hierarchy Process; Planning, Priority Setting, Resource Allocation. 2. Ed. Pittsburgh : R W S Publications, 1996.

[25] Taha, H. A. Pesquisa operacional: uma visão geral. 8. ed. São Paulo: Pearson Prentice Hall, 2008.

[26] Yale. Tranpaleteira MP20-22, 2019. Disponível em: < https://www.yale.com/brasil/pt-br/productoverview/pallet-truck/MP13-30/>. Acesso em 30 maio 2019 


\section{Capítulo 12}

Estudo da influência da geometria de rotores no armazenamento de energia em baterias eletromecânicas

\section{Daniel Coppedé \\ Wagner Costa Botelho}

Resumo: 0 trabalho apresenta um estudo voltado a um tipo específico de roda de inércia, conhecida como flywheel, capaz de acumular energia cinética quando em movimento. Estas rodas são utilizadas em baterias eletromecânicas que detém uma maior vida útil se comparada com outros tipos de bateria comercialmente conhecidas. Foram realizadas análises computacionais sobre a geometria do rotor. Este estudo visa à análise da geometria de uma roda de inércia girando a maior velocidade de rotação possível, assim concentrando maior quantidade de energia e reduzindo dimensões e custos de material. Para tanto, neste trabalho foram criados e simulados, pelo método de elementos finitos, vários tipos de geometrias de rodas de inércia, com a intenção de verificar o comportamento das tensões de resistência mecânica do material na sua elevada velocidade de rotação.

Palavras-Chaves: Flywheel; bateria eletromecânica; elementos finitos. 


\section{INTRODUÇÃO}

0 conceito de utilização de um volante de inércia (Figura 1) é notório e foi largamente empregado na civilização moderna, com uma ampla adoção desde o período da revolução industrial.

O princípio é o armazenamento de energia cinética no movimento rotativo do volante para consumo posterior, uniformizando o movimento do volante uma vez que a energia não se altera abruptamente com a aplicação de forças limitadas. Esta energia é disposta em oposição as acelerações ocorridas em determinados momentos da operação rotativa (movimento circular).

Como exemplos podem ser citados o momento de deformação ou corte que ocorre na operação de uma prensa mecânica, igualmente o movimento do virabrequim de um motor à explosão, o uso do volante no motor amortece os impulsos bruscos dos pistões e origina uma rotação relativamente suave ao virabrequim.

Com o desenvolvimento tecnológico ocorrido nos diversos campos da engenharia, passou a ser objeto de estudo novas utilizações do volante de inércia, bem como novas formas construtivas e conceituais, inclusive com o advento de novas solicitações do equipamento. A ideia de um volante com uma grande massa evoluiu para um volante de massa menor, porém com uma velocidade muito maior (RIBEIRO, 2008).

FIGURA 10 - Volante de inércia.

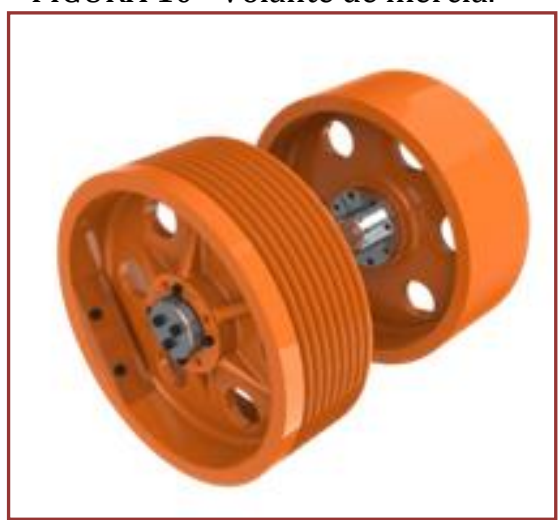

Fonte: SCPOLIAS (2018).

Para utilizar o volante de inércia como uma bateria eletromecânica, o princípio de funcionamento é muito simples: trata-se de colocar basicamente uma roda (volante) a girar em situações em que não esteja sujeita a qualquer força de atrito ou a qualquer outra ação exterior (JUNLING, 2004). É uma forma extremamente simples de armazenar energia mecânica, em que facilmente se converte energia mecânica em energia elétrica e vice-versa, utilizando um simples motor gerador elétrico.

A equação 01 - Cálculo de energia cinética rotacional demonstra que a energia cinética armazenada é proporcional ao momento de inércia I e ao quadrado da velocidade angular $\omega$, demonstrando nitidamente a vantagem do novo conceito.

Pela observação da fórmula, fica evidente que ao aumentar a velocidade angular do volante, a energia cinética armazenada será aumentada na metade do quadrado desta variação, o que justifica o objetivo de otimizar a geometria do rotor para potencializar o acumulo de energia cinética com o aumento da velocidade suportado pelo rotor. Como exemplo para o cálculo do momento de inércia, segue a equação 02 - Cálculo de momento de inércia de um cilindro maciço:

$$
E c=\frac{I \omega^{2}}{2}
$$

$\begin{array}{lll}\text { Em que: } & \text { Ec } & \text { Energia Cinética }(\mathrm{J}) \\ & \mathrm{I} & \text { Momento de Inércia }\left(\mathrm{kg} . \mathrm{m}^{2}\right) \\ & \omega & \text { Velocidade Angular }(\mathrm{Rad} / \mathrm{s})\end{array}$




\begin{tabular}{lll} 
& \multicolumn{1}{c}{$\mathbf{I}=\frac{\mathbf{m R}^{\mathbf{2}}}{\mathbf{2}}$} \\
Em que: & $\mathrm{I}$ & Momento de Inércia $\left(\mathrm{kg} \cdot \mathrm{m}^{2}\right)$ \\
& $\mathrm{m}$ & Massa $(\mathrm{kg})$ \\
$\mathrm{R}$ & Raio em torno do eixo $(\mathrm{m})$
\end{tabular}

O conceito de bateria eletromecânica data da década de 1940, quando foi desenvolvido e implantado um novo modelo de ônibus elétrico, o Gyrobus (Figura 02), pela empresa suíça Maschinenfabrik Oerlikon, na cidade de Yverdon-les-Bains, patenteado pelo engenheiro Bjarne Storsand em 1946. Os primeiros sistemas foram desenvolvidos utilizando-se mancais mecânicos, mas, em função do baixo rendimento do conjunto, motivado pela perda de energia por meio do atrito e da dificuldade em se obter rotações elevadas, esses primeiros sistemas se mostraram inviáveis.

FIGURA 11 - Gyrobus 1ํa geração.

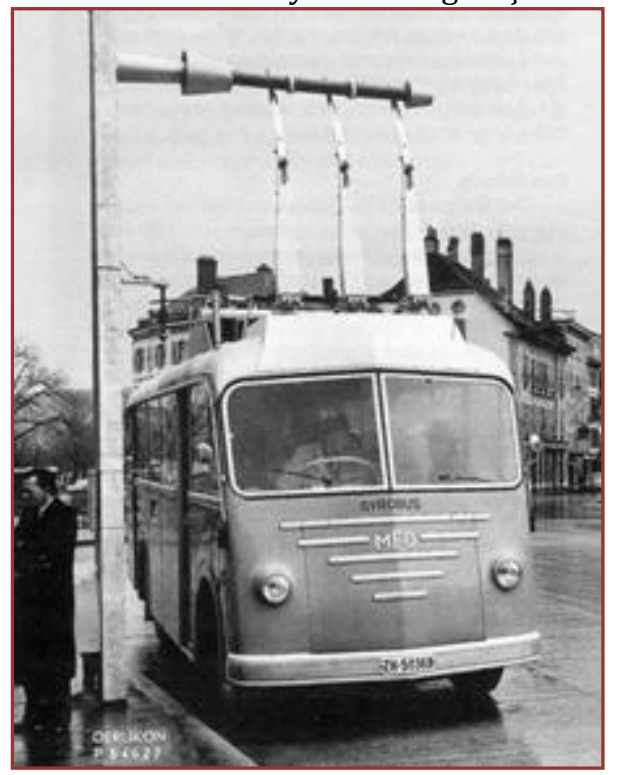

Fonte: PROAKTIVA (2018)

\section{GEOMETRIAS, ANALISES E MATERIAIS}

As geometrias analisadas, exibidas a seguir, tem medidas padrão de diâmetro e altura para efeito de cálculos e simulações, conforme tabela 01.

TABELA 1 - Dimensões dos Modelos.

\begin{tabular}{|l|c|}
\hline Diâmetro externo da coroa & $200 \mathrm{~mm}$ \\
\hline Diâmetro interno da coroa & $120 \mathrm{~mm}$ \\
\hline Altura do rotor & $100 \mathrm{~mm}$ \\
\hline
\end{tabular}

Fonte: $\mathrm{O}$ autor

Os modelos podem ser divididos basicamente em três partes, são elas:

- Coroa: Parte externa do rotor, com medidas padrão de diâmetro externo (200 mm) e interno (120 $\mathrm{mm}$ ) para todos os modelos. A coroa tem como principal função armazenar a energia rotacional, a maior parte da massa do conjunto se encontra na coroa;

- Eixo: Parte interna do rotor, com medidas padrão de diâmetro (30 mm) e altura (100 mm), tem como função guiar o movimento de rotação;

- Disco: Elemento de ligação entre o eixo e a coroa. Foi o objeto deste estudo visto que as alterações em seus formatos influenciaram os resultados, como será demonstrado. 
Para realizar as simulações, o material escolhido foi o aço Maraging AISI 18 Ni 350, com as seguintes características:

TABELA 2 - Característica do material.

\begin{tabular}{|c|c|c|c|}
\hline & $\begin{array}{c}\text { Limite de Resistência à } \\
\text { Tração (MPa) }\end{array}$ & $\begin{array}{c}\text { Limite de } \\
\text { Escoamento } \\
(\mathrm{MPa})\end{array}$ & $\begin{array}{c}\text { Massa específica } \\
\left(\mathrm{g} / \mathrm{cm}^{3}\right)\end{array}$ \\
\hline Aço Maraging - AISI 18 Ni 350 & 2.395 & 2.395 & 8,08 \\
\hline
\end{tabular}

Fonte: 0 autor

Esse estudo foi realizado por meio de análises efetuadas com o software SolidWorks a partir de geometrias e materiais previamente selecionados.

Para cada razão e geometria foi analisado, por meio do SolidWorks, o comportamento mecânico do material como, por exemplo, a resistência à tração pelo Método de Elementos Finitos e, ainda, a capacidade de acumular energia.

Foram utilizados, para análise da geometria e material, como softwares dedicados, as ferramentas SolidWorks Simulation e o SolidWorks Motion da SolidWorks.

\subsection{RESUMO DA ANÁLISE DO MODELO 01}

O modelo 01 teve sua geometria extraída do artigo Low Cost Flywheel Energy Storage, (HEARN, 2007). Tem como característica a ligação entre o eixo e a coroa realizada por um disco descentralizado transversalmente ao eixo. 0 disco apresenta espessura variável, tendo uma menor espessura na conexão com a coroa, em raio, aumentando de forma gradativa até a ligação com o eixo, realizada em raio.

Este modelo apresentou como pontos críticos a seção da coroa oposta à ligação com o disco (Figura 03), que apresentou uma tendência de deformação centrifuga, bem como o estreitamento do disco, o pescoço.

A concentração de tensões nessa seção limitou o estudo a uma rotação máxima de 53.200 rpm.

FIGURA 12 - Resultado da análise do Modelo 01.

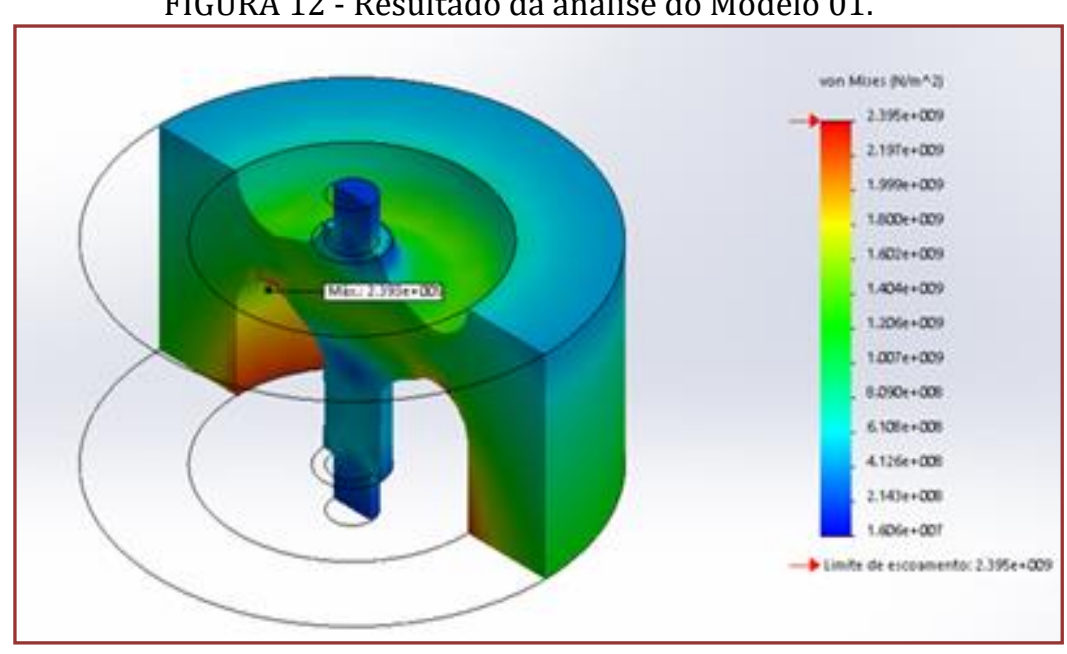

Fonte: 0 autor. 


\subsection{RESUMO DA ANÁLISE DO MODELO 02}

0 modelo 02 tem como principal característica a ligação entre o eixo e a coroa realizada por um disco que possui espessura variável, tendo uma espessura de $60 \mathrm{~mm}$ na conexão com a coroa, diminuindo de forma gradativa até a ligação com o eixo, realizada em raio de $5 \mathrm{~mm}$.

FIGURA 13 - Resultado da análise do Modelo 02.

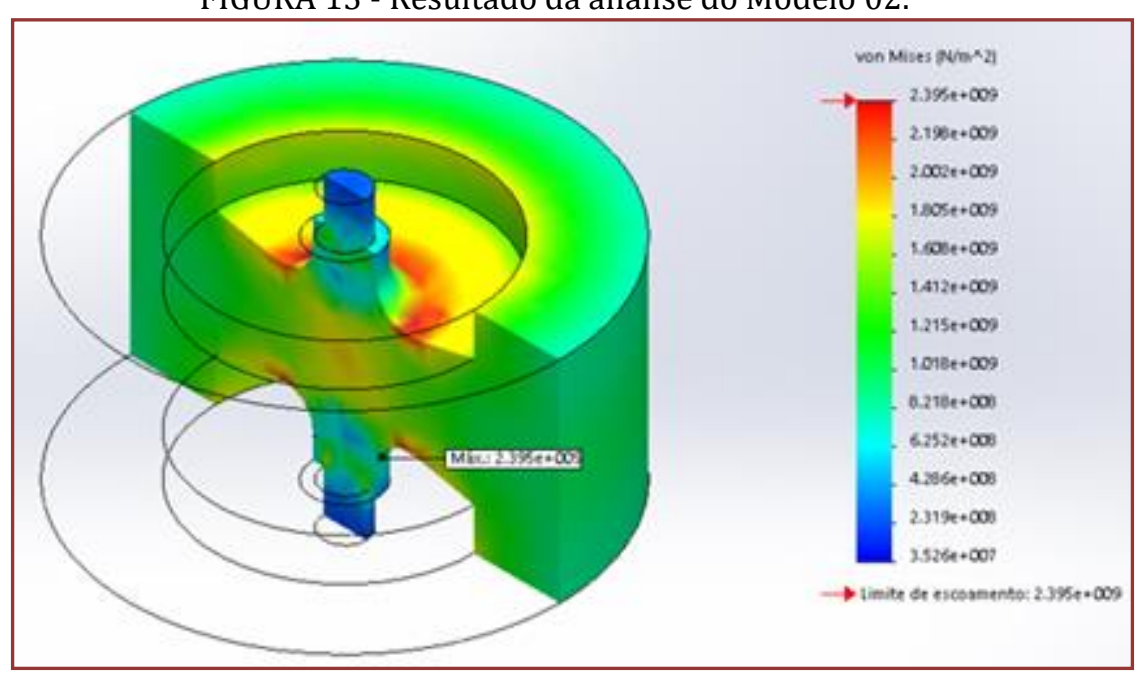

Fonte: $\mathrm{O}$ autor.

O modelo é transversalmente simétrico. Esta configuração do disco é propositalmente a inversa do modelo 01. Este modelo apresentou como ponto crítico a seção próxima ao eixo, ver figura 4, de menor espessura. A concentração de tensões nessa seção limitou o estudo a uma rotação máxima de 61.900 rpm.

\subsection{RESUMO DA ANÁLISE DO MODELO 03}

0 modelo 03 tem como principal característica a ligação entre o eixo e a coroa realizada por um disco que possui espessura variável em curva, tendo uma espessura de $100 \mathrm{~mm}$ na conexão com a coroa, diminuindo gradativamente sua espessura e, antes da conexão com o eixo, volta a aumentar a espessura.

O modelo é transversalmente simétrico. Este modelo apresentou como ponto crítico o pescoço de menor espessura do disco (Figura 05).

A concentração de tensões nessa seção limitou o estudo a uma rotação máxima de 57.370 rpm.

FIGURA 5 - Resultado da análise do Modelo 03.

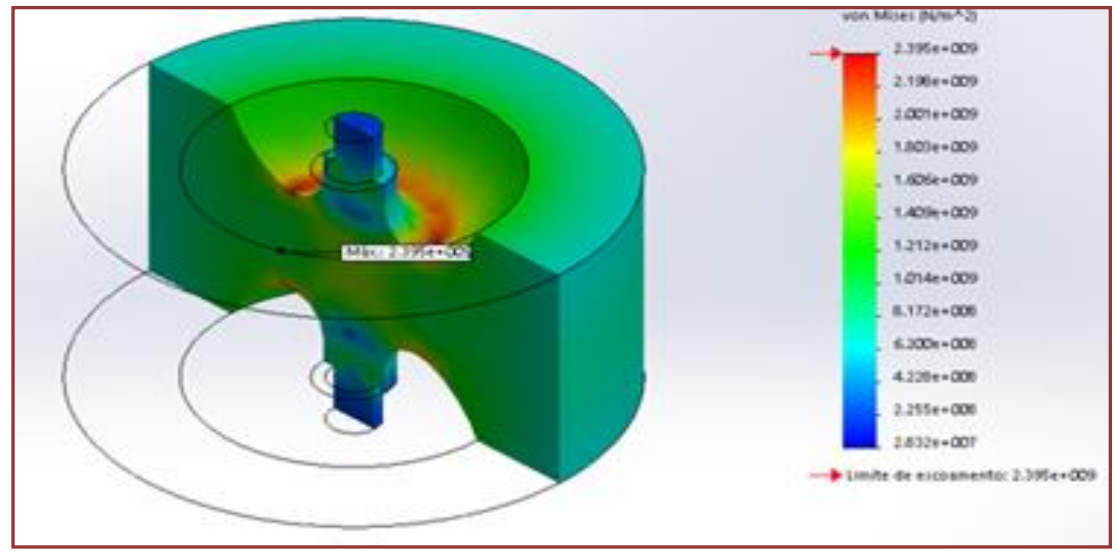

Fonte: $\mathrm{O}$ autor. 


\subsection{RESUMO DA ANÁLISE DO MODELO 04}

O modelo 04 tem como principal característica a ligação entre o eixo e a coroa realizada por um disco plano com espessura constante de $40 \mathrm{~mm}$. 0 modelo é transversalmente simétrico.

Este modelo apresentou uma excelente distribuição de tensão, o que ficou demonstrado na máxima rotação admitida do modelo. As tensões estavam distribuídas de mesma forma pelo disco e parte interna da coroa (Figura 06).

0 limite de escoamento ocorreu a uma rotação máxima de 62.940 rpm.

FIGURA 6 - Resultado da análise do Modelo 04.

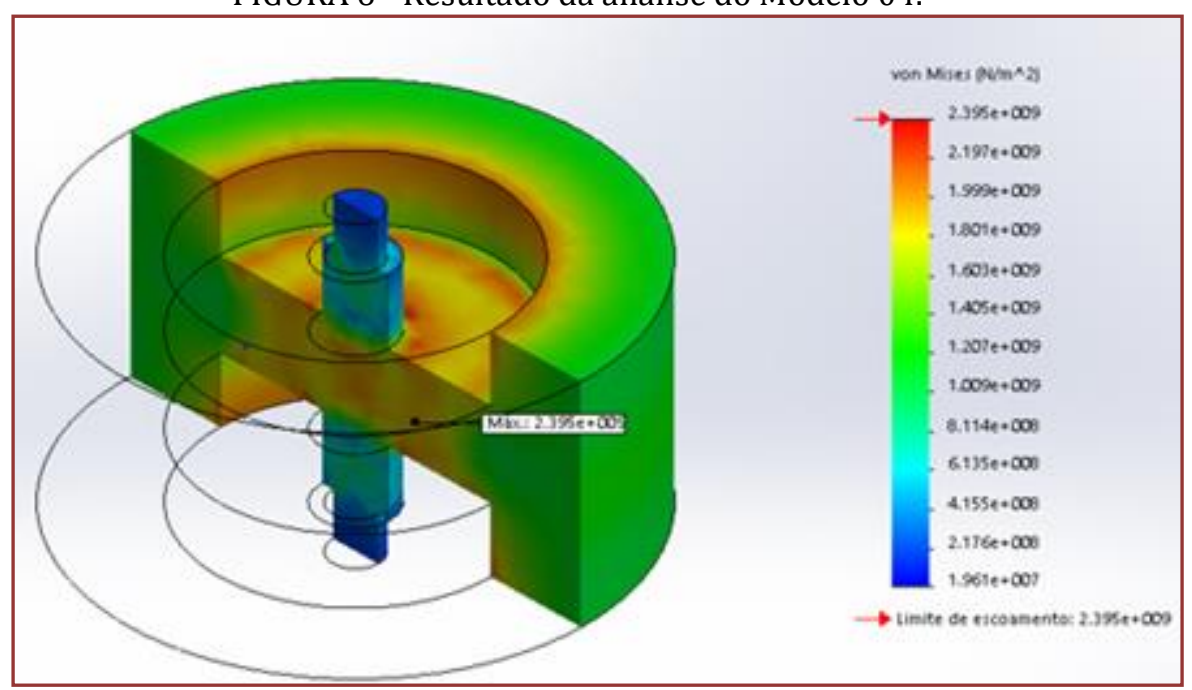

Fonte: $\mathrm{O}$ autor.

\subsection{RESUMO DA ANÁLISE DO MODELO 05}

0 modelo 05 tem como principal característica a ligação entre o eixo e a coroa realizada por um disco apresenta, em corte, um perfil trapezoidal. 0 modelo surgiu a partir de deliberação com os professores orientadores, de forma a melhorar o desempenho do modelo 04.0 modelo é transversalmente simétrico.

FIGURA 7 - Resultado da análise do Modelo 05.

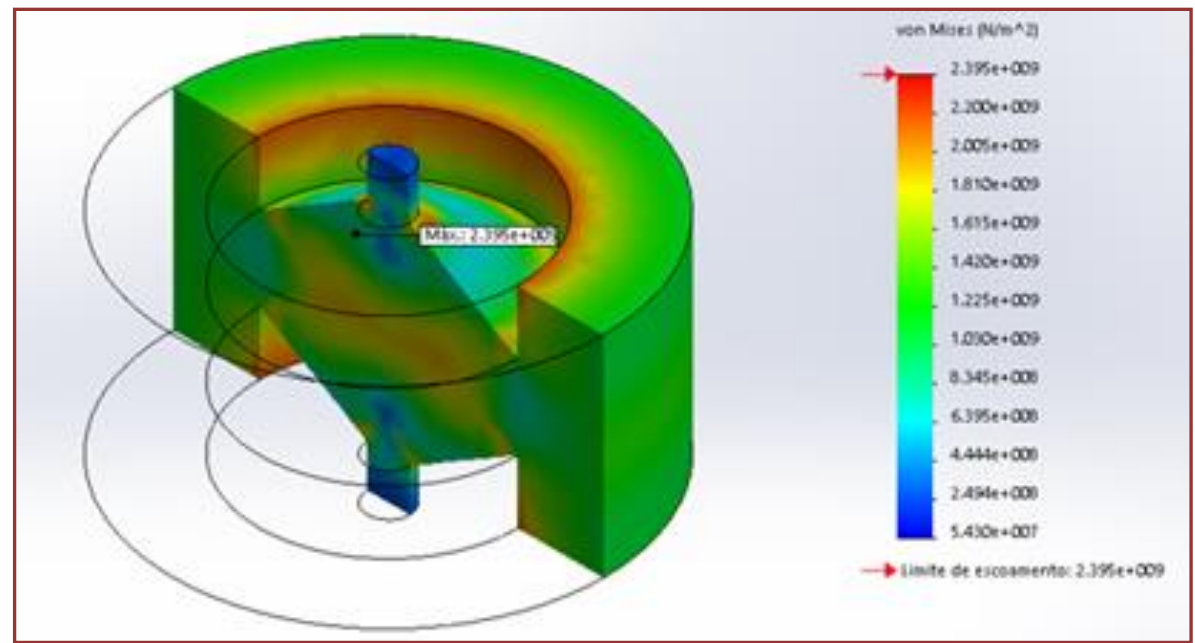

Fonte: $\mathrm{O}$ autor. 
Este modelo apresentou como ponto crítico as extremidades da coroa afastadas do disco, com o melhor desempenho do disco dentre os modelos analisados (Figura 07).

A concentração de tensões nessa seção limitou o estudo a uma rotação máxima de $65.290 \mathrm{rpm}$.

\subsection{RESUMO DA ANÁLISE DO MODELO 06}

0 modelo 06 foi proposto em estudo anterior realizado no IFSP (MURGER 2016), tem como principal característica a ligação entre o eixo e a coroa realizada por um disco em forma de cone raso, com uma espessura constante.

Este modelo apresentou como pontos críticos as conexões do disco com o eixo e com a coroa que possuíam ângulo agudo. Apesar do incremento de um raio nessa ligação, para diminuir a concentração de tensão nesses pontos, os resultados não foram promissores (Figura 08).

A concentração de tensões nessa seção limitou o estudo a uma rotação máxima de 47.720 rpm.

FIGURA 8 - Resultado da análise do Modelo 06.

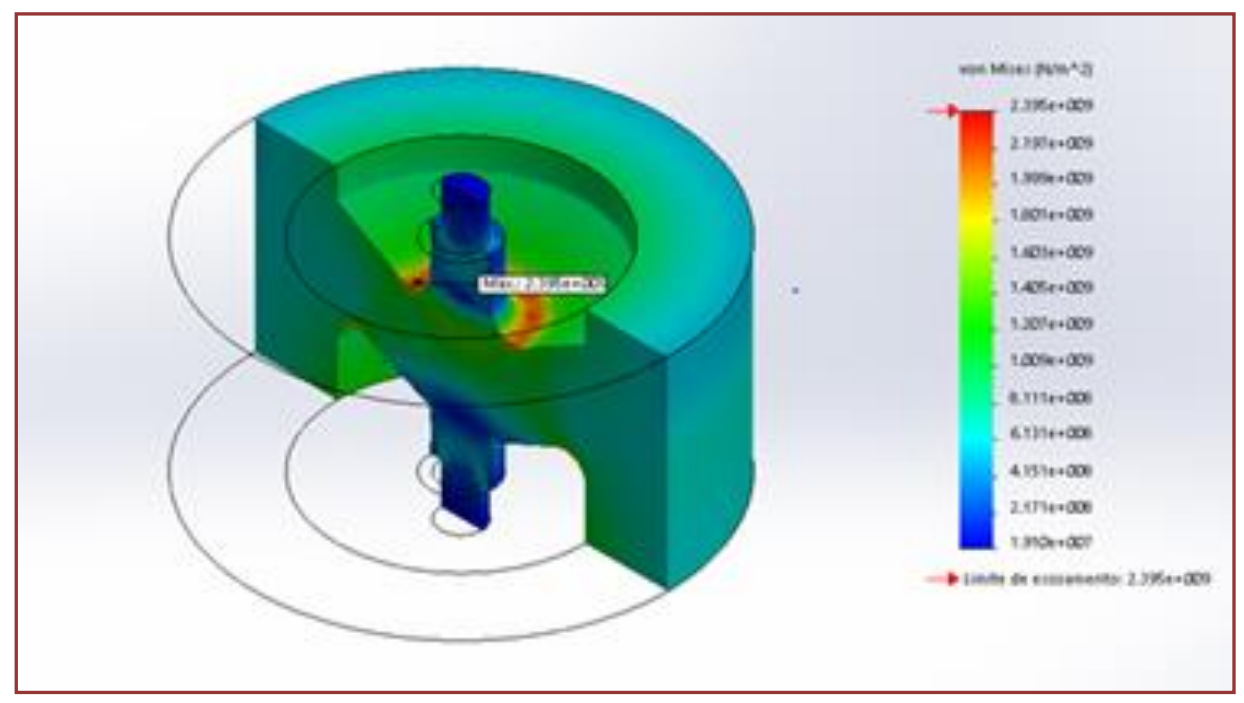

Fonte: 0 autor.

\subsection{RESUMO DA ANÁLISE DO MODELO 07}

0 modelo 07 estava proposto no estudo anterior realizado no IFSP, tem como principal característica a ligação entre o eixo e a coroa realizada por um cone que se inicia junto a coroa e se une ao eixo no limite inverso. Essa geometria previa uma pequena deformação do cone, de forma a absorver as tensões geradas pelo movimento.

Este modelo apresentou como ponto crítico a seção próxima a coroa, ver figura 09, esse comportamento foi verificado tanto nas análises realizadas em aço maraging como nas análises realizadas com fibra de carbono.

A concentração de tensões nessa seção limitou o estudo a uma rotação máxima de 50.890 rpm. 
FIGURA 9 - Resultado da análise do Modelo 07.

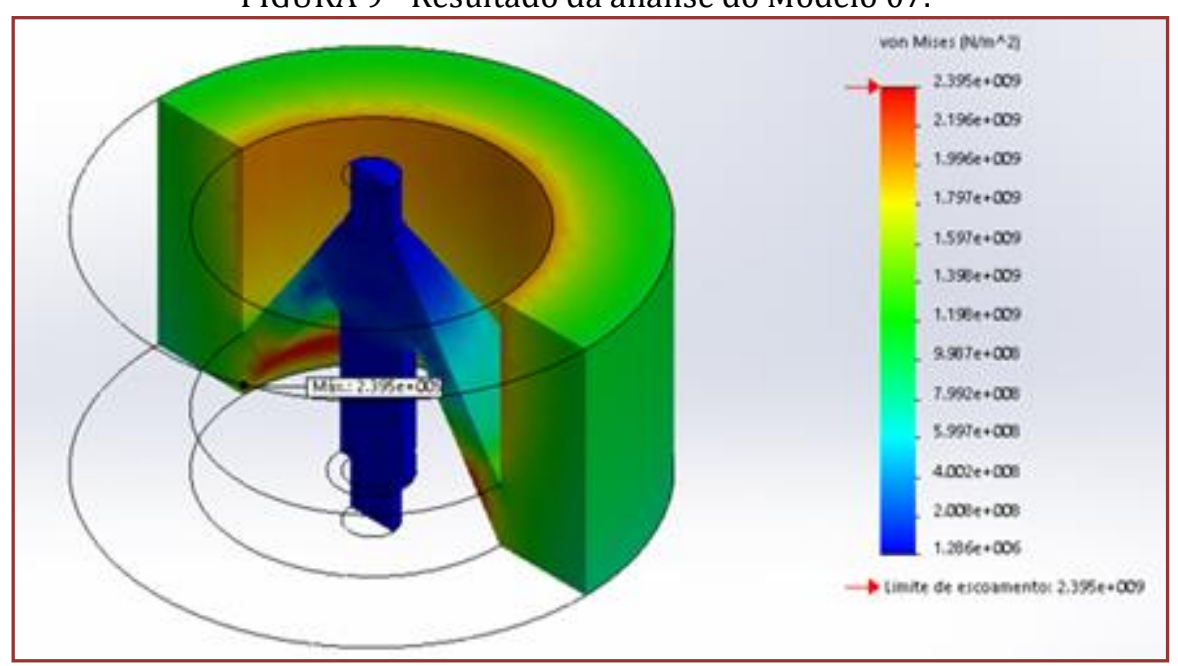

Fonte: $\mathrm{O}$ autor.

\subsection{RESUMO DA ANÁLISE DO MODELO 08}

0 modelo 08 foi concebido para mitigar a concentração de tensão apresentada no modelo 07 , tornando o cone de ligação entre o eixo e a coroa mais delgado, projetando a coroa em sentido do eixo nesta união com o cone (Figura 10).

FIGURA 10 - Resultado da análise do Modelo 08.

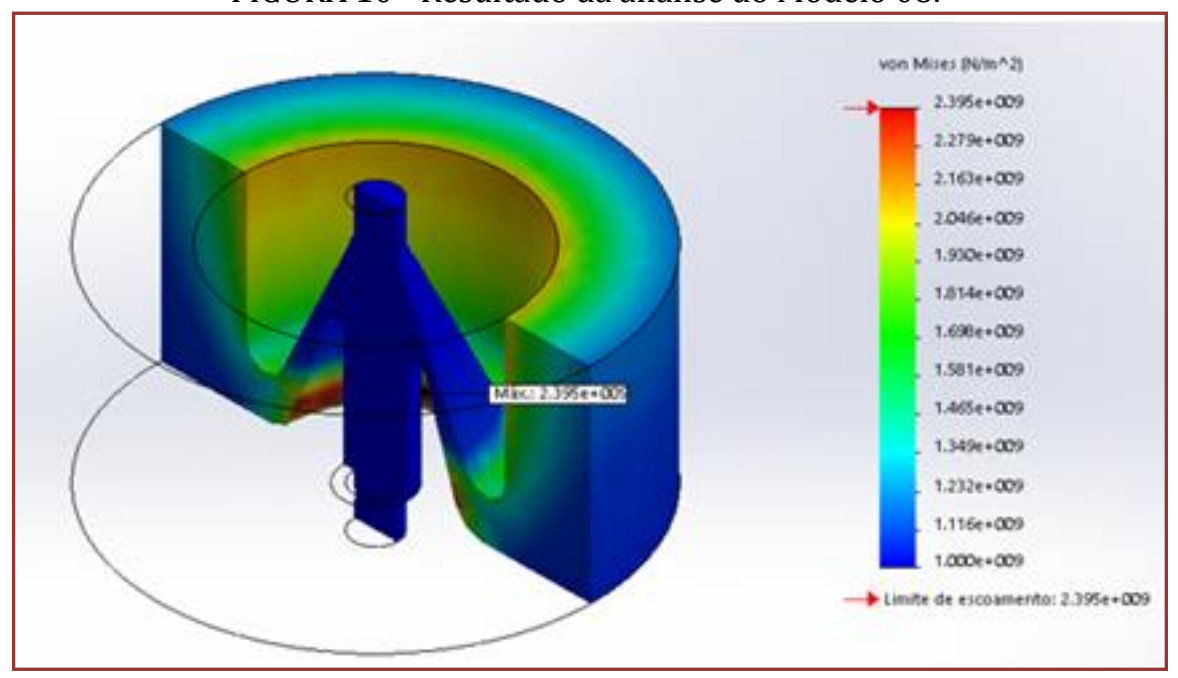

Fonte: $\mathrm{O}$ autor.

Não houve, porém, nenhuma melhora significativa na performance, com os resultados obtidos muito próximos do modelo anterior, modelo 07.

A concentração de tensões nessa seção limitou o estudo a uma rotação máxima de 50.710 rpm.

\section{RESULTADOS E COMENTÁRIOS FINAIS}

Após a realização dos ensaios, os resultados apresentados de rotação máxima e energia rotacional indicaram que a geometria do modelo 05 possuí a melhor performance.

Esse resultado ficou evidenciado também através do estudo da relação entre energia acumulada e a massa do rotor, cujo objetivo é otimizar o acumulo de energia na menor massa possível, conforme demonstrado na tabela 3 . 
Ficou comprovado que a geometria do rotor tem influência direta nos resultados das análises realizadas através do MEF, indicando de forma clara que o estudo do rotor é uma etapa importante no desenvolvimento do equipamento e deve ser realizada de forma criteriosa para otimizar o desempenho da bateria eletromecânica.

TABELA 3 - Compilação de resultados das análises

\begin{tabular}{|l|c|c|c|c|c|c|c|c|c|}
\hline \multicolumn{1}{|c}{ Modelo } & 1 & 2 & 3 & 5 & 6 & 7 \\
\hline Massa do Rotor (Kg) & 19,664 & 21,528 & 22,417 & 20,345 & 22,186 & 20,822 & 19,008 & 18,829 \\
\hline Rotação máxima admitida (RPM) & 53.200 & 61.900 & 57.370 & 62.940 & 65.290 & 47.720 & 50.890 & 50.710 \\
\hline Energia rotacional em rotação máxima (J) & 1.797 .534 & 2.512 .087 & 2.205 .161 & 2.543 .418 & 2.791 .346 & 1.434 .202 & 1.626 .719 & 1.610 .591 \\
\hline Relação Energia/Massa (J/Kg) & 91412,4 & $116.689,30$ & $98.370,00$ & $125.014,40$ & $125.815,60$ & $68.879,20$ & $85.581,70$ & $85.537,80$ \\
\hline
\end{tabular}

Fonte: 0 autor

\section{REFERÊNCIAS}

[1] Hearn, C. S. et al, Low Cost Flywheel Energy Storage for a Fuel Cell Powered Transit Bus. The University of Texas at Austin. 2007.

[2] Junling, C., et al, A Novel Uninterruptible Power Supply using Flywheel Energy Storage Unit, Power Electronics and Motion Control Conference, v. 3, pp. 1180 -1184, Aug. 2004.

[3] Murger, P. R. N., Otimização de Geometria e Material para Baterias Eletromecânicas. 2016. Dissertação de Mestrado em Engenharia Mecânica - Instituto Federal de Educação, Ciência e Tecnologia de São Paulo - IFSP.

[4] Proaktiva 2018 - Disponível em http://photo.proaktiva.eu/digest/2008_gyrobus.html Acesso em $20 / 05 / 2018$

[5] Ribeiro, M. R., Sistema Armazenador de Energia Cinética SAEC - Estratégia de Controle e Simulações. Dissertação de Mestrado, COPPE/UFRJ, Rio de Janeiro, RJ, Brasil, 2008.

[6] Scpolias 2018 - Disponível em http://www.scpolias.com.br/produto/volantes-de-inercia-19 Acesso em $27 / 05 / 2018$ as $18: 00 \mathrm{~h}$. 


\section{Capítulo 13}

Nível de sustentabilidade dos Municípios do Estado do Rio de Janeiro: Uma análise sob a luz do Triple Bottom Line

Ana Luiza Mendes Silva

Sávio Mendes Silva

Luan dos Santos

Resumo: O objetivo deste artigo é a proposição de uma metodologia de análise do Índice de Desenvolvimento Sustentável para Municípios (IDSM), a partir da coleta, tratamento e análise de indicadores de sustentabilidade baseados na literatura. Os índices foram classificados em diferentes níveis e a pesquisa exploratória feita nos municípios do estado do Rio de Janeiro elucidou uma situação de alerta do estado em relação ao tripé da sustentabilidade. 0 estudo é relevante na disseminação do conhecimento e do estudo das oportunidades de crescimento dos municípios de maneira sustentável nas esferas social, econômica e ambiental de maneira igualitária. Os resultados permitiram interpretações de possíveis ações a serem tomadas pelos gestores de maneira a propiciarem condições adequadas para o processo de desenvolvimento local.

Palavras-Chave: Triple bottom line, desenvolvimento sustentável, índice de sustentabilidade 


\section{INTRODUÇÃO}

Parafraseando o pensamento de Ruthes \& Nascimento (2006), apenas através da harmonia e do equilíbrio, uma região consegue promover crescimento econômico com qualidade de vida e respeito ao meio ambiente. Assim sendo, a motivação para este estudo está na abordagem holística que a engenharia é capaz de ter, objetivando a aproximação desses temas aparentemente dissociados. Em 1994, Jacobi já destacava a busca pela sustentabilidade. Afirmava que, simultaneamente, ela relaciona a resolução de questões complexas de forma inter-relacionada, tais como, exploração de recursos naturais, crescimento econômico, pobreza e distribuição de renda, tendo como natureza o que Sachs (2007) denominou de "ecossocioeconomia".

Segundo sua definição geral, sustentabilidade é, basicamente, à capacidade de atender as necessidades da geração atual sem comprometer as necessidades das gerações futuras, (WCED, 1987). Nesse contexto, e aplicando à definição o conceito de desenvolvimento, é relevante considerar o papel dos municípios neste cenário. Diante da necessidade alarmante de olhar para as questões ambientais, novos estudos e discussões surgem e, com isso, os atores sociais e econômicos necessariamente são introduzidos nas discussões.

O objetivo deste estudo é promover uma análise dos municípios do estado do Rio de Janeiro no âmbito da sustentabilidade, de maneira a ranqueá-los com base em um indicador unificado de sustentabilidade, cujos parâmetros são apoiados em uma triangulação de ações sociais, econômicas e ambientais.

O tema do desenvolvimento sustentável é de tamanha relevância em todas as esferas políticas globais, que é um dos temas mais debatidos na Organização das Nações Unidas. Segundo o secretário-geral da ONU, António Guterres, durante conferência global sobre o tema realizada no Quirguistão em 2017, o serviço público é um componente crítico para alcançar os Objetivos de Desenvolvimento Sustentável (ODS). É necessário explorar novas abordagens, trabalhar de forma diferente, correr riscos e inovar. Com essa perspectiva, o foco na esfera municipal é estratégico, uma vez que se trata da área de menor atuação federal, porém que de resultados a curto prazo, tornando mais fácil a implementação de medidas públicas de desenvolvimento sustentável.

\section{O CONCEITO DE TRIPLE BOTTOM LINE}

De acordo com Almeida (2002), o Triple Bottom Line reflete todo um conjunto de objetivos, valores e processos que uma companhia deve ter como objetivo a fim de criar valores econômicos, sociais e ambientais para, através do qual, minimizar todo e qualquer dano resultante de sua atuação. Esse conceito, hoje, é considerado uma ferramenta de vanguarda útil às relações e promotora de certa sustentabilidade econômica, crucial para não somente as empresas como também para os governos, através da manutenção da confiança sobre os valores ambientais desses órgãos.

0 tripé ilustra as relações existentes entre a sociedade, economia e o ecossistema global. Ele entende que a população depende da economia e que esta depende do ecossistema global, uma vez que os recursos são finitos. De maneira prática, as empresas dependem de licenças prévias, de instalação, e de operação para que operem e satisfaçam as expectativas dos stakeholders (partes interessadas), sendo eles internos, como os acionistas e dividendos, e, também a sociedade que é impactada diretamente. Desta maneira, é fundamental a diferenciação entre crescimento econômico (ou sucesso econômico) e desenvolvimento econômico, uma vez que os resultados desse desenvolvimento são cruciais para as dimensões social e ambiental a nível local e global.

A teoria de Elkington (1999) do Triple Bottom Line consistiu em desenvolver algumas açõess a fim de auxiliar empresas do ramo de petróleo e gás embutir os 3 (três) componentes do desenolvimento sustentável - prosperidade econômica, justiça social e proteção ao meio ambiente - às suas operações principais. Para o ele, a transição para um sistema de Triple Bottom Line não é trivial, pois exige mudanças estruturais da operação e organização comercial das empresas (apud Cotrim, S. L. et. al (2006)). Assim, por consequência, resultando em alterações nos negócios locais e globais, como observado na Tabela 1 abaixo: 
Tabela 14 - Alterações nos negócios locais e globais

\begin{tabular}{|ccccc|}
\hline Revolução & Foco & Velho Paradigma & $\Rightarrow$ & Novo Paradigma \\
\hline $\mathbf{1}$ & Mercado & Obediência & $\Rightarrow$ & Competição \\
2 & Valor & Pesado & $\Rightarrow$ & Livre \\
3 & Transparência & Fechado & $\Rightarrow$ & Aberto \\
4 & Tecnologia do Ciclo de Vida & Produto & $\Rightarrow$ & Função \\
5 & Parcerias & Subversão & & Simbiose \\
6 & Tempo & Curto Prazo & $\Rightarrow$ & Longo Prazo \\
7 & Responsabilidade Social Corporativa & Exclusão & $\Rightarrow$ & Inclusão \\
\hline
\end{tabular}

Fonte triple Bottom Line - As Sete Revoluções Fundamentais no Mundo dos Negócios (Adaptado de Elkington,

1198)

\section{RELEVÂNCIA DO ESTUDO PARA A GESTÃo PÚBLICA}

Questões que envolvem necessidades existentes nos ecossistemas e no local de responsabilidade da administração pública municipal devem ser bem conhecidas e sofrer intervenções periódicas por parte desses órgãos. Para tanto, existem políticas ambientais que orientam essas intervenções, assegurando: planejamento da matriz energética, controle dos impactos ambientais e suas consequências econômicas para o município, promoção da educação ambiental, controle dos tipos de poluição, gerenciamento das licenças ambientais, entre outros (S CHNEIDER, E. (2009) apud Carvalho, A.V.d. (2005)). Além disso, as discussões acerca de questões ambientais vêm crescendo ao longo do tempo devido à progressiva degradação que o meio ambiente sofreu por décadas. Também, é possível perceber que a poluição - seja ela do ar atmosférico, da água, dos solos, entre outros - afeta diretamente não apenas a saúde da população, mas, relacionado a isso, o rendimento econômico de uma cidade, estado e, até mesmo, de um país.

Portanto, é preciso que a administração pública trate as questões do meio ambiente com uma ótica mais atenta e voltada para proposição de soluções e implementação de ações mais eficientes e eficazes, através da criação de uma secretaria municipal composta por especialistas na área ambiental, por exemplo. Dessa maneira, seria possível, com um planejamento adequado, viabilizar políticas públicas que controlem os impactos socioambientais gerados por realizações mal planejadas, desenvolvendo cada vez mais na população local a consciência do papel não apenas dos governantes, mas também deles próprios, quanto a preservação do meio ambiente e ao desenvolvimento sustentável.

A efetividade da política ambiental depende, principalmente, da sensibilização e do envolvimento da comunidade para/com as questões ambientais. Além disso, para sua implementação adequada, é necessário a disponibilização de recursos financeiros, técnicos e humanos. Essa sensibilização e a disponibilização de recursos demarcam o nível de poluição socialmente aceitável, isto é, o quanto a sociedade se sente incomodada com a poluição, além do quanto de recursos que está disposta a investir para melhorar esse meio ambiente (TORRESI et al., 2010; LAYRARGUES, 2002, apud Carvalho, A.V.d (2015)). Logo, sendo os municípios a esfera política mais próxima da população, são deles que deve partir essa sensibilização para que, a partir disso, as demais esferas possam disponibilizar os recursos necessários para que se consiga gerir melhor todas essas questões associadas a todo e qualquer tipo de poluição e degradação ambiental, social e/ou econômica.

\section{METODOLOGIA}

É sabido que o termo sustentabilidade envolve uma grande diversidade de aspectos, e neste sentido, se fazem necessárias diferentes abordagens com visões que integrem todas as dimensões e indicadores. Desta maneira, a presente construção metodológica visa a aplicação para o auxílio na tomada de decisões dos governos municipais.

A estruturação do trabalho foi feita com base na análise metodológica de hierarquização proposta por Martins e Cândido (2008) e será descrita nas subseções seguintes. Para determinar as variáveis utilizadas neste estudo, observou-se a análise proposta diversos autores da bibliografia na busca pela compreensão da sustentabilidade como proxy das dimensões do triple Bottom Line que caracterizem os espaços 
geográficos de maneira multidimensional. Além disso, utilizou-se a publicação dos indicadores de desenvolvimento sustentável: Brasil 2004 (IBGE, 2004). Este arquivo foi importante na definição das variáveis mais relevantes considerando as peculiaridades e características do contexto do estado.

Considerando os critérios definidos anteriormente, foram analisados, conforme descrito por Martins e Cândido (2012) algumas características relevantes:

a) Ser significativo para a realidade investigada e para o enfoque do estudo;

b) Ser relevante para as decisões que orientam as políticas públicas;

c) Refletir as mudanças temporais;

d) Permitir um enfoque integrado e sistêmico;

e) Utilizar variáveis mensuráveis;

f) Ser de fácil interpretação e comunicação;

g) Ter uma metodologia bem definida, transparente e objetiva aos propósitos da investigação.

Além desses critérios, o motivo principal para a escolha dos indicadores foi a disponibilidade de todos os dados para os municípios do Estado do Rio de Janeiro.

\subsection{COLETA DE DADOS}

A partir das referências, foram determinadas as vaiáveis analisadas dentro das grandes dimensões conforme mostrado na Tabela 2 abaixo:

Tabela 15 - Indicadores

\begin{tabular}{|c|c|}
\hline Dimensão & Variável \\
\hline \multirow{3}{*}{ SOCIAL } & Escolarização 6 a 14 anos \\
\hline & Mortalidade infantil - óbitos por 1000 nascidos vivos \\
\hline & Número de homicídios por 10.000 habitantes \\
\hline \multirow{3}{*}{ ECONÔMICO } & PIB per capita \\
\hline & População ocupada \\
\hline & Salário médio mensal dos trabalhadores formais \\
\hline \multirow{3}{*}{ AMBIENTAL } & Arborização das vias públicas \\
\hline & Domicílios com água encanada \\
\hline & Esgotamento sanitário adequado \\
\hline
\end{tabular}

Fonte: Realizado pelos autores

Os dados foram coletados a partir de bases fornecidas pelo IBGE acerca dos 92 municípios do Estado do Rio de Janeiro e tabulados no Software Excel através da metodologia descrita na seção seguinte.

\subsection{MÉTODO DE DETERMINAÇ̃̃o DO ÍNDICE DE DESENVOLVIMENTO SUSTENTÁVEL MUNICIPAL (IDSM)}

Os dados municipais coletados possuíam unidades de medida distintas, ou seja, para que pudessem ser comparados, se fez necessária uma padronização destes dados em índices, que variam de 0 a 1 , de modo que, quanto mais próximo de 1, melhor é o desenvolvimento do município em relação ao indicador de sustentabilidade analisado. Primeiramente a padronização foi feita para cada indicador, e, posteriormente, para as dimensões social, econômica e ambiental, definindo o Índice de Desenvolvimento Social (IDS), Índice de Desenvolvimento Econômico (IDE) e Índice de Desenvolvimento Ambiental (IDA).

É importante salientar que alguns indicadores são positivamente correlacionados com a sustentabilidade e outros, negativamente. Tendo em vista estas diferenças, definiram-se os tipos de relação (positiva ou negativa) entre cada variável e a sustentabilidade. Em outras palavras, observou-se o comportamento de cada variável em que, aumentando o valor do indicador favorece ou não o processo de desenvolvimento sustentável. 
menor o indicador, pior o índice), enquanto na relação negativa ocorre o inverso, ou seja, quanto maior o indicador, pior o índice.

Feita a identificação das relações positivas e negativas, o cálculo dos índices é feito da seguinte forma:

- $\quad$ Relação positiva

$$
I=\frac{x-m}{M-m}
$$

- $\quad$ Relação negativa

Onde:

$$
I=\frac{M-x}{M-m}
$$

I: índice calculado para cada variável em cada município

$x$ : valor observado de cada variável em cada município

$m$ : valor mínimo de cada indicador

M: valor máximo de cada indicador

Após a padronização dos dados em índices, foram encontrados os índices de cada dimensão para cada município através da média aritmética dos indicadores. Estes índices globais IDS, IDE e IDA foram agregados à um indicador unificado, denominado Índice de Desenvolvimento Sustentável Municipal (IDSM) através da média aritmética para cada município.

Para representação visual e análise dos resultados, foi definida uma escala de criticidade da situação de cada município conforme ilustrado na Tabela 3 abaixo:

Tabela 16 - Classificação de status de nível de sustentabilidade

\begin{tabular}{|c|c|}
\hline Índice $(0-1)$ & Nível de sustentabilidade \\
\hline $0,00|-| 0,25$ & Crítico \\
\hline $0,25-\mid 0,50$ & Alerta \\
\hline $0,50-\mid 0,75$ & Aceitável \\
\hline $0,75-\mid 1,00$ & Ideal \\
\hline
\end{tabular}

Fonte: Realizado pelos autores

A Tabela 3 indica que os municípios com IDSM entre 0,00 e 0,25 apresentam um nível crítico de sustentabilidade; os índices com valores entre 0,25 e 0,50 demonstram estado de alerta; os índices com valores entre 0,50 e 0,75 descrevem um estado aceitável e os índices com valores maiores que 0,75 revelam um nível ideal de desenvolvimento sustentável.

\section{ANÁLISE DOS RESULTADOS}

Os resultados obtidos e hierarquizados estão sintetizados na Tabela 4 abaixo. Pode-se observar os índices por grupo (social, econômico e ambiental), bem como o índice global (IDSM) e respectiva classificação de status: 
Tabela 17 - Classificação dos municípios

\begin{tabular}{|c|l|c|c|c|c|c|}
\hline \multicolumn{2}{|c|}{ MUNICÍPIO } & IDS & IDE & IDA & IDSM & IDSM \\
\hline 1 & Macaé & 0,542 & 0,828 & 0,686 & 0,685 & ACEITÁVEL \\
\hline 2 & Comendador Levy Gasparian & 0,937 & 0,266 & 0,848 & 0,683 & ACEITÁVEL \\
\hline 3 & Itatiaia & 0,721 & 0,537 & 0,661 & 0,640 & ACEITÁVEL \\
\hline 4 & Rio de Janeiro & 0,592 & 0,477 & 0,835 & 0,635 & ACEITÁVEL \\
\hline 5 & São José de Ubá & 1,009 & 0,101 & 0,758 & 0,623 & ACEITÁVEL \\
\hline 6 & Italva & 0,921 & 0,099 & 0,815 & 0,612 & ACEITÁVEL \\
\hline 7 & Niterói & 0,574 & 0,391 & 0,854 & 0,606 & ACEITÁVEL \\
\hline 8 & Porto Real & 0,486 & 0,652 & 0,651 & 0,597 & ACEITÁVEL \\
\hline 9 & Três Rios & 0,726 & 0,272 & 0,789 & 0,596 & ACEITÁVEL \\
\hline 10 & Itaocara & 0,916 & 0,113 & 0,749 & 0,592 & ACEITÁVEL \\
\hline$\ldots$ & $\ldots$ & $\ldots$ & $\ldots$ & $\ldots$ & $\ldots$ & \\
\hline 82 & Duque de Caxias & 0,162 & 0,248 & 0,712 & 0,374 & ALERTA \\
\hline 83 & Belford Roxo & 0,393 & 0,076 & 0,652 & 0,373 & ALERTA \\
\hline 84 & Sapucaia & 0,082 & 0,231 & 0,712 & 0,342 & ALERTA \\
\hline 85 & Itaguaí & 0,038 & 0,387 & 0,581 & 0,335 & ALERTA \\
\hline 86 & Itaboraí & 0,325 & 0,110 & 0,537 & 0,324 & ALERTA \\
\hline 87 & Sumidouro & 0,183 & 0,106 & 0,636 & 0,308 & ALERTA \\
\hline 89 & Santa Maria Madalena & 0,420 & 0,100 & 0,399 & 0,306 & ALERTA \\
\hline 90 & Japeri & 0,308 & 0,038 & 0,566 & 0,304 & ALERTA \\
\hline 91 & Paraty & 0,241 & 0,185 & 0,392 & 0,273 & ALERTA \\
\hline 92 & São Francisco de Itabapoana & 0,504 & 0,060 & 0,156 & 0,240 & CRÍTICO \\
\hline
\end{tabular}

Fonte: Realizado pelos autores

A Tabela 5 abaixo resume a situação do Estado do Rio de Janeiro em relação aos resultados dos municípios.

Tabela 18 - Resumo da situação do Estado do Rio de Janeiro

\begin{tabular}{|c|c|c|c|}
\hline Ideal & Aceitável & Alerta & Crítico \\
\hline 0 & 42 & 49 & 1 \\
\hline 0 & $46 \%$ & $53 \%$ & $1 \%$ \\
\hline
\end{tabular}

Fonte: Realizado pelos autores

Pode-se inferir pelos resultados que os municípios de Macaé, Comendador Levy Gasparian, Itatiaia e Rio de Janeiro foram os melhores classificados no Índice de Desenvolvimento Sustentável Municipal, com um nível ACEITÁVEL de sustentabilidade de acordo com os parâmetros abordados, enquanto os municípios de Santa Maria Madalena, Japeri, Paraty e São Francisco de Itabapoana encontram-se nas piores posições do estado com níveis de ALERTA e CRÍTICO.

De maneira geral, o estado do Rio de Janeiro encontra-se em nível de alerta, com 53\% dos municípios ranqueados como tal, e nenhum município no estado ideal. Este resultado é esperado, dada a relevância produtora e econômica do estado para o país, pois no Brasil, ser economicamente desenvolvido ainda é diretamente proporcional à degradar o meio ambiente e a sociedade.

Uma interpretação interessante deste resultado é que os municípios melhores ranqueados possuem um equilíbrio entre os índices, ou seja, tais municípios não são necessariamente os mais evoluídos economicamente, como conclusão intuitiva. Esta observação reforça o conceito macro de desenvolvimento sustentável, em que a análise conjunta é mais relevante do que os aspectos observados individualmente.

\section{CONSIDERAÇÕES FINAIS E PERSPECTIVAS}

O presente estudo foi muito relevante pois proporcionou uma visão mais prática e acessível acerca dos problemas reais, uma vez que a esfera municipal tende a ser mais tangível para se enxergar oportunidades de melhorias. Pode-se destacar como perspectiva futura uma implementação mais aprofundada deste estudo no apoio às decisões estratégicas municipais, para avaliar projetos e políticas públicas já implementadas e elucidar domínios em que há necessidade de incentivo e investimento. Além disso, se faz necessária uma análise destes indicadores em agrupamentos de municípios semelhantes, para que seja possível uma comparação dos resultados mais precisa. 
O último ponto relevante nesta análise é a ausência de indicadores mais rigorosos e mais abrangentes no âmbito ambiental e social, como por exemplo ligados à emissões de gases do efeito estufa, desmatamento, reflorestamento, etc, que dariam uma robustez maior na consolidação do indicador final. Esta limitação da pesquisa se dá pela dificuldade de encontrar tais dados na esfera municipal.

Por fim, cabe ressaltar que o tema do desenvolvimento sustentável já está há algumas décadas em foco, porém, mesmo nos dias atuais, os governos e empresas que levam essa abordagem a fundo ainda são consideradas vanguardas. É importante atentar-se para oportunidades de negócios, e, principalmente nichos de aprendizado e disseminação da cultura da sustentabilidade, para que no futuro os objetivos de desenvolvimento sustentável sejam alcançados e passem a ser objetivos intrínsecos à existência das corporações e governos.

\section{REFERÊNCIAS}

[1] Almeida, F. - O bom negócio da Sustentabilidade. Rio de Janeiro: Editora Nova Fronteira, 2002.

[2] Carvalho, A. V. d. - Educação Ambiental no Desenvolvimento Sustentável Municipal. Revista Desafios, 2(1), 97-108. https://doi.org/10.20873/uft.2359-3652.2015v2n1p97

[3] Cotrim, S. L. et. Al - Análise do modelo Triple Bottom Line: Conceito, histórico e estudo de casos. III CNEG. Niterói, 2006

[4] Elkington, J. - Triple bottom line revolution: Reporting for the third millennium. Australian CPA, 69, p. 75., 1999.

[5] Jacobi, Pedro Roberto. 0 complexo desafio da sustentabilidade: desenvolvimento e meio ambiente. São Paulo: Nobel, 1994.

[6] Layrargues, Philippe Pomier - Crise ambiental e suas implicações na educação. 2002.

[7] Macedo e Ferreira - Índice de desenvolvimento sustentável: uma análise apoiada em dea para os municípios do estado do rio de janeiro, 2011

[8] Martins e Candido - Índices de Desenvolvimento Sustentável para Localidades: Uma proposta metodológica de construção e análise, 2012

[9] Ruthes, Sidarta \& Nascimento, Décio Estevão do Desenvolvimento sustentável e os arranjos produtivos locais. In: IX Simpósio de Administração da Produção, Logística e Operações Internacionais - Simpoi. Anais... São Paulo: FGV/Eaesp, 2006. 1 CD-Rom.

[10] Sachs, Ignacy. Rumo à ecossocioeconomia: teoria e prática do desenvolvimento. São Paulo: Cortez, 2007.

[11] Schneider, E. - Gestão ambiental municipal: preservação ambiental e o desenvolvimento sustentável. Porto Alegre: Univates, 2009.

[12] Torresi, S.I.C.; Pardini, V.L.; Ferreira, V.F. - O que é sustentabilidade? Quim. Nova,v.33 n. 1 São Paulo, p:58-67, 2010.

[13] World Commission on Environment And Development - Wced. Our common future. Oxford and New York: Oxford University Press, 1987. 


\section{ANEXO}

Tabela 19 - Classificação geral dos municípios do Estado do Rio de Janeiro

\begin{tabular}{|c|c|c|c|c|c|c|}
\hline & MUNICÍPIO & IDS & IDE & IDA & IDSM & IDSM \\
\hline 1 & Macaé & 0,542 & 0,828 & 0,686 & 0,685 & ACEITÁVEL \\
\hline 2 & Comendador Levy Gasparian & 0,937 & 0,266 & 0,848 & 0,683 & ACEITÁVEL \\
\hline 3 & Itatiaia & 0,721 & 0,537 & 0,661 & 0,640 & ACEITÁVEL \\
\hline 4 & Rio de Janeiro & 0,592 & 0,477 & 0,835 & 0,635 & ACEITÁVEL \\
\hline 5 & São José de Ubá & 1,009 & 0,101 & 0,758 & 0,623 & ACEITÁVEL \\
\hline 6 & Italva & 0,921 & 0,099 & 0,815 & 0,612 & ACEITÁVEL \\
\hline 7 & Niterói & 0,574 & 0,391 & 0,854 & 0,606 & ACEITÁVEL \\
\hline 8 & Porto Real & 0,486 & 0,652 & 0,651 & 0,597 & ACEITÁVEL \\
\hline 9 & Três Rios & 0,726 & 0,272 & 0,789 & 0,596 & ACEITÁVEL \\
\hline 10 & Itaocara & 0,916 & 0,113 & 0,749 & 0,592 & ACEITÁVEL \\
\hline 11 & Volta Redonda & 0,672 & 0,272 & 0,824 & 0,589 & ACEITÁVEL \\
\hline 12 & Miguel Pereira & 0,894 & 0,168 & 0,695 & 0,585 & ACEITÁVEL \\
\hline 13 & Rio Bonito & 0,714 & 0,265 & 0,766 & 0,582 & ACEITÁVEL \\
\hline 14 & Carmo & 0,886 & 0,123 & 0,725 & 0,578 & ACEITÁVEL \\
\hline 15 & Cordeiro & 0,781 & 0,117 & 0,833 & 0,577 & ACEITÁVEL \\
\hline 16 & Santo Antônio de Pádua & 0,828 & 0,164 & 0,739 & 0,577 & ACEITÁVEL \\
\hline 17 & Aperibé & 0,710 & 0,104 & 0,910 & 0,575 & ACEITÁVEL \\
\hline 18 & Piraí & 0,804 & 0,354 & 0,555 & 0,571 & ACEITÁVEL \\
\hline 19 & Vassouras & 0,855 & 0,186 & 0,665 & 0,569 & ACEITÁVEL \\
\hline 20 & Areal & 0,932 & 0,210 & 0,559 & 0,567 & ACEITÁVEL \\
\hline 21 & Porciúncula & 0,796 & 0,073 & 0,813 & 0,561 & ACEITÁVEL \\
\hline 22 & Quissamã & 0,830 & 0,230 & 0,621 & 0,560 & ACEITÁVEL \\
\hline 23 & Quatis & 0,761 & 0,105 & 0,810 & 0,559 & ACEITÁVEL \\
\hline 24 & Bom Jesus do Itabapoana & 0,763 & 0,112 & 0,799 & 0,558 & ACEITÁVEL \\
\hline 25 & Miracema & 0,740 & 0,097 & 0,830 & 0,556 & ACEITÁVEL \\
\hline 26 & Barra do Piraí & 0,787 & 0,109 & 0,766 & 0,554 & ACEITÁVEL \\
\hline 27 & Natividade & 0,748 & 0,090 & 0,809 & 0,549 & ACEITÁVEL \\
\hline 28 & Varre-Sai & 0,841 & 0,083 & 0,704 & 0,543 & ACEITÁVEL \\
\hline 29 & Barra Mansa & 0,735 & 0,171 & 0,720 & 0,542 & ACEITÁVEL \\
\hline 30 & Macuco & 0,813 & 0,205 & 0,597 & 0,538 & ACEITÁVEL \\
\hline 31 & Itaperuna & 0,580 & 0,177 & 0,841 & 0,533 & ACEITÁVEL \\
\hline 32 & Resende & 0,541 & 0,343 & 0,710 & 0,531 & ACEITÁVEL \\
\hline 33 & Rio das Ostras & 0,643 & 0,325 & 0,623 & 0,530 & ACEITÁVEL \\
\hline 34 & Cambuci & 0,848 & 0,066 & 0,674 & 0,529 & ACEITÁVEL \\
\hline 35 & Paraíba do Sul & 0,657 & 0,144 & 0,783 & 0,528 & ACEITÁVEL \\
\hline
\end{tabular}


(Continuação ...)

\section{ANEXO}

Tabela 20 - Classificação geral dos municípios do Estado do Rio de Janeiro

\begin{tabular}{|c|c|c|c|c|c|c|}
\hline & MUNICÍPIO & IDS & IDE & IDA & IDSM & IDSM \\
\hline 36 & Nova Friburgo & 0,775 & 0,205 & 0,601 & 0,527 & ACEITÁVEL \\
\hline 37 & Casimiro de Abreu & 0,798 & 0,166 & 0,617 & 0,527 & ACEITÁVEL \\
\hline 38 & Petrópolis & 0,666 & 0,273 & 0,619 & 0,519 & ACEITÁVEL \\
\hline 39 & Paracambi & 0,643 & 0,076 & 0,835 & 0,518 & ACEITÁVEL \\
\hline 40 & São Fidélis & 0,687 & 0,081 & 0,780 & 0,516 & ACEITÁVEL \\
\hline 41 & Bom Jardim & 0,710 & 0,148 & 0,650 & 0,503 & ACEITÁVEL \\
\hline 42 & Cachoeiras de Macacu & 0,807 & 0,098 & 0,597 & 0,501 & ACEITÁVEL \\
\hline 43 & Pinheiral & 0,649 & 0,063 & 0,787 & 0,500 & ALERTA \\
\hline 44 & Rio das Flores & 0,615 & 0,174 & 0,708 & 0,499 & ALERTA \\
\hline 45 & Arraial do Cabo & 0,832 & 0,128 & 0,531 & 0,497 & ALERTA \\
\hline 46 & Conceição de Macabu & 0,770 & 0,065 & 0,644 & 0,493 & ALERTA \\
\hline 47 & Tanguá & 0,710 & 0,076 & 0,692 & 0,493 & ALERTA \\
\hline 48 & Valença & 0,743 & 0,125 & 0,608 & 0,492 & ALERTA \\
\hline 49 & Laje do Muriaé & 0,826 & 0,079 & 0,569 & 0,491 & ALERTA \\
\hline 50 & Seropédica & 0,661 & 0,252 & 0,553 & 0,488 & ALERTA \\
\hline 51 & Guapimirim & 0,660 & 0,079 & 0,682 & 0,474 & ALERTA \\
\hline 52 & Nilópolis & 0,476 & 0,071 & 0,870 & 0,472 & ALERTA \\
\hline 53 & Engenheiro Paulo de Frontin & 0,810 & 0,083 & 0,517 & 0,470 & ALERTA \\
\hline 54 & Mendes & 0,826 & 0,073 & 0,508 & 0,469 & ALERTA \\
\hline 55 & Silva Jardim & 0,721 & 0,103 & 0,579 & 0,468 & ALERTA \\
\hline 56 & Paty do Alferes & 0,713 & 0,086 & 0,599 & 0,466 & ALERTA \\
\hline 57 & Campos dos Goytacazes & 0,479 & 0,218 & 0,696 & 0,464 & ALERTA \\
\hline 58 & Queimados & 0,474 & 0,142 & 0,769 & 0,462 & ALERTA \\
\hline 59 & Cardoso Moreira & 0,652 & 0,100 & 0,627 & 0,460 & ALERTA \\
\hline 60 & São José do Vale do Rio Preto & 0,699 & 0,104 & 0,563 & 0,455 & ALERTA \\
\hline 61 & Mesquita & 0,474 & 0,070 & 0,812 & 0,452 & ALERTA \\
\hline 62 & Rio Claro & 0,669 & 0,081 & 0,595 & 0,448 & ALERTA \\
\hline 63 & Armação dos Búzios & 0,428 & 0,394 & 0,513 & 0,445 & ALERTA \\
\hline 64 & Angra dos Reis & 0,488 & 0,322 & 0,523 & 0,445 & ALERTA \\
\hline 65 & Teresópolis & 0,630 & 0,200 & 0,500 & 0,443 & ALERTA \\
\hline 66 & Carapebus & 0,636 & 0,109 & 0,585 & 0,443 & ALERTA \\
\hline 67 & Mangaratiba & 0,566 & 0,390 & 0,372 & 0,443 & ALERTA \\
\hline 68 & São Pedro da Aldeia & 0,649 & 0,149 & 0,527 & 0,442 & ALERTA \\
\hline 69 & Trajano de Moraes & 0,682 & 0,078 & 0,536 & 0,432 & ALERTA \\
\hline 70 & Araruama & 0,615 & 0,109 & 0,557 & 0,427 & ALERTA \\
\hline
\end{tabular}


(Continuação ...)

\section{ANEXO}

Tabela 21 - Classificação geral dos municípios do Estado do Rio de Janeiro

\begin{tabular}{|c|c|c|c|c|c|c|}
\hline & MUNICÍPIO & IDS & IDE & IDA & IDSM & IDSM \\
\hline 71 & Nova Iguaçu & 0,426 & 0,102 & 0,742 & 0,423 & ALERTA \\
\hline 72 & Iguaba Grande & 0,619 & 0,071 & 0,575 & 0,422 & ALERTA \\
\hline 73 & Saquarema & 0,615 & 0,221 & 0,412 & 0,416 & ALERTA \\
\hline 74 & São Gonçalo & 0,495 & 0,090 & 0,660 & 0,415 & ALERTA \\
\hline 75 & São João de Meriti & 0,459 & 0,096 & 0,688 & 0,414 & ALERTA \\
\hline 76 & São João da Barra & 0,437 & 0,500 & 0,303 & 0,413 & ALERTA \\
\hline 77 & Maricá & 0,617 & 0,150 & 0,462 & 0,410 & ALERTA \\
\hline 78 & Magé & 0,561 & 0,067 & 0,592 & 0,407 & ALERTA \\
\hline 79 & Cantagalo & 0,393 & 0,229 & 0,559 & 0,393 & ALERTA \\
\hline 80 & São Sebastião do Alto & 0,491 & 0,097 & 0,556 & 0,381 & ALERTA \\
\hline 81 & Cabo Frio & 0,378 & 0,204 & 0,558 & 0,380 & ALERTA \\
\hline 82 & Duas Barras & 0,609 & 0,079 & 0,436 & 0,374 & ALERTA \\
\hline 83 & Duque de Caxias & 0,162 & 0,248 & 0,712 & 0,374 & ALERTA \\
\hline 84 & Belford Roxo & 0,393 & 0,076 & 0,652 & 0,373 & ALERTA \\
\hline 85 & Sapucaia & 0,082 & 0,231 & 0,712 & 0,342 & ALERTA \\
\hline 86 & Itaguaí & 0,038 & 0,387 & 0,581 & 0,335 & ALERTA \\
\hline 87 & Itaboraí & 0,325 & 0,110 & 0,537 & 0,324 & ALERTA \\
\hline 88 & Sumidouro & 0,183 & 0,106 & 0,636 & 0,308 & ALERTA \\
\hline 89 & Santa Maria Madalena & 0,420 & 0,100 & 0,399 & 0,306 & ALERTA \\
\hline 90 & Japeri & 0,308 & 0,038 & 0,566 & 0,304 & ALERTA \\
\hline 91 & Paraty & 0,241 & 0,185 & 0,392 & 0,273 & ALERTA \\
\hline 92 & São Francisco de Itabapoana & 0,504 & 0,060 & 0,156 & 0,240 & CRÍTICO \\
\hline
\end{tabular}




\section{Capitulo 14}

Evolução tecnológica na produção de calçados esportivos: Da produção convencional à Indústria 4.0

\section{Adriana Yumi Sato Duarte \\ Fernando Soares de Lima \\ Regina Aparecida Sanches \\ Rayana Santiago de Queiroz \\ Franco Giuseppe Dedini}

Resumo: A presente pesquisa tem como objetivo apresentar um levantamento bibliográfico sobre a evolução tecnológica da produção de calçados esportivos e comparar o processo convencional de fabricação dos cabedais com os novos sistemas de produção que se encontram alinhados à indústria 4.0. Foram estudados os seguintes sistemas produtivos para a fabricação dos cabedais: máquinas de urdume (malharia convencional), máquinas retilíneas, máquinas circulares de grande diâmetro e máquinas circulares de pequeno diâmetro (3d). As inovações tecnológicas nas máquinas de malharia contribuem para a otimização dos processos produtivos e estão aos poucos tornando a moda mais sustentável, por meio de novas formas de produção têxtil que sejam mais eficientes, evitando o desperdício de água, energia e matéria-prima, além de eliminar a poluição e preparar essa indústria para a quarta revolução industrial.

Palavras-chave: Malharia, malharia 3d, têxtil, calçado esportivo. 


\section{INTRODUÇÃO}

A indústria calçadista é uma das mais antigas do mundo. Na Pré-História, a partir dos sinais gravados em pedra, pode-se afirmar que o ser humano não conhecia o calçado. No período Neolítico o homem cobria seus pés com peles de animais para se mover durante as caminhadas e se proteger das más condições ambientais (BOSSAN, 2007).

As pinturas mais antigas de calçados foram encontradas em cavernas na Espanha e na França e datam de 10.000 a.C.. No início o ser humano confeccionava seu próprio calçado de forma rudimentar, depois os calçados passaram a ser fabricados por artesãos em pequenos estabelecimentos. A formalização dessa indústria veio com a Revolução Industrial, ocorrida quase dois séculos depois. As primeiras fábricas e máquinas usadas exclusivamente pra a fabricação de calçados surgiram nos Estados Unidos e na Europa na década de1870 (UNIDO, 2007).

O primeiro calçado esportivo do mundo surgiu em 1920, mais leves e confortáveis que os calçados de uso diário, visando melhorar o desempenho dos atletas nas práticas esportivas, pois até então as pessoas corriam e praticavam outros esportes com seus sapatos de uso diário, pesados e desconfortáveis (CHOKLAT, 2012).

Desde então houve uma grande evolução no design, nos processos produtivos e nos materiais usados para a fabricação dos calçados e atualmente pode ser considerado um dos acessórios mais usados tanto para a prática de atividades esportivas como para o lazer. Entretanto, o componente humano não foi totalmente substituído pela automação dos equipamentos, parte dos processos de fabricação dos artigos calçadistas ainda possuem características que lembram as atividades desempenhadas pelos primeiros artesãos de sapatos e seus auxiliares, em suas pequenas oficinas (KERR; PEREIRA; KIMURA, 2009).

Neste contexto, o presente artigo tem como objetivo apresentar um levantamento bibliográfico sobre a evolução tecnológica da produção dos calçados esportivos e comparar o processo convencional de produção dos cabedais com os novos sistemas de produção que se encontram alinhados à Indústria 4.0. Foram estudados os seguintes sistemas produtivos para a fabricação dos cabedais: máquinas de urdume (malharia convencional), máquinas retilíneas, máquinas circulares de grande diâmetro e máquinas circulares de pequeno diâmetro (3D).

A definição destes objetos de estudo foi baseada em pesquisas que apontam a caminhada como atividade física mais praticada pelos brasileiros (IBGE, 2013; BRASIL, 2018). Os procedimentos metodológicos adotados na presente pesquisa têm caráter predominantemente exploratório e o estudo dos temas pilares da pesquisa envolve o levantamento bibliográfico de publicações acadêmicas e pesquisa documental como fonte primária de informações.

\section{CONTEXTUALIZAÇÃO DA PESQUISA}

\subsection{CADEIA TÊXTIL E DE CONFECÇÃO (TC)}

A Cadeia TC é composta pela obtenção de matéria prima, fiação, tecelagem ou malharia, beneficiamento e acabamento, confecção e venda. No ano de 2013, o total de exportações de têxteis e vestuário foi de US\$ 766 bilhões, a China foi líder nas exportações tanto de têxteis (39\%) quanto vestuário (35\%) enquanto a União Europeia é a maior importadora de bens (38\%). Prospecções indicam que no ano de 2020 este volume deve movimentar US\$ 851 bilhões (ABIT, 2014).

o Brasil é quinta maior indústria têxtil do mundo, a quarta em confecção e a quinta em produção de algodão. Entretanto, participa com menos de $0,4 \%$ desse mercado marcado pela hegemonia asiática. Cerca de $50 \%$ da produção mundial de têxteis está concentrada na Ásia, com destaque para a China. 0 setor foi responsável pelo surgimento de muitas outras indústrias e motor da revolução industrial no Brasil. Atualmente, emprega 1,7 milhão de pessoas de forma direta, das quais $75 \%$ são mulheres(ABIT, 2014).

\subsection{TECNOLOGIA DE PRODUÇÃO TÊXTIL: DA PRIMEIRA À QUARTA REVOLUÇÃO INDUSTRIAL}

A Primeira Revolução Industrial foi particularmente marcante para a indústria têxtil. No ano de 1733, John Kay patenteou a lançadeira voadora impulsionada por uma corda que aumentou o consumo de artigos produzidos em teares. Antes dessa invenção, o fio era transportado manualmente de um lado para outro no tear, fato que limitava a largura do tecido. Joseph-Marie Jacquard, em 1801, combinou mecanismos já 
existentes para desenvolver o Tear Jacquard. Ele também foi o inventor dos cartõ es perfurados que, mais tarde, foram considerados a base para os cartões de memória usados nos computadores (MCNEIL, 1990).

A transição para a Segunda Revolução Industrial foi marcada pelo aumento na produtividade e na introdução de novas fontes de energia na indústria têxtil. John Thorp criou, no ano de 1828, o filatório de anéis que possibilitava fiar uma quantidade maior de fios simultaneamente. Além disso, a primeira máquina de malharia circular foi patenteada em 1816. Em 1856, Matthew Townsen inventou a agulha de lingueta que simplificou a produção de malhas. Em 1864, William Cotton adaptou uma máquina de propulsão mecânica capaz de tricotar simultaneamente várias meias (MCNEIL, 1990; RIBEIRO, 1984).

A Terceira Revolução Industrial, também conhecida como Revolução Digital, foi caracterizada pelo uso de microprocessador, projeto auxiliado pelo computador (Computer-Aided Design - CAD), fibra óptica, telecomunicação, biogenética e laser. Algumas soluções tecnológicas, tais como escaneamento, modelagem 3D e estamparia digital estão sendo gradualmente adotadas pela indústria têxtil (MCNEIL, 1990).

A Quarta Revolução Industrial preconiza a necessidade de conexão entre todos os fluxos de informação ao longo do processo produtivo, em um sistema autônomo de produção que permite uma produção rápida e flexível (GLOY et al, 2013).Para Hermann et al (2015), Indústria 4.0 é um termo coletivo para tecnologias e conceitos da cadeia de valor de uma fábrica inteligente que monitoram os processos produtivos. Máquinas inteligentes que antecipam a ocorrência de falhas ou problemas de qualidade no processo produtivo e organizam o processo de decisão e auto-otimização são outros cenários para a Indústria 4.0 (GÖLZER et al, 2015).

\subsection{ARTIGOS ESPORTIVOS: MATERIAIS E PROCESSOS PRODUTIVOS}

Este segmento tem grande representatividade na economia mundial. No ano de 2017, o faturamento do setor de varejo esportivo foi de US\$260 bilhões. Deste total, US\$ 82 bilhões representam vendas de material e equipamento esportivo. 0 mercado global evoluiu muito nas últimas décadas, principalmente a partir da década de 1980 com mudanças do estilo de vida da população e da profissionalização e divulgação do esporte (SPORTS VALUE, 2018).

Devido à grande variedade de modalidades esportivas, os artigos têxteis são desenvolvidos de forma a favorecer o desempenho do praticante. Neste sentido, o processo de escolha das fibras utilizadas, da construção do fio, do método de produção do tecido, dos processos de confecção e acabamento são fundamentais para o sucesso do produto final (FILGUEIRAS et al, 2007).

Soutinho (2005) afirma que funcionalidades podem ser aplicadas aos produtos têxteis em três momentos: (1) na fibra, por meio de novas técnicas de produção; (2) no fio, a partir de novas estruturas; e (3) na estrutura, com modificações superficiais.

Para Hayes et al. (2011), a moda esportiva alia os conceitos de funcionalidade, conforto e segurança para atender as necessidades de desempenho de cada atleta em sua modalidade esportiva. Os artigos esportivos incluem roupas, calçados e acessórios usados tanto para atividades competitivas como para o lazer.

A indústria calçadista pode ser dividida, dependendo do tipo de calçado produzido, de acordo com o material de confecção do cabedal, em quatro grupos principais: injetados, sintéticos, couro e têxtil. Grande parte dos calçados injetados é produzida em fábricas que necessitam de pouca mão de obra, pois saem praticamente prontos das máquinas, com cabedal e solado unidos. Os calçados sintéticos, de couro e têxtil, necessitam de maior mão de obra para a fabricação do cabedal e posterior união deste ao solado (GUIDOLIN et al., 2010).

Os primeiros calçados eram fabricados usando apenas o couro como matéria-prima, depois foram desenvolvidos os calçados de borracha e tecido, hoje podem apresentar diferentes materiais em mesmo modelo. Atualmente, as empresas têm como meta projetar um produto inovador e a escolha dos materiais e do design é feita em função da funcionalidade do produto final.

As principais partes dos calçado, segundo Costa (2013), são:

- Cabedal: é a parte superior do tênis responsável pelo conforto do calçado, apoio e proteção dos pés e pela parte estética; 
- Palmilha: é a parte inferior do tênis, onde a planta do pé descansa. Fornece conforto, amortecimento e suporte ao pé do usuário. Influencia no pisar da pessoa e na sua postura física. A palmilha normalmente é removível e lavável;

- Biqueira: é a parte frontal do tênis, pode ser feita de diferentes materiais, sua função é absorver o nível de impacto, amortecer o pé e também serve para controlar os movimentos em pé;

- Solado: é a parte inferior do calçado, responsável por garantir a tração e durabilidade do tênis. Juntamente com a entressola determina fatores como flexibilidade, estabilidade e peso total do calçado;

- Contraforte: está localizado na área do calcanhar da parte superior, rodeia o calcanhar e mantém o pé centrado e estável;

- Língua: possibilita melhor conforto ao reduzir o atrito entre o cadarço e os pés e

- Cadarço: proporciona melhor conforto e ajuste. Sua função é segurar o tornozelo, reduzindo o risco de lesões. A figura $1 \mathrm{~A}$ mostra uma estrutura de malha e a figura $1 \mathrm{~B}$ mostra as partes de um calçado esportivo (figura 1).

Figura 1 - (A) Estrutura da laça da malha. Fonte: Liu et al (2017); (B) Partes de um tênis. Fonte: Tênis para Corrida (2019).

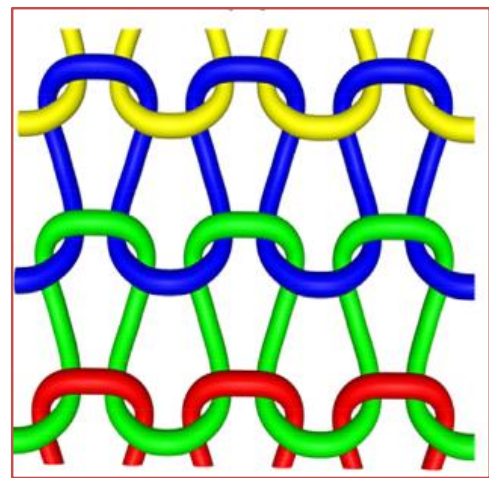

(A)

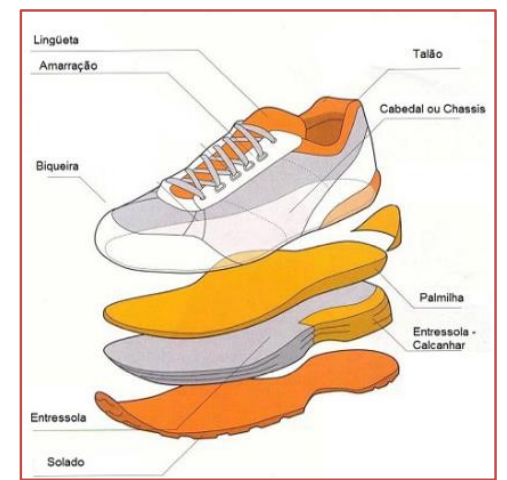

(B)

$\mathrm{Na}$ fabricação dos cabedais de malha pelo processo convencional, a indústria recebe da malharia o tecido, faz o corte das partes do cabedal, a união das partes é realizada em máquina de costura e posteriormente o cabedal e fixado no solado. Os novos processos de fabricação podem ser divididos em dois grupos: no primeiro, os cabedais prontos para serem acolplados aos solados, são fabricados pelas malharias utilizando as máquinas retilíneas e circulares de pequeno diâmetro (3D) e entregues às indústrias calçadistas. No segundo grupo, as malharias fabricam os cadedais em máquinas circulares de grande diâmetro, neste processo há a necessidade de realizar a operação de corte antes dos cabedais serem acoplados aos solados.

\section{RESULTADOS E DISCUSSÃO}

\subsection{PROCESSO DE PRODUÇÃO DOS CALÇADOS ESPORTIVOS A PARTIR DE TECIDOS DE MALHA (CONVENCIONAL)}

Este processo pode ser dividido duas etapas principais: na primeira, obtêm-se o tecido de malha (figura 2a), e na segunda, ocorre a fabricação do tênis que envolve desde o processo de criação até a embalagem do produto acabado (figura 2b) (GARCIA; MADEIRA, 2008). 
Figura 2 - fluxograma com as principais operações do processo de obtenção do tecido (A) e fabricação do tênis (B). Fonte: GARCIA; MADEIRA, 2008

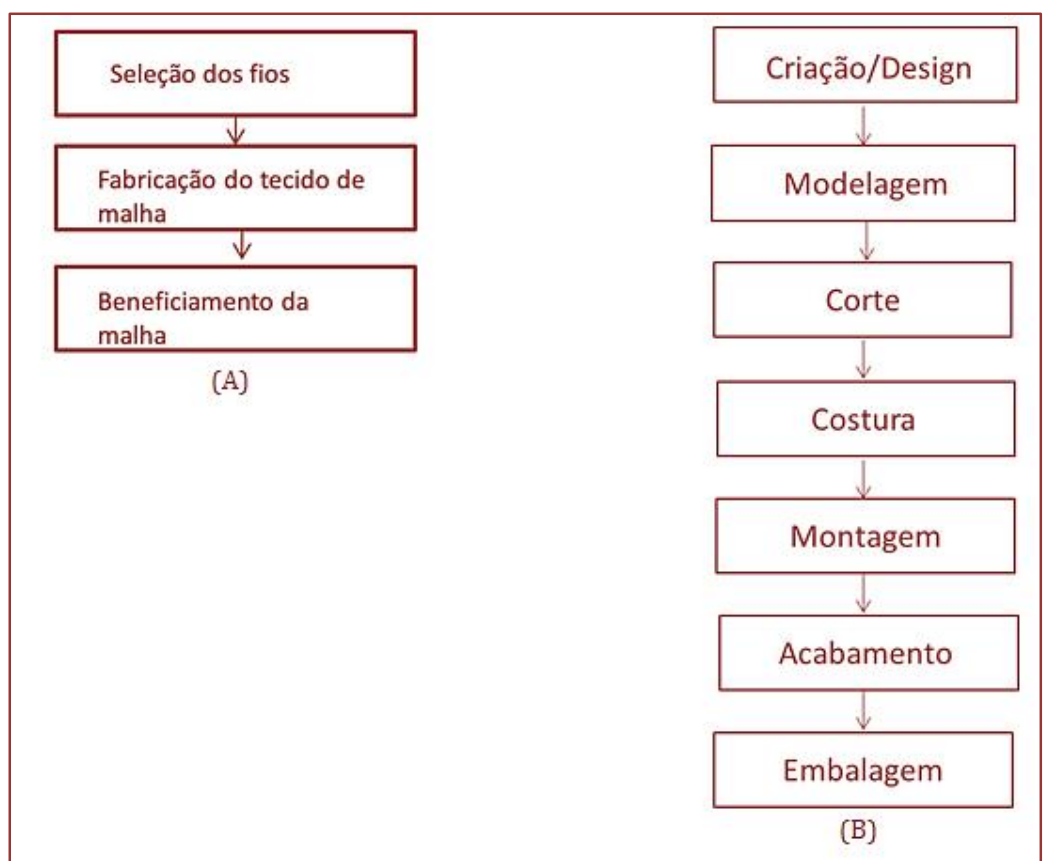

Na etapa do design é desenvolvido o conceito de produto, na modelagem são preparados os moldes, que podem ser feitos de forma manual ou automatizada com CAD (Computer Aided Design), nesta etapa também são definidos os materiais e a numeração. Em seguida, as partes são cortadas, o corte pode ser manual (facas, tesouras e canivetes) ou automatizado (a jato d'água e a laser). As aparas de tecido provenientes do corte são descartadas no meio ambiente. Na etapa da costura as partes do cabedal são unidas através de costuras, dobras, picotes ou cola. Na etapa da montagem, a sola é unida ao cabedal, em seguida são montados outro componentes tais como, a biqueira e calcanheira e a palmilha é preparada. Na fase do acabamento, o calçado é retirado da forma, é colocada a palmilha interna e realizados os retoques finais, em seguida o tênis é normalmente colocado em caixas retangulares de papelão (PROCHNIK et al., 2005).

Por outro lado, a tecnologia de confecção de malhas vem evoluindo, e as grandes empresas de artigos esportivos estão agora produzindo parte superior de calçados (cabedal) em máquinas de malharia retilínea, circular de grande diâmetro e de pequeno diâmetro (3D). As etapas de acabamento e embalagem são iguais em todos os processos produtivos.

\subsection{PROCESSO DE PRODUÇÃO DOS CALÇADOS ESPORTIVOS A PARTIR CABEDAIS DE MALHA FABRICADOS NAS MÁQUINAS CIRCULARES DE GRANDE DIÂMETRO}

As máquinas circulares de grande diâmetro produzem cabedais em tecidos abertos, com diferentes características e em alto volume de produção. 0 desenvolvimento de um produto inicia com a definição do design e a escolha dos fios têxteis que serão transformados em tecido de malha e enviados para as indústrias calçadistas para serem cortados e realizada a montagem do produto final (CARMELO COMERCIAL, 2019). Em quantidade, as aparas de tecidos uriundas da etapa de corte são menores que as do processo convencional, mas também são descartadas no meio ambiente. Na etapa de montagem, primeiramente é aplicado um material para dar estabilidade ao calçado (preparação para a montagem), em seguida as extremidades dos cabedais são fechadas com costura e o solado é acoplado ao cabedal. 0 esquema apresentado na Figura 3 resume estas etapas. 
Figura 3 - Fluxograma malharia circular de grande diâmetro. Fonte: Autores.

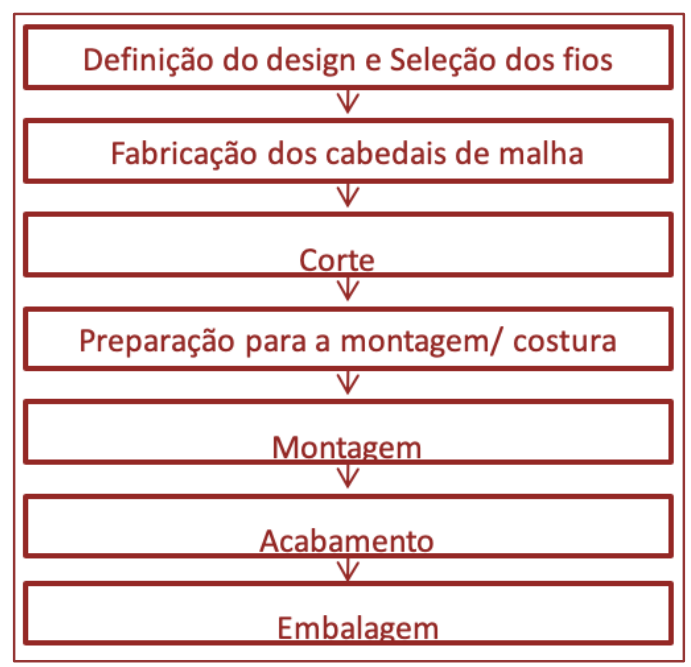

\subsection{PROCESSO DE PRODUÇÃO DOS CALÇADOS ESPORTIVOS A PARTIR CABEDAIS DE MALHA FABRICADOS NAS MÁQUINAS RETILÍNEAS}

Este processo produtivo é similar ao utilizado na fabricação dos cabedais produzidos pelas máquinas circulares de grande diâmetro. Entretanto, nas máquinas retilíneas os cabedais são confeccionados individualmente, ou seja, não é necessário realizar a etapa de corte. A figura 4 mostra o fluxograma para a fabricação dos tênis.

Figura 4: Fluxograma para a fabricação do tênis - malharia retilínea. Fonte: Autores.

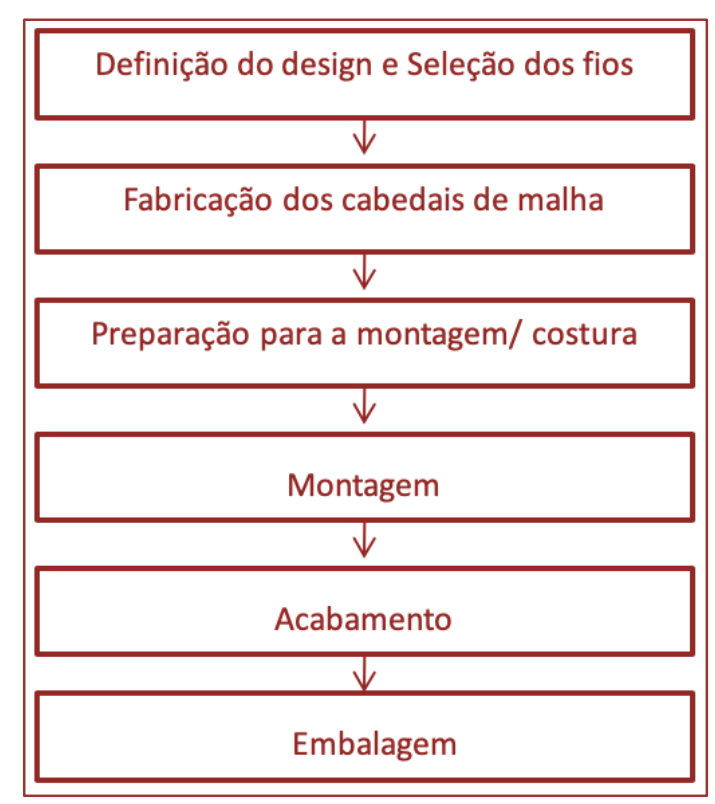

\subsection{PROCESSO DE PRODUÇ̃̃O DOS CALÇADOS ESPORTIVOS A PARTIR CABEDAIS DE MALHA FABRICADOS NAS MÁQUINAS CIRCULARES DE PEQUENO DIÂMETRO (3D)}

As máquinas circulares de pequeno diâmetro produzem cabedais em tecidos tubulares, com diferentes características e em alto volume de produção. Esta tecnologia permite a fabricação do cabedal sem costura, de modo a produzir um produto final praticamente pronto para a aplicação de apenas o solado, para completar a fabricação do tênis (KNITTING INDUSTRY, 2018). 0 desenvolvimento de um produto 
inicia com a definição do design e a escolha dos fios têxteis que serão transformados em tubos de malha e enviados para as indústrias calçadistas para realizar a montagem do produto final, os cabedais são fabricados de forma individual, ou seja, as operações de corte dos cabedais e costura posterior não são realizadas. neste processo não há a necessidade de costura posterior (CARMELO COMERCIAL, 2019). Na etapa de montagem, primeiramente o tubo de tecido, com uma operação manual sem a necessidade de cortes e de costuras, é transformado em cabedal e em seguida o solado é acoplado ao cabedal. 0 esquema apresentado na Figura 5 resume estas etapas.

Figura 5 - Fluxograma do processo produtivo dos cabedais 3D. Fonte: Autores.

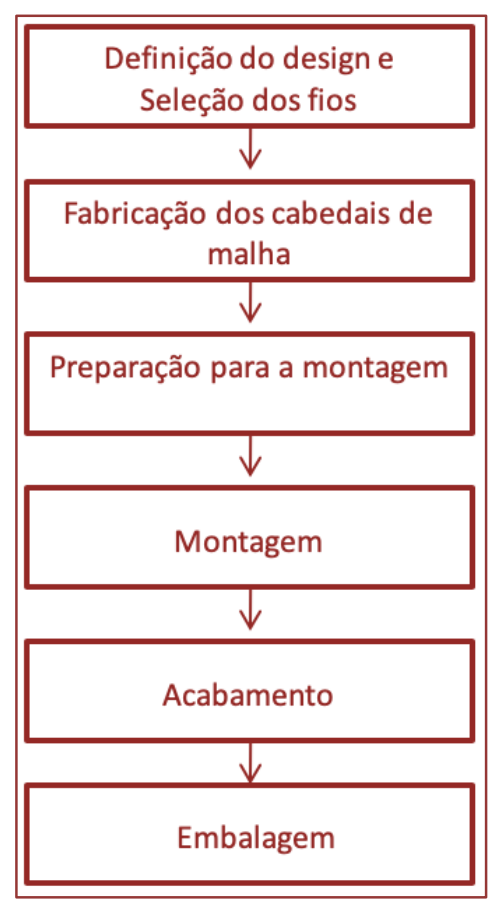

Em um comparativo entre os dois processos (convencional versus 3D), o processo convencional apresenta uma baixa complexidade, com uso de tecnologias simples que pode ser caracterizada como artesanal e com um uso massivo de mão-de-obra. Já a malharia 3D necessita de pouca mão-de-obra que, contudo, precisa ser especializada, exigindo o domínio de conceitos de informática, eletromecânica e microeletrônica (SOUZA et al, 2012). Além disso, todo processo pode ser realizado por uma única empresa, já que etapas intermediárias são eliminadas. A figura 6 apresenta um comparativo entre um cabedal produzido pelos dois diferentes processos.

Figura 6 - (A) Produção convencional (Fonte: Tênis Para Corrida (2019); (B) Produção seamless (Fonte: Autores)

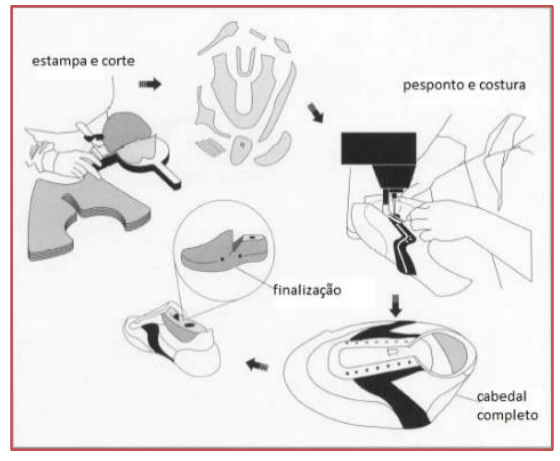

(A)

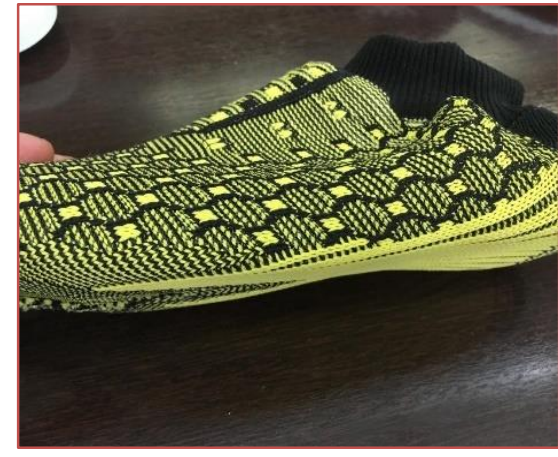

(B) 


\subsection{INOVAÇõES TECNOLÓGICAS E PROSPECÇõES NA INDÚSTRIA 4.0 PARA A MALHARIA}

Em termos gerais, tanto na produção convencional quanto novos sistemas produtivos para a fabricação dos cabedais, percebe-se que o princípio de formação das malhas não mudou de forma significativa. Entretanto, grandes evoluções tecnológicas ocorreram no campo do desenvolvimento de elementos de máquinas, como novos tipos de agulhas, de equipamentos para efetuar a transferência das malhas de uma frontura para outra, velocidade de produção e variação de pontos. Além disso, é notória a incorporação desta tecnologia nos equipamentos estudados para unir etapas do processo produtivo.

Os artigos esportivos são produzidos em massa, desta forma estes se incluem em um dos desafios da Indústria 4.0 que é a transformação da produção em massa para a customização em massa. Este setor produtivo é caracterizado por uma alta demanda de consumo associada à uma expectativa de produtos mais customizados. A customização em massa refere-se a uma estratégia de produção que inclui planejamento, design, produção e serviços que atendam as necessidades diversificadas dos consumidores sem comprometer a economia da produção em escala. A personalização dos produtos gera uma experiência de interação ao usuário, entretanto, é necessário que haja um processo produtivo flexível que atenda os pedidos mais dispersos com uso de maquinário e tecnologias integradoras e menos rígidas. Ademais, é necessária a capacitação de toda a cadeia produtiva, principalmente pequenas e médias empresas com infraestrutura, pessoal e recursos que possibilitem a integração de dados e serviços (ZHANG et al, 2019).

0 mercado para produtos customizados é promissor. No caso de calçados esportivos customizados, há uma projeção de mercado de 92 bilhões de dólares em 2024. Para atender este mercado é necessário focar em três principais parâmetros: estilo (cores padrões, logotipos etc.), conforto (tamanhos, formatos e materiais utilizados) e contexto (ambiente, cultura, época).

A produção dos cabedais de malha com uso desses novos equipamentos apresenta pontos forte como: (1) otimização do processo produtivo: simplifica as etapas do processo produtivo com o objetivo de ganhar competitividade, reduzir custos, aumentar a produção e diminuir erros; (2) customização em massa: diminui etapas do processo produtivo, reduzindo a produção a um único equipamento; e (3) criação de diferentes produtos em um único processo: permite que os fabricantes combinem técnicas de manuseio de têxteis, padronagem e mistura de pontos (TSAI e JHONG, 2019).

Por outro lado, há desafios e barreiras que podem ser encontrados na implantação da Indústria 4.0. Do ponto de vista acadêmico é importante sua pela integração de diferentes áreas do conhecimento. Já para as corporações, a implementação de conceitos digitais se torna mais complexo, principalmente pela constante atualização destes além de não haver uma clareza do custo-benefício desta implementação. Outros aspectos merecem destaque, como:

Redução de empregos: a Indústria 4.0 aponta a substituição de mão-de-obra por automação, o que acarreta na perda de empregos. A mão de obra necessária neste tipo de indústria exige conhecimento especializado e de curto prazo;

Alto custo de implementação: o custo de aquisição e implementação e ausência de dados que comprovem o custo-benefício torna ainda mais complicado o processo de adoção, principalmente por parte de empresas de pequeno e médio porte. Além disso, a crescente atualização destas tecnologias pode gerar um investimento em equipamentos que logo se tornarão obsoletos, acarretando em perdas financeiras sem retorno do investimento;

Ausência de cobertura de internet e facilidades de Tecnologia da Informação (TI): prejudica a comunicação entre componentes e pode comprometer o processo produtivo. Como a Internet das Coisas tem um papel importante na indústria 4.0, é necessária uma conexão de qualidade. Além disso, com o uso da internet é necessário um protocolo de segurança robusto para proteger informações confidenciais que circulam nos sistemas (KAMBLE et al, 2018).

\section{CONCLUSÃO}

Os cabedais de malha podem ser produzidos pelo processo convêncional ou utilizando os novos processos de produção. No processo produtivo convencional, há uma grande quantidade de etapas para a fabricação do tecido e confecção do calçado. Esta última é realizada na indústria calçadista de forma manual e os resíduos oriundos da etapa de corte são descartados no meio ambiente. 
Nos novos processos de fabricação dos cabedais, onde os mesmos são confeccionados nas máquinas de malharia, a fabricação do tecido é reduzida a um único equipamento que pode ser instalado na indústria calçadista. Entretanto, existem diferenças entre os processos, tais como: nos calçados fabricados com cabedais confeccionados em máquinas circulares de grande diâmetro há a necessidade da etapa de corte, de uma única costura para fechamento dos cabedais e os resíduos provenientes da etapa de corte são descartados no meio ambiente. Nos calçados fabricados a partir de cabedais tecidos em máquinas retilíneas não é realizada a etapa de corte, mas ainda há a necessidade de uma única costura para fechamento dos cabedais. 0 processo produtivo mais curto é o dos cabedais confeccionados nas máquinas circulares de pequeno diâmetro (3D), pois são realizadas as etapas de corte e de costura.

Por sua vez, as novas tecnologias para a fabricação dos cabedais reduzem o tempo de trabalho, aumentam a automação dos processos produtivos, diminuem ou eliminam a a operação de corte e a quantidade de resíduos destartados no meio ambiente. Esta tecnologia simplifica as etapas do processo produtivo com o objetivo de ganhar competitividade, reduzir custos, aumentar a produção e diminuir erros. Essas inovações estão tornando a produção dos calçados esportivos mais eficiente, evitando o desperdício de recursos, além de eliminar a poluição e preparar essa indústria para a Quarta Revolução Industrial.

\section{REFERÊNCIAS}

[1] BRASIL. Vigitel Brasil 2017: vigilância de fatores de risco e proteção para doenças crônicas por inquérito telefônico. Ministério da Saúde, Secretaria de Vigilância em Saúde. Brasília: Ministério da Saúde, 2018.

[2] BOSSAN, M. Arte della scarpe. Savigliano: Gribaudo, 2007.

[3] CARDOSO, H.; GUIMARÃES, M.; LOPES, L.; ALVES, J. L. Development of a rubber sole with an integral cushioning system for casual sport shoes. Proceedings of the Institution of Mechanical Engineers, Part L: Journal of Materials: Design and Applications, 2019.

[4] CARMELO COMERCIAL. A tecnologia seamless. São Paulo - SP, 18p., 2019.

[5] CHOKLAT, A. Design de Sapatos. São Paulo: Editora Senac São Paulo, 2012.

[6] COSTA, C. R. Uma análise nos principais aspectos da construção calçadista para o desenvolvimento de um solado-protótipo feito a partir de fibra de coco. Dissertação de Mestrado. Escola de Artes, Ciências e Humanidades (UNiversidade de São Paulo). São Paulo, 2013.

[7] FILGUEIRAS, A.; FANGUEIRO, R.; RAPHAELLI, N. A importância de fibras e fios no design de têxteis destinados à prática desportiva. Estudos em Design, v. 15, n. 1, p.1-20, 2007.

[8] GARCIA, R.; MADEIRA, P. Uma agenda de competitividade para a indústria paulista: cadeia couro e calçados. IPT, São Paulo, fev. 2008.

[9] GLOY, Y-S.; SCHWARZ, A.; THOMAS, G. Cyber-physical systems in textile production: the next industrial revolution?. In: Proceedings of the 1st International Conference on Digital Technologies for the Textile Industry, 5-6 September, Manchester - UK, 2013.

[10] GÖLZER, P.; CATO, P.; AMBERG, M. Data Processing Requirements of Industry 4.0-Use Cases for Big Data Applications. ECIS 2015 Proceedings, 2015.

[11] GUIDOLIN, S. M.; COSTA, A. C. R.; ROCHA, E. R. P. Indústria Calçadista e Estratégias de Fortalecimento da Competitividade. BNDS, 2010. Disponível em: https://web.bndes.gov.br/bib/jspui/handle/1408/2477. Acesso em: 30/05/2019.

[12] HAYES, S.; JEFFREY, M.; MURRAY, R. The applicability of cluster theory to Canada"s small and médium sized apparel companies. Journal of Fashion Marketing and Management, p. 8-26, 2011.

HERMANN, M.; PENTEK, T.; OTTO, B. Design principles for Industrie 4.0 Scenarios: a literature review. Working Paper n.01/2015, Technische Universität Dortmund, 15p, 2015.

[13] INSTITUTO BRASILEIRO DE GEORAFIA E ESTATÍSTICA - IBGE. Diagnóstico Nacional do Esporte: a prática do esporte no Brasil. 2013.

[14] KAMBLE, S. S.; GUNASEKARAN, A.; SHARMA, R. Analysis of the driving and dependence power of barriers to adopt industry 4.0 in Indian manufacturing industry. Computers in Industry, v. 101, p. 107-119, 2018.

[15] KERR, R. B.; PEREIRA, L. C. J.; KIMURA, H. Estratégias de internacionalização da indústria de calçados: conhecendo o consumidor americano. Simpósio de Administração da Produção, Logística e Operações Internacionais (SIMPOI), São Paulo, 2009. 
[16] KNITTING INDUSTRY. Santoni introduces $\mathrm{X}$ machine for footwear. Disponível em: https://www.knittingindustry.com/hosiery-seamless/santoni-introduces-x-machine-for-footwear/. Acessoem 28/06/2019.

[17] LIU, D. et al. On the role of material architecture in the mechanical behavior of knitted textiles. International Journal of Solids and Structures, v. 109, p. 101-111, 2017.

[18] LU, Z. et al. The Development of the flat-knitted shaped uppers based on ergonomics. AutexResearchJournal, v. 16, n. 2, p. 67-74, 2016.

[19] MAGNUS, E. B.; BROEGA, A. C.; CATARINO, A. P. Tecnologia seamless: perspectivas futuras. In: Congresso do 9o Congresso Brasileiro de Pesquisa e Desenvolvimento em Design 2010. 2010.

[20] MCNEIL, I. An Encyclopedia of the History of Technology. London: Routledge, 1081p., ISBN 0-415-013062, 1990.

[21] MODERN LIFE BLOGS. How Can Circular Knitting Machines Contribute To The Sewing Industry?. Disponível em: $\quad$ https://www.modernlifeblogs.com/2017/08/can-circular-knitting-machines-contribute-sewing-industry/. Acesso em 27/06/2019.

[22] NAWAZ, N.; NAYAK, R. Seamless garments. In: Garment Manufacturing Technology. WoodheadPublishing, 2015. p. 373-383.

[23] PROCHNIK, V. et al. Perfil do setor de calçados. In: Prochnik, V.. Relatório final de pesquisa para o SEBRAE. Rio de Janeiro: IE/UFRJ, 2005.

[24] RIBEIRO, L. G. Introdução à tecnologia têxtil. CETIQT/SENAI, 1984.

[25] SAYER, K.; WILSON, J.; CHALLIS, S. Seamless knitwear-The design skills gap. The Design Journal, v. 9, n. 2, p. 39-51, 2006.

[26] SERVIÇO NACIONAL DE APRENDIZAGEM INDUSTRIAL - SENAI. Malharia. São Paulo: SENAI-SP, 2015.

[27] SILVA, M. Malharia - Bases de Fundamentação. Natal. Universidade Federal do Rio Grande do Norte Centro de Tecnologia Departamento Têxtil. 2008.

[28] SOUTINHO, H. F. C. Vestuário desportivo - novos desenvolvimentos e novas funcionalidades. Dissertação de Mestrado de Design e Marketing. DET/EE/UM. Universidade do Minho - PT, 2005.

[29] SOUZA, V.; DE PAULA, N. M.; FUCK, M. P. Os desfios da indústria calçadista brasileira: competir ou proteger?. Revista Economia \& Tecnologia, v. 8, n. 4, 2012.

[30] SPORTS VALUE. A competição global das marcas de material esportivo. Agosto, 2018. Disponível em: https://www.sportsvalue.com.br/estudos/competicao-global-das-marcas-de-material-esportivo/. Acesso em 05/05/2019.

[31] STOLL. Knit \& Wear Disponível em: https://www.stoll.com/en/machines/knitwear/. Acesso em 28/06/2019.

[32] TÊNIS PARA CORRIDA.Como Escolher o Tênis Ideal Para Você. Disponível em: http://www.tenis-paracorrida.com/como-escolher-tenis-ideal/. Acesso em 27/05/2019.

[33] TSAI, Wen-Hsien; JHONG, Shi-Yin. Production decision model with carbon tax for the knitted footwear industry under activity-based costing. Journal of Cleaner Production, v. 207, p. 1150-1162, 2019.

[34] UNIDAS (UNIDO). A resposta mundial ao rápido crescimento do suprimento de calçados do sul da Ásia. Painel Industrial do couro e produtos do Couro, 16, Gramado, Brasil, 2007.

[35] ZHANG, C. et al. Data Driven Smart Customization. Procedia CIRP, v. 81, p. 564-569, 2019.

[36] ZHANG, X.; MA, P. Application of knitting structure textiles in medical areas. Autex Research Journal, v. 18, n. 2, p. 181-191, 2018. 


\section{Capítulo 15}

\section{Desafios da Siderurgia na Indústria 4.0 no Brasil}

\section{Ricardo Luiz Perez Teixeira}

Cynthia Helena Soares Bouças Teixeira

\section{Max Leandro de Araújo Brito}

Priscilla Chantal Duarte Silva

Resumo: Este trabalho, publicado recentemente com o mesmo título na revista The Brazilian Journal of Development, aborda as recentes mudanças provocadas pelo avanço das tecnologias de informação e processos produtivos. Elas têm transformado a indústria tradicional modificando sua forma de pensar, gerenciar e produzir, conduzindo a um novo patamar em termos de desenvolvimento. Com isso, urge uma nova forma de ensinar os discentes das Engenharias e da Administração de Empresas a se preparem para a nova realidade. 0 objetivo deste estudo é investigar os caminhos da indústria 4.0 no Brasil, em especial no setor siderúrgico. Utiliza-se uma revisão bibliográfica a fim de investigar na literatura os principais componentes da indústria 4.0, sua evolução e os principais desafios para responder às exigências atuais, no intuito de preparar melhor os discentes para a nova realidade. Adota-se como ferramenta didática este novo cenário que apresenta paradigmas socioeconômicos importantes que podem afetar tanto o desenvolvimento industrial do mundo, quanto do Brasil com ele. Os resultados da investigação apontam para uma necessidade de atualização da indústria, bem como das universidades em preparar o futuro gestor e engenheiro para as novas tecnologias e à integração delas nos processos industriais. Conclui-se que ainda há muitos desafios, pois requer uma mudança de mentalidade, sobretudo. Como nas revoluções anteriores, surgirão novos processos de produção, novos produtos, novos paradigmas e consequentemente novos impactos socioeconômicos.

Palavras chave: Administração, Engenharia, Ensino Superior, Indústria 4.0, Siderurgia. 


\section{INTRODUÇÃO}

Este trabalho, publicado recentemente com o mesmo título na revista The Brazilian Journal of Development, aborda as mudanças provocadas pelo avanço das tecnologias de informação e processos produtivos pela chegada da denominada revolução industrial 4.0 (Teixeira et al., 2019). Eles têm transformado a indústria tradicional modificando sua forma de pensar, gerenciar e produzir, conduzindo a um novo e importante patamar, em termos de desenvolvimento, frente às outras revoluções industriais.

A importância das revoluções industriais para a aplicação e o desenvolvimento de soluções tecnológicas frente aos paradigmas industriais vivenciados pode ser percebida ao longo de mais de 200 anos de história. Na Figura 1, tem-se a representação esquemática das diversas revoluções industriais e o seu grau de crescente de complexidade das demandas, tecnologias e processos produtivos industriais.

Figura 1 - Revoluções industriais

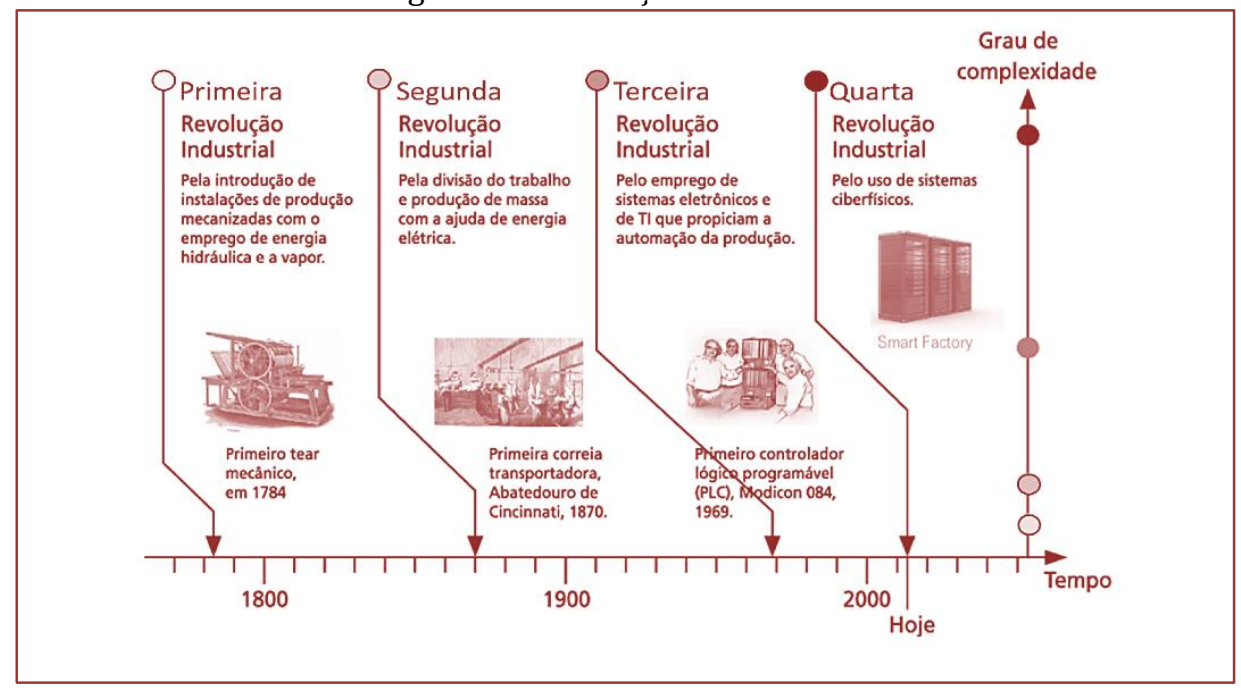

Fonte: Adaptado de Calabrò (2019)

A 1ํㅡ Revolução Industrial teve grande importância na introdução da mecanização da produção. Com o emprego da máquina a vapor, trouxe um grande salto na produtividade industrial. Com a $2^{2}$ Revolução Industrial, o uso da eletricidade nas linhas de montagem possibilitou o início da produção em série (produção em massa), tornando possível também a divisão do trabalho. Essa revolução ficou conhecida como a revolução do Fordismo, devido à famosa linha de montagem de Henry Ford. Na 3a Revolução Industrial, o grande diferencial foi a automação dos processos, através da introdução de técnicas de eletrônica e de tecnologia da informação, da introdução de computadores e eletrônicos nos processos industriais, trazendo novos conceitos como a produção enxuta (Enacom, 2019; Stearns, 2018). Já a 4aㅡ Revolução Industrial, que é presente para alguns e está para acontecer para outros, traz como foco a digitalização, através de várias tecnologias e incrementos mecânicos, elétricos e eletrônicos para melhorar a inteligência, trazendo maior autonomia frente aos novos desafios da indústria (Agenda brasileira para a indústria 4.0, 2019; Enacom, 2019; Schwab, 2017).

As 3 primeiras revoluções industriais contribuíram para o desenvolvimento industrial trazendo a competição tecnológica como ponto central para o desenvolvimento econômico. Já a $4^{\text {a }}$ revolução industrial prevê um impacto bem superior, pois envolve um conjunto de tecnologias que permitem a fusão do mundo físico, digital e biológico (Schwab; Davis, 2018).

As principais tecnologias envolvidas na $4 \underline{\underline{a}}$ Revolução Industrial estão reunidas no Tabela 1. São elas: a Manufatura Aditiva (3D), a Inteligência Artificial (IA), a Internet das Coisas (IoT), a Biologia Sintética (SynBio) e os Sistemas Ciber-Físicos (CPS) (Agenda brasileira para a indústria 4.0, 2019; Pinon et al., 2018; Pereira; Simonetto, 2018). 
Tabela 1 - Tecnologias relacionadas à Industria 4.0

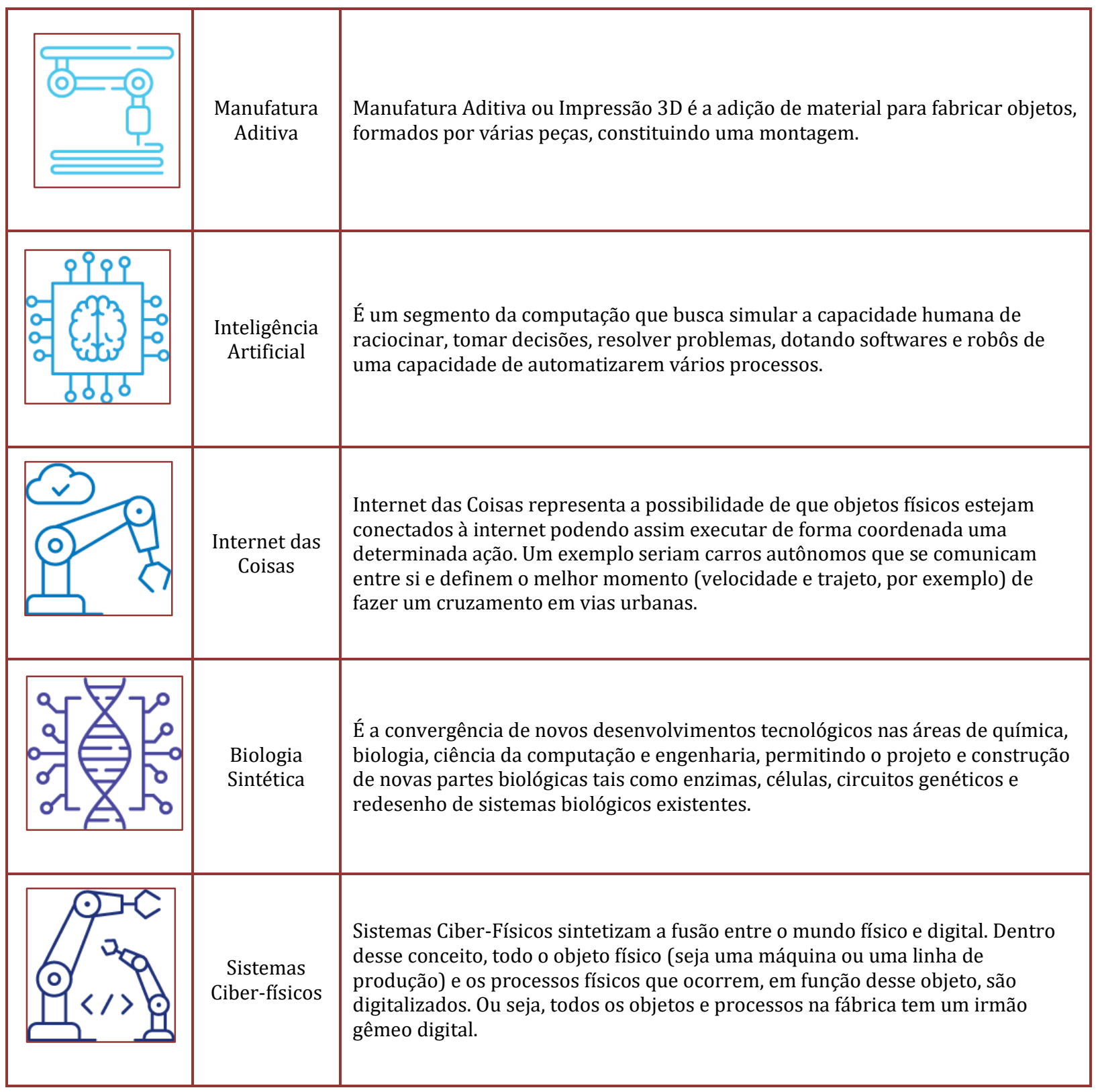

Fonte: Agenda brasileira para a indústria 4.0 (2019)

O nome Indústria 4.0 surgiu de um projeto de estratégia de alta tecnologia financiado pelo governo federal alemão, sendo mencionado pela primeira vez na feira de tecnologia de 2011 em Hannover. Dois anos depois, em 8 de abril de 2013, na mesma feira, um conjunto de recomendações de implementação foi apresentado ao governo federal alemão. Os princípios são (diferentemente da internet "para pessoas", a que estamos usando atualmente) destinados à produção industrial.

Países como Estados Unidos, Alemanha e China estão entre os que mais avançam na renovação de suas indústrias para a Manufatura Avançada, destacando-se na liderança mundial nos esforços de implantação da indústria 4.0. Nesse contexto, o cenário internacional é, então, de grande movimentação como respostas a estas três grandes economias, que correspondem acerca de 35\% (15\%, 3,3\% e 18\% respectivamente) da economia mundial em PIB (PPC). Enquanto isso, o Brasil e outras nações investem de maneira menos "agressiva", buscando, sobretudo, manterem-se competitivas face à nova realidade produtiva das três grandes economias mundiais. No Brasil, o atual desenvolvimento produtivo siderúrgico apresenta iniciativas de implantação da indústria 4.0 através de seus Clusters tecnológicos, principalmente, nas áreas de redução, de aciaria e de laminação. 
A indústria 4.0 representa uma evolução natural dos sistemas industriais anteriores, desde a mecanização do trabalho ocorrida no século XVIII até a automação da produção nos dias atuais; Nos últimos anos e aplicação de automação e sistemas de informação como ERP (Enteroprise Resource Plannig) e MES (Manufacturing Execution System) melhoraram significativamente a produtividade nas fábricas (Santos et al. 2018, p.115).

De um modo geral, a evolução no uso e aplicação das mais diversas tecnologias proporcionou um avanço na produção industrial. Além de se produzir em menos tempo, maior velocidade, e com menor custo, as tecnologias ainda auxiliaram na solução de problemas e melhoria na qualidade (Cheng et al. 2015).

As tecnologias digitais formam as bases para a transformação da Indústria 4.0. Essas tecnologias podem ser empregadas de diversas formas de acordo com o projeto da empresa gerando soluções específicas na resolução de problemas. Algumas tecnologias já são empregadas nas indústrias, porém a novidade está na integração de tecnologias e na possibilidade de soluções diferentes das já conhecidas Além das tecnologias citadas na Figura 2, algumas dessas e outras tecnologias que se podem abordar na transformação da Indústria 4.0 são apresentadas na Tabela 2.

A Indústria 4.0 tem uma forte base na digitalização que pode ser de processos, produtos, serviços, modelos de negócios e acesso aos clientes. Os dados e análises funcionam como bases para o processo de integração com as tecnologias de digitalização de dados, como apresentada na Figura 2. Os agrupamentos dessas tecnologias chaves dão origem a sete Clusters Tecnológicos: Inteligência Artificial, Big Data e Computação em Nuvem; Tecnologia de Redes de Comunicação Rápidas e Seguras; Internet das Coisas e dos Serviços; Produção Inteligente e Conectada; Materiais Avançados; Nanotecnologia; Armazenamento e Coleta de Energia.

A Indústria 4.0 é um dos termos utilizados para descrever a estratégia de alta tecnologia promovida pelo governo alemão que está sendo implementada pela indústria. Abrange um conjunto de tecnologias de ponta ligadas à internet com objetivo de tornar os sistemas de produção mais flexíveis e colaborativos (Santos et al. 2018, p.112).

A integração entre o mundo físico e o mundo digital a partir dos sistemas ciber-físicos passa a ser um importante aspecto. Tais sistemas podem ser empregados quando sistemas físicos complexos precisam se comunicar com o mundo digital em busca de melhorar seu desempenho e eficiência. Cada vez mais, dados provenientes de processos são gerados e coletados, através de dispositivos como sensores que podem ser dispositivos móveis, plataformas de IoT (Internet of Things), tecnologias de localização ou sensores inteligentes. Tais tecnologias, uma vez conectadas à nuvem (Cloud Computing), tornam possível a análise e o processamento massivo de dados (Big data Analytics) (Bonilla, 2018; Chen, 2017).

No caso das plataformas de IoT, torna-se possível a integração de objetos físicos e virtuais em redes conectadas à Internet, permitindo a coleta, troca e armazenamento de enorme quantidade de dados, que uma vez processados e analisados, podem gerar informações e serviços em larga escala.

Atzori, Iera e Morabito (2010) afirmam que a principal força da ideia da IoT é o alto impacto que ela terá em vários aspectos, como no comportamento dos usuários e na vida cotidiana. A domótica, a vida assistida, a saúde, a aprendizagem avançada são apenas alguns exemplos de possíveis aplicações em que o novo paradigma exercerá um papel num futuro próximo. Na indústria, o discurso não é diferente.

Dalenogare et al. (2018) afirmam que as normas da concorrência têm tomado outros rumos, baseando-se em novos paradigmas, pois os modelos de negócios das empresas estão sendo reformulados pela adoção de conceitos de IoT e digitalização de fábricas.

Outro conceito interessante é o da "Internet dos Serviços" que é basicamente a utilização da Internet para criar alternativas de valor para o setor de serviços. Assim, têm-se as "Fábricas Inteligentes", que representam as unidades nas quais os sistemas ciber-físicos comunicam-se entre si e com outras entidades, por meio da "Internet das Coisas" e da "Internet dos Serviços", auxiliando máquinas e pessoas na execução de suas tarefas (Salah, 2019; Leusin, 2018). 
Tabela 2 - Tecnologias relacionadas à Industria 4.0

\begin{tabular}{|c|c|}
\hline $\begin{array}{l}\text { Sensores e } \\
\text { Atuadores } \\
\text { Internet das Coisas }\end{array}$ & $\begin{array}{l}\text { Os sensores e os atuadores estão na base de processos de automação digital. } \\
\text { São sistemas conectados entre si ou bens de consumo conectados com outros produtos. }\end{array}$ \\
\hline Big Data & $\begin{array}{l}\text { Dispor de grandes bases de dados necessária à personalização de um pedido também está na } \\
\text { base da automação digital e da robotização de processos industriais nas quais os robôs } \\
\text { autônomos tendem a assumir maior relevância. }\end{array}$ \\
\hline $\begin{array}{l}\text { Computação em } \\
\text { Nuvem }\end{array}$ & $\begin{array}{l}\text { Infraestrutura compartilhada e acessada através da internet, a partir de diversos dispositivos de } \\
\text { acesso, tais como computadores, tabletes e celulares. }\end{array}$ \\
\hline Inteligência Artificial & $\begin{array}{l}\text { A inteligência artificial viabiliza que produtos e processos produtivos tomem decisões sem a } \\
\text { interferência humana. }\end{array}$ \\
\hline $\begin{array}{l}\text { Tecnologias de } \\
\text { Comunicação sem } \\
\text { Fio }\end{array}$ & $\begin{array}{l}\text { São sistemas constituídos por equipamentos, dispositivos, componentes e por softwares que } \\
\text { viabilizam a comunicação de voz e de dados sem fio em tempo real (tecnologia } 5 \mathrm{G} \text { ). }\end{array}$ \\
\hline $\begin{array}{l}\text { Sistemas Integrados } \\
\text { de Gestão }\end{array}$ & $\begin{array}{l}\text { São diferentes softwares de gestão que integram diferentes atividades de uma unidade } \\
\text { industrial, ou que aumentam a eficiência da gestão produtiva, comercial ou financeira da } \\
\text { empresa, ou que integram diferentes unidades produtivas de uma mesma corporação. }\end{array}$ \\
\hline Robótica & $\begin{array}{l}\text { Os robôs são equipamentos de automação industrial controlados automaticamente, podendo ser } \\
\text { programados e reprogramados a distância e com maior ou menor grau de autonomia no } \\
\text { processo produtivo. }\end{array}$ \\
\hline Manufatura Aditiva & É o processo de produção de peças através da deposição de materiais. \\
\hline Novos Materiais & $\begin{array}{l}\text { Há nova geração de materiais que podem ser nanoestruturados ou não, que possuem aplicações } \\
\text { diversas e que estão contribuindo para o desenvolvimento das tecnologias apontadas } \\
\text { necessárias à indústria } 4.0 \text {. }\end{array}$ \\
\hline
\end{tabular}

Fonte: IEDI (2019)

No campo da interface homem-máquina, essa interação é fundamental, podendo-se citar como exemplo a utilização de roupas robóticas, o que possibilita que pessoas possam realizar trabalhos que por si só seria impossível como carregar grandes quantidades de peso. Outra relação homem-máquina é pelo uso da realidade virtual, Augmented Reality, que nada mais é do que transformar informações do mundo digital visíveis ao mundo real. Outra possibilidade é a criação de novos objetos através da Impressão 3D, o que permite alcançar um grau de complexidade de formas jamais vista pelos métodos convencionais de conformação plástica de materiais. Complementando, quanto à questão de segurança, os mecanismos de autenticação e detecção de fraude (Authentication and Fraud Detection) podem trazer novos recursos de segurança frente às novas tecnologias (Barreto; Amaral; Pereira, 2017).

Figura 2 - Tecnologias relacionadas à Industria 4.0

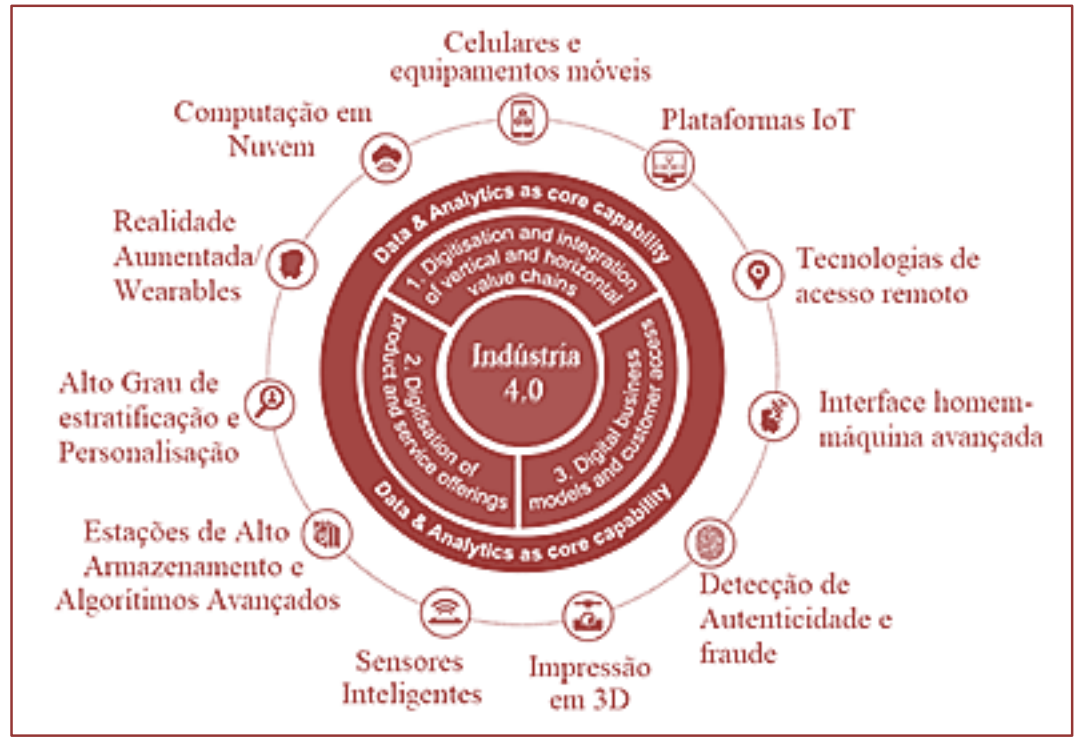


A transformação tecnológica da Indústria 4.0 que ora lança novas tecnologias, ora funde tecnologias já existentes, tem um forte apelo no ganho gerado pela redução de custos. 0 processo de transformação das indústrias necessita de investimentos e somente cada empresa pode definir individualmente, de acordo com suas possibilidades financeiras, alinhada à sua estratégia qual caminho seguir (Tidd; Bessant, 2018).

As tecnologias da Indústria 4.0 podem impactar tanto os processos industriais, quanto os produtos, e, tanto a empresa em si, quanto a cadeia produtiva. Os impactos também podem variar de acordo com o tipo de indústria, se de processos contínuos ou discretos. No primeiro caso, incluem-se em geral empresas de grande faturamento, com elevadas escalas de produção, altos volumes de matérias-primas e insumos, como as indústrias siderúrgica e química. No Brasil, esses segmentos são os que estão mais próximos da tendência mundial, contando com elevada automação em processos (Martins, 2019; Liao et al., 2018).

No caso da indústria de processos discretos, incluem-se empresas de tamanhos variados e de maior ou menor capital e planta industrial, cujas cadeias produtivas podem ser mais extensas e complexas, tendo em vista que o produto final depende de várias partes, componentes ou peças, tais como: as indústrias automotiva, de máquinas e equipamentos. Para esse tipo de indústria, os impactos da indústria 4.0 são maiores, devido as maiores possibilidades de flexibilização do processo, permitindo uma maior customização da produção. Algumas tecnologias que podem viabilizar a customização são a integração das atividades produtivas (engenharia de produto, engenharia de processo, planejamento da produção, programas de gestão da produção), integração da empresa montadora com fornecedores, a integração da empresa montadora com sistemas de distribuição e comercialização, bem como integração das máquinas, equipamentos e sistemas (IEDI, 2019).

As empresas são capazes de oferecer produtos e serviços de maior valor agregado com base na maior capacidade de customização de produtos e na maior assertividade dos serviços oferecidos. Assim, modelos de negócios inteligentes integram novas alternativas tecnológicas, podendo ocasionar mudanças no mercado, dificultando a entrada de concorrentes ou o estabelecimento de novos grupos de negócios através de fusões e parcerias (Zhong, 2017).

Com a transformação tecnológica da indústria 4.0, a indústria torna-se capacitada para atender diferentes demandas dos clientes através de uma programação de produção eficiente. Esse ganho em flexibilidade é mais viável na indústria de processos discretos devido à menor rigidez de seus processos (Lu, 2017).

Os impactos da Indústria 4.0 podem ser variados como a melhoria da eficiência de processos: com o uso de mais sensores e variáveis de processo controladas automaticamente; com a economia de energia devido ao uso de máquinas, equipamentos ou programas de controle mais inteligentes; com a melhoria de qualidade de produtos devido à redução de imperfeições, com o uso de máquinas e equipamentos mais inteligentes com sensores e atuadores mais dedicados; com a redução dos custos de produção devido à integração de equipamentos e otimização da produção; a redução do tempo de setup de máquinas e equipamentos com o processo de automação; a redução dos custos de manutenção e de paradas não previstas, devido ao maior e melhor controle de parâmetros, podendo viabilizar a manutenção preditiva com o uso da inteligência artificial; a redução de custos administrativos e estoques, com otimização da logística, através da integração entre departamentos, plantas, fornecedores, prestadores de serviços e clientes; a redução de tempo no desenvolvimento de novos produtos, através do uso da inteligência artificial; o uso de programas de gestão da produção também poderão simular alternativas de processo em busca da melhor eficiência; uso de programas de simulação e de realidade aumentada poderão ser empregados no desenvolvimento de novos produtos, entre outras possibilidades (Zennaro et al., 2019).

Com efeito, pode-se notar que a implantação da indústria 4.0 traz muitos benefícios para o desenvolvimento da produção brasileira. Contudo, como seu sucesso depende de uma série de processos tecnológicos, tem-se, pois, as necessidades de as universidades preparem o discente para o domínio dessas tecnologias e da integração entre elas no período de formação do engenheiro.

Os ganhos são diversos, conforme apontados anteriormente podendo gerar desde a redução de custos de produção, aumento da flexibilidade dos processos produtivos, ganhos de eficiência, aumento da produtividade, redução de custos com manutenção de equipamentos e consumo de energia, aumento desenvolvimento tecnológico de produtos, processos até a geração de novos produtos e modelos de negócio (Hammer, 2017).

Cada indústria em busca da transformação deve estipular seus objetivos e traçar metas para construir a indústria do futuro. Através dos desafios da 4a revolução industrial, a indústria se torna capaz de utilizar de forma mais eficiente seus próprios recursos a fim de oferecer produtos e serviços mais competitivos no mercado. 


\section{O CONTEXTO BRASILEIRO}

Os paradigmas e desafios do setor industrial e da economia brasileira como um todo são grandes, o que não abandona a 4⿳亠丷a revolução industrial como uma grande oportunidade para o país. Trata-se mais do que uma questão de avançar, trata-se de estar ou não preparado ou se preparar para as mudanças necessárias (Evans, 2018; Tortorella; Fettermann, 2017).

O setor industrial brasileiro representa grande importância na economia do país, gerando riquezas e empregando pessoas, e por outro lado, exigindo investimento. Ao mesmo tempo, retrações na economia afetam a indústria, provocando consequências desagradáveis para o setor. Dessa forma, a relação entre o setor industrial e a economia pode ser analisada através de índices como: a participação da indústria de transformação no Produto Interno Bruto (PIB), o Índice Global de Inovação (IGI), a Produtividade da indústria, o Índice Global de Competitividade da Manufatura e o Produto Interno Bruto (PIB).

A participação da indústria de transformação brasileira no PIB (Produto Interno Bruto) atingiu cerca de $27 \%$ na década de 1980, estando na presente década (dados até 2018 ) reduzida a cerca de $11 \%$, ou seja, o valor mais baixo da série histórica. Essa participação tem apresentado uma redução nos últimos anos (Figura 3), o que revela um afastamento do Brasil frente a revolução tecnológica industrial, e, perante as grandes economias mundiais: Estados Unidos, Alemanha e China, cujas participações da indústria no PIB mundial somam cerca de 35\%. Em última análise essa queda é resultado se deve às mudanças na estrutura produtiva do país, política e dos novos modelos de negócios trazidos pela evolução (disrupção) tecnológica (Agenda brasileira para a Indústria 4.0, 2019; Gilpin, 2018; Kumar; Sundarraj, 2018; Fukuyama, 2017).

Figura 3 - Gráfico da participação da indústria de transformação brasileira no PIB de 1948 a 2018

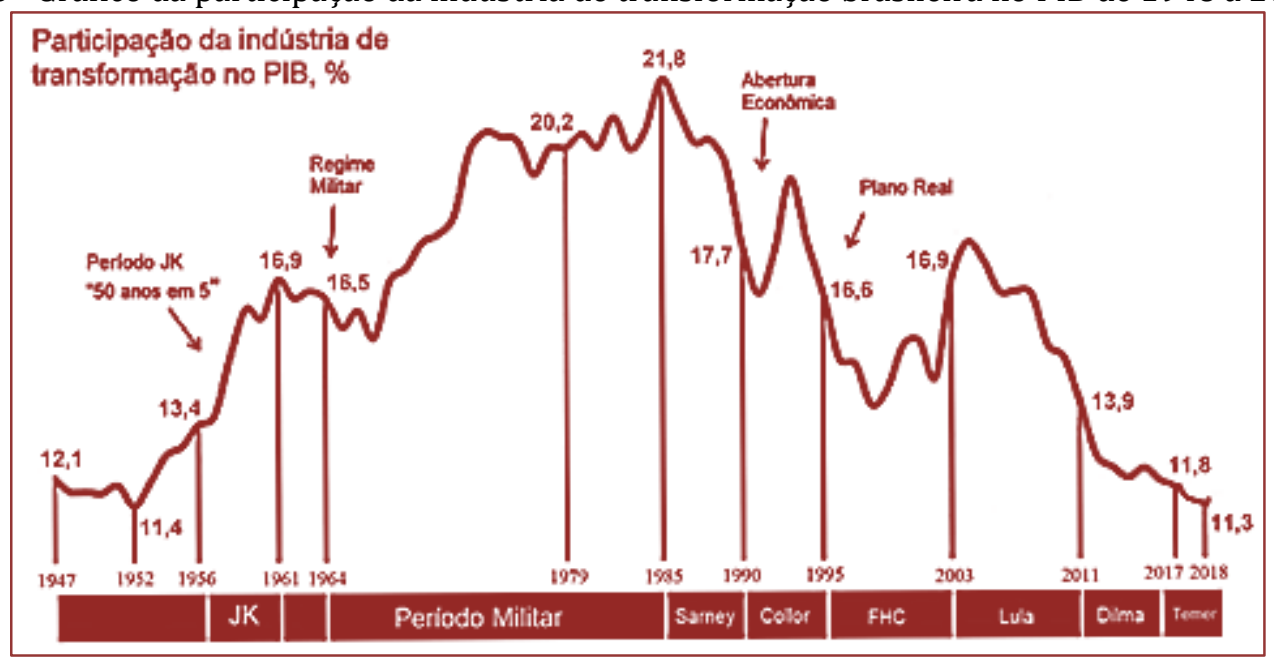

Fonte:Adaptado de Infonews (2018)

O Índice Global de Inovação busca avaliar critérios de performance de diferentes países no quesito inovação. Esse índice avalia quesitos como crescimento da produtividade, investimentos em pesquisa e desenvolvimento (P\&D), educação, exportações de produtos de alta tecnologia, dentre outros tópicos (Feng; Reich; Sheng, 2018; Kumar; Sundarraj, 2018). Quanto à inovação, segundo a Agenda brasileira para a indústria 4.0 (2019), o Brasil ocupa a 69a colocação no Índice Global de Inovação e tem apresentado perda de produtividade e competitividade, conforme Figura 3 e Figura 4, decorrentes do modelo socioeconômico, da utilização da regra de ouro para o controle das contas públicas e perdas de investimentos externos da indústria manufatureira nos últimos anos (Pires, 2019; Callegari; Melo; Carvalho, 2018). 
Figura 4 - Índice Global de Inovação e Competitividade da Manufatura.

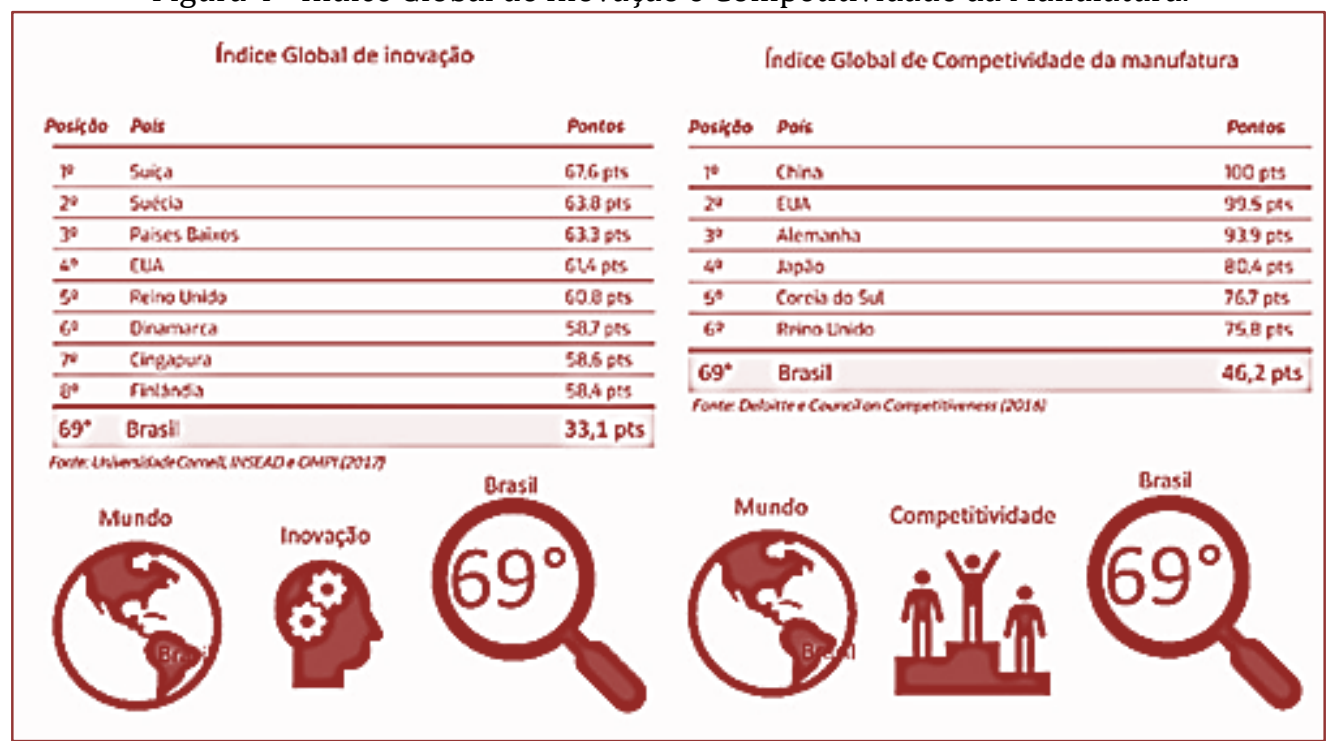

Fonte: Adaptado de Agenda brasileira para a indústria 4.0 (2019).

Nos últimos 3 anos, o governo brasileiro buscou melhorar a economia pela austeridade fiscal, diminuição da burocracia direcionados a certas áreas produtivas de exportação e busca de parcerias externas que, entre outras iniciativas, têm fomentado uma retomada do crescimento econômico do Brasil, conforme apresentado na Figura 5. Esse crescimento impacta diretamente os investimentos da indústria brasileira (Iedi, 2019; Santos; Basso; Kimura, 2018, Alban, 2018).

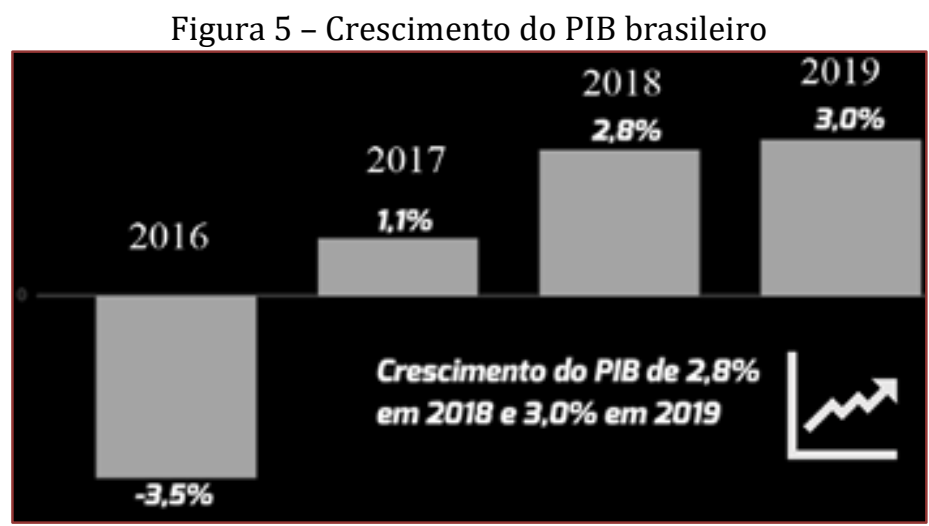

Fonte: Adaptado de Agenda brasileira para a indústria 4.0 (2019)

\section{SIDERURGIA BRASILEIRA E A INDÚSTRIA 4.0}

Nos postulados de Martins e de Tropia (2017) é possível verificar estudos sobre os desafios da implantação da indústria 4.0 no setor siderúrgico, bem como as principais mudanças em nível de relações na cadeia produtiva, organização geral da empresa, organização da produção e do trabalho com a constituição da Indústria 4.0. Como resultados pode-se concluir que as expectativas são otimistas quanto à produtividade, integração de processos e acesso às informações das operações. Entretanto, há questões preocupantes com relação às consequências laborais, segurança da informação e novos perfis de mão de obra (Martins, 2019). Esse é o discurso mais comum a respeito dos efeitos da implementação da indústria 4.0 no cenário brasileiro.

No Quadro 1 resumem-se as principais perspectivas frente às mudanças nos parâmetros organizacionais (Tropia, 2017). Assim como as relações na cadeia produtiva, a organização da empresa, da produção e do trabalho requerem mudanças para adequação às novas exigências, bem como novas posturas e objetivos estratégicos mais inovadores nas empresas. 
Quadro 1 - Perspectivas comuns aos entrevistados em relação aos parâmetros organizacionais

\begin{tabular}{|c|l|}
\hline \multicolumn{1}{|c|}{ Níveis } & \multicolumn{1}{c|}{ Percepções } \\
$\begin{array}{c}\text { Relações na cadeia } \\
\text { produtiva }\end{array}$ & $\begin{array}{l}\text { Maior integração das unidades de negócio e dinamismo para as operações. } \\
\text { Riscos quanto ao compartilhamento de informação. } \\
\text { Orientação aos serviços e flexibilidade. }\end{array}$ \\
\hline $\begin{array}{c}\text { Organização da } \\
\text { empresa }\end{array}$ & $\begin{array}{l}\text { Redução de níveis hierárquicos e menor dependência de profissionais que detêm o } \\
\text { controle de informações. } \\
\text { Revisão dos processos de recrutamento e seleção devido às exigências de habilidade e } \\
\text { perfil da mão de obra atual. }\end{array}$ \\
\hline $\begin{array}{c}\text { Organização da } \\
\text { produção }\end{array}$ & $\begin{array}{l}\text { Flexibilidade no direcionamento de ordens de produção. } \\
\text { Controles mais assertivos de processos de produção devido ao desenvolvimento de } \\
\text { máquinas mais robustas e manutenções preventivas. }\end{array}$ \\
\hline $\begin{array}{c}\text { Organização do } \\
\text { trabalho }\end{array}$ & $\begin{array}{l}\text { Transformações no chão de fábrica tanto na garantia da profissão quanto no escopo de } \\
\text { trabalho. } \\
\text { Uma dependência maior da interface homem-máquina e exigência de novos treinamentos } \\
\text { para adequar os trabalhadores atuais para novos papéis. }\end{array}$ \\
\hline
\end{tabular}

$$
\text { Fonte: Tropia (2017) }
$$

Segundo Martins (2019), o desenvolvimento de Clusters tecnológicos da indústria 4.0 na siderurgia pode ser dividido atualmente em três níveis: "1) Muito Baixo: Nanotecnologia; 2) Baixo: Internet das Coisas e dos Serviços, Inteligência Artificial, Big Data e Computação em Nuvem, Produção Inteligente e Conectada, Materiais Avançados, e Armazenamento e Coleta de Energia; 3) Moderado: Tecnologia de Redes de Comunicação Rápidas e Seguras. A Figura 6 apresenta o ritmo de difusão dos Clusters tecnológicos da indústria 4.0 na siderurgia brasileira. Esse ritmo é ditado pela busca de maiores retornos em ganhos em eficiência nos processos, produtividade e competitividade para melhores patamares produtivos.

Conforme Martins (2019), a hipótese da presença de Clusters Tecnológicos da Indústria 4.0 tende a fomentar as inovações de processos de produtos, a diminuir os custos e a demanda de matérias primas na siderurgia brasileira. Quanto à aplicação das novas tecnologias no processo produtivo, prevê-se que as etapas de redução, aciaria (refino) e laminação estão mais aptas a incorporar um número maior de Clusters Tecnológicos. Segundo Martins (2019), "Os resultados demonstram que a etapa de refino do aço é a única fase do processo produtivo que pode se beneficiar de todos os Clusters investigados, enquanto a etapa de redução somente não se beneficiaria da Nanotecnologia. Já as aplicações nas etapas de preparação das cargas e laminação estariam concentradas em alguns campos da Indústria 4.0". Segundo Anonymous (2017), os Clusters tecnológicos tendem a fortalecer os pontos fortes da siderurgia brasileira e não revolucionar o setor.

Figura 6 - Ritmo de difusão de Clusters tecnológicos na siderurgia brasileira

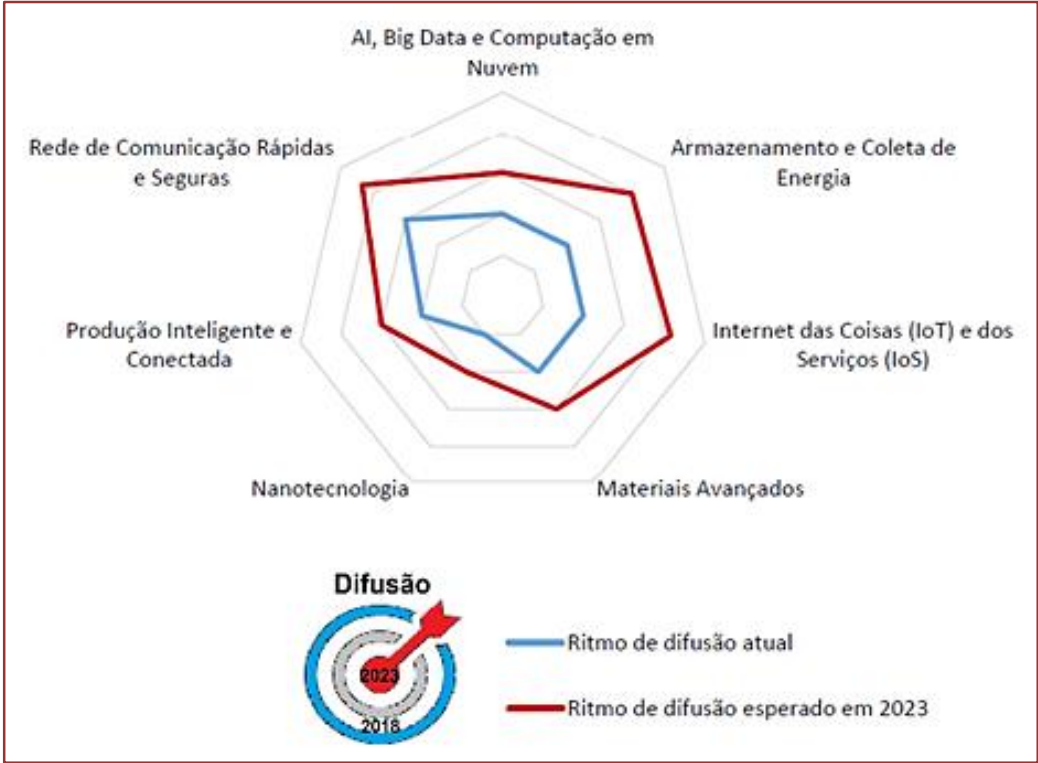

Fonte: Adaptado de Martins (2019) 
Conforme Segundo Anonymous (2017), as siderúrgicas brasileiras que não aderirem à indústria 4.0 sofrerão com o ambiente competitivo, isto é, com a concorrência e, possivelmente, não resistirão às pressões de mercado. No Brasil, a aplicação de tecnologias digitais e sistemas cada vez mais complexos (Clusters tecnológicos) demanda transformações nas linhas industriais, como também nas estruturas organizacionais além de uma melhor segurança para eles. Além disso, tem-se também a necessidade de alta qualificação de mão de obra para as tecnologias trazidas pela indústria 4.0.

\section{CONSIDERAÇÕES FINAIS}

Para a indústria brasileira, a implementação das tecnologias da Indústria 4.0 carece, num primeiro momento, de uma maior difusão, do dimensionamento da importância dessas tecnologias perante a competitividade industrial, da divulgação dos ganhos de seu uso que vão além da redução de custos e do aumento de produtividade, da relação custo/benefício, do retorno do investimento. Algumas tecnologias já estão sendo utilizadas pela produção industrial, tais como sistemas modernos de gestão, a automação eletrônica de processos produtivos e robotização, a comunicação móvel, sensores e atuadores etc.

A indústria siderúrgica brasileira, integrada à economia global, deve buscar condições para se manter competitiva nos mercados interno e externo. Com isso, sente-se a necessidade de atualização da indústria, de incorporação das novas tecnologias, a fim de capacitar-se frente à competitividade global. A adaptação para a Indústria 4.0 ainda tem um longo caminho a percorrer, bem como paradigmas sociais e econômicos a resolver para sua real implantação. Para pesquisas futuras, sugere-se uma pesquisa-ação a fim de propor uma intervenção no ensino de engenharia nas universidades, no intuito de levar ao conhecimento dos discentes as novas exigências da indústria.

\section{REFERÊNCIAS}

[1] Agenda Brasileira para a Indústria 4.0. 0 Brasil preparado para os desafios do futuro. Ministério da Indústria, Comércio e Serviços. Governo Federal, 2019. Recuperado de: http://www.industria40.gov.br/.

[2] Alban, Marcus. The degradation of Brazilian socioeconomics. Brazilian Journal of Political Economy, v. 38, n. 1, p. 167-183, 2018.

[3] Anonymous. Data, Big; Moderate, Cloud Computing Low Moderate. Industry 4.0-the steelmaker's view. 2018. Recuperado de: https://search.proquest.com/docview/2210886422?pq-origsite=gscholar.

[4] Atziori, Luigi; IERA, Antonio; MORABITO, Giacomo. The Internet of Things: A Survey COMPUTER Networks. 2010. Recuperado de: <http://citeseerx.ist.psu.edu/viewdoc/download?doi=10.1.1.719.9916\&rep=rep1\&type=pdf>.

[5] Barreto, Luis; Amaral, Antonio; Pereira, Teresa. Industry 4.0 implications in logistics: an overview. Procedia Manufacturing, v. 13, p. 1245-1252, 2017.

[6] Bonilla, Silvia et al. Industry 4.0 and sustainability implications: A scenario-based analysis of the impacts and challenges. Sustainability, v. 10, n. 10, p. 3740, 2018.

[7] Calabrò, V. Work 4.0: What is it and why does it matter? 2019. Recuperado de: https://www.coople.com/uk/future-of-work/work-4-0/.

[8] Callegari, Julia; MELO, Tatiana Massaroli; Carvalho, Carlos Eduardo. The peculiar insertion of Brazil into global value chains. Review of Development Economics, v. 22, n. 3, p. 1321-1342, 2018.

[9] Chen, Y. (2017). Integrated and intelligent manufacturing: Perspectives and enablers. Engineering, 3(5) 588595.

[10] Cheng, Chih-Hong et al. Semantic degrees for industrie 4.0 engineering: Deciding on the degree of semantic formalization to select appropriate technologies. In: Proceedings of the 2015 10th Joint Meeting on Foundations of Software Engineering. ACM, 2015. p. 1010-1013.

[11] Dalenogare, Lucas Santos et al. The expected contribution of Industry 4.0 technologies for industrial performance. International Journal of Production Economics, v. 204, p. 383-394, 2018.

[12] Enacom. Afinal o que é a indústria 4.0 - ENACOM da Ciência ao produto. 2019. Recuperado de: https://www.enacom.com.br/blog-post.html?slug=afinal-o-que-e-a-industria-40\&gclid=EAIaIQobChMI5fWskc3e4AIViQSRCh0Vwgt7EAAYAyAAEgLUYvD_BwE.

[13] Evans, Peter B. Dependent development: The alliance of multinational, state, and local capital in Brazil. Princeton University Press, 2018.

[14] Feng, Wei; REICH, Robert W.; SHENG, Shirley Y. Factors of Global Innovation Index. 2018. 
[15] Fukuyama, Francis. The great disruption. Profile Books, 2017.

[16] Gilpin, Robert. The challenge of global capitalism: The world economy in the 21st century. Princeton University Press, 2018.

[17] Hammer, Markus et al. Profit per hour as a target process control parameter for manufacturing systems enabled by Big Data analytics and Industry 4.0 infrastructure. Procedia Cirp, v. 63, p. 715-720, 2017.

[18] Iedi. Políticas para o desenvolvimento da indústria 4.0 no Brasil. Instituto de Estudos para o Desenvolvimento Industrial (IEDI). 2019. Recuperado de: https://web.bndes.gov.br/bib/jspui/handle/1408/15486. Acessado em: 05/05/20019.

[19] Infonews. Panorama da indústria de transformação brasileira 2018 - E-Business Consultoria. 2018. Recuperado de: https://www.ebusinessconsultoria.com.br/infonews/panorama-da-industria-de-transformacaobrasileira-.

[20] Kumar, Vijay; SUNDARRAJ, R. P. The Value of Disruptive Innovations. In: Global Innovation and Economic Value. Springer, New Delhi, 2018. p. 189-256.

[21] Leusin, Matheus et al. Solving the Job-Shop Scheduling Problem in the Industry 4.0 Era. Technologies, v. 6, n. 4, p. 107, 2018.

[22] Liao, Yongxin et al. The impact of the fourth industrial revolution: a cross-country/region comparison. Production, v. 28, 2018.

[23] Lu, Yang. Industry 4.0: A survey on technologies, applications and open research issues. Journal of Industrial Information Integration, v. 6, p. 1-10, 2017.

[24] Martins, M. S. Inovações Tecnológicas da Indústria 4.0: aplicações e implicações para a siderurgia brasileira. 2019. 110 f. Dissertação (Mestrado em Economia) - Universidade Federal de Uberlândia, Uberlândia, 2019. Recuperado de: http://dx.doi.org/10.14393/ufu.di.2019.932.

[25] Pereira, Adriano; de Oliveira Simonetto, Eugênio. Indústria 4.0: Conceitos e Perspectivas Para o Brasil. Revista da Universidade Vale do Rio Verde, v. 16, n. 1, 2018.

[26] Pinon, Marcia M. Barreto et al. Applications and Advantages of the Internet of Things (IoT) at Industry (189194). Journal of Engineering and Technology for Industry Applications, v. 4, n. 15, p. 189-194, 2018.

[27] Pires, Manoel. An analysis of Brazilian Golden rule. Brazilian Journal of Political Economy, v. 39, n. 1, p. 39-50, 2019.

[28] Salah, Bashir et al. Virtual Reality-Based Engineering Education to Enhance Manufacturing Sustainability in Industry 4.0. Sustainability, v. 11, n. 5, p. 1477, 2019.

[29] Santos, Beatrice Paiva et al. Indústria 4.0: Desafios E Oportunidades. Revista Produção e Desenvolvimento, v. 4, n. 1, p. 111-124, 2018.

[30] Santos, David Ferreira Lopes; BASSO, Leonardo Fernando Cruz; Kimura, Herbert. The trajectory of the ability to innovate and the financial performance of the Brazilian industry. Technological Forecasting and Social Change, v. 127, p. 258-270, 2018.

[31] Schwab, Klaus. The fourth industrial revolution. Currency, 2017.

[32] Schwab, Klaus; Davis, Nicholas. Shaping the future of the fourth industrial revolution. Currency, 2018.

[33] Stearns, Peter N. The industrial revolution in world history. Routledge, 2018.

[34] Teixeira, R. L. P. et al. Os discursos acerca dos desafios da siderurgia na indústria 4.0 no Brasil. The Brazilian Journal of Development, v. 5, n. 12, p. 2525-8761, 2019.

[35] Tidd, Joe; Bessant, John R. Managing innovation: integrating technological, market and organizational change. John Wiley \& Sons, 2018.

[36] Tortorella, Guilherme Luz; Fettermann, Diego. Implementation of Industry 4.0 and lean production in Brazilian manufacturing companies. International Journal of Production Research, v. 56, n. 8, p. 2975-2987, 2018.

[37] Tropia, Eduardo Célio Zacharias; Silva, Pedro Paulo; DIAS, Ana Valéria Carneiro. Indústria 4.0: Uma Caracterização Do Sistema De Produção. In: XVII-ALTEC 2017-Congresso Latino Americano de Gestão Tecnológica. 2017. p. 0-14.

[38] Zennaro, Ilenia et al. Big size highly customised product manufacturing systems: a literature review and future research agenda. International Journal of Production Research, v. 57, n. 15-16, p. 5362-5385, 2019.

[39] Zhong, Ray Y. et al. Intelligent manufacturing in the context of industry 4.0: a review. Engineering, v. 3, n. 5, p. 616-630, 2017. 


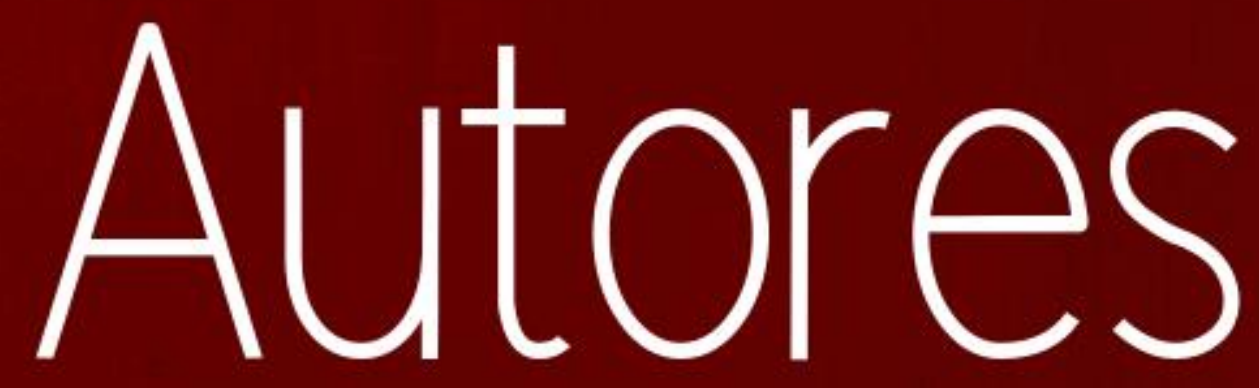




\section{ADRIANA YUMI SATO DUARTE}

Graduada (2009) em Bacharelado em Têxtil e Moda pela Universidade de São Paulo, Mestrado (2013) e Doutorado (2017) em Engenharia Mecânica pela Universidade Estadual de Campinas. Realizou um período de Estágio de Doutorado Sanduíche no Exterior (SWE) no período 2015-2016 no laboratório Fachgebiet Datenverarbeitung in der Konstruktion (Dik), Universidade Técnica de Darmstadt, Alemanha. Atualmente é professora do Ceunsp e pesquisadora de Pós-Doutorado na USP e IPT.

\section{AELSO ROCHA BRITO}

Possui graduação em Engenharia da Computação pela Universidade São Francisco (2014) e graduação em TECNOLOGIA EM GESTÃo EMPRESARIAL pelo Centro Paula Souza - FATEC, FATEC BRAGANÇA PAULISTA/SP (2019). Tem experiência na área de Administração, com ênfase em Administração de Empresas.

\section{ALEXANDRE CAMACHO DA PAIXÃO}

Mestre em Engenharia pela UFF, Pós-graduado em Gerenciamento de Projetos pela Escola Politécnica da UFRJ, Especialista em Projeto de Válvulas Industriais pela USP/PROMINP, Graduação em Engenharia de Produção pela UVA e Técnico em Mecânica. Atuação como coordenador de curso das instituições: SENAI CETIQT, UVA e ESTÁCIO. Experiência como professor de graduação no SENAI CETIQT, UVA, UNIGRANRIO, UNICARIOCA e UNIESP. Experiência de 15 anos em Gestão de Projetos, com atuação em: Planejamento Programado de Parada de Plataformas da PETROBRAS, Planejamento e Controle para o Processo de Inspeção da Regional Sudeste, Manutenção de Tanques e Esferas TRANSPETRO, Planejamento de Avaliações Técnicas de Fornecedores da PETROBRAS, Expansão e comercialização do Gás Natural no Rio de Janeiro, Projetos da área de Facility e Projeto Industrial (Logística/Processos).

\section{ANA LUIZA MENDES SILVA}

Engenheira de Produção formada pela Universidade Federal do Rio de Janeiro com mestrado em Engenharia de Materiais e Processos pelo Desenvolvimento Sustentável na École Nationale Supérieure d'Arts et Métiers - Bordeaux-FR.

\section{ANGÉLICA RODRIGUES DE LIMA}

Possui graduação em Logística pela Universidade Estácio de Sá (2010). Bacharel em Engenharia de Produção pelo Centro de Tecnologia da Indústria Química e Têxtil (SENAI CETIQT).

\section{ANGÉLICA RODRIGUES DE LIMA}

Engenheira de Produção graduada pela Faculdade SENAI CETIQT e Tecnóloga em Logística Empresarial pela UNESA. Atualmente pesquisadora na UFF em Gestão da Cadeia de Suprimentos e Tecnologia da Informação e Tomada de Decisão em Cenários Prospectivos (GPCSTIDCP). Consultora no segmento de pequenas empresas do ramo artesanal e produtora de conteúdo acadêmico. Construiu sólida carreira em planejamento e controle da produção, logística de serviços e gestão de processos.

\section{ARI MATEUS CARVALLIO NETO}

Graduando em Engenharia de Produção pela Universidade Federal de Pelotas (UFPel). 


\section{ARIANE PEREIRA GATTI}

Possui curso-tecnico-profissionalizante em Técnico Florestal pelo Instituto Federal de Educação Ciência e Tecnologia de Rondônia(2014). Atualmente é (TAE) - Herbário EAFM do Instituto Federal de Educação, Ciência e Tecnologia do Amazonas.

\section{BARBARA STEPHANY SERRA LITTER}

Engenheira de Produção graduada pela Faculdade SENAI CETIQT. Atualmente coordenadora de produção e qualidade na INDIPEL; Com experiência em gestão de contas a pagar e a receber, compras, PCP, estoque, qualidade e processos administrativos.

\section{CAMILA WOLFFGRAMM OTTO}

Graduada em Engenharia de Produção pela Universidade Federal de Rondônia. Analista de processos de produção em uma indústria de bicicletas.

\section{CARLOS FRANCISCO SIMÕES GOMES}

Foi gerente de projetos, pesquisador no Centro de Análises de Sistemas Navais (CASNAV) de 1997 a 2007 (trabalhando durante 10 anos atividades de desenvolvimento tecnológico, nas áreas de TI, software, usabilidade interface entre outros), em 2007 foi Chefe do Departamento de Engenharia de Sistemas do, CASNAV. Posteriormente Vice-Diretor deste Centro (última função que assumiu) até 2008, quando se desligou do serviço ativo da Marinha. Tem experiência na área de Administração Informação (TI) e Arquitetura da Informação, com ênfase em Gestão de Risco, atuando principalmente em Decisão Multicritério, Pesquisa Operacional e Engenharia de Produção. Ocupa a função de professor Associado da Universidade Federal Fluminense.

\section{CARLOS ROBERTO DANTAS}

Possui graduação em Segurança da Informação pelo Centro Universitário das Faculdades Metropolitanas Unidas (2014). Tem experiência na área de Ciência da Computação, com ênfase em Ciência da Computação.

\section{CASSIUS TADEU SCARPIN}

Doutor (2012) e Mestre (2007) em Pesquisa Operacional pelo Programa de Pós-Graduação em Métodos Numéricos em Engenharia pela UFPR. Engenheiro de Produção (2010) e Licenciado em Matemática (2002) pela mesma universidade. Atualmente ocupa o cargo de Docente no Departamento Administração Geral e Aplicada (DAGA) da UFPR. Atua em três programas de pósgraduação Stricto Sensu: Programa de Pós-Graduação em Métodos Numéricos em Engenharia, Programa de Pós-Graduação em Engenharia de Produção e o Programa de Pó-Graduação em Gestão de Organizações, Liderança e Decisão.

\section{CYNTHIA HELENA SOARES BOUÇAS TEIXEIRA}

Possui graduação em Engenharia Química pela Universidade Federal de Minas Gerais (1998), mestrado em Engenharia Metalúrgica e de Minas pela Universidade Federal de Minas Gerais (2001), doutorado em Engenharia Metalúrgica e de Minas pela Universidade Federal de Minas Gerais (2005) e certificação em Engenharia da Qualidade pela ASQ (2015). Possui experiência profissional nas áreas de Pesquisa \& Desenvolvimento, Gestão do Conhecimento, Transferência de Tecnologia e Propriedade Intelectual em empresa do ramo siderúrgico. Em especialização pela Faculdade de Ciências Econômicas da Universidade Federal de Minas Gerais. Atua nas áreas de Ensino em Engenharia, de Metodologias e Ferramentas Estatísticas para Processos Industriais e de Administração de Empresas. 


\section{DANIEL COPPEDÉ}

Mestre em Engenharia Mecânica (IFSP, 2018), Graduação em Administração de Empresas pela Universidade São Marcos (2005), Graduação em Gestão da Produção Industrial (IFSP, 2014), Graduação em Engenharia de Produção pela Unidrummond (2019). Tem experiência na área de Administração, com ênfase em Administração da Produção.

\section{DEVISSON MESQUITA DOS SANTOS}

Aluno do curso de Engenharia de Produção da UEPA. Técnico em eletrônica formado pelo IFPA. Estagiário na Base da Ipiranga em Belém.

\section{ENAILE MARIA DE MORAES OLIVEIRA}

Graduanda de Engenharia de Produção pela Universidade Federal de Rondônia.

\section{FABIANE LETÍCIA LIZARELLI}

Professora do Departamento de Engenharia de Produção da Universidade Federal de São Carlos (UFSCar) desde 2011, Mestre e Doutora em Engenharia de Produção. Possui, como pesquisadora, interesse e projetos no tema Programas de Melhoria Contínua, como Lean, Seis Sigma e Lean Sigma aplicados a diversos contextos como manufatura e serviços. É professora do Programa de PósGraduação em Gestão de Organizações e Sistemas Públicos (PPGGOSP), do Programa de PósGraduação em Engenharia de Produção (PPGEP) e faz parte do grupo GEPEQ (Grupo de Estudo e Pesquisa em Qualidade).

\section{FABIANO RODRIGUES SORIANO}

Possui graduação em ENGENHARIA DE PRODUÇÃO (2007), Mestrado em Engenharia de Produção pela Universidade Federal de São Carlos (2012) e Doutorado em Engenharia de Produção pela Universidade Federal de São Carlos (2015). Atualmente é professor Adjunto na Universidade Estadual de Santa Cruz. Tem experiência na área de Garantia e Controle de Qualidade, atuando principalmente nos seguintes temas: Seis Sigma, Melhoria Contínua, Analise de dados multivariados e implantação do Controle Estatístico de Processo.

\section{FABRICIO MAIONE TENÓRIO}

Graduado em Engenharia de Produção pela Pontifícia Universidade Católica do Rio de Janeiro (PUCRIO) e mestrando em Sistemas e Computação pelo Instituto Militar de Engenharia (IME). Atua como professor no Curso de Engenharia de Produção e no Curso Técnico em Portos no Centro Federal de Educação Tecnológica Celso Suckow da Fonseca (CEFET/RJ). Interessa-se pelo desenvolvimento e aplicação de modelos e métodos de apoio à tomada de decisão.

\section{FELIPE FERREIRA SERENO}

Escolas Técnicas Estaduais (Etecs) Trajano Camargo - Limeira-SP. Habilitação: Técnico em Mecânica 2012/2013. Curso de Graduação FAAL - Faculdade de Administração e Artes de Limeira Habilitação: Bacharel em Design de Produto 2014/2017. Mestrado em andamento em Mestrado Engenharia de Produção e de Manufatura. Universidade Estadual de Campinas, UNICAMP, Brasil. Título: Avaliação de ciclo de vida com ênfase na gestão da qualidade: principais métodos e análise de radar rodoviário fixo.,Orientador: Prof. Dr. Paulo Sérgio de Arruda Ignácio. Coorientador: Prof. Dr. Francisco Ignácio Giocondo Cesar. 


\section{FERNANDA LEANDRA LEAL LOPES}

Graduanda em Engenharia de Produção pela UEPA. Estagiária no setor de Desenvolvimento Logístico \& Suprimentos na Endicon Engenharia de Instalações e Construções. Técnica em Telecomunicações pelo IFPA. Atuou como Diretora Administrativo-Financeiro na Empresa Jr. de Engenharia e Tecnologia da UEPA e Conselheira na Federação de Empresas Juniores do Pará.

\section{FERNANDO HENRIQUE DA PAIXÃO DUARTE}

Possui ensino-medio-segundo-graupelo Centro de Educação Tecnológica do Amazonas(2014). Tem experiência na área de Engenharia de Produção.

\section{FERNANDO SOARES DE LIMA}

Engenheiro de Produção Química pelas Faculdades Oswaldo Cruz, Licenciado em química pela Universidade de Mogi das Cruzes e mestre em Processos Industriais pelo Instituto de Pesquisas Tecnológicas do Estado de São Paulo (IPT). É responsável pelo Laboratório de Têxteis Técnicos e Produtos de Proteção do IPT. Atua nos seguintes temas: tecidos técnicos, ensaios de caracterização e avaliação do desempenho de têxteis, intemperismo e microencapsulação aplicada a têxteis.

\section{FRANCISCO IGNÁCIO GIOCONDO CESAR}

Formação Acadêmica ? Engenheiro Mecânico (UNESP) com Mestrado e Doutorado em Engenharia de Produção pela Universidade Metodista de Piracicaba ? UNIMEP. Atualmente cursa pos-doc em Engenharia de produção na FCA - UNICAMP. Possui certificado de qualificação me Project Management (PMI) e Green Belt. Curso de especialização em Melhoria Contínua (5S, Kaizen, Lean) no Japão (Jan. 2018) pela JICA - Japan International Cooperation Agency. Atividades Atuais ? Atualmente é Professor no Departamento Industrial do Instituto Federal de Educação, Ciências e Tecnologia de São Paulo (IFSP - Campus Piracicaba) desde 2011. Também é Professor Pesquisador Colaborador no Programa de Pós Graduação da Engenharia de Produção da Universidade Estadual de Campinas (FCA ? UNICAMP ? Campus Limeira) desde 2016. Coordenado do SB-Lab (Sustainable Business Lab ? Laboratório de Negócios Sustentáveis - http://sblaboratory.wixsite.com/sblabteste). Possui experiência profissional de 23 anos como Gerente de Projetos Internacionais na TRW e Caterpillar Brasil. Pesquisa de Interesse atual - Melhoria Continua / Lean Production / Six Sigma Industry 4.0 / Manufatura Avançada / Industrial Internet of Things - Empreendedorismo / Business Canvas - Tecnologias Emergentes / Disruptive Technologies Colaborador nas seguintes instituições - Collaborative Research Network on Supply Chain 4.0 (http://supply-chain.e-wallet.ca/) Membro Fundador da SC4 - Associação Nacional de Pesquisa e Desenvolvimento de Empresas Inovadoras (ANPEI). (http://anpei.org.br/) Membro do Comitê de Interação em Ciências e Tecnologia - Usina da Inovação / AgTechValley (http://www.startagro.agr.br/usina-de-inovacao-monte-alegre-querser-o-celeiro-high-tech-da-agricultura-em-piracicaba/) Startup Mentoring.

\section{FRANCO GIUSEPPE DEDINI}

Possui graduação (1980) e Mestrado em Engenharia Mecânica pela Universidade Estadual de Campinas (1985) e PhD em Mecânica Aplicada pelo Politécnico de Milão (1993). Atualmente é professor associado da Universidade Estadual de Campinas. Atua nas linhas de desenvolvimento de produtos, dinâmica veicular, projeto de máquinas e metodologia de projeto. 


\section{GUSTAVO VALENTIM LOCH}

Possui graduação em Matemática Industrial pela UFPR (2007), graduação em Ciências Contábeis pela Universidade Positivo (2011), mestrado em Métodos Numéricos em Engenharia pela UFPR (2010) e doutorado em Métodos Numéricos em Engenharia pela UFPR (2014). Atualmente é professor do Departamento de Administração Geral e Aplicada da Universidade Federal do Paraná, atuando principalmente nos seguintes temas: Otimização combinatória, Problema de Transporte, Engenharia da Qualidade e métodos de auxilio à decisão. Em 2015 foi premiado com Menção Honrosa no Prêmio Capes de Tese 2015.

\section{JOSÉ EDUARDO PÉCORA JÚNIOR}

Professor do Departamento de Administração Geral e Aplicada da UFPR, doutor em Administração de Empresas (2008), pelo Departamento de Operações e Sistemas de Decisão na Université Laval no Canadá, mestre em Matemática Aplicada e Computacional pela Universidade Estadual de Campinas (2002) e Bacharel em Matemática Aplicada e Computacional pela Universidade Estadual de Campinas (1998). Tem experiência na área de Pesquisa Operacional, com ênfase em Matemática Discreta e Combinatória.

\section{KAROLINE CONTE DOS SANTOS}

Graduada em Engenharia de Produção pela Universidade Federal de Rondônia. Assistente de ecommerce.

\section{LEONARDO ROSA ROHDE}

Possui graduação em Administração pela Universidade Federal do Rio Grande do Sul (1999), mestrado em Administração pela Universidade Federal do Rio Grande do Sul (2002) e doutorado em Administração pela Universidade Federal do Rio Grande do Sul (2008). Atualmente é professor adjunto da Universidade Federal de Pelotas. Tem experiência na área de Administração, com ênfase em Sistemas de Informação e Apoio à Decisão.

\section{LUCAS SANTIAGO DE SOUSA}

Graduação Completa em Engenharia de Produção - Unigranrio (conclusão em 12/2019), CR : 8,93. Experiência profissional. Icatu Seguros - (10/2015 a 06/2019). Técnico em Operações Junior Experiência na gestão de contratos e aditivos físicos dos contratos previdenciários, implementação e alteração dos contratos em sistema, análise das cláusulas contratuais, análise e aplicação de penalidades dos clientes, elaboração de relatórios sobre as inconsistências do faturamento, análise das propostas individuais dos clientes.. Icatu Seguros - (06/2019 - Atual). Técnico em Operações Senior. Experiência na elaboração dos relatórios e cálculos rotineiros das comissões direcionadas aos corretores e parcerias associadas à empresa, verificação dos cálculos diários realizados pela área da Produção, ajustes e recálculos das regras e os valores calculados em sistemas para o devido pagamento aos bancos e parcerias.

\section{MARCONE FREITAS DOS REIS}

Doutorando e Mestre em Engenharia Civil pela UFF. Especialista em Gerenciamento de Projetos pela UERJ, Graduação em Engenharia de Produção pela UERJ. Consultor. Experiência como professor na graduação UNESA, SENAI CETIQT, UVA e Pós-Graduação no SENAI CETIQT. Tem 11 anos de experiência em indústrias (Automotiva, Filmes e Laminados PVC e Farmacêutica), com expertise nas áreas de Produção, Logística, Gestão da Qualidade e Lean Manufacturing e 7 anos de experiência em Gestão de Projetos no setor de Petróleo e Gás natural em Gestão de Manutenção de plataformas offshore. Experiência na Gestão de serviços de infraestrutura predial e industrial. 


\section{MARCOS DOS SANTOS}

Pesquisador de Pós-Doutorado em Ciências e Tecnologias Espaciais do Instituto Tecnológico da Aeronáutica (ITA). Possui Pós-Doutorado e Doutorado em Engenharia de Produção (UFF) - Linha de Pesquisa: Sistemas, Apoio à Decisão e Logística. Mestre em Engenharia de Produção pela COPPE/UFRJ (Pesquisa Operacional). Licenciado em Matemática e Especialista em Instrumentação Matemática (também pela UFF). Bacharel em Ciências Navais pela Escola Naval - com habilitação em Engenharia de Sistemas. Professor do Programa de Pós-graduação em Sistemas e Computação (PPgSC) do Instituto Militar de Engenharia (IME). Professor colaborador da UFF, atuando no Instituto de Estudos Estratégicos (INEST UFF) e no Programa de Pós-graduação em Engenharia de Produção. Na Universidade Federal de Pelotas (UFPel), participa do projeto de pesquisa "Política Internacional e Gestão do Espaço Oceânico: o planejamento espacial marinho voltado aos estudos de defesa e segurança" onde desempenha a função de Coordenador da subárea "Segurança e Defesa". Faz parte da Diretoria da Sociedade Brasileira de Pesquisa Operacional (SOBRAPO). Possui uma produção acadêmica composta por livros, artigos científicos publicados em periódicos e trabalhos publicados em anais de eventos nacionais/internacionais. É revisor de 13 periódicos, dentre eles a Revista Applied Soft Computing e a Revista Exacta. Atua como referee parecerista do SBPO, CNEG, SIMPEP, SEGeT, SIMEP, EMEPRO, ENFEPRO, SIMEPRO e CONTEXMOD. Oficial Superior com 26 anos de carreira na Marinha do Brasil, desempenha a função de Gerente de Projetos e Pesquisador no Centro de Análises de Sistemas Navais (CASNAV). Em 2013, representando a SecCTM, viabilizou parcerias estratégicas junto à Marinha do Chile e à Universidade Federal do Rio Grande (FURG). No ano de 2014, exerceu a função de Coordenador Geral (CEO) da 17a edição do SPOLM, que ocorreu nos dias 05 e 06/agosto/2014, contando com a presença de 1.200 pesquisadores nacionais/internacionais e com palestrantes EU.

\section{MARCOS DOS SANTOS}

Pesquisador de Pós-Doutorado em Ciências e Tecnologias Espaciais do Instituto Tecnológico da Aeronáutica (ITA). Possui Pós-Doutorado e Doutorado em Engenharia de Produção (UFF) - Linha de Pesquisa: Sistemas, Apoio à Decisão e Logística. Mestre em Engenharia de Produção pela COPPE/UFRJ (Pesquisa Operacional). Professor do Programa de Pós-graduação em Sistemas e Computação (PPgSC) do Instituto Militar de Engenharia (IME). Professor colaborador da Universidade Federal Fluminense (UFF), atuando no Instituto de Estudos Estratégicos (INEST UFF) e no Programa de Pós-graduação em Engenharia de Produção. Faz parte da Diretoria da Sociedade Brasileira de Pesquisa Operacional (SOBRAPO).

\section{MARCOS DOS SANTOS}

Pesquisador de Pós-Doutorado em Ciências e Tecnologias Espaciais do ITA. Possui Pós-Doutorado e Doutorado em Engenharia de Produção pela UFF. Licenciado em Matemática e Especialista em Instrumentação Matemática pela UFF. Bacharel em Ciências Navais pela Escola Naval, com habilitação em Engenharia de Sistemas. Professor do Programa de Pós-Graduação em Sistemas da Computação do IME. Professor colaborador da UFF, atuando no Instituto de Estudos Estratégicos e no Programa de Pós-Graduação em Engenharia de Produção. Participa do Projeto de Pesquisa Política Internacional e Gestão do Espaço Oceânico pela UFPel. Faz parte da Diretoria da SOBRAPO. Oficial Superior com 26 anos de carreira na Marinha do Brasil. Engenheiro, Matemático e Psicopedagogo, possui 20 anos de experiência no magistério. Professor da graduação do IME, SENAI CETIQT e UNIGRANRIO.

\section{MAX LEANDRO DE ARAÚJO BRITO}

Docente Permanente do Programa de Pós-Graduação em Administração (PPGA) da Universidade Federal do Rio Grande do Norte. Pós-doutorado e Doutorado pela Universidade Federal do ABC, com Graduação e Mestrado em Administração pela UFRN. 


\section{PEDRO CARLOS OPRIME}

Possui graduação em Engenharia de Producao pela Universidade Federal de São Carlos (1989), mestrado em Engenharia de Produção também pela Universidade Federal de São Carlos (1995) e doutorado em Ciências da informação e comunicação - Université Aix Marseille III (2001). Fez estágio de Pós Doutorado no Culverhouse College of Commerce, Universidade do Alabama, e no Instituto de Tecnologia da Universidade de Nantes, França. Em 1993 foi Certified Quality Engineer, CQE, pela American Society for Quality (ASQ/USA), e em 1997 recebeu treinamento em planejamento estratégico pelo INNESTEC, México. Trabalhou nas empresas Freios Varga (depois TRW) e Hudson-Sharpe, nesta última como Gerente Industrial. Atualmente é professor Associado IV da Universidade Federal de São Carlos. Tem experiência na área de Engenharia de Produção, com ênfase em Garantia de Controle de Qualidade, atuando principalmente nos seguintes temas: melhoria contínua, controle estatístico da qualidade, sistema da qualidade e arranjos produtivos locais. Recebeu o prêmio Awards for Excellence - 2018, Outstanding Papers, Emerald, pelo artigo The X-bar control chart with restriction of the capability indices, publicado na International Journal of Quality \& Reliability Management, Volume 1 number 34.

\section{PEDRO MATHEUS D'OLIVEIRA}

Aluno do curso de Engenharia de Produção pela UEPA. Estagiário de Gestão Estratégica e Mercado no Sebrae-PA.

\section{PHILIP SOARES DO AMARAL}

Graduado em Engenharia de Produção pela Universidade Federal de Pelotas (UFPel).

\section{PRISCILLA CHANTAL DUARTE SILVA}

Professora Adjunto IV da Universidade Federal de Itajubá, na área de Comunicação e Expressão e Metodologia de Pesquisa, nas Engenharias. Graduou-se em Letras com Habilitação em Português / Inglês, pela Pontifícia Universidade Católica de Minas Gerais, em 2005 e obteve o título de Mestre em Linguística e Língua Portuguesa pela mesma instituição, em 2008 (bolsista CAPES). Em seu mestrado, estudou, na Análise do discurso e na Filosofia da Linguagem, a intencionalidade da mente, com um enfoque na intencionalidade discursiva em charges políticas, visando identificar a direcionalidade semântica nesse gênero textual.

\section{JEFFERSON DE SOUZA PINTO}

Pesquisador Colaborador do Departamento de Engenharia de Manufatura e Materiais da Faculdade de Engenharia Mecânica da UNICAMP. Pós-doutorando em Engenharia Mecânica pela Universidade Estadual de Campinas (UNICAMP) (atual). Pós-doutor em Engenharia Mecânica pela Universidade Estadual de Campinas (UNICAMP) (2014, 2016 e 2018, atual). Doutor em Engenharia Mecânica pela Universidade Estadual de Campinas (UNICAMP) com pesquisa na área de Gestão de Projetos (2012). Mestre em Engenharia Mecânica pela Universidade Estadual de Campinas (UNICAMP) (2004). Especialista em Gestão de Processos Industriais pela Universidade Estadual de Campinas (2002). Possui graduação em Administração de Empresas com habilitação em Comércio Exterior pela Universidade São Francisco (1999). Professor colaborador do Programa de Pós-Graduação do Departamento de Engenharia de Manufatura e Materiais da Faculdade de Engenharia Mecânica da UNICAMP. Atualmente é professor concursado do Instituto Federal de São Paulo - Campus Bragança Paulista e pesquisador colaborador da Faculdade de Engenharia Mecânica da Universidade Estadual de Campinas (UNICAMP). Desempenhou a função de Gerente Educacional, Coordenador da Área de Informática, Coordenador do Curso de Tecnologia em Análise e Desenvolvimento de Sistemas e Coordenador do Curso de Especialização em Gestão Estratégica da Tecnologia da Informação do Instituto Federal de São Paulo - Campus Bragança Paulista. Tenho experiência em Administração da Produção e Operações, Logística, Gestão da Qualidade, Empreendedorismo, Estatística e Gestão de Projetos, áreas que me dedico à pesquisa. Membro dos seguintes grupos de pesquisa da Faculdade de Engenharia Mecânica da Universidade Estadual de Campinas: Sistemas Produtivos e Engenharia de Produção; e, Processos de Fabricação. Membro dos seguintes grupos de pesquisa do IFSP: Gestão 
da Produção, Operações, Projetos e Sustentatibilidade - GPOPS; e, Interdisciplinar em Educação, Matemática e Gestão. Possuo 29 artigos publicados.

\section{RACHEL MEDINA TRINDADE}

Graduanda em Engenharia de Produção pela Universidade do Grande Rio (UNIGRANRIO), Técnica em Eletromecânica pela Fundação de Apoio à Escola Técnica (FAETEC). Atuou como estagiária em uma multinacional de distribuição logísticas e interessa-se por Análise de Dados, Melhoria Continua e Pesquisa Operacional.

\section{RAUL CÉSAR DO CARMO MATOS}

Programador, sócio-proprietário da empresa Pixel Desenvolvimento, responsável pela equipe de desenvolvimento web e mobile. Atualmente cursando Gestão Estratégica da Tecnologia da Informação no IFSP campus Bragança Paulista, sou formado em Logística de Transportes e Informática para Gestão de Negócios pela Faculdade de Tecnologia da Zona Leste - São Paulo. Trabalho na área de informática, com foco em web development, desde 2003. No ano de 2010 iniciei as atividades de minha empresa Pixel Desenvolvimento, uma agência de publicidade com principal atuação na área on-line no desenvolvimento de websites, aplicativos e sistemas corporativos personalizados, e desde então atuo como gestor e principal desenvolvedor da equipe. Participei no projeto da startup Mundo das Frutas em 2014, projeto Home to go de 2010 a 2014 e participo atualmente nos projetos Greenk, desde 2016, e Jobman, desde 2013, bem como em outros projetos com clientes como Titan Pneus, Bayer, Sakata, Maxprint, IpCorp e Bolsa de Imóveis.

\section{RAYANA SANTIAGO DE QUEIROZ}

Doutoranda em Engenharia Têxtil pela Universidade do Minho (Portugal), mestre (2013) e graduada (2009) pelo curso de Têxtil e Moda da Universidade de São Paulo. É pesquisadora do Laboratório de Têxteis Técnicos e Produtos de Proteção do Instituto de Pesquisa Tecnológicas, tendo atuado especialmente nos seguintes temas: fibras têxteis vegetais, corantes naturais, conforto, caracterização e avaliação de desempenho de têxteis técnicos.

\section{REGINA APARECIDA SANCHES}

Possui graduação em Engenharia Mecânica - Ênfase Têxtil pelo Centro Universitário da FEI (1987), mestrado em Engenharia Mecânica pela Universidade Estadual de Campinas (2001), doutorado em Engenharia Mecânica pela Universidade Estadual de Campinas (2006) e livre-docência pela Escola de Artes, Ciências e Humanidades da Universidade de São Paulo (2011). É pesquisadora da USP, da Universidade de Lisboa (Portugal) e da Università degli Studi della Campania Luigi Vanvitelli.

\section{RENATO OLIVEIRA SERAFIM}

Graduando em Engenharia de Produção pela Universidade Federal de Pelotas (UFPel).

\section{RICARDO LUIZ PEREZ TEIXEIRA}

Professor adjunto na Universidade Federal de Itajubá Campus de Itabira, Curso de Engenharia dos Materiais. Doutor em Ciências, Engenharia Metalúrgica e de Materiais pela Universidade Federal do Rio de Janeiro (2011) com doutorado em cotutela em Engenharia Mecânica pela Faculdade de Engenharia da Universidade do Porto (2011), Mestre em Engenharia Metalúrgica e de Minas pela Universidade Federal de Minas Gerais (2004), Graduado em Engenharia Química pela Universidade Federal de Minas Gerais (1996) e especialista em Engenharia de Segurança do Trabalho pela Universidade Federal de Minas Gerais (1998). Professor de magistério superior pela Universidade Federal de Itajubá campus avançado de Itabira para cursos envolvendo materiais metálicos e compósitos (2013). 


\section{ROZA MARIA ZOELLNER LOPES}

Graduada em Engenharia de Produção pela PUCPR (2017) e mestranda em Engenharia de Produção pela UFPR.

\section{RUANY BATISTA LEITE DOEHNERT}

Licenciatura em matemática pela Universidade Federal do Paraná (2016). Pós - Graduação em Docência do Ensino Superior, Faculdade São Braz(2017). Cursando Mestrado em Métodos Numéricos em Engenharia pela Universidade Federal do Paraná

\section{RUBENS AGUIAR WALKER}

Doutorando em Engenharia de Produção pela UFF, com mestrado pela COPPE UFRJ e graduação pela PUC - RIO. Experiência Internacional com ótimas referencias. Atuação em grandes empresas, como a Volkswagen, no setor de produção. Experiência em logística na distribuição de produtos. Docente no curso de Engenharia de. Produção com desenvolvimento de protótipos e processo. Pesquisa sobre utilização lúdica de para desenvolvimento de jogos e competições acadêmicas. Caracteriza a atuação pela integração da otimização nos modelos de gestão.

\section{SÁVIO MENDES SILVA}

Graduando em Engenharia Mecânica na Universidade Federal do Rio de Janeiro.

\section{SUELLEN SILVA DE OLIVEIRA}

Graduanda de Engenharia de Produção pela Universidade Federal de Rondônia.

\section{SYANNE DO SOCORRO LOBATO GONÇALVES}

Aluna do curso de Engenharia de Produção na Universidade do Estado do Pará. Estagiária no setor comercial na empresa Inspira Rede de Educadores.

\section{TATIANE APARECIDA DE LAZARI}

Docente no curso de Engenharia de Produção da Universidade Federal de Rondônia. Atuação e pesquisas nas áreas de sistemas agroindustriais, indústria familiar, gestão e controle da produção. Doutoranda pela Universidade Nacional de Missiones, Argentina.

\section{THAYS MARQUES RODRIGUES}

Graduada em Engenharia de Produção pela Universidade do Grande Rio (UNIGRANRIO), Técnica em Mecânica pela Centro Federal de Educação Tecnológica Celso Suckow da Fonseca (CEFET/RJ). Atuou como estagiária em uma multinacional de agronegócio e interessa-se por Análise de Dados, Modelagem de Processos e Pesquisa Operacional.

\section{VITOR ABEL MONTEIRO ALVES}

Engenheiro de Produção graduado pela Universidade Federal de Pelotas com período sanduíche na Universidade Federal de Santa Catarina. Experiência profissional nas áreas de Desenvolvimento de produto e projetos, ergonomia e pesquisa operacional. Monografia realizada na área de Ergonomia Cognitiva em que realizou um mapeamento de índices de saúde emocional no centro de Engenharias da UFPel. Atualmente atua no mercado no ramo de consultoria pela EY Brasil. 


\section{WAGNER COSTA BOTELHO}

Profo. Doutor em Engenharia de Produção (UNIP, 2013), Mestre em Engenharia de Produção (UNIP, 2005), Graduação em Engenharia Elétrica pela Universidade de Mogi das Cruzes (UMC, 1989). Pósgraduações: Engenharia de Segurança do Trabalho (UNIP, 1996), Complementação Pedagógica em Matemática (FATEMA, 1997), Engenharia de Produção (USJ, 2003), MBA em Gestão Ambiental (UNINOVE, 2009) e Gestão Escolar (FAMOSP, 2017). Atuando há 26 anos na área da educação de nível técnico, graduação e pós-graduação, e 29 anos na de engenharia elétrica, produção e segurança do trabalho. Perito judicial e assistente. Consultor técnico.

\section{WILLIAN A.M DA SILVA-HAXWELL}

Autor tem graduação em ciências econômica , mestrado em engenharia da produção. participou de estudos de planejamento logístico para cadeia produtiva de produtos da Amazônia. Desenvolve estudos no campo de desenvolvimento sustentável e de engenharia econômica.

\section{YVELYNE BIANCA IUNES SANTOS}

Doutora em Engenharia de Recursos Naturais da Amazônia pelo Instituto de Tecnologia da Universidade Federal do Pará. Mestre em Engenharia Civil, pela Pontifícia Universidade Católica do Rio de Janeiro. Pesquisadora nas áreas de sustentabilidade e otimização de processos produtivos. Professora dedicação exclusiva da Universidade do Estado do Pará - UEPA. Coordenadora do curso de graduação em Engenharia de Produção da UEPA. Autora de programas computacionais, capítulos de livros, artigos em periódicos e em anais de eventos. Membro do Grupo de Pesquisa Núcleo de Pesquisa Aplicada ao Desenvolvimento Regional (NUPAD) e do Grupo Gestão de Sistemas Logísticos e de Sistemas Produtivos para o Desenvolvimento Regional. 


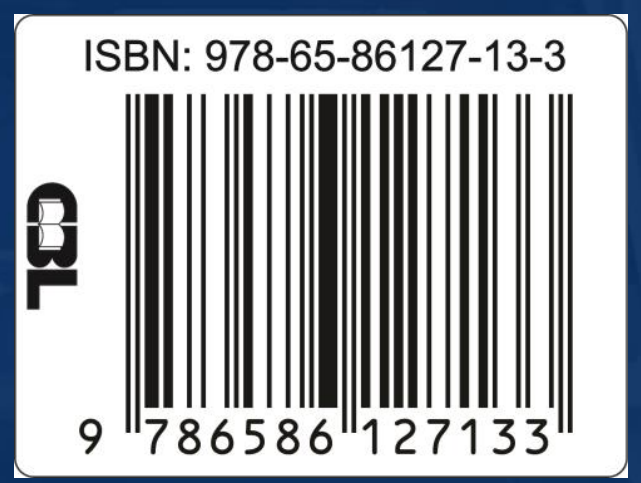

